\title{
Abstracts
}

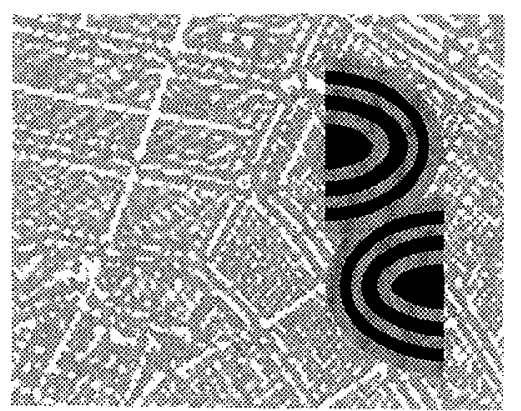

The 28th Annual Meeting of the European Society for Paediatric Nephrology

September 25-28, 1994

Amsterdam, The Netherlands

Springer International 
L2

CHARACTERISATION OF WATER CHANNELS IN THE KIDNEY C.H. van Os

Although channel-mediated water transport has been described accurately from a biophysical point of view, the molecular bas is of water channels remained elusive for a long period of time. A recent breakthrough, the discovery of aquaporinCHIP, has opened up an exciting field in medicine, namely the molecular aspects of water homeostasis in human. The nephron is composed of epithelial ce11 layers which have either constitutively very high or very low water permeabilities ( $P_{f}$ values). Moreover, in the collecting duct the water permeability can increase dramatically within minutes under the influence of AVP. High $P$, values along the nephron are accompanied by two phenomena, classically ascribed to pore-mediated water flow: low activation energies and sensitivity to mercurial $\mathrm{SH}$-group reagents.

The search for water channels has been hindered by a lack of specific inhibitors which selectively label mercurial-sensitive water transport. Two techniques were pivotal to pinpoint water channel proteins: the Xenopus oocyte expression system and radiation inactivation studies. Injection of oocytes with unfractionated mRNA isolated from the kidney revealed that the kidney contains mRNA coding for mercurialsensitive water channels (Zhang et al., JBC 265:15375, 1990). Furthermore, target analys is after irradiation of isolated brush border membrane vesicles had shown that the water channel protein in proximal tubules has a functional unit of $30 \mathrm{kDa}$ (Van Hoek et a1., JBC 266:16633, 1991). Meanwhile, CHIP28 was isolated from human red blood cells and was shown to be a water channel or aquaporin (Preston et a]., Science $256: 385,1992$ ). Aquaporin-CHIP was subsequent Ty shown to be responsible for the constitutive high $P_{f}$ values in the proximal tubule and the thin descending limb of the loop of Henle. Recently, a multitude of studies have been published dealing with the structure-function relationship of this unique water channe 7 protein. In short, aquaporinCHIP belongs to an ancient family of channeT-like proteins (the MIP family), which contain 6 transmembrane domains and are present in the membrane as homotetramers, resulting in a characteristic set of tetragonal structures which can be visualised by freeze-fracture EM. Each monomer of aquaporinCHIP forms, however, a functional water channe?. AquaporinCHIP has been shown to be selective for water, excluding protons, urea, hydroxyl ions and salts.

A second renal water channel was cloned by Fushimi et al. (Nature 361:549, 1993) and this aquaporin-CD was exclusively expressed in collecting duct cells, suggesting that this is the AVP-regulated water channel. In principal cells, AVP modulates the $P$ of of the apical membrane by shutt 1 ing functional water channels localised in subapical vesicles between the apical membrane and an endosomal compartment. In Nephrogenic Diabetes Insipidus, NDI, the kidney fails to respond to AVP. In most NDI patients a mutation in the vasopress in $V_{2}$-receptor gene could be detected which explains the $X$-linked recessive inheritance. However, in some families NDI is inherited in an autosomal recessive form. The hypothes is was tested whether mutations in the gene coding for aquaporin-CD could cause this second form of NDI. The human aquaporin-CD gene was cloned and assigned to chromesome 12. So far, direct sequencing revealed mutations in aquaporin-CD genes of seven NDI patients. Functional expression studies, using Xenopus oocytes as expression system, revealed that these mutations resulted in non-functional water channe 7 proteins (Deen et a)., Science 264:92, 1994). These results demonstrate clearly that aquaporin-CD is essential for AVP-regulated concentration of urine and that mutated aquaporin-CD genes cause NDI in some patients with an autosomal recessive mode of inheritance.

Recently, a Mercurial-Insensitive Water Channel, MIWC, was cloned, which is also expressed in the kidney but, was restricted to the inner medulla, probably vasa recta (Hasegawa et al., JBC 269:5497, 1994). Also, the AVP-regulated water channels in frog and toad have been cloned. Therefore, research continues into the molecular biology, physiology and pathophysiology of aquaporins to acquire a better understanding of human diseases caused by disturbed osmotic water transport.

Department of Ce11 Physiology, University of Nijmegen, P.0.Box 9101, 6500 HB Nijmegen, The Netherlands 
I3 3

\section{PATHOGENESIS OF POLYCYSTIC KIDNEY DISEASE} P.Wilson.

Polycystic kidney disease in humans is a genetic disorder, commonly inherited as a dominant trait (ADPKD) with 1:1,000 prevalence and more rarely as a recessive trait (ARPKD) with a prevalence of 1:20,000. To date, genetic analyses have revealed the chromosomal locations of the human ADPKD-1, ADPKD-2 and ARPKD genes and although the ADPKD-1 gene sequence has recently been identified, the protein products of these genes are unknown. Despite differences in typical age of onset and severity of symptoms, ADPKD and ARPKD share several features, including cystic enlargement of renal tubules resulting from proliferative, secretion, cell polarity and extracellular matrix abnormalities. However, ADPKD cysts derive from every segment of the nephron, while in endstage kidneys, ARPKD cysts are derived from collecting tubule epithelia only. Correlative in vivo and in vitro studies on ADPKD and ARPKD cystic epithelia and age-matched normal renal epithelia of defined segmental origin have defined major biological abnormalities including hypersensitivity to the mitogenic activity of epidermal growth factor (EGF) in cultured epithelia derived from human ADPKD and a mouse model of human ARPKD. Synthesis and processing of EGF by ADPKD cyst epithelia in vivo, apically directed secretion into cyst lumens and apical mislocation of functional EGF receptors to the apical cell membranes of ADPKD and ARPKD cyst epithelia suggest a major role for autocrine stimulation of aberrant proliferation as an underlying mechanism of cyst expansion. Additional changes associated with increased proliferation of cyst epithelia include apical location of calpactin (EGF receptor substrate) and the aberrant expression of PCNA PAX-2, WT-1 and AKT proteins. Secretion of fluid is also an important component of cyst enlargement which is particularly extensive in ADPKD and is associated with a reversal of the polarized location of the sodium pump (NaK-ATPase enzyme) to the apical membranes of cyst epithelia in vivo and in vitro where it is responsible for reversal of vectorial transport of sodium (Wilson et al AJP 260: F420, 1991). Recent studies suggest co-expression of the beta-2 subunit of NaK-ATPase with the normally occurring alpha- 1 and beta- 1 subunits plays an important role in the apical membrane disposition of functional NaK-ATPase heterodimers. Phenotypic analysis of the polarity of several membrane proteins suggests a specific abnormality in the intracellular trafficking mechanisms in PKD cyst epithelia, but only in those responsible for the sorting of certain subsets of proteins including NaK-ATPase, ankyrin, fodrin, E-cadherin, EGF receptor, calpactin, hepatocyte growth factor receptor (c-met), NaK2Cl symporter, cathepsins B and $L$ and metallo-proteinases. The localization of other membrane proteins including those linked to glycosyl phosphatidyl inositol, the multidrug resistance $P$-glycoprotein, the band 3 protein and alpha 6 integrin laminin receptor are unchanged. Several characteristic features of cystic kidneys not found in normal adult kidneys are, however, seen in normal human fetal kidneys during specific stages of nephrogenesis. These include NaK-ATPase located at the apical plasma-membrane, expression of the beta-2 subunit of NaKATPase, apically located EGF receptor, Pax-2 and WT-1 expression, and the ultrastructural localization of glycogen deposits, dense microfilament bundles and multiple lamellar bodies. Taken overall, analysis of the pathogenesis of polycystic kidney disease suggests a loss of regulation of the complex transcriptional programming essential for normal nephrogenesis, leading to the formation of cysts. Future therapies will focus on retardation of cyst enlargement by inhibition of cell proliferation and fluid secretion and ultimately, gene replacement therapy.

The Johns Hopkins University School of Medicine, Division of Nephrology, Department of Medicine, Ross 954, 720 Rutland Avenue, Baltimore, MD 21205, USA.
I.5

ANTINEUTROPHIL CYTOPLASMIC ANTIBODIES (ANCA) IN RENAL DISEASE

C.G.M. Kallenberg

Autoantibodies producing a particular cytoplasmic staining on ethanol-fixed neutrophils by indirect immunofluorescence (C-ANCA) have been described as sensitive and specific markers for Wegener's Granulomatosis (WG). The target antigen of most C-ANCA positive sera is proteinase 3 , a third serine protease - besides elastase and cathepsin $G$ - of human myeloid cells. Following the description of $c$ ANCA, autoantibodies were detected that produced a perinuclear staining of ethanol-fixed neutrophils ( $p$-ANCA). Within patients populations with primary vasculitides and glomerulonephritides most $p$ ANCA positive sera are directed against myeloperoxidase (MPO) However, p-ANCA and antibodies producing an atypical cytoplasmic fluorescence pattern are frequently found also in sera from patients with a wide range of inflammatory disorders such as ulcerative colitis, theumatoid arthritis, autoimmune liver diseases, etc. The antigens in the latter disorders have only partly been characterized and include lactoferrin, cathepsin $G$, and other myeloid proteins. Thus, a positive test for ANCA by IIF should at present be followed by antigen-specific assays including at least assays for anti-proteinase 3 and anti-MPO

Keeping these considerations in mind, the presence of anti-proteinase 3 or anti-MPO (and anti-elastase) are highly specific for one of the primary vasculitides including idiopathic necrotizing and crescentic glomerulonephritis (Tab.1).

Table 1

\begin{tabular}{lcc}
\hline Disease entity & \multicolumn{2}{c}{ Sensitivity of } \\
& anti-proteinase 3 (\%) & anti-MPO (\%) \\
\hline Wegener's granulomatosis & 85 & 10 \\
Microscopic polyangitis & 45 & 45 \\
Idiopathic crescentic & 25 & 65 \\
glomerulonephritis & & 60 \\
Churg-Strauss syndrome & 10 & 15 \\
Polyarteriiis nodosa & 5 &
\end{tabular}

The clinical significance of $\mathrm{p}$-ANCA in other inflammatory disorders has not been definitely established and awaits further characterization of the antigens involved. Although IgA-class ANCA have been described in Henoch-Schoenlein disease, this has not been confirmed by other studies. ANCA of diverse specificities (not including $\operatorname{Pr}$ 3) may occur in SLE, anti-MPO particularly in hydralazineinduced (lupus) nephritis.

A pathophysiological role for ANCA has been suggested by the following observations:

a. ANCA of diverse specificities in vitro can activate primed neutrophils to the production of reactive oxygen species and the release of lysosomal enzymes, which appears to be a FcyRIIA-dependent process;

b. ANCA in vitro can damage endothelial cells that either express proteinase 3 when activated or to which cationic enzymes such as MPO and proteinase 3 are attached;

c. ANCA in vitro can induce adherence of primed neutrophils to endothelial cells as well as lysis of endothelium by the latter cells;

d. anti-proteinase 3 can inhibit the inactivation of proteinase 3 by $a_{1}$-antitrypsin;

e. MPO-immunized rats in which the kidney is perfused with products of activated neutrophils develop pauci-immune necrotizing and crescentic glomerulonephritis.

Key References:

- Kallenberg CGM et al. Anti-neutrophil cytoplasmic antibodies: a still growing class of autoantibodies in inflammatory disorders. Am. J. Med 1992; 93: 675-682.

- Kallenberg CGM et al. Anti-neutrophil cytoplasmic antibodies: current diagnostic and pathophysiological potential. Kidney Int 1994; in press.

*Present address: Department of Clinical Immunology, University Hospital Groningen, Oostersingel 59, 9713 EZ Groningen, The Netherlands.

\section{L4 No abstract submitted}




\section{Symposia (S)}

S01

PLASMAPHERESIS (PF) IN CHILDREN

\section{D.E.Müller-Wiefel}

The use of PF as an extracorporeal method of blood purification to clear the patients' blood from pathogenetically important high molecular weight proteins/protein containing compounds has been progressively introduced within recent years in the treatment of patients with mostly renal but also non renal disorders even in childhood. Among different techniques membrane plasma separation of about $150 \%$ of plasma volume on alternate days, mainly achieved by polypropylen filtcrs $\left(0.1-0.5 \mathrm{~m}^{2}\right)$, combined with the substitution of an albumin (5\%) / electrolyte solution (therapeutic plasma exchange) has become the routine method. In contrast to this methodological standardization the indication for $\mathrm{PF}$ has been changing within recent years duc to progressive clinical experience partially dcrived from prospective therapeutic studics. No convincing evidence for the beneficial use of PF could be detected in acute liver failure, malignancies and lupus nephritis. Controversial results have been obtained with glomeruloncphritis (MPGN, IgA), vascular transplant rejection, septic shock, and Guillain-Barré syndrome. More convincing seems the indication for the use of $P F$ in children suffering from rapidly progressive glomerulonephritis (including Wegcner's granulomatosis and HenochSchoenlein purpura), focal segmental glomcrulosclerosis especially recurring in renal transplants, poisoning with highly protein bound drugs, homozygous familial hypercholesterolemia (using specific techniques) and last not leas scvere hemolytic uremic syndrome (HUS). In a prospective randomized multicenter study of children with dialysis dependent HUS $(N-61)$ we have becn able to detect a significantly superior clinical outcome in those high risk patients treated with PF (median $\mathrm{N}=4$ ) concerning the following parameters: duration of oliguria ( 14 vs 28 days), dialysis ( 17 vs 43 days) and proteinuria (1.3 vs 20 weeks) velocity of $\mathrm{SCR}$ decrease $(2.9 \mathrm{vs} 5.2 \mathrm{mg} / \mathrm{d} 1$ after 1 week of treatment) and complete recovery (62 vs $22 \%$ after 24 months). Today one can assume that at least $10 \%$ of all children suffering from HUS will be treated by PF. It can be regarded as a safe method of treatment which has contributed a great dcal to the recovery of nephrologically ill children. Nevertheless, further controlled therapentic studies are nceded to more accuratcly define its indication within the management of especially renal diseases.

University Children's Hospital Hamburg

Martinistraße 52, D - 20246 Hamburg, FRO

S02

HAEMODIALYSIS IN SMALL CHILDREN : FEASIBILITY AND LONG-TERM RESULTS. M.F. Gagnadoux.

We report on 50 children (68\% males) in whom haemodialysis (HD) therapy had been started before the age of 3 years (at 5 to 35 months of age, mean 23 months) in 14 french paediatric centers, between 1969 and 1993 . Their weight at the first $\mathrm{HD}$ ranged from 4,5 to $13,5 \mathrm{~kg}$ (mean $8 ; 3 \mathrm{~kg}$ ). HD was the first method of renal replacement therapy (RRT) in 30 patients (pts), whereas 20 had been treated initially by peritoneal dialysis (PD) for some months. The initial vascular access was external in $38 \%$ of cases (arteriovenous shunt in the initial 7 pts, Hickmann catheter in the latest 12) and internal (A.V. fistula, brachial in $9 \mathrm{pts}$ and radial in 22) in the remaining $62 \%$, in whom HD treatment could be planned. The total duration of HD therapy ranged from 2 months to 25 years (mean 3 yrs). The most frequent complications were related to vascular access but only 3 pts had to be switched back to PD because of access failure. Compared to older children, hyperkaliemia, hyperphosphoremia and hypertension were more difficuit to control ; however life-threatening manifestations were rare. Seven pts died before transplantation from causes unrelated to $\mathrm{HD}$ in 3 cases, withdrawal of treatment in 2 and cardiovascular complications in 2 . Growth has been poor in most children : the mean height SD score increased from -3 to $-3,5 \mathrm{SD}$ in boys and from $-1,3$ to $-2,7 \mathrm{SD}$ in girls during the HD period.

Thirty-eight pts ( $76 \%$ ) could be transplanted after 4 months to 13 years of $\mathrm{HD}$ (mean 2,6 yrs), whereas 5 have not yet been successfully grafted and have now been dialyzed for 1 to 25 yrs. The patient survival rate on RRT was $96 \%$ at 1 year, $85 \%$ at 2 yrs, $80 \%$ from 5 to 10 yrs and $69 \%$ at 20 yrs. At latest follow-up, 13 pts were older than 15 yrs (15 to 26 yrs ), 9 were 10 to 14 yrs old, and 18 were younger than 10 . The latest height of the pubertal children depended on their renal function : the SDS was - 1.7 in 4 boys with normal graft function, but - 5 in 4 boys and -3.6 in 3 girls with poor function or on $\mathrm{HD}$. Among the 4 pts older than $18 \mathrm{yrs}, 3$ have achieved a normal educational level. However only $50 \%$ of the 30 school-age pts ( 6 to 18 yrs old) have a normal level, the others being more or less behind in their schooling, according to the length of the HD period.

In conclusion, long-term haemodialysis can be performed in infants and small children without major complications and, if followed by a successful graft, may result in a satisfactory rehabilitation at the adult age.

Hôpital Necker-Enfants-Malades, 75743 Paris Cedex 15, France
503

\section{UREA KINETIC MODELLING: ITS ROLE IN ACHIEVING OPTIMAL DIALYSIS} J T Brocklebank. Leeds

Mathematical modelling of haemodialysis treatnent developed from The National Co-operative Dialysis Study (NCDS) on adequacy of dialysis and is widely used in the management of adult patients. The most widely used models are single pool and yield the indices $\mathrm{Kt} / \mathrm{V}$ and protein catabolic rate (PCR) where $\mathrm{K}$ is the dialyser clearance during time $(\mathrm{t})$ and $\mathrm{V}$ is the volume of distribution of urea. Both $\mathrm{Kt} / \mathrm{V}$ and PCR can either be measured directly or calculated using computer based iterative techniques and in the NCDS study were accurate indicators of dialysis morbidity. There are no data upon which to define the optimum haemodialysis prescriptions in children. We have undertaken studies to evaluate these mathenatical models in children. Studies were done in children whasing a dicot dialy sis quantification net!ind using partial dialysis collection (PDC) with both the classical variable volume 3 sample $\left(\mathrm{UKM}_{3}\right)$ and 2 sample $\left(\mathrm{UKM}_{2}\right.$ ) methods of urea kinetic modelling and $\mathrm{PCR}$. High correlations were found between all the results, although the 2 indirect methods tended to over estimate the urea generation rate. It was concluded that all methods could be used to model urea kinetics in children, although each requires its own references range. These models assume a single pool distribution of urea and ignore movement between ICF and ECF spaces. This assumption is probably acceptable in adults where the dialyser urea clearance is substantially less than the mass transfer coefficient of urea between the ICF and ECF. However, in children studies of serial timed plasma concentrations during and after haemodialysis have shown that the observed data best fit a two pool model. In addition there is a marked rebound of plasma urea after dialvsis ends which probably represents equilibration between the two pools. Dialysis efficiency in children can be over-estimated by up to $20 \%$ if there observations are ignored. An algorithm has been developed to predict dialysis efficiency yet avoiding the need for blood sampling post dialysis. Urea kinetic modelling can be used but a number of modifications are suggested before guidelines can be developed aiming to achieve optimal dialysis in children

Dept of Paediatrics \& Child Health, St James's University Hospital, Leeds LS9 7TF, UK

\section{4}

GLOMERULAR HEMODYNAMICS AND THE PROGRESSION OF RENAL DAMAGE

A.P. Provoost

Renal damage may advance despite proper treatment of the underlying renal disease. Brenner and coworkers proposed that hemodynamic adaptations to nephron loss, aiming to maintain normal glomerular filtration, may actually be maladaptive, and in the long-range injurious to remaining glomeruli. Additional investigations accumulated ample evidence in favour of an important role of intraglomerular pressure in the progression of renal damage. As direct pressure measurements are not possible in humans, this evidence stems from experimental rat models. Micropuncture studies provided direct proof for the presence of an increased intraglomerular pressure, preceding the development of progressive proteinuria and a decline in glomerular filtration rate, both markers of renal function deterioration. Glomerular hypertension has been observed in the presence and absence of systemic hypertension. Furthermorc, when systemic hypertension is present without glomerular hypertension, markers of early glomerular damage are also absent. On the other hand, some rat models have been reported to develop proteinuria and renal damage without the presence of an elevated intraglomerular pressure. Thus, progressive renal damage is frequently, but not unif ormly associated with glomerular hypertension.

A second line of evidence is derived from findings that treatments preventing or delaying the progression of renal damage also lower intraglomerular pressure. This is the case with reduced protein intake and effective antihypertensive treatment, particularly with angiotensin converting enzyme inhibitors (ACEI). Analyzing the published reports revealed that ACEIs unif ormly lower intraglomerular pressure, and reduce the incidence of renal damage. Total and single nephron filtration rate remain unchanged due to an increase in ultrafiltration coefficient. The size of the glomeruli is not affected by the treatment. Antihypertensive agents that lower systemic blood pressure without reducing intraglomerular pressure are usually not effective in reducing proteinuria and renal damage.

Taken together, the experimental findings imply an important role of glomerular hypertension in the initiation and progression of proteinuria and glomerular damage.

Department of Pediatric Surgery, Erasmus University, P.O. Box 1738, 3000 DR Rotterdam, The Nethcrlands 
S05

Pathobiology of glomerular injury and progressive glomeruloscierosis. Jan J. Weening. Dept. of Pathology. Academic Medical Center, Amsterdam

The dellcate network of the renal glomerulus, filtering large amounts of solute while being exposed to relatively high flows and pressures, can easily be damaged by hemodynamic, immunologic, toxic or metabolic events. The primary cellular responses to injury (see figure) include endothellal cell activation with increased adhesiveness, loss of anti-coagulatory activity, and changes in the production of endothelin and nitric oxide; increased numbers of activated mesangial macrophages by influx and proliferation with subsequent production of autocrine and poracrine cytokines: activation of smooth muscle-like mesangial cells characterized by cell proliferation changes in phenotype, increased and abnormal production of matrix proteins and metalioproteinases; and podocyte atierations such os loss of foot processes, decreased adhesion, increased production oxygen species and altered patterns of matrix production. The final outcome, resolution or progression, is largely determined by the balance between cell influx and cell proliferation versus cell death by necrosts or apoptosis; excessive and abnormal extracellular matrix formation to allow wound healing versus protein degradation as a determinant of remodeling; and expression

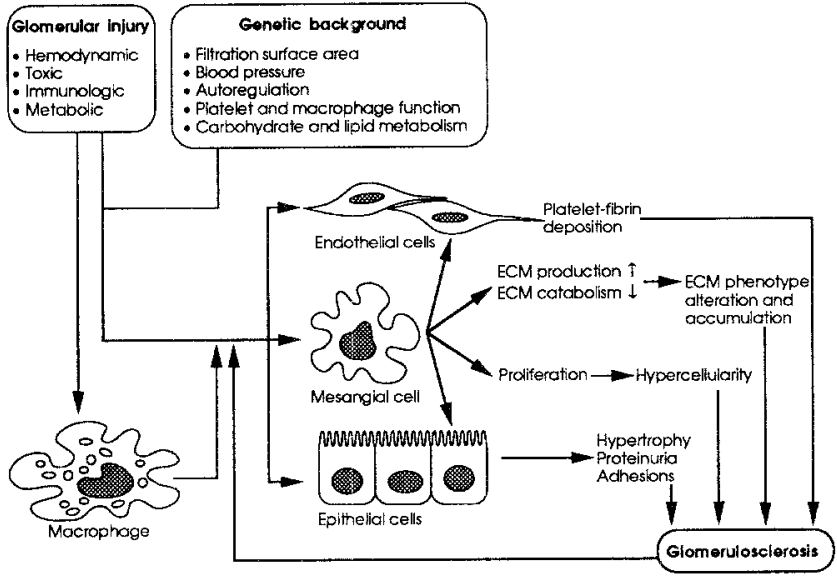

Rets.: Wolthu's A, Goor Hvan, Weening J, Grand J: Pathotialogy of focalsclerasis. Cur. Op. Nephrol typert. 1993:2:458-464.

Weening IJ, Boukers, UB, Grond J, Elema JD: Genetic foctors in focal segmental glomentoscterasis.

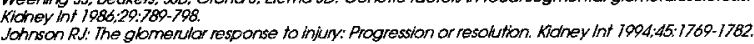

506

\section{PROGRESSION OF RENAL FAILURE IN CHILDHOOD U.B. Berg}

Great interest has been focused on how to evaluate progression of rena disease with regard to different therapeutic interventions such as proteir restricted diet, antihypertensive treatment etc. Difficulties with such evaluations are the large variability in rates of progression between patients the long period of time necessary to document this, and the difficulties ir finding the best method of evaluating progression. In adults the reciproca serum creatinine concentration (1/creat) have often been used and beer reported to decline linearly with time. This method is not the best in childrer because of the normal fall in 1/creat with age as a consequence of the increase in serum creatinine with increasing muscle mass. The best methoc of evaluating progression rate is by using a reliable method for determinin glomeruluar filtration rate (GFR) such as the clearance of inulin

In order to evaluate the progression rate of children with CRF, 126 childrer (74 boys) aged 0.1-19.5 (median 6.1) years at first investigation were followed to the ages of 1.1-24.1 (median 11.1) years with 1-18 (median 4 renal functional investigations. 75 children had congenital nephropathies (CN) such as dysplastic kidneys, juvenile nephronophthisis, polycystic kidney disease (PKD) and 51 had acquired diseases (AN) such a glomerulonephritis GN), focal segmental sclerosis (FSGS), neonatal rena insufficiency and children with chronic rejection following rena transplantation ( $\mathrm{t} x, 8$ of these children were also investigated before $\mathrm{tx}$ ) Renal function was followed every 3rd to 12 th month by glomerular filtration rate (GFR) determined by the clearance of inulin. Patients with $\mathrm{CN}$ had significantly lower GFR at first investigation than those with AN ( $32 \pm 2$ vs $47 \pm 4 \mathrm{ml} / \mathrm{min}$ per $1.73 \mathrm{~m}^{2}$ ). The yearly decline in GFR was however, greater in AN than in CN (-15 $\pm 5 \mathrm{vs}-7 \pm 3 \mathrm{ml} / \mathrm{min}$ per year). Th greatest declines were found in patients with FSGS, GN and following tx Among $\mathrm{CN}$ the greatest fall was found in patients with PKD. The fall ir GFR measured by clearance of inulin in comparison with that calculated by formula clearance agreed fairly well except for patients with FSGS anc following tx. In conclusion children with $\mathrm{CN}$ showed a slower progressior rate than those with AN.

Department of Pediatrics, Karolinska Institute, Huddinge Hospital, S-14186 Huddinge, Sweden
S07

ENDOCRINE AND METABOLIC FFFECTS OF INSULIN-LIKE GROWTH FACTOR-I AND GROWTH HORMONE M. A. HUSSAIN AND E. R. FROESCH

Insulin-like growth factor-I (IGF-I) is synthesized upon stimulation by growth hormone $(\mathrm{GH})$ by various tissues, whereby most of the circulating IGF-I originates from the liver. IGF-I inhibits pituitary $\mathrm{GH}$ secretion by way of feedback control. In order to investigate similarities and differences of the metabolic effects of these hormones, GH-deficient adults - kept on a weight maintaining diet - were treated, respectively, with $\mathrm{GH}\left(2 \mathrm{IU} / \mathrm{m}^{2}\right.$ s.c. qid), IGF-I $(10 \mu \mathrm{g} / \mathrm{kg} \cdot \mathrm{h}$ s.c.), and both hormones together for seven days. Energy expenditure and substrate oxidation rates were assessed by indirect calorimetry and insulin sensitivity was assessed by the euglycemic, hyperinsulinemic clamp technique. During treatment with GH or IGF-I basal energy expenditure, lipolysis, and lipid oxidation were elevated, protein oxidation was reduced, and carbohydrate oxidation unchanged. During GH treatment glucose levels were elevated in the face of increased insulin secretion. GH induced relative insulin resistance as compared to the situation without GH treatment. During IGF-I treatment, glucose levels were slightly reduced, insulin secretion was reduced and increased insulin sensitivity is demonstrable. When GH-deficient subjects were treated with IGF-I on top of GH, the effects on substrate combustion was more pronounced as compared to treatment with either hormone alone, whereas insulin sensitivity was similar to a control situation without hormone treatment. The mechanism behind these metabolic changes during treatment with IGF-I or GH are different. Whereas IGF-I leads to reduced insulin levels and thus to a loosening of the brakes on lipolysis, GH directly stimulates lipolysis in adipose tissue. Both hormones possess antiproteolytic effects. When both hormones are given together, their effects are synergistic with respect to the stimulation of energy expenditure, lipolysis, lipid oxidation and the inhibition of protein oxidation whereas they balance each other with respect to basal and stimulated insulin secretion and glucose metabolism.

Department of Internal Medicine, University Hospital, Rämistr. 100, 8091 Zürich, Switzerland. Tel: +41-1-255 36 25, FAX: +41-1-255 4447

S08

EFFECTS OF IGF I ON RENAL FUNCTION IN END-STAGE CHRONIC RENAL FAILURE

S.B. Miller, M. Moulton, M, O'Shea, and M.R. Hammerman.

It is known that insulin-like growth factor I (IGF I) increases the glomerular filtration rate (GFR) in humans with normal renal function. We have shown recently (Am. J. Physiol. 264:F917-F922, 1993) that IGF I increases GFR in humans with moderate chronic renal failure (inulin clearances between 22-55 $\mathrm{ml} / \mathrm{min} / 1.73 \mathrm{~m}^{2}$ ). To determine whether IGF I affects kidney function in patients with end-stage chronic renal failure, we administered recombinant human IGF I (rhIGF I) (100ug/kg body weight subcutaneously twice daily) to 9 individuals with baseline inulin clearances below $21 \mathrm{ml} / \mathrm{min} / 1.73 \mathrm{~m}^{2}$ Four patients were treated for 4 days (short-term treatment) and 5 for periods between 13-27 days (long-term treatment). Administration of rhIGF I iircreased inulin clearance, p-aminohippurate (PAH) clearance and the percent tubular reabsorption of filtered phosphate during short-term administration. Kidney volume was unchanged in patients receiving the growth factor. ThIGF I did not cause weight gain, proteinuria or hypoglycemia. Inulin clearance was no longer increased significantly above baseline after 13 or 20 days of IGF I administration. PAH clearance remained elevated after 13 days, but not after 20 days of IGF I. Levels of total circulating IGF I were elevated above basal levels during the entire course of long-term IGF I administration. In contrast, levels of circulating IGF binding protein 3 (IGFBP3) declined over time. Side effects related to IGF I forced discontinuation of its use in 2 of 5 patients undergoing longterm treatment, and side-effects possibly related to IGF I prompted discontinuation of its use in 2 others. We conclude that rhIGF I can enhance glomerular filtration rate and plasma flow when administered short-term to humans with end-stage chronic renal failure. Further studies will be required to define its efficacy and usefulness long-term.

*Present address: Washington University School of Medicine, Renal Division, Box 8126, Department of Internal Medicine, 660 South Euclid Avenue, St. Louis, MO 63110 USA. 
Sog

GROWTH HORMONE TREATMENT IN CHILDREN WITH RENAL TRANSPLANTS A.C.S. Hokken-Koelega, M.C.J.W. de Jong, E.D. Wolff, and R.A. Donckerwolcke

Growth failure is a psychosocial problem for many patients who have undergone renal transplantation.

18 adolescents (mean age 15.6, range 11.3-19.5) with severe growth retardation after renal transplantation were treated with biosynthetic growth hormone (GH) for 2 years. All received prednisone, administered daily or on alternate days, with azathioprine and/or cyclosporin A. 16 were blindly assigned to one of two $\mathrm{GH}$ doses $\left(4 \mathrm{vs} 8 \mathrm{lU} / \mathrm{m}^{2} /\right.$ day). Growth, bone maturation, renal graft function, plasma insulin-like growth factors, serum binding proteins, bone mineral content ( $\mathrm{mm} \mathrm{Al}$ $\mathrm{eq} / \mathrm{mm}^{3} \times 10^{3}$ ) and other biachemical parameters were checked regularly. Glomerular fittration rate and effective renal plasma flow were tested with ${ }^{125}$ Thalamate and ${ }^{131} 1$-Hippuran. Data on growth and glomerular filtration rate during GH treatment were also compared with those of matched non-GH-treated controls.

Mean (SD) increment in height after 2 years of $\mathrm{GH}$ was 15.7 (5.1) $\mathrm{cm}$, significantly greater $(P<0.0001)$ than in matched controls, $5.8(3.4) \mathrm{cm}$. Results were similar for the two $\mathrm{GH}$ dasage groups. Bone maturation was not accelerated. Mean glomerular filtration rate and effective renal plasma flow did not change significantly. The incidence of a $>25 \%$ reduction in glomerular filtration rate over 2 years was not significantly higher in GH-treated patients than in non-GH-treated controls (39\% vs $32 \%, P=0.97)$. Although a few patients had deterioration of graft function, we could not find a relation with $\mathrm{GH}$ treatment. All patients showed a continuous and significant increase $(P<0.0001)$ in bone mineral content.

Our results show that sustained improvement of height can be achieved with $\mathrm{GH}$ in severely growth-retarded adolescents after renal transplantation.

Department of Pediatrics, Subdivisions of Endocrinology and Nephrology, Sophia Children's Hospital, Erasmus University Rotterdam, Dr. Molewaterplein 60, 3015 GJ Rotterdam, The Netherlands

510

FLUID KINETICS IN CHILDREN ON CONTINUOUS AMBULATORY PERITONEAL DIALYSIS (CAPD).

\section{R.E. Reddingius*, C.H. Schröder, H.L. Willems, M. Lelivelt, L.A.H. Monnens}

It has been reported that it is difficult to achieve sufficient ultrafiltration in young children treated by CAPD. Ultrafiltration is the difference between inflow of fluid into the abdominal cavity by transcapillary ultrafiltration (TCUF) and removal of fluid, mainly by lymphatic absorption (LA). In children LA has always been estimated from the disappearance rate of intraperitoneally administered macromolecules, the marker clearance (MC) rate. Calculation from tracer appearance rates in blood is not feasible in the clinical setting. Different markers have been used (human albumin, autologous haemoglobin and dextran 70). Since peritoneal surface area is proportional to body surface area, data must be corrected for body surface area in order to enable comparison to adult data. Human albumin was used by Mactier et al. (1988) to measure MC and TCUF in 6 children and 10 adults and both were found to be higher in children. In 1991 we studied 17 children with this marker and established no differences between adults and children. An important disadvantage of human albumin is the fact that endogenous patient albumin enters the peritoneal cavity during the dwell. Also, augmentation of peritoneal solute transport by intraperitoneally administered albumin has been reported. In 1993 we performed a study using autologous haemoglobin as a marker and obtained a high mean MC in 9 children, while TCUF was similar to adults. This substance also has a number of disadvantages. The preparation of the haemoglobin solution is time-consuming and carries the risk of contamination The haemolysate may influence $M C$, it can cause abdominal pain and large amounts have to be added to the dialysis fluid, changing its composition. Recently we performed a study in 15 children with dextran 70 as a marker. Marker clearance and TCUF, corrected for body surface area, were similar to adult patients. There was a trend towards a low TCUF in young children. It is concluded that dextran 70 is the most suitable marker for the study of fluid kinetics in children on CAPD. Fluid kinetics in children and adults are similar, when corrected for body surface area. Transcapillary ultrafiltration tends to be lower in young children, possibly caused by the fact that in these children dwell volume, which is calculated from body weight, is relatively small in relation to peritoneal surface area.

"Address for correspondence: Department of Paediatrics, Sint Radboud University Hospital, Geert Grooteplein Zuid 22, 6525 GA Nijmegen, The Netherlands
$S 11$

USE OF PET, SMALL OR MIDDLE MOLECULE CLEARANCES AND UREA KINETIC MODELING TO DEFINE THE ADEQUACY OF PERITONEAL DIALYSIS IN CHILDREN: EXPERIENCE IN A LARGE PEDIATRIC POPULATION

Franz Schaefer and Mid European Pediatric CAPD/CCPD Study Group (MPCS)

The Peritoneal Equilibration Test (PET) is gaining increasing acceptance as a too to define and monitor the individual characteristics of peritoneal solute transport in patients on continuous peritoneal dialysis. The use of the PET in children requires standardized procedural guidelines and reliable reference values for peritonea solute equilibration. In the MPCS, PETs are being performed every six months and after each episode of peritonitis in order to examine the range of peritonea solute permeability in children, its evolution in the course of PD treatment and the effect of peritoneal inflammation on solute and water transport rates. The dialysate volume is standardized as $1000 \mathrm{ml} / \mathrm{m}^{2}$ surface area. In addition, (dialysate and total) small and middle solute clearances are measured. The data obtained from the first 100 PETs in patients on PD for less than 6 months without prior peritonitis show a large inter-individual variability of transport rate constants, and a slightly more rapid equilibration in children as compared to published adult data. The creatinine and glucose equilibration curves (mean $\pm 2 \mathrm{SD}$ ) are shown below.
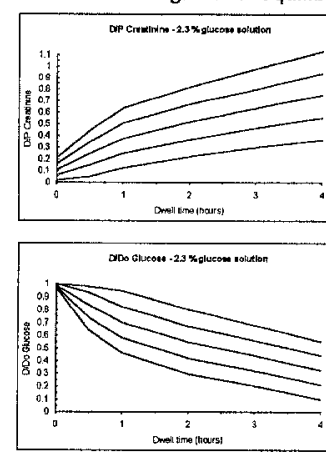

These curves allow to categorize the solute transport properties of an individual patient relative to a large pediatric $P D$ population. The longitudinal analysis reveals a high degree of stability of the individual peritoneal transport characteristics. Commensurately with the variability of peritoneal solute transport, large interindividual differences in daily clearances were observed in our population. In accordance with the different specific solute transport rates, CCPD patients achieved higher urea but not creatinine clearances than children on CAPD. The protein catabolic rate calculated from urea kinetic modeling was also higher in children on CCPD. Further longitudinal analysis will have to show whether the intensity of PD and/or residual renal clearance are related to indicators of clinical well-being.

Pediatric Nephrology Division, University Children's Hospital, Im Neuenheimer Feld 150, D-69120 Heidelberg, Germany
$\mathrm{S} 12$

METABOLIC EFFECTS OF INTRAPERITONEAL AMINO ACID INFUSION ON CHILDREN TREATED WITH CCPD.

R. Gusmano, F. Perfumo, A. Canepa, E. Verrina, M.L. Degl'Innocenti, A. Trivelli.

Attempts to improve the nutritional status by the intraperitoneal administration of amino acids ( $A A$ ) have been carried out with conflicting results. These results could, at least in part,be due to the lack of the simultaneous supply of calories and to the utilization of infused AA for energy production.

The aim of our study is to verify if the combined intraperitoneal administration of $\mathrm{AA}$ and glucose ( 1 bag with $1.1 \%$ AA solution, 2 bags with $2.27 \%$ glucose, I bag with $3.86 \%$ glucose) could favour,by the calories supplied through the absorbed glucose, the incorporation of infused AA into new proteins. We studied the effects i.p. AA infusion in 8 children on NPD (volume exchange $1000 \mathrm{ml} / \mathrm{sm}, 8$ exchanges, dwell time $60 \mathrm{~min}$ ). Blood and dialysate samples were taken at start of dialysis and at every exchange for the measurement of glucose, urea, $A A$, insulin. Absorption of glucose and of different AA groups was: glucose $42+16 \%$, BCAA $47+11 \%$, EAA (except BCAA) $55+12 \%$, NEAA contained in the bag $60 \pm 8 \%$.

Most of the AA contained in the solution showed a rather stable plasma level except for a slight reduction of SER, ARG, LEU, TYR and an increase of VAL at the end of the study period. Plasma insulin levels were elevated $18.5+3.2 \mathrm{~J} / \mathrm{ml}$ in the first 2 hours of the study (these data could be attributed to the stimulation by the dinner) and subsequently decreased to values ranging from 7 to $10 \mathrm{U} / \mathrm{ml}$.

Combined intraperitoneal infusion of glucose and AA showed that it is possible: to compensate the $A A$ losses with peritoneal fluid; to preserve plasma AA levels during CCPD; to supply $1.6 \mathrm{~g} / \mathrm{s} . \mathrm{m} /$ exchange of $\mathrm{AA}$ with a ratio of non protein calories to nitrogen of $116: 1$.

Present address: Nephrology Dept., G. Gaslini Institute, 16148 Genoa, Italy 
$\mathrm{S} 13$

ENTERAL NUTRITION IN THE INFANT AND YOUNG CHILD WITH CHRONIC RENAL FAILURE

S.E. Ledermann, M. Randall, V. Shaw and R.S. Trompeter.

Overcoming the symptoms of poor appetite and vomiting in the young child with chronic renal failure (CRF) remains a therapeutic challenge. Enteral fecding is often necessary, but its long-term consequences are poorly documented. We therefore evaluated the growth, nutritional intake, and outcome for oral feeding in 26 children with CRF (20m, 6f) who were fed overnight with a nasogastric (20) or gastrostomy tube (6) for at least one year (yr). Data were available at $2 \mathrm{yr}$ for 16 children and at $3 \mathrm{yr}$ for 6 . At the start of enteral feeding their mean (range) age was $1.8(0.02-5.7)$ yr. Twenty-two were managed conservatively with a mean initial GFR of 11.4 (6-22) $\mathrm{ml} / \mathrm{min} / 1.73 \mathrm{~m}^{2} \mathrm{SA}$. Four children were on peritoneal dialysis (2 requiring a period of hemodialysis), and 11 were subsequently transplanted.

The mean (SD) standard deviation score (SDS) for weight at the start of enteral feeding was $-2.9(0.94)$, at $1 \mathrm{yr}-1.66(1.32)$, at $2 \mathrm{yr}-0.94$ (1.47), and at $3 \mathrm{yr}-1.37$ (1.37). The

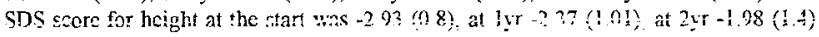
and at $3 y \mathrm{yr}-1.88(0.92)$. The children thus gained weight and acheived catch-up growth in height. There was no change in the percentage estimated average requirement (EAR) for energy during the study with a mean (SD) EAR of $98.1 \%(21.8)$ at the start, $96.3 \%$ (17.6) at lyr, and $95.2 \%(18.2)$ at $2 \mathrm{yr}$. The clinical impression of reduced vomiting with enteral feeds was supported by the weight gain with no increase in energy intake. The mean protein intake as a percentage of the reference nutrient intake (RNI) for the conservatively managed children did not change significantly during the study: $126 \%$ (37) at the start, 123\% (44) at $1 \mathrm{yx}$, and $139 \%(72)$ at $2 \mathrm{yr}$. At the end of the study period the mean percentage protein calories for this group was $5.8 \%(2.3)$, less than the $8 \%$ usually recommended. The plasma urea and albumin increased from $16.8(7.9)$ to 20.5 (6.6) $\mathrm{mmol} / 1$ and from 36 (4) to 40 (4) g/l respectively. The bicarbonate requirement decreased from $1.3(1.1)$ to $0.9(1.0) \mathrm{mmol} / \mathrm{kg} /$ day. The percentage energy intake from the feed remained constant at $76.3 \%(20)$, i.e. there was no objective evidence of change in appetite. All the children who had renal transplants discontinued enteral feeding, as did 3 who remained in CRF

Early instigation of overnight enteral feeding with encouragement of oral feeding alleviates parental anxiety and reduces vomiting. Weight gain is often rapid with subsequent catch-up growth which is maintained. A unified team approach to support these families with constant reappraisal of their needs is vital but in our experience long-term enteral feeding does not prevent the development of normal eating habits following succesful renal transplantation.

Renal Unit, Great Ormond Street Hospital for Children, London, WCIN 3JH UK

S 14

THE RELEVANCE OF THE IMMUNE RESPONSE AGAINST ENDOTHELIAL CELLS FOR RENAL ALLOGRAFT REJECTION.

\section{F.H.J. Claas}

Matching for the HLA class I and class II antigens has shown to be beneficial for renal allograft survival. Furthermore a serological crossmatch is necessary in order to prevent hyperacute graft rejection due to circulating donor specific HLA antibodies in the potential recipient.

Both HLA typing and crossmatching is routinely performed using donor leucocytes as they do express these HLA class 1 and class II molecules and are easy to obtain. However, a potential disadvantage of this procedure is that a kidney is transplanted and not these leucocytes.

Therefore, antibodies direct against kidney specific antigens (present on endothelial or tubular cells) are not considered in the donor selection. Several studies have shown that antibodies direct against endothelial and epithelial cells, which do not react with lymphocytes may indeed be detrimental for kidney graft survival. Some of the endothelial cells specific antigens are shared by monocytes. The target antigens involved in these endothelial and epithelial cells specific immune reactions are still poorly defined. Although the frequency of such non-HLA antibodies is rather low, an endothelial or epithelial crossmatch may be indicated for a subgroup of patients.

Similarly, $T$ cell responses direct against endothelial/epithelial cell specific peptides presented by donor HLA antigens can be involved in acute and chronic rejection.

In conclusion, next to immune responses directed against the HLA alloantigens, endothelial and epithelial cell specific immune reactions certainly play a role in clinical renal transplantation.

Address: Department of Immunohaematology and Blood Bank, University Hospital of Leiden, P.O. Box 9600, 2300 RC Leiden, The Netherlands
S15

\author{
INFECTIOUS COMPLICATIONS AFTER KIDNEY \\ TRANSPLANTATION \\ M. Broyer, G. Guest, MF. Gagnadoux and P. Niaudet \\ Hôpital des Enfants Malades, Paris, France
}

The files of the 889 kidney transplantations performed in the Enfants Malades Unit ( 800 cadaver donors, 89 LRD) from 1973 to Dec. 93 have been reviewed for this study. Infection represented $32 \%$ of the causes of death in this series $(16 / 51)$. In the postoperative period viral infections represented the main problem especially CMV infection symptomatic in 125 cases ( 4 deaths), mucosal herpes in 64 cases, EBV symptomatic infection in 10 cases ( 1 death).Pneumocystis pneumopathy was recorded in 15 cases (1 death) and other pneumopathies (1 death) mainly post atelectasy in 30 cases. Except urinary tract infection (UTI) recorded in 140 cases other postoperative bacterial infections were relatively few with 20 septicemia and 14 wound abscesses. Beyond the first 2 months UTI were the most frequently recorded with 41 pyelonephritis and 30 recurrent UTI mainly in patients with UT malformation, orchiepididimitis was observed in 4 cases. Pneumopathies were the second localisation of infection recorded in 36 cases ( 1 death). Tuberculosis was observed in 6 cases. Various other late bacterial infections have been observed localised in the oropharyngeal area (6), subcutaneous tissue (12), joints and bone (4), gastrointestinal and biliary tract (4), fallopian tube ( 3,1 death) meninges and CNS $(3,1$ death), 7 had a septicemia of which 2 had been splenectomised ( 2 deaths). Among viral infections, varicella was the most frequent with 47 cases ( 3 deaths). Other common viral diseases were recorded with a benign course: measles (5), mumps (11), rubeola (2). Three patients had been contaminated by the HIV before or at time of grafting and 2 died, 2 patients had a mild or severe symptomatic late CMV infection. Mycotic infections were rare : 3 cases of oesophagitis, 3 onychomycosis and 12 with important dermatophytosis. Seventy developped recurrent warts and/or condylomas and 1 of them became malignant.

Prophylaxis of infectious diseases was applied regularly: 1) all patients received prophylactic antibiotics at the time of grafting; 2) since 1985 attempts were made for CMV prophylaxis, with hyperimmune IgG, and presently with acyclovir; 3 ) since 1992 TMP sulfa was also systematically administrated during the first 3 months. Early diagnosis and treatment of any infectious complication was also the way to decrease the mortality related to these complications in the last years.

\author{
S16 \\ CYCLOSPORINE AND FK 506 NEPHROTOXICITY \\ M.J. Mihatsch
}

No abstract submitted. 
F01

\author{
EFFECT OF PLASMA FROM CHILDREN WITH IDIOPATHIC \\ NEPHROTIC SYNDROME ON MESANGIAL CELLS \\ N. Benador, A de Agostini, E. Girardin
}

Idiopathic nephrotic syndrome (INS) still has an unclear etiology. A loss of anionic charges (mainly heparan sulfate proteoglycans) of the glomerular basement membrane could be the cause of the proteinuria. Immune regulation is abnormal and a lymphocyte dysfunction is suspected with production of a circulating factor acting on the glomerulus. The effects of this factor on glycosaminoglycans synthesis by mesangial cells (MC) are unknown. To study these effects in vitro, we used a model of cultured primary rat MC The cells were exposed to nlasma of 5 untreated proteinuric patients with INS or with plasma of controls added at concentrations of 2 and $5 \%$. Cellular and secreted glycosaminoglycans were quantified by a solid-phase assay using a cationic nylon blot. When exposed to $2 \%$ plasma from patients with INS the cellular fraction of the glycosaminoglycans decreased by $10.5 \pm 15.2 \%$ $(p=0.069)$ and the secreted fraction by $3.7 \pm 11.7 \%(p=0.093)$ compared to the cells exposed to normal plasma. When exposed to $5 \%$ plasma, the cellular fraction decreased by $40.8 \pm 7.0 \%(\mathrm{p}=$ $0.007)$ and the secreted fraction by $46.8 \pm 4.8 \%(p=0.007)$ These data indicate that plasma from INS patients induce a dose dependent decrease of glycosaminoglycans produced by $\mathrm{MC}$. We conclude that a circulating factor in the plasma of INS patients may induce proteinuria by directly affecting the synthesis of proteoglycans by MC

Present address: Department of Pediatrics, Hôpital Cantonal, 1211 Geneva 14, Switzerland.

F02

INCREASED HUMAN ENDOTHELIAL CELL PROLIFERATION BY SERA FROM PATIENTS WITH IDIOPATHIC NEPHROTIC SYNDROME (INS) G. Deschênes, B. Khalfoun, H. Watier, S. Benoit, P. Bardos, H. Nivet, Y Lebranchu

The aim of this study was to test the effect of sera from patients with steroidsensitive INS on human aortic endothelial cell (HAEC) proliferation. Thirteen patients ( 4 girls, 9 boys), aged 3.5 to 18 years $(m=10.4)$ were studied both with massive proteinuria (group $\mathrm{P}+$ ) and without proteinuria (group P-). Fourteen matched patients without INS or proteinuria were included in the control group (group C). Six patients from group $\mathrm{P}+$ were treated with prednisone $(\mathrm{m}=22 \mathrm{mg} / \mathrm{d}$ ) and 3 with cyclosporine $A$. Twelve patients from group P- were treated with prednisone $(\mathrm{m}=21 \mathrm{mg} / \mathrm{d})$ and 3 with cyclosporine. Proteinuria ranged from 0.88 to prednisone $(\mathrm{m}=21 \mathrm{mg} / \mathrm{d})$ and 3 with cyclosporine. Proteinuria ranged from 0.88 to
$16 \mathrm{~g} / \mathrm{d}(\mathrm{m}=6.4)$ in group $\mathrm{P}+$. Serum albumin was lower in group $\mathrm{P}+(\mathrm{m}=21.2 \mathrm{~g} / \mathrm{l})$ than in group $\mathrm{P}-(\mathrm{m}=37.6 \mathrm{~g} / \mathrm{l})$. Ninety-six-well plates were seeded with 10,000 $\mathrm{HAEC} /$ well in $100 \mu \mathrm{l}$ M199 with $20 \%$ fetal calf serum. After 24 hours, the initial medium was removed and replaced by the sera diluted with M199. The heparin concentration of each dilution was $10 \mathrm{\mu g} / \mathrm{ml}$. HAEC were then incubated for 48

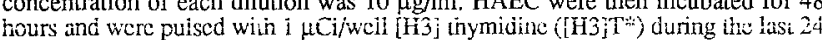

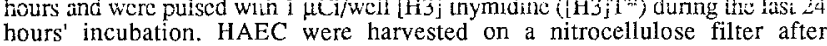
hours' incubation. HAEC were harvested on a nitrocellulose filter after
trypsinization and radioactivity was measured with a scintillation counter in cpm Assays were performed in triplicate. At dilution 1/10 and 48 hours of incubation, [H3] $\mathrm{T}^{*}$ incorporation (mean \pm sem) was significantly higher $(\mathrm{p}<0.0001)$ in group $\mathrm{P}+(27003 \mathrm{cpm} \pm 3586)$ and in group P- $(26131 \mathrm{cpm} \pm 3248)$ than in group $\mathrm{C}$ ( $16022 \mathrm{cpm} \pm 2376$ ). This difference progressively decreased at dilutions $1 / 20$ $(10968 \pm 680$ and $9945 \pm 787$ vs $7214 \pm 520)$ and $1 / 40(5831 \pm 416$ and $6794 \pm$ 480 vs $5317 \pm 323$ ) but remained significant $(p<0.05)$. Conversely, no statistical differences were observed at $1 / 80$ or after 24 and 72 hours of incubation at dilution 1/10. After ultrafiltration through 10,000 and 50,000 MW cut-off membranes, the difference in [H3] T* incorporation between groups $\mathrm{P}+$ and $\mathrm{P}$ - and group $\mathrm{C}$ remained in the retention compartment $(\mathrm{p}<0.0001)$. Adsorption of the diluted seri using heparin-acrilyc beads led to a decrease in [H3] T* incorporation in the groups but did not affect the difference between groups $\mathrm{P}+$ and $\mathrm{P}$ - and group $\mathrm{C}$. I addition, [H3] T* incorporation with INS patients related to control patients wats significantly $(\mathrm{p}<0.0001)$ more increased in group $\mathrm{P}$ - with heparin adsorption $(\mathrm{m}=141 \%$; $\mathrm{sem}=18)$ than without heparin adsorption $(\mathrm{m}=68 \% ; \mathrm{sem}=11)$ while no difference was observed in group P+. In conclusion, 1) at 48 hours of incubation INS patients' sera have a higher angiogenic effect on HAEC, with a dose effect compared to controls, 2) the angiogenic effect is similar in the presence or absence of proteinuria at the moment of sampling, 3) increased angiogenic effect with heparin adsorption in the group P- suggests an inhibitor which is not present in the sera of group $\mathrm{P}+$.

Pædiatric Nephrology Unit. Hôpital Clocheville F37044 Tours Cedex. FRANCE
F03

T-CELL ACTIVATION IN STEROID-SENSITIVE NEPHROTIC SYNDROME

T.J. Neuhaus, V. Shah, R.E. Callard, T.M. Barratt

It has been postulated that steroid-sensitive nephrotic syndrome (SSNS) is due to a disorder of T-lymphocytes. In the present study we sought evidence of T-cell activation in children with SSNS by two-colour flow cytometry of the following lymphocyte subsets: Total $T$ cells (CD3), T-helper (CD4), cytotoxic-T (CD8), naive- $T$ (CD45RA), nemory- $T$ (CD45RO). The activation markers CD25 ( $\alpha$-chain of the IL2 receptor). MHC Class II DR, intercellular adhesion molecule-I (ICAM-1), and leucocyte adhesion molecule-1 (LAM-1) were also studied. Soluble IL2 receptor (sIL2R) was measured in serum and urine by ELISA. 29 SSNS children were seen in remission on 1-5 occasions and 15 of them were subsequently seen in relapse within $3-4$ days of the onset of proteinuria. These 15 had a median age of $11.5 \mathrm{yr}$ SIL2R was also measured in 11 healthy. agc-matched controls. The observation in relapse was compared with the mean of the results observed in remission in the same child by paired t-test.

\begin{tabular}{|c|c|c|c|c|}
\hline & Remission & Relapse & Mean Diff $(95 \% \mathrm{CI})$ & $p$-value \\
\hline GoCD+ $25^{+} / 1$ yniplioutes & 5.6 & 7.0 & $1 .+(0.8-1.9)$ & $=0.0005$ \\
\hline$\% \mathrm{CD} 4^{+} 25^{+} / \mathrm{CD}^{+}{ }^{+}$ & 15.8 & 19.1 & $3.3(1.6-5.1)$ & $<0.001$ \\
\hline $\mathrm{CD}^{+} 25^{+}\left(\mathrm{x} 10^{9} / 1\right)$ & 0.14 & 0.17 & $0.03(0.01-0.05)$ & $<0.05$ \\
\hline Serum & 713 & 710 & 3 & n.s. \\
\hline Urine sIL $2 \mathrm{R}$ (U/mg creat) & 272 & 592 & $320(91-549)$ & $<0.01$ \\
\hline
\end{tabular}

In relapse there was a highly significant increase in $\mathrm{CD}^{+} 25^{+}$lymphocytes, whether expressed as \% of all lymphocytes. \% CD $4^{+}$cells or absolute numbers. Lesser increases. when expressed as \% lymphocytes, were observed for $\mathrm{CD}^{+} 25^{+}, \mathrm{CD}^{+} \mathrm{DR}^{+}, \mathrm{CD}^{+}+5 \mathrm{RO} 0^{+}$ $\mathrm{CD}^{+} \mathrm{LAMI}^{+}, \mathrm{CD}^{+} 45 \mathrm{RO}^{+}$. CD $4 \mathrm{LAM} 1^{+}$and $\mathrm{CD}^{+} \mathrm{DR}^{+}$cells $(\mathrm{p}<0.05)$. Mcan plasma albumin concentration fell from +2 to $31 \mathrm{~g} / \mathrm{l}$, and cholesterol rose from 4.55 to 6.86 mmol/I. But there was no significant correlation between the change in $\mathrm{CD}^{+} 25^{+}$cclls and the change in plasma albumin or cholesterol, suggesting that the observed changes were not secondary consequences of the nephrotic state. No differences in lymphocyte subsets were observed in remission between the patients who subsequently relapsed and those who did not. Urine sIL2R was increased in relapse. but there was no change in serum concentration (which was also similar to controls) suggesting that increased urine sIL2R was due to increased glomerular permeability rather than lymphocyte activation. We conclude that CD4 T-helper cells are activated and express CD25 ( $\alpha$-chain of the IL2 receptor) early in relapse of SSNS

Medical and Cellular Immunology Units. Institute of Child Health. 30 Guilford Street. London WCIN 1EH. UK

E0 4

SOLUBLE INTERLEUKIN-2 RECEPTOR (SIL2-R) IN STEROID
RESPONSIVE NEPHROTIC SYNDROME (SSNS) OF
CHILDHOOD

M.J. Kemper, T. Meyer-Jark , J. Strehlau, D.E. Müller-Wiefel

Various clinical and immunological data point to an immune pathogenesis of childhood SSNS. We investigated serum levels of SIL2-R as indicator of T-cell activation in 31 patients with SSNS (age 3-16, median 9.5 years) and 14 controls (C) (age 3-16, median 10 years). 10 patients were studied during relapse (RL) before steroid treatment and 21 during remission (RM) (ISKDC criteria). 7 patients were investigated in both phases of the disease. We used an ELISA highly specific for the high-affinitiy slL2-R (Tac p 55; Immunotech, Marseille, France). Mean (+/- SD) sil2-R levels in RL were significantly elevated compared to $R M$ and $C(139.3+/-70.4$ vs. $72.7+/-29.1$ vs. $78.5+/-41.1 \mathrm{pMOL} / \mathrm{L}$ $\mathrm{P}<0.05$ respectively). In patients studied in both phases of SSNS this elevation could be confirmed. IN RM patients with infrequent relapses ahad significantly lower siL2-R levels than frequent relapser $(F R)$ ( $59.2+/-20.4$ vs. $87.8+/-30.5$ pMol/L; $P<0.05$ ) These data confirm alterations in the release of sIL2-R in SSNS Elevated levels in RL could reflect a T-cell activation; by expressing IL $2-R$ and releasing SIL2-R free IL 2 could be bound. IN FR elevated levels of sIL 2-R in RL could indicate a chronic T-cell activation as cause or consequence of frequent relapses. Further longitudinal studies of sIL 2-R are needed to elucidate the pathogenetic role and clinical usefullness of this marker in SSNS.

University Children's Hospital, Martinistr. 52, D-20246 Hamburg, FRG 
F05

LONG-TERM EFFICACY AND SAFETY OF CYCLOSPORIN A IN IDIOPATHIC NEPHROTIC SYNDROME

J Lim, C Turner, N Dalton,GB Haycock, SPA Rigden, C Chantier, G Clark

Eleven children (2 females) with steroid responsive nephrotic syndrome (SRNS) have been treated with cyclosporin A (CYA, $5 \mathrm{mg} / \mathrm{kg} / \mathrm{d}$ or less) for a mean period of 54.1 months (range 24-77). Serial renal biopsies were performed every 12-24 months. When in remission, nine underwent standard clearances of inulin (In) and paraaminohippurate (PAH) performed during water diuresis after 31 months of CYA therapy. $\mathrm{LiCO} 3$ was given the night before and frusemide 2 hours from the start of the clearance study. Plasma renin activity (PRA), aldosterone (Aldo) and tubular proteinuria (alburnin, retinol binding protein, NAG) were measured. Three children not taking CYA were also studied.

Results

Prednisolone was withdrawn in 17 of 22 CYA courses prescribed (77\%).The nephrotic relapse rate was 0.9 relapses per patient year. One renal biopsy showed very mild tubular atrophy, and peritubular capillary thrombi (PTCT) after 66 months of CYA therapy: this patient's CYA trough levels were satisfactory throughout most of this period. 2 other biopsies had PTCT. At the time of the clearance study (mean duration of CYA therapy $=31$ mos, range 5.53 ), no patient was hypertensive, mean CYA trough levels were $75 \mathrm{mg} / \mathrm{L}$ (range 14-235), mean dose was $3.8 \mathrm{mg} / \mathrm{kg} / \mathrm{d}$ (range 2.8-5.6).

\begin{tabular}{|c|c|c|c|c|c|c|c|c|c|}
\hline $\begin{array}{l}\text { SRNS } \\
\text { pts }\end{array}$ & $\begin{array}{l}\mathrm{C}_{\mathrm{ln}} \\
\mathrm{ml} / \mathrm{min} / \\
1.73 \mathrm{~m}^{2}\end{array}$ & $\begin{array}{l}\mathrm{PRA} \\
\text { baseline } \\
\mathrm{pg} / \mathrm{ml}\end{array}$ & $\begin{array}{l}\text { PRA } \\
\text { post } \\
\text { diuretic }\end{array}$ & $\begin{array}{l}\text { Aldo } \\
\text { beseline } \\
\text { fpost } \\
\text { diuretic } \\
\text { pg/ml }\end{array}$ & $\begin{array}{l}\mathrm{FE} \\
\mathrm{N \alpha} \\
\%\end{array}$ & $\begin{array}{l}\mathrm{EE} \\
\mathrm{Li} \\
\%\end{array}$ & $\begin{array}{l}\text { UAlb } \\
\text { g/ } \\
\text { mole } \\
\text { Cr }\end{array}$ & $\begin{array}{l}\mathrm{RBP} \\
\text { mg/ } \\
\text { mole } \\
\mathrm{Cr}\end{array}$ & $\begin{array}{l}\text { NAG } \\
\text { mmol } \\
\mathrm{h} / \\
\text { mole } \\
\mathrm{Cr}\end{array}$ \\
\hline $\begin{array}{l}9 \\
\text { on } C Y A\end{array}$ & 133 & 29 & 35 & $78 / 61$ & 2.6 & 28 & 1.06 & 6.3 & 58,1 \\
\hline $\begin{array}{l}\text { No.Ab- } \\
\text { normal }\end{array}$ & 0 & 0 & 0 & 0 & & & $L^{*}$ & $1^{*}$ & $1^{*}$ \\
\hline $\begin{array}{l}3 \text { not } \\
\text { on CYA }\end{array}$ & 131 & 22 & 44 & $66 / 61$ & 1.7 & 32 & 1.2 & 5.2 & 19.2 \\
\hline
\end{tabular}

All values are means. ${ }^{*}=$ patient with tubular atrophy.

We conclude that long-term CYA therapy at this dose is efficacious and scre in children with steroid responsive nephrotic syndrome.

Dept of Paediatric Nephrology, Guy's Hospital, London SEI 9RT, UK

\section{CELL DEATH IN CYSTIC KIDNEY DISEASES. P. J. D. Winyard, D. S. Lirenman, R. A. Risdon, V. R. Sams and A. S. Woolf.}

Extensive normal programmed cell death occurs in the mouse metanephros. This process, called apoptosis, may have a role in nephron morphogenesis. In addition, mice with homozygous null mutations of $B C L-2$, a gene which prevents cell death, have excessive renal apoptosis and die in infancy from polycystic kidney disease. In this study we examined sections of 7 normal human embryonic kidneys (5-34 weeks gestation) using the propidium iodide technique to enhance apoptotic nuclei. Cell death was prominent in collecting duct epithelia and in nephron precursors. In contrast, only rare apoptotic cells were noted in 2 normal post-natal kidneys. Next, we examined 5 autosomal recessive polcystic kidneys (ARPKD) and 4 multicystic dysplastic kidneys (MDK). In ARPKD, apoptotic nuclei were present in collecting ducts of normal diameter and also in cyst epithelia; extensive cell death was also noted in degenerating tubules between large adjacent cysts. In MDK, cell death was observed in cyst walls and in undifferentiated mesenchyme; in contrast, apoptosis was not found in the primitive ducts. We conclude that cell death is prominent in normal human nephrogenesis and in childhood renal cystic diseases. In the latter conditions extensive cell death may reflect a lack of renal differentiation and could contribute to tubule destruction in ARPKD and to the tissue involution that has been reported in MDK.

Medical and Histopathology Units, Institute of Child Health, London WC1 1EH, and UCLMS, London, UK.
$\mathrm{F} 07$

IS RENAL DYSFUNCTION IN GLYCOGEN STORAGE DISEASE TYPE I (GSD-I) PRIMARILY TUBULAR?

P.J. Lee', RN. Dalton ${ }^{2}$, V. Shah ${ }^{3}$ and J.V. Leonard'.

Patients with GSD-I have been shown to have glomerular hyperfiltration prior to the onset of proteinuria. However in previous reports controls have not been studied and the aetiology of the renal disturbance remains unclear. Therefore we assessed urinary excretion of protein and calcium and renal ultrasonography in 79 patients with the hepatic GSDs: 30 with GSD-I, 25 with GSD-III and 24 with GSDs-VI/LX (median age 11.7 years, range 1.2-35.4). Continuous inulin and paraaminohippuric acid (PAH) clearances were also performed in 18 with GSD-I, 9 with GSD-III and 6 with GSDs-V/IX.

$\begin{array}{llll}\text { Geo mean, range } & \text { GSD-I } & \text { GSDs-III,VI.IX } & \underline{\mathrm{P}} \\ \text { Alb/Creat, g/mol } & 1.25(0.04-44.1) & 0.25(0.04-1.64) & <0.001 \\ \text { RBP/Creat, g/mol } & 64.0(0.7-5728) & 7.6(2.2-127.9) & <0.001 \\ \text { NAG/Creat, } \mathrm{mol} / \mathrm{hr} / \mathrm{mol} & 11.5(2.2-59.2) & 6.2(1.9-19.9) & 0.001\end{array}$

$11 / 30(37 \%)$ with GSD-I and $7 / 49(14 \%)$ with other GSDs had hypercalciuria (Chi $\mathrm{sq}=5.3, \mathrm{p}=0.02)$. In GSD-I, GFR $\left(146.6(46.1)\right.$ v $106(19.7) \mathrm{mls} / \mathrm{min} / 1.73 \mathrm{~m}^{2}$, $p=0.003)$ and mean renal length $(109(15.6)$ y $94(16.0) \mathrm{mm}, \mathrm{p}<0.001)$ were significantly increased, but PAH clearance and filtration fraction were not. In GSDI, GFR was greater than $140 \mathrm{mls} / \mathrm{min} / 1.73 \mathrm{~m}^{2}$ in $12 / 18$ patients and correlated inversely $(r=-0.5, p<0.001)$ with age, whereas urinary albumin excretion was normal in younger patients and correlated positively $(r=0.42, p<0.01)$ with age. Excretion of RBP, calcium and NAG to a lesser degree, were generally high in al age groups. We conclude that hyperfiltration in GSD-I is associated with renal tubular proteinuria which occurs in younger patients than does albuminuria. These data suggest that glucose-6-phosphatase deficiency within the proximal renal tubule primarily causes tubular dysfunction with glomerular hyperfiltration being a secondary phenomenon. Study of the renal dysfunction in GSD-I may help our understanding of hyperfiltration associated with other disorders.

Address: The Medical Unit, Institute of Child Health'; Department of Paediatric Biochemistry, Floor 12, Guy's Tower, Guy's Hospital2; Department of Renal Biochemistry, Institute of Child Health ${ }^{3}$, London WC1N 1EH, U. K.

F08

EPIDEMIOLOGY OF PRIMARY HYPEROXALURIA TYPE 1

P Cochat*, A Deloraine, F Olive, M Rotily, N Deries, on behalf of the Société de Néphrologie

Primary hyperoxaluria type $1(\mathrm{PHI})$, an autosomal recessive inborn error of glyoxalate metabolism, always leads to insoluble oxalate accumulation throughout the body, called oxalosis. Except when renal replacement therapy (RRT) is required, no epidemiological data are currently available.

French nephrologists (Société de Néphrologie Registry) were questioned in 1993 about PH1 patients who were referred to them between 1988 and 1992. Exhaustive answers were obtained either by mail or by phone. 95 cases (male/female 1.33) of hyperoxaluria were collected : 39 were new patients and 4 were excluded ( 3 PH2 $1 \mathrm{PH} 3,1$ incomplete observation). The average prevalence rate was $1.04 / 10^{6}$ hab and the average incidence rate was $0.12 / 10^{6}$ hab ner year. The median age at clinical onset was 5 years (range $0-63$ ) and the first symptom involved the urinary tract in $82 \%$ of the cases. Half patients were younger than 10 years at the time of diagnosis (median 10 years, range $0-65)$ that was established by urine oxalate $(89 \%) \pm$ urine glycolate $(43 \%) \pm$ plasma oxalate $(71 \%) \pm$ hepatic alanineglyoxylate aminotrasferase activity (48\%). At the time of the survey, $36 \%$ were on conservative treatment, $37 \%$ were transplanted and $27 \%$ were on dialysis. Patients on dialysis started RRT at a median age of 25 years $(21 \%<10$ yrs of age). Transplanted patients received their first transplint at a median age of 29.5 years $(13 \%<$ 10 years of age) ; 32 out of them were followed for more than 1 year : 17 isolated kidney transplantation (1 success), 1 isolated liver transplantation (1 success) and 14 combined liver/kidney transplantation (10 successes). The overall mortality rate was $19 \%$ (median age 36 years, $1 / 3$ died before 20 years of age).

These data confirm the rarity of PHI (5 to 9 new cases per year in France) together with its poor prognosis that requires early liver and/or kidney transplantation

* Unité de Néphrologie Pédiatrique, Hôpital Edouard Herriot and Université Claude Bernard, 69437 Lyon, France 
F09

COL5A1 AND THE NAIL PATELLA LOCUS ARE CO-LOCALIZED ON THE LONG ARM OF CHROMOSOME 9.

F. Cappa, G. Caridi, G.M. Ghiggeri, A. Pezzolo*, G. Gimelli*, G. Piaggio, F. Perfumo, R. Gusmano.

Linkage studies have recently mapped the locus of the Nail-Patella syndrome (NPS1) on the q34-qter region of the chromosome 9 , but definitive evidence for a candidate gene is still lacking. Since NPS1 is an inherited autosomal dominant disease involving a defective assemblement of connective tissue in bones and kidneys, it is possible to suspect a link with extracellular matrix proteins. Studies on the genomic localization of the collagen are currently in progress. We present data indicating the co-localization of the NPS1 with COL5A.1 which is the gene coding for the alpha 1 chain of collagen $V$. The following methods were utilized: a) amplification of a 353 bp segment of COL5A1 by PCR and subcloning in a PCR1000 vector; b) chromosome localization with fluorescent "in situ" hybridization. With these techniques CoL5AI was, in fact, mapped on chromosome 9q34.3.

These data indicate that COL5A1 maps on the long arm of chromosome 9 near the locus of NPS1. Since this encoded chain of collagen $V$, is a major struc tural components of connective tissue in bone and kidney, we hypothesize its involvement in NPS1.

Molecular studies involving collagen $V$ expression by renal tissue in patients with NPS1 are currently

in progress to demonstrate a direct implication.

Present address: Department of Nephrology, G. Gaslini Institute, Largo G. Gaslini 5, 16148 Genoa-Italy.

*Lab. of Cytogenetics, G. Gaslini Institute.

Molecular and immunological studies in X-linked and autosomal recessive Alport syndrome.

H.H. Lemmink ${ }^{1^{*}}$, L. van den Heuvel ${ }^{1}$, T. Mochizuki ${ }^{3}$, C.A.H.Schröder ${ }^{1}$, W. Nillesen $^{2}$, B.A. van Oost ${ }^{2}$, H.G. Brunner ${ }^{2}$, S.T. Reeders ${ }^{4}$, L.A.H. Monnens ${ }^{1}$, H.J.M. Smeets ${ }^{2}$.

Departments of Pediatrics ${ }^{1}$ and Human Genetics ${ }^{2}$, University Hospital Nijmegen, Nijmegen, The Netherlands.

Department of Medicine ${ }^{3}$, Albert Einstein College of Medicine, 1300 Morris Park Avenue, Bronx, New York, USA.

Brigham and Women's Hospital, Renal Division', 75 Francis Street, Boston, USA.

Alport syndrome is a hereditary, progressive kidney disorder with characteristic ultrastructural lesions of the glomerular basement membrane (GBM). As yet, four type IV collagen genes have been shown to be mutated in Alport syndrome patients. Most mutations ( 9 in our group of 45 patients) have been detected in the X-linked COL4A5 gene. Recently, we have identified the first mutations in the COL4A3 and COL4A4 genes in autosomal recessive forms of Alport syndrome. Three different COL4A3 mutations were detected in 3 of our patients and in 2 patients both COL4A3 genes were mutated. Patients, who lacked the major part of either the COL4A5 or COL4A3 NC-domain, were at risk for the development of a post-transplant anti-GBM nephritis. ELISA studies performed with anti-GBM antibodies of such patients showed that the targets of the antisera correlated with the mutations in their respective genes. Furthermore, antibodies against either the COL4A5 or the COL4A3 NC-domains did not bind to kidney biopsies of patients withframeshift mutations in either the COL $4 A 5$ or the COL4A3 gene. The absence of both collagen proteins in the GBM of these patients may be explained by an obligatory interaction between the COL4A3 and COL4A5 chains in the GBM.

": Adress; Department of Human Genetics, University Hospital Nijmegen, P.O. Box 9101, 6500 HB Nijmegen, The Netherlands.
F11

THE NEPHROPATHY OF TYPE I TYROSINEMIA AFTER LIVER TRANSPLANTATION IN CHILDREN

J. Laine, M.K. Salo, L. Krogerus, J. Kärkkäinen, Ö. Wahlroos, and C. Holmberg

Type I tyrosinemia is an autosomally recessively inherited disease caused by deficiency of the enzyme fumarylacetoacetate hydrolase (FAH) in the liver and the kidneys. The disease manifests itself as early liver failure (acute form), milder abnormalities in liver function (chronic form, risk of hepatic carcinoma 37\%) and a renal Fanconi-like syndrome with hypophosphatemic rickets. Liver transplantation (OLT) is the treatment of choice. Although OLT cures the liver disease, the long-term prognosis of the renal lesion is unclear. Severe nephrocalcinosis and decreased GFR have been reported prior to OLT. At least 3 renal transplantations have been performed on these patients.

We investigated renal function and histopathology after OLT in 8 patients with type I tyrosinemia. The patients were on triple immunosuppression (CsA+Aza+MP). 7/8 paticnts are consanquinous at a distance of 9 to 14 generations and 4 patients have toc same mutation in the FAH-gene (others not investigated). Mean age was 0.4 years (range 0.1-0.6) at diagnosis and 1.5 years $(0.4-2.7)$ at OLT. Mean follow-up is 3.2 years (2.34.3). All patients excreted succinylacetone in the urine after OLT. Mean GFR before OLT was $82 \mathrm{ml} / \mathrm{min} / 1.73 \mathrm{~m} 2$. It was 102 at 18 and $92 \mathrm{ml} / \mathrm{min} / 1.73 \mathrm{~m} 2$ at 36 months after OLT. Before OLT all patients showed amino-aciduria or glucosuria, were hypophosphatemic and 4 had rickets. At 18 months $3 / 8$ patients showed aminoaciduria/giucosuria, $3 / 8$ phosphaturia and $6 / 8$ hypercalciuria. Renal histopathology showed mesangial cell proliferation ( $3 / 4$ biopsies), tubular epithelial vacuolation (4/4) and swelling (3/4) at OLT. Most changes were mild. In biopsies taken at 18 ( 7 patients) and at 36 months ( 3 patients) no evidence of progressive renal disease or nephrocalcinosis was seen. However, one patient showed mild glomerulosclerosis at 36 months.

In conclusion, rapidly progressing renal disease was not seen. However, tubular abnormalities were common 18 months after OLT and may persist even longer. Careful follow-up of renal function is indicated after liver transplantation for type I tyrosinemia.

Children's Hospital, University of Helsinki, Stenbäckinkatu 11, FIN-00290, Helsinki, FINLAND
F12

\section{CONGENITAL NEPHROTIC SYNDROME - A DIAGNOSTIC PROBLEM}

M.Bulla ${ }^{1}$ M. Cramer-Timmer ${ }^{1}$, R. Waldherr ${ }^{2}$

A nephrotic syndrome before 3 months of life is considered as congenital (CNS), later in the first year as infantile (INS). CNS/INS can be differentiated in 1. CNS of Finnish type (CNF), 2. diffuse mesangial sclerosis (DMS), 3. CNS of childhood type, 4. secondary CNS associated with other conditions. Clinical course and prognosis shows great variations, therefore classification has to be based on histopathology. But, by the great morphological variation this may be difficult. By a german questionnaire over the period 1980-1993, we collected 127 cases of INS/CNS. 88 cases were german offsprings, 39 of turkish/arabic origine: incidence $1,2 / 100000$ births in germans, 8,3 in turkish/arabic. In germans $17 / 88$ were CNS $(19,3 \%)$, in the oriental group 27/39 (69,2\%). In germans, CNS were histological classified: $37,5 \%$ CNF, 6,3\% DMS, 58,8 \% CNS of childhood type. Clinical course was in favour with histopathology. But in the orientals the early histological pictures present diagnostic problems escaping prevailing classification. First diagnosis with $44,4 \% \mathrm{CNF}, 29,6 \%$ DMS, $14,8 \%$ CNS of childhood type were in contrast to the extreme bad prognosis with high mortality in the first weeks of life (21/27), the rapid progression in terminal renal failure and to the false-negative results in prenatal diagnosis. By reexamination, we experienced in a considerable number of cases that the early histological picture of DMS was confused with CNF and other glomerular diseases with mesangial hypercellularity. The revised classification $(21,6 \% \mathrm{CNF}, 48,2 \%$ DMS, $7,4 \% \mathrm{CNF} / \mathrm{DMS}$, $14,8 \%$ CNS of childhood type) was in better agreement with the clincial course. Summary: Histological classification in CNS should be performed by two independent pathologists. In unexpected clinical course reexamination is demanded. The diagnosis has to be critically evaluated before genetic conselling and prenatal diagnostic.

\footnotetext{
' Pädiatrische Nephrologie, WWU Münster, Germany

${ }^{2}$ Pathologisches Institut, Universität Heidelberg, Germany
} 
F13

REPORT OF THE PAEDIATRIC REGISTRY OF THE EDTA ON RENAL REPLACEMENT THEFAPY OF CHILDREN IN EUROPE JHH Ehrich and Chantal Loirat, Berlin and Paris Until 31 December 1993 almost 10,000 children with end stage renal failure were reported to the European Dialysis and Transplant Association Registry to have started renal replacement therapy (RRT) under 15 years of age in Europe. The report will mainly focus on 1 . preemptive transplantation, 2. HUS, 3. RRT in infants and 4. malignancies before and after start of RRT. 422 preemptive transplantations were performed in children from 1981-92. 25\% of all LRD grafts and 9\% of al1 CAD grafts were preemptive transplantations. Preemptive $\mathrm{Tx}$ were performed more frequently in young children, in Nordic countries, in recent years, and in patients with renal hypo- or dysplasia. Patient and graft survival after preemptive $\mathrm{Tx}$ were not different from grafted patients with prior dialysis.

833 patients with HUS starting RRT <40years were reported from $1978-92$. 2.5\% of all 17,916 patients $<20 y r s$ had a HUS, and $0.5 \frac{5}{8}$ of 78,297 patients aged $20-$ 39 yrs. HUS both in children and adults was mainly reported from the Netherlands, Belgium, France and Germany. Survival of patients and of grafts in patients with HUS will be given.

510 patients were reported to have started RRT between. 1979-92 under two years of age. Patient and graft survival in this young age group increased in recent years, however, 2 years after start of RRT only $36 \%$ of the surviving patients lived with a functioning graft and compared to $51 \%$ in children starting RRT between 2 and 5 years of age

152 patients were reported to have had a malignancy before start of RRT under 20 years of age. $49 \%$ had a Wilms tumour. 191 patients starting RRT < 20yrs developed a malignancy thereafter, $24 \%$ had leukaemias or reticuloses and $21 \%$ genital tract or breast tumours.

\section{F 14}

\section{PROGRESSIYE IMPAIREMENT OF RENAL FUNCTION IN PEDIATRIC RENAL TRANSPIANT RECIPIENTS \\ C. GUYOT for the French Society of Pediatric Nephrology}

The slow decrease in renal function is a major barrier to long term renal allogreft survival. The aim of this cooperative study, organised by the French Society of Pediatric Nephrology, was to investigate the impact on the incidence of graft function variation of these variables : acute rejection episodes during the first year, CSA dosage at 1 year, antinypertensive treatment, ratio of the body surface aera between donor and recipient ( $D / R$ ratio) and donor source.A total of 314 pediatr ic renal transplant recipients were registered between January 1987 and December 1991. For 66 of these recipients, the long term graft function has been investigated up to four years. Renal function was evaluated at 1 year (GFR1) and at 4 years (GFR 4). The variation of GFR ( $\% \triangle G F R$ ) was given by the following formula ${ }_{\Delta} \Delta F R=($ GFR $4-$ GFR 1$) /$ GFR $1 * 100$. During the first year rejection episodes occured in 27 of 66 transplantations. Mean $\% \Delta G F R$ was not significantly different in chidren with acute rejection episodes compared with that in children without acute rejection episode $(-7.2 \pm 22 \%$ versus $-6.8 \pm 32 \%$ ). According to CSA dosage at 1 year mean $\$ \triangle G F R$ was not significantly different $-83+25$ \% with a CSA dosage $<5 \mathrm{mg} / \mathrm{kg} / \mathrm{d},-8.3 \pm 24 \%$ with CSA dosage > 5 $\mathrm{mg} / \mathrm{kg} / \mathrm{d}$ and $<8 \mathrm{mg} / \mathrm{kg} / \mathrm{d},-4.3 \pm 34 \mathrm{~s}$ with $\mathrm{CSA}>8 \mathrm{mg} / \mathrm{kg} / \mathrm{d}$. Mean \% $\triangle$ GFR was significantly higher in children without antihypertensive treatment compared with that in children who required antihypertensive medication ( $-16 \pm 23 \%$ versus $-0.6 \pm 24 \%$ ). Mean \% $\Delta G F R$ was higher in children with a $D / R$ ratio $>1.3$ compared with that in children with a $D / R$ ratio $<0.8$. According to donor source, mean $\% \triangle G F R$ was significantly higher in recipients with living related donors compared with that of recipients who received a cadaver kidney $(-21.6 \pm 8 \%$ versus $-4.4 \pm 24 \%$ ).

Conclusion: The rate of impairement of renal function was not related to 1) rejection episodes during the first year 2) CSA dosage at 1 year (although the hightest dosages had the slowest rates of renal deterioration). The incidence of renal impairement was lower among recipients with antihyper tensive therapy. Living related donor source and a hight $D / R$ ratio were aggravating factors of renal function.

Hôpital Mère et Enfant - CHR de Nantes 44035 Nantes - France
F15

\section{MALIGNANCY IN CHILDREN WITH RENAL REPLACEMENT THERAPY \\ G.Offner on behalf of the Arbeitsgemeinschaft Pädiatrische Nephrologie}

'The increased incidence of cancer following renal transplantation is well documented in adult recipients. Less is known about malignant disorders in children with renal replacement therapy (RRT).

A questionnaire concerning this complication was sent to all 19 paediatric dialysis and transplant units in Germany. We gathered 34 children with cancer who started RRT under 15 years of age in the time between 1971 and 1991. During this period, EDTA reported from Germany 1239 children < 15 years, $60 \%$ renal allografted.

13 children had experienced the malignant disorder before RRT (10 wilms tumors) and 21 developed malignancy during RRT, 18 after renal transplantation. The immunosuppressive regimen was Azathioprine in 13 children and Cyclosporine in 15 . The 18 posttransplant tumors are summarized in the table:

\begin{tabular}{llll} 
Tumor & $\mathrm{N}$ & $\begin{array}{c}\text { Time post Tx } \\
\text { (years) }\end{array}$ & $\begin{array}{c}\text { 1 year } \\
\text { survival }\end{array}$ \\
\hline Lymphoma & 8 & $0.0-11.0$ & $50 \%$ \\
AML & 2 & $5.4-9.7$ & $0 \%$ \\
Adenocarcinoma & 4 & $11.0-14.0$ & $80 \%$ \\
Kaposi sarcoma & 2 & $1.5-5.5$ & $80 \%$ \\
Gonadal & 2 & $0-15.1$ & $100 \%$ \\
\hline
\end{tabular}

In children with RRT the risk of developing a malignant disorder was $2.5 \%$. Successfully treated malignancies prior to RRT did not recur after renal transplantation.

Kinderklinik Medizinische Hochschule Hannover D 30625 Hannover FRG

\section{F 16}

DISEASE-SPECIFIC GROWTH CHARTS FOR PREPUBERTAL CHILDREN WITH CHRONIC RENAL FAILURE (CRF) DUE TO CONGENITAL RENAL DISORDERS

F. Schaefer, S. Rigden, A.-M. Wingen, M. Hännicke, O. Mehls, and European Study Group on Dietary Intervention in Children with CRF

Despite the high prevalence of and therapeutic attention to growth failure in children with CRF, systematic evaluations of spontaneous growth patterns in CRF are lacking. Therefore, we collected retrospective, longitudinal growth and biochemical data in 319 prepubertal patients treated in 22 pediatric nephrology centers in 11 European countries for CRF due to congenital renal disorders (mainly hypo-/ dysplastic kidney disease). Data were recorded at 3 month intervals during the first two years of life and six-monthly thereafter, up to the age of 10 years. $70 \%$ of the patients were male. The mean follow-up time was $3.7 \pm 3.1$ years. The mean calculated GFR averaged for each subject was $25 \pm 12 \mathrm{ml} / \mathrm{min} / 1.73 \mathrm{~m}^{2} .90 \%$ of the height measurements were recorded in preterminal CRF, $10 \%$ on dialysis. A total of 2272 height measurements were available for analysis, i.e. around 100 measurements per age interval. Hcight velocity could be calculated for 1096 one-year intervals, where pairs of height rccordings 11-13 months apart were available. Mixed-longitudinal percentile curves of height and height velocity were constructed and smoothed by a nonparametric, weighted moving average algorithm. In addition, a statistical comparison with the standards of the Zurich Longitudinal Growth Study was performed. The CRF children had normal heights at birth but dropped below the third normal percentile during the first 18 months of life. Thereafter, growth patterns usually were centile-parallel, with a mean height SDS of $-2.37 \pm 1.6$ SDS. Height velocities were consistently lower in patients with GFRs below one third of the lower normal limit (25 ml/min/ $1.73 \mathrm{~m}^{2}$ for patients $>2$ years) than in patients with better renal function. This difference in growth rates resulted in a mean height SDS of $-1.65 \pm$ 1.5 SDS and $-2.79 \pm 1.4$ SDS (age 1-10 years) in the subgroups with relatively better and worse GFR, respectively. Separate height and height velocity percentiles were constructed for these subgroups. No sex differences in growth rate or attained height were observed at any age in this prepubertal population. Although height velocity was correlated with certain biochemical parameters (hemoglobin, bicarbonate) in individual age groups, multiple regression analysis did not disclose any GFR-independent effects of these variables on growth rates.

Pediatric Nephrology Division. University Children's Hospital, Im Neuenheimer Feld 150, D-69120 Heidelberg. Germany 
EFFECTS OF CHRONIC METABOLIC ACIDOSIS (CMA) IN 24-HOUR GROWTH HORMONE SECRETION.

A. CALDAS and M. FONTOIJRA*

Chronic Metabolic Acidosis is usually accompanied by severe growth retardation. A causal relationship has been both documented in several experimental and clinical studies with or without chronic renal failure (CRF). The mechanisms responsible for the growth retardation associated with CMA are still unknown in spite of motivating various publications. We are not avare of any other data in man. in which the physiological concentration of $\mathrm{GH}$ is studied in CMA. Spontaneous GH secretion (24 hr profile), GH secretion in arginine-insulin tolerance test (AITT) and plasma IGF-1 were evaluated in 3 groups of prepubertal children:(a) with CRF(n-6) aged $8.2 \pm 2.2 y r$; (b) with Renal Tubular Acidosis (RTA) $(\mathrm{n}=6)$ aged $8.5 \pm 2.3 \mathrm{yr}$ and (c) control children (n-6) aged $8.5 \pm 2.1 y r$. In CRF and RTA children the study was perlormed in two different periods: during acidosis $(A)$ and without acidosis (WA)

(" $p<0.05$; $^{\text {nt }}$ p $<0.001 ;$;*a $p<0,0001$ vs A.; Mean \pm SEM).

\begin{tabular}{|c|c|c|c|c|c|c|}
\hline \multirow[b]{2}{*}{ CAF } & & \multicolumn{2}{|c|}{$24 \mathrm{hr}$ profilei $\beta \mathrm{g} / \mathrm{L})$} & AITT $(\mu \mathrm{g} / L)$ & IGF-1 & \\
\hline & $\mathbf{w}$ & $\begin{array}{l}\text { mean } \mathrm{GH} \\
5.23 \pm .3^{*+4}\end{array}$ & $\begin{array}{l}\text { Peak GH } \\
19.6 \pm 1.4^{*}\end{array}$ & $\begin{array}{l}\text { Peat } \mathrm{GH} \\
20.5 \pm 1.5^{\circ+4}\end{array}$ & $\begin{array}{l}(n g / m l) \\
330 \pm 21^{+1}\end{array}$ & $\begin{array}{l}\left(W / H^{2}\right) \\
15.5 \pm .6\end{array}$ \\
\hline & $\mathbf{A}$ & $3,05 \pm .2$ & $8.86 \pm 0.4$ & $9.50 \pm 0.9$ & $166 \pm 15$ & \\
\hline ATA & $\mathbf{m}$ & $4.88 \times .2^{4 * 4}$ & $15.7 \pm 0.9+0$ & $17.1 \pm 1.7^{* 0}$ & $271_{ \pm} 19^{\circ}$ & $14.3 \pm .8$ \\
\hline & $\boldsymbol{\Lambda}$ & $2.76 \pm .2$ & $7.2 \pm 0.9$ & $7.93 \pm 0.8$ & $156 \pm 17$ & \\
\hline & & $5.18 \pm .3$ & $18.2 \pm 1.8$ & $19.3 \pm 2.2$ & $270 \pm 20$ & 15.8 \\
\hline
\end{tabular}

2 ahr hormone profile suggests that acidosis cause disturbance of the hypothalamic-pituitary axis with blunting of spontaneous overnight pulsatility of $\mathrm{GH}$. The significant correlation between the $24-\mathrm{hr}$ GH secretion and the plasma IGF- 1 levels with plasma $\mathrm{pH}$ and $\mathrm{HCO}$ - concentration suggests a direct action of acidosis on $\mathrm{GH}$ secretion. The decrease of $\mathrm{GH}$ secretion and the IGF-1 plasma levels may be the main mechanism involved in growth retardation observed in children with renal CMA.

* Present adress Department of Paediatrics. IIniversity of Porto 4200 Parto Portugal

F 18

THE USE OF RECOMBINANT HUMAN GROWTH HORMONE (rhGH) IN RENAL. DISEASE : COMBINED BRITISH DATA

H.Maxwell, L.Rees for the British Association of Paediatric Nephrology

Twelve of the 13 British centres for paediatric nephrology entered 98 children into a study of 1 year of 1 iu/ $\mathrm{Kg} /$ week rhGH in 7 categories; $\mathrm{Gp1}$ transplantation (Tx), Gp2 chronic renal failure (CRF) and $G p 3$ dialysis (D), with each group being subdivided into prepubertal(a) and pubertal(b). Gp2a(i) are all CRF $<3 y r s$. Mean (SD) age (yrs), GFR (m/s/min/1.73m2), HtSDS and height velocity (HV $\mathrm{cm} / \mathrm{yr}$, before treatment are given below. Gp1 a were taking prednisolone 9.0(3.6) $\mathrm{mg} / \mathrm{m} 2$ on alternate days; Gp1b 8.2(3.3). Results to date are shown.

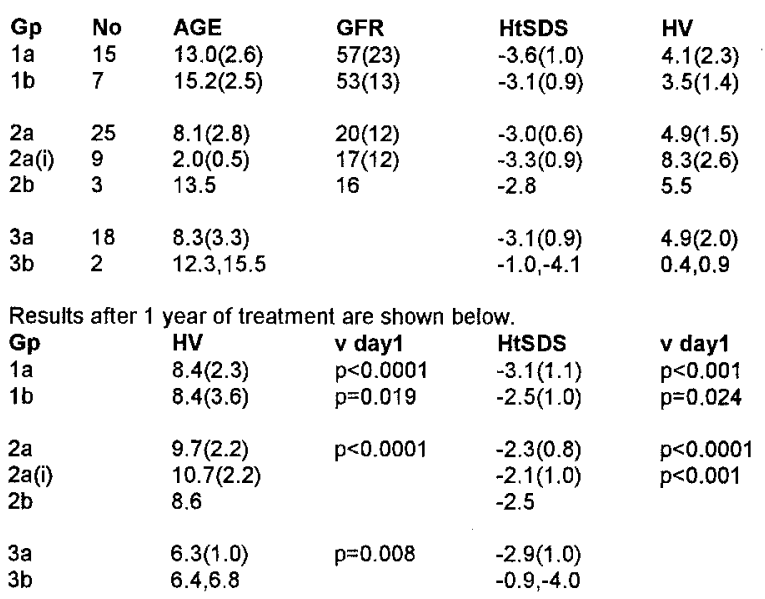

Response was greatest in prepubertal CRF, with the <3yrs showing a marked improvement in HtSDS. Both Tx groups responded well, whereas growth in Dx was more variable. Further results in $D x$ are awaited and may help predict those likely to respond to $\mathrm{rGH}$.

Paediatric Nephrology, Royal Free Hospital, Pond St, London NW3 2QG
GROWTH HORMONE (GH) TREATMENT IN SHORT CHILDREN WITH CHRONIC RENAL FAILURE (CRF): A 5 YEAR FOLLOW-UP D.. Haffner, E. Wühl, B. Tönshoff, and $O$. Mehls for the German Study Group for Growth Hormone Treatment in Chronic Renal Failure.

Recombinant human (rh) GH has become a new treatment modality for short children with CRF but long term effects are uncertain. For up to five years 82 children with CRF were treated with rhGH (1 IU/ $/ \mathrm{kg} /$ week). Inclusion criteria were a basal height $<-2$ standard deviation scores (SDS) and a basal height velocity (HV) $<0$ SDS. 49 children were on conservative treatment [median age 8.3 yrs (1.6-14.5); median CCR $24 \mathrm{ml} / \mathrm{min} / 1.73 \mathrm{~m}^{2}$ (8-59)], 33 were dialysed [median age $8.8 \mathrm{yrs}(2.7-18.4)$ ]. HV doubled from $4.3 \pm 2.4 \mathrm{~cm} /$ year (mean $\pm S D$ ) to $8.8 \pm 2.5$ during the first treatment year and remained above basal HV (2nd yr: $7.7 \pm 2.0$; 3rd yr: $5.9 \pm 1.2$; 4th yr: $5.8 \pm 1.2$ and 5 th $y r: 5.7 \pm 1.0$ ). Mean height improved more than 2 SDS (basal: $-3.6 \pm 1.0 ; 5$ th yr: $-1.5 \pm 0.9$ ). This resulted in normalisation of height in 26 out of 82 patients. Growth response was significantly lower $(p<0.05)$ in children on dialysis compared with preterminal CRF. There was no inadequate bone age advancement. Oral glucose tolerance did not change significantly whereas insulin secretion increased significantly $(p<0.01)$ after 6 month and remained high. The mean loss of CCR during $\mathrm{rhGH}(2.7 \pm 2.6$ $\mathrm{ml} / \mathrm{min} / 1.73 \mathrm{~m}^{2} /$ year) was not significantly different from the pretreatment year $(4.6 \pm 3.5)$ and did not differ to a matched "control group" (2.3 \pm 1.6$)$. - In summary, rhGH treatment (I) increases growth rates in short children with CRF for up to five years (II) to improve height (III) without obvious side effects.

Department of Pediatrics, University of Heidelberg, Im Neuenheimer Feld 150, D- 69120 Heidelberg, Germany
F 20

EFFECTS OF VEROCYTOTOXIN-1 (VT) ON VIABILITY AND PROTEIN SYNTHESIS OF HUMAN GLOMERULAR CAPILLARY ENDOTHELIAL CELLS (GCEC)

${ }_{\text {P.A. } \text { van Setten }}{ }^{1}$, L.P.W.J. van den Heuvel ${ }^{1}$, J.D. Mahan ${ }^{2}$, C.McAllister ${ }^{2}$, L.A.H. Monnens ${ }^{1}$.

Infection with a verocytotoxin-1 (VT) E.coli, mainly $0157 \mathrm{H} 7$, is strongly implicated in the etiology of the epidemic form of the hemolytic uremic syndrome (HUS). Injury to the glomerular endothelial cells has a pivotal role in the pathogenesis of HUS. Until recently only the effect of VT on human umbilical vein endothelial cells (HUVEC) and renal microvascular endothelial cells (RMEC) has been studied. VT appears to be cytotoxic in HUVEC only after cytokine exposure. In RMEC the level of the VT receptor seems to be increased. The responsiveness of human GCEC to VT has not been previously investigated. For this reason we studied the cylotoxicity of VT on human GCEC, the presence of the globotriosylceramide $\left(G_{3}\right)$ receptor, which was proven to be the receptor for VT in HUVEC, lymfocytes and monocytes and finally the underiying mechanisme of the obscricd cytotoxicity (protein synthesis). Human GCEC were isolated from human kidneys and purified by cell sorting. GCEC were incubated with purified VT $(0.1 \mathrm{M}$ to $1 \mathrm{nM})$ for up to 24 hours. Cytotoxicity was determined by cell counts as well as by lactate dehydrogenase (LDH) release. The presence of $\mathrm{GB}_{3}$ was defined by flow-cytometry using a monoclonal against the receptor. In order to study the protein synthesis the incorporation of ${ }^{35} \mathrm{~S}$-labeled methionine in proteins was measured during an 5.5 to 24 hours incubation with VT. VT $(0.1 \mathrm{pM})$ produced cell detachment and characteristic "spindle shaped" morphology. Cytotoxicity was first noted after 10 hours of VT (0.1 pM) and increased with longer exposure to VT. In contradiction with HUVEC, VT is cytotoxic for GCEC without preincubation with cytokines. Receptor analysis revealed the presence of the $G_{3}$ receptor and again there was no effect of cylokine preincubation on the amount of positive cells by flow cytometry, assuring the statement decribed above. The protein synthesis was inhibited as early as 5.5 hours (VT 1fM), this effect increased after 15 and 24 hours of VT incubation. We conclude from this study that human GCEC appear to be particularly susceptible to the toxic effects of VT. The GCEC seem to possess the $\mathrm{GB}_{3}$ receptor and binding of VT to this receptor results in inhibition of protein synthesis as shown previously in other cell types.

Dept. of Pediatrics, St. Radboud Hospital ${ }^{1}$, Nijmegen, the Netherlands and The Ohio State University ${ }^{2}$, Columbus, Ohio. 
F21

HEMOLYTIC UREMIC SYNDROME (HUS) IN CHILDREN WTTH VTTAMIN B12 INTRACELLULAR METABOLISM DEFICIENCY.

C. Loirat, H. Ogier de Baulny, V. Baudouin, M. Peuchmaur.

HUS in early life is unusual. We report 5 cases of HUS occuring in newboms with hereditary deficiency of vitamin B12 intracellular metabolism. Two of them have been partially reported by Russo et al (human Pathol 1992; $23: 504$, cases 2 and 3 ).

The 5 children had feeding difficulties, poor weight gain, hypotonia and lethargy, starting before day 15 . HUS occured between day 30 and 60 , with severe hemolytic anemia schizocytosis, thrombocytopenia (4), hematuria, proteinuria, high blood pressure (3), renal failure ( 4 documented cases, plasma creatinine $100-210 \mu \mathrm{mol} / \mathrm{l})$. Severe acidosis $(5)$ and leuconeutropenia (4) were present. Multivisceral involvement rapidly developed hepatocellular failure (5) ; gastrointestinal bleeding (3) ; severe interstitial pneumonitis (4) major hypotonia (5), lethargy (5), coma (2). Pigmentary retinopathy was present in $2 / 4$ cases. High plasma levels of homocysteine and methylmalonic acid, low plasma levels of

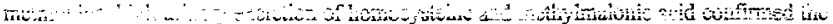
diagnosis of vit B12 metabolism deficiency, CblC group. Three children died from multivisceral failure, at age 42 to 71 days. In the 2 most recent observations, treatment (vit B12, folinic acid and betaine) was started 5 days after onset of HUS in 1 case, less than $24 \mathrm{~h}$ after onset in the other case. Metabolic anomalies were corrected after 5 and 7 days, renal and pulmonary symptoms within 15 and 20 days. The first child developed hydrocephaly and cerebral leucodystrophy at MRl, therefore treatment was stopped at 3 months and the child died 20 days later. The second child is now 2 years 2 months old and appears completely normal.

Histology showed diffuse glomerular and arteriolar thrombi with glomenular thrombotic microangiopathy in 2 cases (autopsy at day 41 and 44), ischemic glomeruli in 1 case (autopsy at age 3 months 20 days); diffuse thrombi in the pulmonary arterioles and small arteries and severe interstitial pneumonitis in 3 cases (early death), parietal fibrosis of pulmonary medium size and small arteries with calcium and iron deposits in 1 case (late death) ; total atrophy of gastric mucosa with extensive cystic changes and mononuclear cells infiltration in 2 cases (gastrointestinal bleeding), mild atrophic gastritis in 1 case (no digestive symptoms). CNS histology was normal in 2 cases.

Four other cases in the literature were similar to those reporied here. All of them died. The child of our serie who survives without clinical symptoms was the only patient treated very early. This outlines the necessity of early diagnosis and treatment, which may be the only way to avoid death or permanent neurologic damage.

Service de Néphrologie, Hôpital Robert Debré, Paris, France

F22

ROLE OF TNF RECEPTORS AND PROTEIN KINASE C IN THE INDUCTION OF THE VEROCYTOTOXIN RECEPTOR, GB3, IN HUMAN ENDOTHELIAL CELLS.

N.C.A.J. van de Kar, T Kooistra, L.A.H. Monnnens, V.W.M. van Hinsbergh.

Verocytotoxin (VT) producing E.coli infections have been strongly implicated in the hemolytic uremic syndrome (HUS). Endothelial damage plays a central role in HUS. In vitro studies have shown that VT can damage endothelial cells after interaction with its receptor Gb3. TNF $\alpha$ and IL-1 potentiate the toxic effect of VT by inducing an protein synthesis-dependent increase in VT receptors (Gb3) on endothelial cells. To investigate which proteins are involved in this induction, cells were incubated with and without TNF $\alpha$ in the presence of ${ }^{14} \mathrm{C}$-galactose or ${ }^{14} \mathrm{C}$-glucose. TLC analysis of the glycolipid extracts demonstrated a markedly enhanced incorporation of ${ }^{14} \mathrm{C}$-galactose in Gb3 suggesting that TNF $\alpha$ enhanced Gb3 synthesis by increasing galactosyl-transferase activity(ies). To examine the role of the two recently cloned TNFreceptors, TNFR75 and TNFR55, cells were incubated with TNF $\alpha$ or TNF $\alpha$ mutants selective for either TNFR75 or TNFR55. The effect of TNF $\alpha$ could be largely, but not completely mimicked by the TNF $\alpha$ mutant, which recognizes specifically the TNFR55. A contribution of the TNFR75 was mainly present during the first hours of incubation. Activation of PKC by phorbol ester could partly mimick the effect of $\mathrm{TNF} \alpha$. Involvement of PKC in the TNF $\alpha$-mediated increase in VT-1 receptors was further demonstrated by the specific PKC inhibitor Ro318220. Our results indicate that the increase in VT-receptors on endothelial cells by TNF $\alpha$ mainly occurs via the TNFR55 and depends on PKC activity.

Present address: Department of Pediatrics, Sint Radboud Hospital, P.O.Box 9101, Nijmegen, the Netherlands.

Gaubius Laboratorium, TNO-PG, P.O.Box 2215, 2301 CE, Leiden
523

\section{NEONATAL RENAL VENOUS THROMBOSIS IN GERMANY} A. Bökenkamp, R. von Kries* and P.F. Hoyer

Background: Renal venous thrombosis (RVT) in children occurs mainly in the neonatal period. To date, epidemiological data are based on autopsy studies dating between 1930 and 1965 , where an incidence of 0,4 to 1,9\% was found. Important factors for the manifestation of RVT have changed since these ealier studies. At present, there is no generally accepted therapeutic regimen for neonatal RVT.

Aim of the study was to estimate the incidence of neonatal RVT in Germany and to document the therapeutic modalities presently employed.

Patients and methods: In July 1992, the German registry on rare paediatric diseases (ESPED) started a nationwide survey on neonatal thrombosis. By December 31, 1993, 82 cases of neonatal thrombosis were reported, 23 of which were classified as RVT based on the findings of sonographically enlarged, hyperechogenic kidneys and macrohaematuria. During this period the response rate to the registry rose from 50 to $90 \%$. The population denominator for this period was $1,200,000$ births.

Results: RVT was reported in 17 boys and 6 girls with a gestational age of $36.2+5.3$ weeks. Median age at diagnosis was 2.5 days. RVT was located to the left kidney in 14 , to the right in 3 , with bilateral disease in 6 . Caval occlusion was noted in 6 . Full heparinization or a thrombolytic therapy were preferred over supportive care or low-dose Heparin by the treating physicians only in cases with an associated caval occlusion. Followup beyond 2 months showed renal scarring in $10 / 17$ patients:

\begin{tabular}{|l|c|c|c|}
\hline Therapy & Unilat & Bilateral & Scarring / total \# \\
Heparin 4-12U/kg/h & 8 & 1 & $4 / 6$ \\
Heparin >12 U/kg/h & 5 & 1 & $4 / 5$ \\
Streptokinase & 1 & 1 & $0 / 2$ \\
ASS & 1 & 0 & $1 / 1$ \\
Supportive & 2 & 3 & $1 / 3$ \\
\hline
\end{tabular}

Conclusion: From the ESPED data, a minimum incidence of 1.9 per 100,000 births can be estimated in Germany. In view of the high rate of residual renal pathology, which is in accordance with the literature, the efficacy of the various therapeutic regimens currently employed should be studied prospectively.

Kinderklinik Medizinische Hochschule Hannover, 30623 Hannover, FRG *ESPED Registry, Universitătskinderklinik, 40001 Düsseldorf, FRG

\section{F24}

TREATMENT OF SEVERE HENOCH-SCHÖNLEIN NEPHRTTIS (HSN) MA Macher, P Brun, M Peuchmaur, E. Bambi, C Loirat.

We report our experience concenning 33 children with severe HS nephritis, who received steroid therapy. Criteria for treatment were : focal and segmental glomerulonephritis (FSGM) either with $\geq 50 \%$ of glomeruli affected ( 16 cases) or with $<50 \%$ of glomenuli involved but with nephrotic syndrome (NS) (9 cases), diffuse mesangial proliferative GN with crescents ( 8 cases). Twenty nine children received methylprednisolone bolus $(1 \mathrm{~g} / 1,73 \mathrm{~m} 2 \times 3)$, followed by oral prednisone ( $1 \mathrm{mg} / \mathrm{kg} / \mathrm{d} \times 1 \mathrm{month}, 1 \mathrm{mg} / \mathrm{kg}$ every other day $\times 2$ months). Five of them also received cyclophosphamide, associated with plasmapheresis in 2. Nine children received oral prednisone only.

At last follow-up, 29 children $(88 \%)$ had a good outcome : complete recovery in 17 $(52 \%)$, minimal urinary abnomalities in $12(36 \%)$ (proteinuria $0,22 \pm 0,15 \mathrm{~g} / \mathrm{d}$ ). Poor outcome was observed in 4 children (12\%), with proteinuria $\geq 2 \mathrm{~g} / \mathrm{d}$ in 2 , renal insufficiency in 2

When compared with an historical group of 28 untreated natients with similar initial brological and histological features, treated patients arpeared to nave a better outcome, although differences were not statistically significant : $88 \%$ of treated patients had a favorable outcome versus $53 \%$ of untreated patients $(p=0.058)$.

\begin{tabular}{|c|c|c|}
\hline & No steroid therapy $(n=28)$ & Steroid therapy $(n=33)$ \\
\hline Mean age : years, (range) & $8.56(4-15.3)$ & $7.8(2.3-15.8)$ \\
\hline Mean follow-up : years, (range) & $4.33(1-12)$ & $3(1-8)$ \\
\hline Mean proteinuria at $\mathrm{RB}^{*}( \pm \mathrm{SD}$ ) & $3.3 \pm 3$ & $4.6 \pm 2.5$ \\
\hline$g / d$ & & \\
\hline \multicolumn{3}{|l|}{ FSGN } \\
\hline Number of cases & 22 & 25 \\
\hline $\begin{array}{l}\% \text { glomeruli with crescents } \\
(m \pm S D)\end{array}$ & $36 \pm 21$ & $52 \pm 20$ \\
\hline \multicolumn{3}{|l|}{$\begin{array}{l}\text { Diffuse proliferative GN with } \\
\text { crescents }\end{array}$} \\
\hline Number of cases & 6 & 8 \\
\hline $\begin{array}{l}\% \text { glomeruli with crescent } \\
(m \pm S D)\end{array}$ & $31 \pm 23$ & $52 \pm 20$ \\
\hline \multicolumn{3}{|l|}{ At last follow-up } \\
\hline Favorable outcome $n(\%)$ & $15(53 \%)$ & $29(88 \%)$ \\
\hline Persistent nephropathy $n$ & 5 & 2 \\
\hline Renal insutficiency & 5 & 2 \\
\hline
\end{tabular}

We conclude that steroid therapy may benefit patients with severe HSN.

Service de Néphrologie, Hôpital Robert Debré, Paris, France 
F25

\section{ROLE OF NITRIC OXIDE IN REGULATING RENAL HEMODYNAMICS IN NEWBORN RABBITS}

L. Ballèvre, M. Thonney and JP. Guignard

Nitric oxide (NO) is known to promote vasorelaxation of renal vessels in vitro. The purpose of the present study was to assess the role of $\mathrm{NO}$ in regulating renal hemodynamics in vivo. Renal blood flow (RBF), glomerular filtration rate (GFR), arterial blood pressure and pulse rate were studied in 9 anesthetized mechanically ventilated newborn rabbits (aged $6.1 \pm 0.3$ days, body weight $114.8 \pm 4.1 \mathrm{~g}$ ) both before and after the i.v. administration of a NO synthesis inhibitor, $N^{G}$-nitro-L-arginine methyl ester (L-NAME) at a dose of $50 \mu \mathrm{g} . \mathrm{kg}-1$ followed by an infusion of $10 \mu \mathrm{g} . \mathrm{kg}^{-1} \cdot \mathrm{min}^{-1}$. The experimental protocol included a control period followed by 3 measurement periods (I to III). Each animal acted as his own control. Such a dose of L NAME did not modify mean arterial blood pressure or pulse rate. Urine flow rate and sodium excretion remained constant. By contrast, the renal vascular resistance progressively increased by $31 \pm 9 \%$ ( $p<0.01$ ) while RBF progressively decreased by $20 \pm 6 \%$ ( $<<0.01$ ). Glomerular filtration rate (GFR) remained constant in period I and II but decreased slightly in period $\mathrm{II}$, by $13 \pm 5 \%(\mathrm{p}<0.05)$

The overall results suggest that (1) the renal vascular bed has a higher sensitivity to the inhibition of $\mathrm{NO}$, as compared to other vascular territories (2) the renal vasoconstriction observed after the inhibition of NO synthesis is related primarily to the afferent arteriole and to a lesser extent to the efferent arteriole.

In normal conditions NO thus appears to play a significant role in maintaining the perfusion of the immature kidney of newborn rabbits, primarily by decreasing the renal vascular resistances, without altering systemic arterial blood pressure.

Service de pédiatrie, CHUV, Lausanne, Switzerland.

F26

THE HEPATOCYTE GROWTH FACTOR (HGF) AXIS IN NORMAL AND ABNORMAL NEPHROGENESIS. A. S. Woolf, M. Kolatsi, E. Andermarcher, C. D. Moorby, M. D. Noble and E. Gherardi.

The signals which mediate ureteric bud and renal mesenchyme interactions are unknown. We now implicate HGF as a renal mesenchyme-derived signal, essential for nephrogenesis. HGF is known to be secreted by non-renal mesenchymal cells and, via the MET receptor tyrosine kinase, is a growth factor for epithelia. Moreover, HGF induces branching of an adult renal epithelial line, a process resembling collecting duct morphogenesis. We located MET throughout the metanephros on day 1 of mouse nephrogenesis, while only undifferentiated renal mesenchyme expressed HGF. We then isolated metanephric cell lines, one of which secreted immunoreactive and bioactive HGF. Another clonal line, an epithelial precursor, expressed MET and proliferated in response to HGF, suggesting a paracrine role for HGF. Finally, we studied immunological blockade of HGF in metanephric organ culture. When grown in defined media, the ureteric bud branched and nephrons formed. In contrast, anti-mouse HGF antibody produced increased mesenchymal cell death with cystic expansion of the ureteric bud, a phenotype which resembled the human multicystic dysplastic kidney. We conclude that: 1) HGF is an important morphogenetic signal during normal development of the mammalian kidney. 2) Aberrant HGF expression may be implicated in the genesis of human kidney malformations.

Medical Unit, Institute of Child Health, London WC1N 1EH, UCLMS, and Cambridge University Medical School, UK.
ENDOTHELIN-1 IS NOT THE MEDIATOR OF THE HYPOXEMIC RENAL VASOCONSTRICTION IN NEWBORN RABBITS

D.S. Semama, M. Thonney, J.-P. Guignard

In animals experiments, acute normocapnic hypoxemia increases the renal vascular resistance, leading to renal hypoperfusion and decreased glomerular filtration rate. Because endothelin, a potent vasoconstrictor peptide produced by vascular endothelial cells, induces a longlasting vasoconstriction of both the afferent and the efferent arterioles, we speculated that it could mediate in part the hypoxemia-induced vasoconstriction. To test this hypothesis, experiments were performed in 24 anesthetized and mechanically ventilated newborn rabbits aged 5 to 8 days. Renal blood flow and glomerular filtration rate were determined by the clearance of para-aminohippuric acid and inulin, respectively. Each animal acted as its own control. In eight newborn rabbits (group 1), a bolus injection of 5 nmol. $\mathrm{kg}^{-1}$ of endothelin (human Endothelin-1, Peptides International) caused a marked increase in mean blood pressure and renal vascular resistance, leading to a significant fall in glomerular filtration rate $(-12 \pm 4 \%)$ and renal blood blow $(-16 \pm 3 \%)$. A second group of animals $(\mathrm{N}=8)$ confirmed the neutralizing activity of the endothelin1 antiserum in vivo (Endothelin-1 antiserum, Peptides International). In spite of pretreatment with endothelin-1 antiserum, hypoxemia induced an increase in renal vascular resistance $(+40 \pm 18 \% ; P<0.05)$ associated with a significant fall in glomerular filtration rate $(-18 \pm 7 \%)$ and renal blood flow $(-29 \pm 6 \%)$ in eight newborn rabbits (group 3). The present results suggest that endothelin-1 does not mediate the hypoxemia-induced renal changes.

Service de Pédiatrie, CHUV, 1011 Lausanne - Switzerland

F28

IFOSFAMIDE NEPHROTOXICITY: FREQUENCY AND PROGNOSIS OF SEVERE TUBULAR DAMAGE.

R. Rossi, B. Rath, Th. Deufel, M. Riepenhausen, H. Jürgens

Ifosfamide may induce tubular damage resulting in renal Fanconi's syndrome. In a cross-sectional study, 140 pediatric patients after successful treatment of their malignancies were screened for the occurrence of ifosfamide-induced renal damage. Proximal tubular function was assessed by measuring percent amino acid and glucose reabsorption, fractional phosphate reabsorption, and fractional sodium excretion using a spot urine and a serum sample during outpatient follow-up. Reference values for these parameters had previously been established using the same method. In addition to the aforementioned parameters, serum bicarbonate level and creatinine clearance (Schwartz formula) were measured. Renal hyperaminoaciduria was seen in highest frequency $(65.6 \%)$, reduced fractional phosphate reabsorption in $44.3 \%$ of patients. Low glucose reabsorption and high sodium excretion were found less frequently (25.8\% and $17.2 \%$, respectively). Acidosis and low creatinine clearance were rare and exclusively seen in patients with severe tubular damage. Overall, 8 patients were identified as having renal Fanconi's syndrome $(5,7 \%)$. In another 18 patients $(12.9 \%)$ a generalized, but subclinical proximal tubular damage was noted. Beside the cumulative dose, unilateral nephrectomy and concomitant cisplatinum therapy could be identified as independent risk factors. Prognosis of severe tubular damage after ifosfamide was poor in that there was no recovery from overt renal Fanconi's syndrome and normalization of tubular function in only 2 out of 18 patients with generalized subclinical tubular damage.

Dept. of Pediatrics and Pediatric Hematology/Oncology, University Children's Hospital, Albert-Schweitzer-Str. 33, 48129 Münster, Germany 
F29

DTFFERENCES IN DIURNAL RHYTHM OF BLOOD PRESSURE IN CHILDREN WITH RENAL FAILURE AND GLOMERULAR OR NONGLOMERULAR DISEASES

M. Bald, B. Lettgen and K.E. Bonzel.

The diumal rhythm of arterial blood pressure (BP) with a decline of BP during night-time is preserved in adults with essential hypertension, but it is attenuated in patients with chronic renal failure. To study this hypothesis in children and adolescents, we performed 24-hour blood pressure monitoring in 37 patients with chronic renal failure not treated by dialysis (age 1.35 to 23 years, 22 males and 15 females) using a portable device (SL 90207, SpaceLabs).

The patients were divided according to their underlying diseases: Group 1: dysplastic kidneys and obstructive uropathy $(n=14)$; Group 2: glomerulonephritis and hemolytic uremic syndrome ( $n=14$ ); group 3: miscellaneous others (Alportsyndrome, Wegener-syndrome, cystinosis) $(n=9)$. There were no differences for mean BP during day-time between the groups when corrected for body-height. The differences of mean BP between day and night for systolic BP (SBP) and diastolic blood pressure (DBP) where calculated as percentage of the daily mean BP. The results are given in the table (median, lower and upper quartile).

\begin{tabular}{|c|c|c|c|}
\hline & \multicolumn{2}{|c|}{ Difference day-night $(\%)$} & \multirow{2}{*}{$\begin{array}{c}\text { GFR } \\
\left(\mathrm{ml} / \mathrm{min} \times 1.73 \mathrm{~m}^{2}\right)\end{array}$} \\
\hline & SBP & DBP & \\
\hline group 1 & $-10.5(-15.2--7.7)$ & $-15.6(-27.5--10.7)$ & $27.6(14.1-55.8)$ \\
\hline group 2 & $-6.0(-8.3--1.4) *$ & $-10.6(-16.1--4.9)$ & $42.6(32.8-53.1)$ \\
\hline group 3 & $-6.6(-9.7-4.9)$ & $-13.6(-15.3--10.0)$ & $9.9(7.4-26.2) * *$ \\
\hline
\end{tabular}

$* p<0.05$ between group 1 and $2 ; * * 0<0.05$ between group 2 and 3

We conclude that the diurnal rhythm of blood pressure is preserved in children and adolescents with non-glomerular diseases even in advanced renal failure, whereas it may be blunted in patient $\$$ with glomerular diseases especially for systolic blood pressure.

University Childaren's Hospital, Hufelandstr. 55, D-45122 Essen, F.R.G.
F30

IDENTIFICATION OF TWO SEPARATE GENETIC MARKERS RESPONSIBLE FOR RENAL FAILURE AND HYPERTENSION IN THE FAWN-HOODED (FHH) RAT.

A.P. Provoost, D.M. Brown, M.J. Daly, E.S. Lander, and H.J. Jacob

End-stage renal disease (ESRD) is a serious potential complication of hypertension. However, only a minority of patients with hypertension will eventually develop ESRD. We have investigated the relationship betwecn hypertension and ESRD using the genetically hypertensive and protcinuric fawn-hooded (FHH) rat. Previous studies in the FHH have suggested that systemic and/or glomerular hypertension were the primary cause of renal failure. We approached the interaction between hypertension and renal failure using molecular genetics. Linkage analysis was performed in a genetic cosegregation study using the FHH and the normotcnsive and nonproteinuric ACI rat. A total of 84 genetic markers covering at least $50 \%$ of the rat genome, were genotyped in the male progeny $(n=125)$ of the FHHx(FHHxACI)F1 backcross brecding. These animals were analyzed for linkage with a macroscopic renal sclerosis score (RSS), proteinuria, and systolic blood pressurc (SBP). Strong evidence was found for a locus, named renal failure $1(R f-I)$ on chromosome 1 , that is responsible for $55 \%$ of the total variance in RSS, and $36 \%$ of the variance in protcinuria. Interestingly, the region was found to have no significant effect on SBP. We did, however, locate another locus accounting for $15 \%$ of the variance in SBP, which also mapped to chromosome 1. This locus appeared to contain the $S_{A}$ gene, but it failed to account for variance in the renal failure phenotypes. These results demonstrate that development of hypertension-associated renal damage does not result simply from the effects of systcmic hypertension on the kidney, but also involves the presence of other genctic susceptibility factors. In this respect, our study is the first to demonstrate that the genetic predisposition to renal failure appears to be a disease within a discase.

Department of Pediatric Surgery, Erasmus University, P.O. Box 1738 , 3000 DR Rotterdam, The Netherlands,

Cardiovascular Rescarch Center, Massachusetts General Hospital/ Harvard Medical School, Charlestown, MA, USA, and

Whitehcad Institute for Biomedical Research/Massachuset s Institute of Technology Genome Center, Cambridge, MA, USA

\section{Posters (P)}

$\mathrm{P} 001$

IMMUNE RESPONSE I YEAR AFTER PNEUMOCCOCAL VACCINATION IN CHILDREN WITH CHRONIC RENAL DISEASES AND EFFECT OF BOOSTER-VACCINATION

A. Fuchshuber ${ }^{1}$, O. Kühnemund ${ }^{2}$, B. Keuth ${ }^{1}$, R. Lütticken ${ }^{2}$, U. Querfeld ${ }^{1}$

Streptococcus pneumoniae (SP) is a ubiquitous pathogen and a source of substantial morbidity and mortality. Pneumococcal vaccination (vacc) has been $r e$ commended for immunocompromised children over 2 years including patient with chronic renal failure (CRF), nephrotic syndrome (NS), undergoing dialysi: (HD/PD) and organ transplant recipients (TX) receiving immunosuppressive $\mathrm{mx}^{\mathrm{C}}$ dication [MMWR 1989; 38: 64-76]. The prevalence of protective antibody (Al3) against SP in those children is low. However, the effect of vacc and booster-vace in those patients is variable and the indication for immunizing is subject of sonv: controversy.

Methods: 41 children with chronic renal diseases (NS, CRF, TX, HD/PD) wher vaccinated with the currently available pneumococcal 23-valent vaccine (Pneumovax ${ }^{\circledR} 23$; Merck, Sharp \& Dohme/Behring). The efficacy of vacc was evaluated by measuring the geometric mean $A B$-titers of the 23 administered serotypes (capsular polysaccharide AB-ELISA). 22 patients, who lost protective $A B$-levels, were submitted to a booster-vacc 1 year after the first vacc.

Results: A sufficiant protection (increase of post-vaccinal AB-titer of more than two steps and protective $A B$-levels $>200 \mathrm{ng} / \mathrm{ml}$ ) was observed in $83 \%$ of the patients 4 weeks after vacc, but only in $67 \%$ after 6 months, and $55 \%$ after one year. The booster-vacc produced a significant immune response ( $>2$ titer steps) 4 weeks after vacc, comparable to the effect after the first vacc. Both vace were well tolerated, minor side effects were noted in 4 patients after the first. The results at 6 months after revacc will be provided.

Conclusion: 1) The currently available vaccine is without major side effects and highly effective in producing a significant $A B$-response 4 weeks after vacc. 2) $\mathrm{AB}$ response should be monitored in vaccinated patients with chronic renal diseases regarding the rapid decline in $A B$-levels as early as 6 months after vacc. 3) The duration of immune protection after the booster-vace will be discussed.

1 Univ-Children's Hospital, Joseph-Stelzmannstr. 9, 50924 Cologne, Germany

2 Institute of Microbiology, University Hospital of Aachen, Germany
$\mathrm{P} 002$

EFFICACY OF RECOMBINANT HEPATITIS B VACCINE IN CHILDREN WITH CHRONIC RENAL FAILURE.

P. Grzesiowski, M. Sieniawska

Immune response to hepatitis $B$ (HB) vaccine was evaluated in 40 children (mean age $9+4$ years) with chronic renal failure (15 dialysed and 25 non-dialysed). Patients with no serological evidence of previous HB virus infection were vaccinated at $0,1,2,6$ month (mth) schedule with double dose of vaccine (Engerix B). Eight patients received steroids before and/or during vaccination course. Antibody titers to HB surface antigen (anti-HBs) were measured $1 \mathrm{mth}$ after $3 \mathrm{rd}$ dose and 1 and 12 mths after 4 th dose of the vaccine. Seroprotection was defined by anti-HBs antibody titer greater than $10 \mathrm{mIU} / \mathrm{ml}$ (ELISA).

After 3rd dose seroprotection was found in $65 \%$ of patients (40\% dialysed and $80 \%$ non-dialysed) and increased after 4 th dose to $72.5 \%(47 \%$ and $88 \%$ respectively). Protective anti-HBs antibody titers were maintained in all examined responders 12 mths after last dose of the vaccine. Six non-responders who developed acute HB 1-6 mths after last dose of the vaccine were probably in the incubation period during vaccination. In one patient 2 days after injection autoimmune haemolytic anaemia and thrombocytopenia were observed. All clinical signs and laboratory changes resolved after $1 \mathrm{mth}$ of steroid treatment.

University Children's Hospital, Dept, of Pediatrics \& Nephrology;00-576 Warsaw,Marszalkowska 24, Poland 
P003

IMPAIRED B-CELL FUNCTION IN CHILDREN WITH CHRONIC RENAL FAILURE

G.C. Lavoratti*, D.Seracini, M.E. Rossi, C. Azzari, M. Materassi, 1. Pela, G. Bartolozzi

The aim of the present research was to investigate $T$ and $B$-cell dependent immunity in children with chronic renal failure (CRF). We studied 9 patients ( $7 \mathrm{M}, 2 \mathrm{~F}$; mean age $11 \pm 5$ years; range $7-16$ years) undergoing haemodialysis $(H D)$ and 15 patients $(13 \mathrm{M}, 2 \mathrm{~F}$; mean age $7 \pm 5$ years; range 2-12 years) with CRF (GFR $8-40 \mathrm{~mL} / \mathrm{min} 1.73 \mathrm{mq}$ ) on conservative treatment. As controls, we examined 10 healthy children of similar age. In dialyzed patients, blood was drawn before dialysis. The dialyzers used were equipped with polyacrylonitrile membranes. By mean of monoclonal antibodies and FACScan cytofluorimeter (Becton Dickinson, Mountain View, Ca, U.S.) we enumerated lymphocytes of phenotype CD 3 (PAN-T cell), CD 4 (helper/inducer), CD 8 (suppressor/cytotoxic), $C D 16 / C D 56$ (Natural Killer cell) and $C D 19$ (B lymphocyte). Lymphocyte "in vitro" proliferation was also evaluated. The mitogens used in the tests were the following: phytohemoagglutinin (PHA), pokeweed mitogen (PWM) and concanavalin A (Con A). Serum immunoglobulin levels were measured by standard methods. The results were summarized as follows: (1) the number of T lymphocytes and their subsets as well as Natural Killer cells was normal both in $H D$ patients and in patients on conservative treatment: moreover, their "in vitro" proliferation was normal in the two groups of patients; (2) the number of CD 19 lymphocytes was significantly lower $(p=0.0017)$ only in HD patients. The "in vitro" proliferation of lymphocytes was normal with PHA and Con A but was significantly lower in $H D$ patients with PWM $(\mathrm{p}=0.0000017)$. The immunoglobulin production was normal in the two groups of patients.

The present study showed that the number of B cells (CD 19) and their function were reduced in HD patients, while $T$ cell subsets and their function was normal in two groups.

It is concluded that altered function in B cells might be responsible for some immunological abnormalities observed in patients with chronic. renal failure on $\mathrm{HD}$.

*Present address: Department of Pediatrics, Unit of Nephrology, University of Florence, O. Meyer, via Luca Giordano 13, 50135 Florence, Italy.

$\mathrm{P} 004$

BONE ABSORPTIOMETRY (DEXA) IN RENAL OSTEODYSTROPHY CONTROL IN CHILDREN WITH CHRONIC RENAL FAILURE.

H. Ziolkowska, M. Sieniawska

The study was performed in 31 children with CRF (5 non-dialysed, 26 dialysed). All pts were given oral $\alpha$-calcidol and $\mathrm{CaCO}_{3}$. Total body-bone mass density (TB-BMD) and blood levels of calcium, phosphorus, osteocalcin and 1.84 iPTH were measured. Morphometric analysis of iliac crest bone biopsies was performed in 10 pts. Index WBMD was calculated by dividing TB-BMD value in pts with CRF by the mean TB-BMD in healthy children.

In 24 pts WBMD was $<1$ (group I), in $7>1$ (group II). The level of iPTH was increased in 21 pts from group I (mean $317.7 \mathrm{pg} / \mathrm{ml}$ ). In 17 of them, iPTH level decreased later, what was accompanied by increase of TB-BMD. In 4 of them with fast decrease of iPTH level, the increase of TB-BMD was 0.009-0.014 g/cm2/mth (normal value: $0.002-0.005$ ) In group II the level of iPTH was low (mean 31.01 $\mathrm{pg} / \mathrm{ml}$ ), in 6 pts episodes of hypercalcemia were observed. In 2 of them, bone biopsy showed adynamic bone disease, osteocalcin level was also lower than in others. DEXA may be helpful in monitoring treatment of renal osteodystrophy. Rapid increase of the bone density could indicate markedly suppression of PTH and could be indication to the modification of treatment.

University Children's Hospital, Dept.of Pediatrics \& Nephrology;00-576 Warsaw, Marszalkowska 24,Poland
P005

DESOPHAG]-GASTRODUDDENOSCOPY FINDINGS DF PEDIATRIC PATIENTS UITH CHRONIC RENAL FAILURE

I.BILGE, A.SIIRIN, S. EMRE, A. NAYIR, S. SÖKİCÜ, H. ALPAY, F. TANMAN

Hypergastrinemia and hypochlorhydria lead to gastruintestinal system disturbances in patients with chronic renal faiIure(CRF). Le investigated gastroduodenal tract in $105 \mathrm{chil}$. ren ( 42 girls, 63 boys) with CRF by gesophagogastroduodenoscopy. The mean age was 14.6 years (2-20 years). Gastric and duadenal mucasae of all cases were pale. In 9 pati.ents( $8 \%$ ), cesophagitis associated with hiatal insufficiency, in 19 patients (18\%), different degrees of duodenitis, in 19 patients $(18 \%)$, gastritis and in 4 patients $(3.7 \%)$ peptic ulcer were observed. Six patients with gastritis had acute superficial circumscribed multiple mucosal erosions. and and same erasions were surrounded by atrophic mucosae. Histapathological evaluation could be performed in 12 patients with abnormal endoscapical findings. The histopathological findings revealed errsions were surrounded by mucosae with increased staining for MPS and NA and some infiltration with chronio inflamatory cells were also detected. H.PyIori was present in five specimens. Desophago-gastroduodenoscapy was repeater in 6 patients. Three patients with initially normal findino were reevaluated because of gastrointestinal symptoms and pathological findings were found. The control endoscopies of the patients with previously pathological findings showed only pale mucosae after medical therapy.

We cocluded that mucosal diseases of the gastrointestinal tract complicating uremia is not rare in pediatric population with CRF. This is a significant clinical problem and early diagnosis and treatment are very important for the patients who are being prepared for renal transplantation.

Present address: Department of Pediatric Nephralogy, Medjcal Faculty of Istanbul. 34390 Çapa Istanbul, TURKEY.

P006

RED BLOOD CELL SUPEROXIDE DISMUTASE AND CATALASE IN CHILDREN WITH RENAI DISEASE

İ.Podracká, M.Śašinka, O.Rácz, A.šipulová, A.Böör oxygen free radicals have been suggested to contribute to many pathological conditions, including renal diseases. In the present study we measured antioxidant enzymatic activities of scavangers superoxide dismutase (SOD) and catalase (CAT) in red blood cells in 63 children with various renal diseaes (39 with chronic glomerulonephritis, 8 with nephrotic syndrome and 17 with chronic renal failure). SOD was measured spectrophotometrically (RANSOD kit), whereas the activity of CAT was assayed spectrophotometrically at $240 \mathrm{~nm}$ according to its ability to destroy H2O2. The actvities of SOD 1632 $\pm 102 \mathrm{U} / \mathrm{g} \mathrm{Hb}$, upper and lower quartiles 591- 691 $\mathrm{U} / \mathrm{g} \mathrm{Ho}$ respectively) and of cat (3.29 \pm 0.54 ukat/g: $\mathrm{Hb}$ (upper and lower quartile 2.91-3.61 ukat/g Hb respectively) were in the normal range in the whole group of the patients. In this group of 63 children with renal diseases, we found a positive correlation between total plasma protein and SOD in red blood cells $(r=0.32, p<0.05)$ and a negative correlation between the red cell hemoglobin concentration and SOD $(r=-0.29 p<0.05)$. Moreover, in the 39 patients with chronic glomerulonephritis, the SOD correlated positively with glomerular filtration rate $(r=0.40, p<0.05)$ and negatively with the plasma creatinine concentration ( $r=$ $-0.43, p<0.05)$. There was no significant relationship between the activities of SOD and CAT. These data are consistent with the suggestion about a relationship between kidney function and activity of a key antioxidant defense enzyme, SOD.

Dept. of Pediat. Univ. Hosp. 04066 Košice, Slovakia 
$\mathrm{P} 007$

STABILIZATION OF RENAL FUNCTION WITH RECOMBINANT HUMAN ERYTHROPOIETIN (rhEPO) IN CHILDREN WITH PRETERMINAL CHRONIC RENAL INSUFFICIENCY

\section{O. Amon, K. Daniel, D.E. Müller-Wiefel}

To determine the influence on the progression of renal insufficiency by correction of renal anemia due to rhEPO, we calculated the glomerular filtration rate (GFR) by means of the Schwartz formula in 16 children aged 0.3 to 13.2 (mean 6.1) years with an initial hemoglobin $(\mathrm{Hb})$ level of $8.3 \mathrm{~g} / \mathrm{d}$ l and an initial serum creatinine of $2.9 \mathrm{mg} / \mathrm{dl}$ during a $\mathrm{rhEPO}$ treatment period of 12 months (mean $\mathrm{Hb} 11.5 \mathrm{~g} / \mathrm{dl}$ ) and 24 months (mean $\mathrm{Hb} 11.4 \mathrm{~g} / \mathrm{dl}$ ), respectively, and compared these results to a pretreatment period of 12 months. Whereas GFR declined by a rate of $8 \mathrm{ml} / \mathrm{min} / 1.73 \mathrm{~m}^{2}$ in the pretreatment period corresponding to a decline of $24 \% /$ year, the mean decline was only $0.06 \mathrm{ml} / \mathrm{min} / 1.73 \mathrm{~m}^{2}(\mathrm{p}<0.05)$ within the first year and $1.0 \mathrm{ml} / \mathrm{min} / 1.73 \mathrm{~m}^{2}(\mathrm{p}<0.05)$ within the second year of treatment. GFR even improved in 5 patients within the first and in 4 patients within the second year of rhEPO application. Data demonstrate a positive influence of rhEPO treatment on the progression of renal insufficiency and support the clinical notion that the begin of renal replacement therapy can be postponed by correction of renal anemia.

University Children's Hospital, Martinistr. 52, 20246 Hamburg, Germany

P008

THE USE OF INDIRECT CALORIMETRY TO MEASURE RESTING ENERGY EXPENDITURE AND FUEL OXIDATION RATES IN CHILDREN WITH RENAL INSUFFICIENCY

NE Moghal. E Pitt. S Wolfc. JT Brocklebank

Resting energy expenditure (REE) and fucl oxidation rates were measured in 14 children with GFRs $<30 \mathrm{ml} / \mathrm{min} / 1.73 \mathrm{~m}^{2}$ with various renal pathologies and requiring conservative management (patient group). Their mean age was 11.2 years. (range $5-16 y$ ). height standard deviation score (SDS) median 1.3, (range -3.4 to +1.8 ). They were compared with 7 healthy controls. mean age 12.3. (range 7-16yr). height SDS median 0.1. (range-0.6 to 12). The height SDS was significantly lower in the patient group $(p<0.05)$. REE was measured by indirect calorimetry following a 12 hour fast. Fuel oxidation rates were calculated from equations using the constants of Ferranini with urinare nitrogen excretion measured br the Kehldahl method following a timed urine collection. Mean REE for the control trotp $1 \mathrm{as} 5196 \mathrm{kj} / 24 \mathrm{hr}$ (SD 46I) and for the patient group 45! lkj/24hu (SD 750). This shows a significantly lower REE $(p<0.02)$ for the paticnt group but when corrections are made for differences in total body weight the pationt group REE was significantly higher $(\mathrm{p}<0.05)$, mean $154 \mathrm{kj} / \mathrm{kg} / 24 \mathrm{hr}$, compared to the controls. mean REE $129 \mathrm{k} / \mathrm{k} / 24 \mathrm{hr}$. REE was also higher in the patient group when corrections were nade for surface area (SA). (patients mean REE $4236 \mathrm{kj} / \mathrm{m}^{2} / 24 \mathrm{hr}$. control mean REE $4020 \mathrm{kj} / \mathrm{m}^{2} / 24 \mathrm{hr}$ ) and for fat free mass (FFM) (paticnt mean REE $36.4 \mathrm{kj} / \mathrm{kgFFM} / 2+\mathrm{hr}$. control mean REE $326 \mathrm{k} / \mathrm{kgFFM} / 24 \mathrm{hr}$ ). Fuel oxidation rates expressed as a pereentage of the measured REE shows that the renal insufficiencs group on average preferentially oxidised carbolydrate $(62 \%)$ at the expense of fat $(29 \%)$, (protein oxidation accounted for $10 \%$ of REE) when compared to the control group (carbohydrate $+5 \%$. fat $+1 \%$. protcin 11\%). This studs shows that children with renal insufficiency have a higher REE whon corrected for total body weight. SA and FFM comparcd to hoalthy controls i.e. hypermetabolic and carbohydrate is preferentialk oxidised.

Department of Pacdiatrics and Child Health. St James's University Hospital, Leeds LS9 7TF. UN
P009

SECONDARY HYPERPARATHYROIDISM IN CHILDREN WITH CHRONIC RENAL FAILURE TREATED WTTH CALCITRIOL.

M. Navarro. MJ Sanchez-Cabezudo*. ME Martinez* A. Alonso

We studied hyperparathyroidism evolution in 15 prepuberal children (mean age: $7.15+2.9 \mathrm{yr}$ ) with chronic renal failure (CRF) (mean: $15.6+5.6 \mathrm{~m} / \mathrm{min} / 1.73 \mathrm{~m} 2)$ treated with oral calcitriol and calcium carbonate for 28 months. All patients received restrictive phosphorus diet. Hypercalcemia ( $\mathrm{n} \%$ patients/period) was defined as a Total $\mathrm{Ca}>11 \mathrm{mg} / \mathrm{dL}$ and ionized $\mathrm{Ca}>1.35 \mathrm{mrno} / \mathrm{L}$. Biochemical and clinical control was made 1-2 months. The results are analized according to their plasma iPTH levels $\&$ and $>$ $100 \mathrm{pg} / \mathrm{mL})$.

\begin{tabular}{|c|c|c|c|c|c|c|}
\hline \multirow[t]{2}{*}{$\left(^{*}\right) \mathrm{p}<0.05$} & \multicolumn{3}{|c|}{$\begin{array}{c}\text { Initial } \mathbf{i P T H}<100 \mathrm{pg} / \mathbf{m L} \\
\mathrm{n}=10 \text { and initial age: } 6.7 \pm 3.3 \mathrm{yr} .\end{array}$} & \multicolumn{3}{|c|}{$\begin{array}{c}\text { Initial iPTHi }>100 \mathrm{pg} / \mathrm{mL} \\
\mathrm{n}=5 \text { and initial age: } 5.0 \pm 2.4 \mathrm{yr} .\end{array}$} \\
\hline & Initial & 12month & 28 months & Initial & 12 months & 28 month \\
\hline SDS & $-1.91 \pm 1.1$ & $-2.0 \pm .8$ & $-1.62 \pm .9^{*}$ & $-2.0 \pm 1$ & $-2.0 \pm .8$ & $-2.1 \pm .9$ \\
\hline GFR & $18 \pm 5$ & $16 \pm 5$ & $15.2 \pm 7.3$ & $16.6 \pm 4.3$ & $15 \pm 3.3$ & $11.5 \pm .2$ \\
\hline $\mathrm{Cr} \& \mathrm{r}$ & $3.4 \pm 0$ & $4 \pm 1$ & $4.8 \pm 1.8^{*}$ & $3.2 \pm 6$ & $5.1 \pm 4$ & $5.7 \pm 6$ \\
\hline $\mathrm{iPTH}$ & $52 \pm 20$ & $35 \pm 9 *$ & $44 \pm 18$ & $195 \pm 87$ & $110 \pm 18$ & $130 \pm 62$ \\
\hline $\mathrm{Ca}++$ & $1.27 \pm .04$ & $1.29 \pm .04$ & $1.27 \pm .04$ & $1.24 \pm .04$ & $1.27 \pm .04$ & $1.23 \pm .03$ \\
\hline $\mathrm{TCa}$ & $9.9 \pm .4$ & 10.3 & 10.1 & $10.1 \pm .1$ & $10.2 \pm .4$ & $9.8 \pm .6$ \\
\hline $\mathrm{P}(\mathrm{m}$ & $5.2 \pm 1.2$ & $4.7 \pm .5$ & $4.8 \pm .6$ & $4.7 \pm .8$ & $5.1 \pm 4$ & $5.4 \pm .6$ \\
\hline ALP & $277 \pm$ & $362 \pm 108$ & $499 \pm 121$ & $578 \pm 167$ & $467 \pm 185$ & $750 \pm 199$ \\
\hline $\begin{array}{l}\mathrm{CO} 3 \mathrm{Ca} \\
(\mathrm{mg} / \mathrm{K} / \mathrm{dia})\end{array}$ & $164 \pm 61$ & $179 \pm 72^{*}$ & $131 \pm 68$ & $71 \pm 34$ & $147 \pm 67$ & $139 \pm 12$ \\
\hline Calcitriol & $11 \pm 6$ & $10 \pm 5$ & $9 \pm 5$ & $18 \pm 7.3$ & $15 \pm 10$ & $16 \pm 9$ \\
\hline Hipercalcemia & & $0.2 / .13$ & $0.15 / .09$ & & $0.1 / .05$ & $0.08 / .01$ \\
\hline
\end{tabular}

Plasma iPTH levels was correlated with ALP $(r=0.49, \mathrm{p}<0.05)$ and with total calcium $([=-0.35, p<0,05$ ). The biochemical parameter wich had more dependence of plasma PTH was Cat+ $(\mathrm{r}=-0.52, \mathrm{p}<0.05)$. The calcitriol and calcium carbonate intake increased $(r=0.51, p<0.05)$ and decreased $(r=-0.32 . p<0.05)$ according to iPTH levels. We conclude than in severe CFR. iPTH levels remained stable with increased dose of calcitriol without risk of a significative loss of renal function. Lineal growth is maintained or improved in relation with severity of hyperparathyroidism. The risk of hypercaleemia has been higher with low iPTH levels.

Biochemical* and Paediatric Nephrology Services. Hospital "La Paz". Paseo de la Castellana 261 -28046 Madrid, Spain.

$\mathrm{P} 010$

\section{PROCOLLAGEN TYPE 1 C-TERM PEPTIDE AND C-TERM} TELOPEPTIDE IN HAEMODIALYSIS CHILDREN

D.Seracini*, G.C. Lavoratti, M. Tommasi, I. Pela, M. Materassi, G. Bartolozz

Because the collagene type 1 is the most abundant protein of bone, serum levels of procollagen $1 \mathrm{C}$-terminal peptide (PICP) may have advantages over measurements of other markers of bone formation moreover, serum levels of C-terminal telopeptide of collagene type 1 (ICTP) correlate with bone resorptive activity.

For this reason we measured PICP, ICTP, intact PTH (iPTH), alkaline phosphatase (AP) and osteocalcin (OC) in 11 children on haemodialysis ( $8 \mathrm{M}$ and $3 \mathrm{~F}$; mean age $11 \pm 4$ years, range $7-15$ years; mean time of dialysis $7 \pm 3$ years) and in 50 healthy control subjects (CS) of comparable age. PICP and ICTP were measured with RIA melhod. Statistical analysis was performed with correlation test.

The results of the present investigation showed that PICP and ICTP levels were significantly higher in the children on haemodialysis compared to CS (PICP $411.6 \pm 207 \mathrm{ng} / \mathrm{mL}$ versus $268.5 \pm 89 \mathrm{ng} / \mathrm{mL}, \mathrm{p}<0.0001$; ICTP $171.6 \pm 71 \mathrm{ng} / \mathrm{mL}$ versus $18 \pm 5.2 \mathrm{ng} / \mathrm{mL}, \mathrm{p}<0.00001$ ). There was a significant correlation between the levels of PICP and PTH $(p<0.008)$, OC $(p<0.002)$, and AP $(p<0.002)$. ICTP levels correlated with IPTH $(p<0.04)$, AP $(p<0.03)$, and OC $(p<0.04)$.

There was no correlation between the serum levels of the two peptides (PICP, ICTP) and the duration of haemodialysis.

In conclusion: (1) PICP and ICTP levels showed a remarkable increase in children undergoing haemodialysis; (2) serum levels of PICP and ICTP correlated with other markers of bone turnover; (3) the higher specificity of the two peptides may be a better guide for management of uraemic osteodystrophy.

*Present address: Department of Pediatrics, Unit of Nephrology, University of Florence, O. Meyer, via Luca Giordano 13, 50135 Florence, italy. 
P011

HEMODIALYSIS PRESCRIPTION IN CHILDREN. EFFECT OF HIGH Kt $N$ : FACTOR OF GOOD NUTRITION OR ONLY ADAPTED TAC. A FRENCH COLLABORATIVE STUDY

B. Boudailliez *, M. Fischbach, M. Foulard

On behalf the French Society for Paediatric Nephrology

On the basis of the retrospective reanalysis of the data from NCDS in adults hemodialysis prescription is based on urea kinetic modelling with the view to adjus $\mathrm{Kt} / \mathrm{V}$ [ie. normalized whole body urea clearance determinated by the ratio : urea cleared volume (Kt) over urea volume of distribution $(\mathrm{V})$ ] for the protein catabolic rate (PCR) to obtain a low urea time average concentration (urea $T A C<20 \mathrm{mmol} / \mathrm{l}$ ).

A multicentric survey was conducted in the 21 french hemodialysis units during february 94 in order to study hemodialysis prescription : study included plasmatic urea and creatinine dosage perfomed before, immediatly and $30 \mathrm{~min}$ after the end of a midweek dialysis session conducted as usual, and before the next session. Protein inlake was assessed by a 2 day dietary protocol perfomed by dietetician. 129 sessions were available (exhaustivity $86 \%$ ). KW was estimated from the $\%$ reduction of urea (PRU) (JINDALL index). TAC and mechanistic $\mathrm{PCR}$ was calculated by bedside index derived from UKM. Since the post-dialysis rebound urea increase was $25 \%$ (SD 20), the $30 \mathrm{~min}$ post-dialysis urea values were used for calculation. Population of children weighing less than $35 \mathrm{~kg}$ and with residual clearance less than $3 \mathrm{ml} / \mathrm{min} / 1,73 \mathrm{~m}^{2}$ was isolated. Results of these 64 children are summarized below.

\begin{tabular}{lcccccc} 
& $\begin{array}{c}\text { Weight } \\
(\mathbf{k g})\end{array}$ & $\mathbf{K t N}$ & $\begin{array}{c}\text { TAC } \\
(\mathbf{m M} / \mathbf{)})\end{array}$ & $\begin{array}{c}\text { Protein } \\
\text { intake } \\
\mathbf{g} / \mathbf{k g} / \mathbf{d}\end{array}$ & $\begin{array}{c}\text { Calories } \\
(\mathbf{k g} / \mathbf{d})\end{array}$ & $\begin{array}{c}\text { PCR } \\
\text { mechanistic } \\
\mathbf{g} / \mathbf{k g} / \mathbf{d}\end{array}$ \\
\hline mean value & 22.8 & 1.68 & 16.7 & 1.6 & 59 & 1.2 \\
SD & 7.6 & 0.34 & 4.8 & 0.6 & 23 & 0.27 \\
range & $7.4-35$ & $0.4-2.4$ & $9-28$ & $0.5-3$ & $17-113$ & $0.6-2.1$
\end{tabular}

$\mathrm{Kt} / \mathrm{V}$ was hight in this population compared to published series and negatively correlated with TAC ( $r: 0.5 p<0.0001)$. Conversely no correlation was found between dietary protein intake and TAC suggesting that hemodialysis prescription was adjusted acording to protein intake in order to maintain correct TAC or suggesting that hight $\mathrm{Kt} / \mathrm{V}$ induced high protein intake (good nulrition). Although it was observed a relation between protein intake and $\mathrm{K} \mathrm{K} N$, no significative correlation was found between protein intake, mechanistic $\mathrm{PCA}$ and $\mathrm{Kt} / \mathrm{V}$ in this population whilst it was on the whole population. Further studies using dialysate quantification are required to validate these bedside index for adequate dialysis prescription in pediatric population.

(*) Nephrology Unit, Paediatric Department, CHU Nord, 80054 Amiens, FRANCE

P0 12

OXALIC ACID ELIMINATION VIA HEMO- COMPARED TO PERITONEAL DIALYSIS IN CHILDREN WITH CHRONIC RENAL FAILURE: B. Hoppe*, D. Graf, G. Offner, K. Latta, D.J. Byrd, D. Michalk*, J. Brodehl

Oxalic acid elimination and oxalate clearance via hemo- or peritoneal dialysis (CAPD) was up to now only sufficiently examined in adult patients. Hemodialysis (HD) is said to be more effective, nevertheless plasma oxalate increases in both procedures. We studied oxalic acid elimination, oxalate clearance and plasma oxalate levels in 15 infants and children undergoing peritoneal dialysis $(9 \mathrm{~g}$, $60^{\circ}$, aged 9 months -18 years) and in 10 children with hemodialysis $\left(4 q, 60^{\circ}\right.$ aged 7 - 18 years), with special emphasis on 2 children with primary hyperoxaluria $(\mathrm{PH})$ in each group. Mean duration of dialysis prior to examination was 12 $+/-11$ months in CAPD and $31+/-23$ months in HD. Four patients on CAPD experienced 12 peritonitis in all, but at least 4 weeks before examination. Oxalate in dialysate and plasma was analyzed by ion chromatography. The results [mean (range), see table I] were related to a $3 \times 5 \mathrm{~h}$ bicarbonate hemodialysis, or CAPD consisting of 5 daily exchanges in 5 patients and 4 changes in the remaining 10 children (dwell volume $40 \mathrm{ml} / \mathrm{kg}$ body weight, $2.3 \mathrm{~g} / \mathrm{l}$ glucose):

\begin{tabular}{|c|c|c|c|c|c|}
\hline \multirow{3}{*}{ CAPD } & \multirow{3}{*}{$\begin{array}{c}\text { Non } \mathrm{PH}(13) \\
\text { PH }(\mathrm{n}=2)\end{array}$} & $(\mathrm{ml} / \mathrm{min})$ & \multicolumn{2}{|c|}{ ( $\mu \mathrm{mol} /$ week $)$} & $(\mu \mathrm{mol} / \mathrm{l})$ \\
\hline & & $7.14 \quad(5.17-10.17)$ & 3478 & $(1904-6027)$ & $49 \quad(28-84)$ \\
\hline & & $6.7 / 9.7$ & & $8 / 10283$ & $83 / 167$ \\
\hline & & $(87-146)$ & 3915 & $(2310-5$ & $56 \quad(33-1$ \\
\hline
\end{tabular}

Conclusion: Oxalic acid elimination/week is not significantly different in both renal replacement therapies. Plasma oxalate remained elevated in both procedures. Oxalate clearance is significantly higher in HD, leading to an increase in oxalate elimination if daily dialysis is performed.

* University Children 's Hospital, Josef-Stelzmann Str. 9, D-50924 Köln, Medizinische Hochschule Hannover, Konstanty-Gutschow Str. 8, D-30624 Hannover
P013

THE RELATIONSHIP BETWEEN HAEMODIALYSIS KT/V AND PROTEN CATABOLIC RATE

M Bradbury, T Buur, S W Smye, E J Will

A correlation between the normalised haemodialysis whole body clearance $(\mathrm{Kt} / \mathrm{V})$ and normalised protein catabolic rate (NPCR) has been shown in some studies. The relationship could be explained by underdialysis suppressing appetite, but has also been claimed to be a mathematical artefact. To examine this, we computed $\mathrm{Kt} / \mathrm{V}$ and NPCR by the classic method. However, to get a mathematically independent equivalent of NPCR, nomalised urea generation rate (NUGR) was found from a oneweek collection of dialysate and urine divided by total body water as found by bioelectrical impedance technique. Eight paediatric and twelve adult

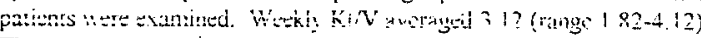
There was a statistically significant correlation between $\mathrm{Kt} / \mathrm{V}$ and NPCR (r $=0.59)$ and between $\mathrm{Kt} / \mathrm{V}$ and NUGR $(r=0.60)$. Correlations of similar orders were found, when children and adults were examined separately. The correlation between $\mathrm{Kt} / \mathrm{V}$ and NPCR is not a mathematical artefact. Since a relationship between serum urea levels and dialysis prescription could be excluded with certainty in the adult group. we conclude that a low $\mathrm{Kt} / \mathrm{V}$ suppresses protein intake.

Department of Paediatrics \& Child Health. St James's University Hospital, Leeds LS9 7TF. UK

P014

\section{DRY WEIGHT EVALUATION AND INTRA-DIALYTIC} MORBIDITY IN HEMODIALYSED CHILDREN

M.Kanaan, F.Bouissou, J.Durand, A.Tifoura, G.Mauco, F.Heitz, J. Fabre, M. Remesy, Ph. Barthe

Dry weight evaluation is crucial in hemodialysed children ; clinical evaluation (dialysis tolerance, blood pressure) and chest X-Ray control are the usual criteria.

We tried to evaluate some objective parameters, and we studied 40 HD sessions in 14 children over several months (2 to $12 \mathrm{~m}$.) We determined at each session (pre and post) : Atrial Natriuretic Factor (ANF), renin activity, total body impedance (Holtain Corp ; 50Khtz), echocardiography and vena-cava diameter mensuration. Chest $X-R a y$ and extra cellular volume by DTPA Tc99 were performed at the end of the sessions, furthermore an impedance profile was recorded in 12 sessions. The correlation have been done with the clinical parameters, the intra-dialytic morbidity (hypotension, headache, nausea, cramps) and the dialysis efficiency (ultrafiltration rate, blood purification).

ANF decreased (from $394 \pm 48$ to $229 \pm 58 \mathrm{pg} / \mathrm{ml}$ ) and impedance increased (from $530 \pm 90$ to $609 \pm 90 \mathrm{ohms}$ ) during the sessions, but with wide intra and inter individual variations ; the end session values were not useful for the dry weight evaluation. However the impedance profile during the sessions was well correlated with the ultrafiltration tolerance. The best approach seems to be the echocardiographic data and especially the determination of the vena-cava diameter ; the optimal value at the end of the session sets between 8,5 and $11,5 \mathrm{~mm} / \mathrm{m}^{2}$ body surface.

Unité de Néphrologie Pédiatrique. CHU Purpan - 31059 TOULOUSE Cédex - FRANCE 
P015

NITRIC OXIDE (NO) RRODUCTION DURING DIALYSIS:

IN VITRO EVALUATION BY A NEW TEST

A.Amore, R. Bonaudo, \#D. Grigo, F. Bussolino, B. Gianoglio,

P.Cirina, \#C.Costamagna, I.Peruzzi, and R.Coppo.

The evaluation of dialysis biocompatibility, as circulating molecules and lympho-monocyte products, does not examine directely the endothelial (E) reactivity, triggered by mediator release. $\mathrm{NO}$ is a powerful vasoactive product of $\mathrm{E}$ origin and its major effect is a vasodilation leading to hypotension.

The Authors present an original assay to test the effects of the interaction between blood-dialysis membrane and the $E$ layer. To this aim the NO production by $\mathrm{E}$ cells in culture (EC) was measured after the mediator release induced by dialysis (HE). Three "in vitro" HE sessions were performed using Cuprophane (Cu) and Polymethylmethacrylate (PMMA) membranes. Recirculating donor blood samples at $0,5,15,30$ and $60 \mathrm{~min}$ were coincubated with murine $E C$ for $6 \mathrm{~h}$. Then, MRNA for inducible NO synthase (NOS) and NOS activity as H3-citrulline procuced from H3-arginine were measured. ILland TNF released by coincubated lymoho-monocytes were also detected.

The time course of the ND synthase activity of $\mathrm{EC}$ is reported : At the 15th min values were greater with Cu than PMMA (p<0.01). EC MRNA for inducible NOS was more expressed after Cu than PMMA HD. ILI and TNF paralieled the NO profile.

In conclusion, the Cu membrane emhanced the production of NO, endothelial mediator provided with imediate vasodilatory effect and long-term vasosclerotic potential.

Nephrology and Dialysis Dept, Regina Margherita Hospital, Piazza Polonia, 94 - 10126 Torino Italy.

\section{P016}

MEASUREMENT OF KTN IN A PAEDIATRIC PERITONEAL DIALYSIS POPULATION

TLM Walk*, CH Schröder, RE Reddingius, M Lelivelt, LAH Monnens

Adequate dialysis is crucial for the wellbeing of patients with endstage renal disease. Urea has become an established marker of small solute removal. Kinetic models have been developed to quantitate therapy prescription based upon this principle. Such kinetic approaches have led to the development of the KT/V urea index. For adult peritoneal dialysis (PD) patients a weekly KT/V urea of 1.7 or more is considered sufficient. For the paediatric population such guidelines are not available. The present study aims to inventory the urea kinetics in a paediatric population.

In a group of 15 children on PD (median age 9 years; range $0.3-17$ ) $\mathrm{KT} / \mathrm{V}$ and creatinine clearances (the sum of peritoneal and residual renal clearance) were measured. Eleven children were on CAPD, 4 on CCPD. Six children were anephric, 9 had residual renal function.

Mean KT/V per week in this group was $2.25 \pm 0.82$ with a creatinine clearance of $71.7 \pm 51.4 \mathrm{l} / \mathrm{wk} / 1.73 \mathrm{~m}^{2}$. The correlation between weekly $\mathrm{KT} / \mathrm{V}$ urea and creatinine clearance was $0.90(p<0.001)$. The KT/V tended to be higher in those children with a relatively high serum albumin concentration. $(r=0.47, p=0.1)$. $\mathrm{KT} / \mathrm{V}$ urea was not related to duration of therapy, serum urea level or age.

In conclusion, mean $K T / V$. in this patient group was higher than the values reported for most adult patients groups. The fact that it is common practice in our center to prescribe a relatively high protein intake of approximately $1.23 \mathrm{~g} / \mathrm{kg} / \mathrm{day}$ in children may explain the high $\mathrm{KT} / \mathrm{V}$ in comparison with adult patients. It is difficult to say what KT/V should be in pediatric patients, since quality criteria are hard to establish in a quantitative way.

*Address for correspondence: Department of Paediatrics, Sinı Radboud University Hospital, Geert Grooteplein Zuid 22, 6525 GA Nijmegen, The Netherlands.
P017

PHARMACOKINETICS OF RECOMBINANT HUMAN ERYTHROPOIETIN IN CHILDREN ON CONTINUOUS AMBULATORY PERITONEAL DIALYSIS (CAPD).

\section{R.E. Reddingius*, C.H. Schröder, A.M. Koster, L.A.H. Monnens}

Renal anaemia can be effectively treated with recombinant human erythropoietin ( $\mathrm{rHu}-\mathrm{EPO}$ ). In young children with chronic renal failure CAPD is the first choice treatment. In these children intraperitoneal administration of rHu-EPO is preferable since subcutaneous administration is painful and frightening for the child. A disadvantage of intraperitoneal administration is the somewhat higher maintenance dose with higher expenses as a consequence. The bioavailability can be improved when erythropoietin is given in a smaller amount of dialysate.

Pharmacokinetics were studied in 3 groups of patients:

Group $\mathrm{SC}, \mathrm{N}=5$, median age 7.3 years $(1.8-10.4) ; 100$ units $/ \mathrm{kg}$ of $\mathrm{TH}$-EPO were administered subcutaneously at TO.

Group IP1, $N=8$, median age 3.4 ycars $(0.6-12.5) ; 100$ units $/ \mathrm{kg}$ of $\mathrm{rHu}$-EPO were added $1020 \mathrm{ml} / \mathrm{kg}$ Dianeal $1.36 \%$ (= talf of the normally used amount of dialysis fluid). The peritoneal fluid remained in the abdomen during 12 hours.

Group IP2: $N=8$, median age 8.2 years $(3.3-14.1) ; 100$ units $/ \mathrm{kg}$ of $\mathrm{rHu}-\mathrm{EPO}$ were given in $50 \mathrm{ml}$ of dialysate, irrespective of body weight, from T0 to T12. The abdomen was not drained at T12

The serum EPO level was measured at T0, T4, T8, T12, T18, T24, T36 and in group SC also at $\mathrm{T} 48$. The area under the curve (AUC) was calculated by trapezoidal fit, with subtraction of the arca represented by the baseline value at TO.

The median AUC at T36 was 1698 (570-5514) $\mathrm{mU} . \mathrm{hr} / \mathrm{ml}$ in group IP1 and 3577 (1225-6555) in group IP2. In group SC the median AUC extrapolated to To was 4064 (2647-24357). In comparison to subcutaneous administration resorption, measured as AUC, was $42 \%$ in group IP1 and $88 \%$ in group IP2. The difference in AUC between group SC and group IPI was statistically significant (Wilcoxon; $\mathrm{P}=0.02$ ), whercas the difference between group $\mathrm{SC}$ and group IP2 was not.

We conclude that the resorption of rHu-EPO, measured as $\mathrm{AUC}$, is similar to subcutaneous administration, when $\mathrm{rHu}-\mathrm{EPO}$ is given intraperitoneally in $50 \mathrm{ml}$ of dialysatc. The dose needed to treat renal anaemia with erythropoietin administered intraperitoneally this way will have to be established in a therapeutic study.

- Address for correspondence: Department of Paediatrics, Sint Radboud University Hospital, Geerl Grooteplein Zuid 22,6525 GA Nijmegen, The Netherlands

P018

COMPLEMENT IN SERUM AND DIALYSATE IN CHILDREN ON CONTINUOUS AMBULATORY PERITONEAL DIALYSIS (CAPD)

R.E. Reddingius", C.H. Schroder, M.R. Daha, A.M. Koster, L.A.H. Monnens

Complement factors are important for opsonization and killing of bacteria entering the peritoneal cavity during CAPD. A decreased opsonic activity of peritoneal fluid is related to a high peritonitis rate. In a previous study we established high serum levels of $\mathrm{Clq}, \mathrm{C} 4, \mathrm{C} 3 \mathrm{~d}, \mathrm{D}$ and $\mathrm{P}$ in children on CAPD, and high levels of $D$ and $P$ in children with preterminal renal failure, when compared to normal controls. High levels of the low molecular weight complement factors $\mathrm{C} 3 \mathrm{~d}$ and $\mathrm{D}$ can be explained by reduction of their elimination by the kidney. The increased levels of the other factors were presumed to be the result of increased synthesis. During CAPD activation of complement in the peritoneal cavity could theoretically occur, with inappropriately high or low levels of complement factors in dialysate as a consequence. Low levels of complement in the peritoneal cavity could impair host defence. Fourteen children ( 4 girls, 10 boys) treated with CAPD were studied. The median age of these children was 7.8 years (range 2.1-13.2). They had been on CAPD for a median period of 42.4 months (range $0.4-89.1$ ). The children did not suffer from peritonitis or other infections. Seven complement factors ( $\mathrm{C} 1 \mathrm{q}, \mathrm{C}, \mathrm{CA}, \mathrm{C} 3 \mathrm{~d}, \mathrm{~B}, \mathrm{D}, \mathrm{P})$ were simultaneously measured in dialysate and serum. Four non-complement proteins ( $\beta 2$-microglobulin, albumin, IgG, $\alpha 2$-macroglobulin) were also measured. Assuming a linear relationship between the $\log$ base 10 of molecular weight and the log base 10 of the dialysate/serum ratio for these non-complement proteins, the expected levels of the complement factors were determined. Possible effects of molecular structure or charge were neglected. The actual and expected dialysate/serum ratios were compared with a modified i-test, taking into account the inaccuracy of the estimate. The ratios of factor $D$ $(\mathrm{P}<0.001)$ and $\mathrm{C3d}(\mathrm{P}=0.035)$ were elevated, whereas those of $\mathrm{C} 3(\mathrm{P}<0.001), \mathrm{C} 4$ $(\mathrm{P}<0.001)$ and factor $\mathrm{P}(\mathrm{P}=0.012)$ were decreased. Relatively low dialysate levels of $\mathrm{CA}, \mathrm{C} 3$ and factor $\mathrm{P}$ could be caused by intraperitoneal consumption of complement. High dialysate/serum ratios of C3d are a logical consequence of consumption of C3. High ratios of factor D indicate intraperitoneal production of factor D. These results provide evidence for activation of complement in the peritoneal cavity in children on CAPD. Further research to elucidate the cause is necessary.

* Address for correspondence: Department of Paediatrics, Sint Radboud University Hospital, Geert Grooteplein Zuid 22, 6525 GA Nijmegen, The Netherlands 
P019

CREATININE AND UREA CLEARANCES IN CHILDREN TREATED WITH NIGHTLY INTERMITTENT PERITONEAL DIALYSIS AND TIDAL PERITONEAL DIALYSIS

G. Consalvo, M. Picca, M. Giani, L. Ghio, B. Damiani, A. Edefonti

To achieve a more adequate dialysis dose in a shorter treatment time, 7 children, mean age $13 \pm 5$ years, mean body weight $33 \pm 15.5 \mathrm{~kg}$, classified as high/high average (H/HA: 5 patients) and low/low average (L/LA: 2 patients) transporters according to the peritoneal equilibration test, were treated with tidal peritoneal dialysis (TPD) for $13.7 \pm 5.7$ months, after being treated with nightly intermittent peritoneal dialysis (NIPD) for $15 \pm 10.3$ months. Dietary protein intakes were comparable during the two treatments (NIPD:1.36 $\pm 0.36 ;$ TPD:1.34 $\pm 0.27 \mathrm{~g} / \mathrm{kg} /$ day). We compared the solute clearances (clr) obtained with the use of NIPD and TPD and effects on serum concentrations of urea nitrogen (UN) and creatinine (crt) and on treatment diration. Dialysis flow rate was significantly higher in TPD than NTPD $(68.5 \pm 13$ vs $29.5 \pm 13 \mathrm{~mL} / \mathrm{kg} / \mathrm{h} ; \mathrm{p}<0.001)$, due to a reduction of dwell time and an increase in number of exchanges.

\begin{tabular}{|c|c|c|c|c|c|c|}
\hline $\begin{array}{l}\text { Peritor } \\
(\mathrm{L} / \mathrm{w} /\end{array}$ & & $\begin{array}{l}\text { Tota } \\
\text { (L/w/1 }\end{array}$ & $\begin{array}{l}\text { clr } \\
73 \mathrm{sqm} \text { ) }\end{array}$ & $\begin{array}{l}\text { Serum } \\
\text { (mg }\end{array}$ & evels & \\
\hline crt & urea & crt & urea & $\mathrm{crt}$ & UN & $(\min )$ \\
\hline \pm & $55.1 \pm 15$ & $71.5 \pm 22$ & $70.5 \pm 19$ & $8 \pm 1.5$ & $61 \pm 12$ & $625.7 \pm 50$ \\
\hline+7 ? & $6+3$ & $1.6 \pm 23^{\circ}$ & $106+$ & $7.5 \pm 1$ & $48 \pm 11^{\bullet}$ & $583 \pm 85$ \\
\hline
\end{tabular}

$$
\mathrm{p}^{*}<0.01 \quad \mathrm{p}^{\wedge}<0.02 \quad \mathrm{p}^{\bullet}<0.05
$$

The improvement of solute clearances and serum urea nitrogen and creatinine was more significant in $\mathrm{H} / \mathrm{HA}$ than L/LA patients. In conclusion, irrespective of the BUN-target considered adequate, high-flux TPD can achieve higher solute clearances than NIPD and a time-averaged BUN level as low as $50 \mathrm{mg} / \mathrm{dL}$ with an acceptable treatment duration.

Present address: $\quad$ Pediatric Dialysis Unit, Department of Pediatrics II, University of Milan, via Commenda, 9 - 20122 Milan, ITALY (Fax 2-55195341)

P020

RANDOMIZED, PROSPECTIVE, MULTICENTER TRIAL ON TREATMENT OF CPD-ASSOCIATED PERITONITIS WITH CONTINUOUS VS INTERMITTENT VANCOMYCIN/TEICOPLANIN AND CEFTAZIDIME IN CHILDREN

M. Zimmering, F. Schaefer, G. Klaus, D.E. Müller-Wiefel, O. Mehls and Mid Europcan Study Group on Pediatric CAPD/CCPD

Bacterial peritonitis remains a major problem in the care of children on CAPD/ CCPD. In view of the increasing incidence of infections with multiresistant staphylococci and gram-negative organisms, a recent treatment update recommends firstline use of intraperitoneal vanconycin and ceftazidime. Teicoplanin has recently been introduced as a potentially less toxic alternative glycopeptide antibiotic. As the plasma hal -lives of vancomycin, teicoplanin and ceftazidime are markedly prolonged in cnd-stage renal failure, convenient intermittent application schedules may be suitable when using these drugs for treatment of CPD-associated peritonitis. Therefore, a prospective trial has been started in 15 pediatric dialysis centers in Mid Europe to evaluate the efficary and safety of intraperitoneally administered vancomycin and teicoplanin, combined with ceftazidime, in the treatment of CPD-associated peritonitis. Vancomycin or teicoplanin is administered either continuously with each bag of dialysate for two weeks, or as two single doses at day 1 and 8 of treatment. Ceftazidime is applied either continuously or in only one dialysate per day. At the time of writing, 47 episodes of bacterial peritonitis ( 39 primary, 8 relapses) have been treated according to this protocol. 21 primary episodes were caused by staphylococci ( 10 cpidermidis, 11 aureus), 8 by gram-negative organisms, 6 by other bacteria, and in 4 cases cultures remained sterile. A primary treatment response was obscrved in $28 / 32(88 \%)$ episodes under continuous and $13 / 15(87 \%)$ episodes under intermittent treatment. 5 of the 6 cases of primary treatment failure were causcd by gram-negative rods (thereof 3 in vitro ceftazidime-resistant), one by staph. aurcus. Relapsing peritonitis within 4 wecks after termination of treatment occurred in 6 of $26(23 \%)$ continuously and in 2 of $13(15 \%)$ intermittently treated peritonitis rpisodcs. All relapse episodes were caused by staphylococci. No difference in primary response or relapse rates were observed between the groups treated with vancomycin and tcicoplanin. Allergic reactions were reported in two patients treated with vanconncin (dialysate eosinophilia, red man syndrome). The preliminary results accumulated so far suggest that intermittent glycopeptide/ceftazidime treatment of the CPD-nssociatcd peritonitis in children is equally effective and safe as continuous treatment

Pediatric Nephrology Division, University Children's Hospital Heidelberg, Im Neuenheimer Feld 150. D-69120 Heidelberg, Germany
P021

HUMAN PERITONEUM MESOTHEIIIAL CELLS (PMC): A NOVEL SET OF ANTIGEN PRESENTING CELLS FOR AUTOLOGOUS SPECIFIC T LYMPHOCYTES.

M.L. Degl'Imncenti, M.T, Valleo, F. Perfumo, F. Manca, R. Gusmano.

The immune responses that occur in the peritoneum are of special relevance in CRF patients treated with continuous peritoneal dialysis (CPD). For this reason we decided to investigate whether the cells that line the peritoneal cavity can participate in specific immune responses by exhibiting antigen presenting function.

PMC were cultured in vitro from human peritoneal tissue samples from mentum fragments obtained during surgical insertion of peritoneal catheters for CPD from 7 children. PMC lines were tested for antigen presenting capacity by pulsing with soluble antigens (tetanus toxoid and PPD) or with a corpuscolate antigen (C. albicans bodies). Autologous peripheral blood mononuclear cells depleted of adherent: monocytes were used as the read out system.

The PMC exhibited a phenotype that was different from macrophages, but MHC class II molecules were well expressed. PMC could effectively present the soluble and corpuscolate antigens to autologous lymphocytes, indicating that they are endowed with both endocytic and phagocytic activity, and with processing and presenting capacity. Preincubation of PMC with human recombinant gamma interferon up-regulated MHC class II and ICAM-1 expression. Since PMC are important component of the peritoneal environment, they may participate, along with macrophages, in the activation of specific $T$ cells and in the generation of local cell mediated imrunity to various pathogens.

Present address: Department of Nephrology, G. Gaslini Institute; Largo G. Gaslini 5, 16148 Genoa-Italy opepartment of Immunology, University of Genoa, Italy.
$\mathrm{P} 022$

HYDROSTATIC INTRAPERITONEAL PRESSURE (IPP) IN CHILDREN ON PERITONEAL DIALYSIS (PD) : PRACTICAL IMPLICATIONS

M. Fischbach, Ph. Desprez, F, Donnars, A. Lahlou, J. Geisert*

IPP is easy to measure routinely in children on PD (specially with the two bags $Y$ set) as described in adults : value expressed in $\mathrm{cm}$ of water, average of IPP (mean IPP) at inspiration and at expiration with point zero located on the midaxiliary line while the patient rests in perfectly supine position.

Despite the number of tested patients is too small to give definitive normal values, it seems firstly that IPP mean is slowly lower in children $(10+/-2 \mathrm{~cm})$ than in adults $(13.4+/-3.1 \mathrm{~cm})$, secondly that IPP mean is lower in infants $(5+/-3 \mathrm{~cm})$ than in children. These results could argue against reduction (blindly) of dialysate volume prescription in infants compared to children in order to limit the risks of excessive intra-abdominal fluid.

IPP were followed after 6 surgical peritoneal catheter implantations realized in 4 children. During the first 2 to 3 days post-operative, IPP remained high $(15+/-4 c m)$ despite use of low dialysate volume $(10 \mathrm{ml} / \mathrm{kg})$; IPP were directly related to abdominal pains and so could monitore analgesic drug need. Thereafter IPP stayed lower $(10 \mathrm{t} / \mathrm{-2 \textrm {cm }})$ and stable despite increasing dialysate volume per exchange from 10 to $50 \mathrm{ml} / \mathrm{kg}$ over a 12 days period. IPP monitoring after surgical peritoneal catheter implantation could be of help to limlt the risks of excessive intra-abdominal fluid.

After more than two years of clinical experience, we couldn't Imagine to perform routinely peritoneal dialysis without IPP measurements. Of special interest are the practical implications : on the one hand tolerance (optimal intra-abdominal volume without pain and risks of excessive pression), on the other hand adequacy (optimization of ultrafiltration limited by IPP increase and maximal dialysate volume prescription adapted to IPP in order to enhance clearances).

*Present address :

Nephrology-Dialysis-Transplantation Children Unit,

Strasbourg, France; Hôpital de Hautepierre, 67098 Cédex. 
$\mathrm{P} 023$

ESTIMATION OF LEFT VENTRICULAR MASS INDEX AS AN INDICATOR OF

LEFT VENTRICULAR HYPERTROPHY IN CHILDREN ON RENAL

M.Litwin, W.Kawalec, J.Latoszyñska, R.Grenda.

Left ventricular hypertrophy (LVH) is a common finding in children on renal replacement therapy (RRT). Left ventricular mass index (LVMI) assessed by echocardiography is a good indicator of LVH in general population. The aim of the study was to estimate and validate LVMI as the indicator of LVH in children on RRT.

Patients and methods: 14 children on continuous ambulatory peritoneal dialysis (CAPD) and 26 children on hemodialysis (HD) were examined echocardiographically. All patients (pts) were examined in a state of good hydration; CAPD pts $30 \mathrm{~min}$. after emptying their peritoneal cavity; HD pts on a day between 2 HD sessions, $\mathrm{M}$-mode and 2-D echocardiography measurements were performed by the same experienced examiner. All obtained results were indexed per square meter of body surface area. LVMI was caiculated according to Penn's formula. Average values of IVSd, LVPWd, LVIDd and LVIDs in CAPD and HD groups were respectively: $9.0 \mathrm{vs} 7.3 \mathrm{~mm} ; 7.5$ vs $6.5 \mathrm{~mm} ; 39,9$ vs $40.9 \mathrm{~mm} ; 26.3 \mathrm{vs} 22.3 \mathrm{~mm}$. Values of LVMI in CAPD and HD pts were respectively: 67.6 vs $84.2 \mathrm{~g} / \mathrm{m} 2$.

Linear regression analysis was done comparing values of LVMI with IVSd, LVPWDd, LVIDd and LVIDs. There were not found any correlations between above mentioned values and LVMI.

We conclude that 1) variations in left ventricule volume are dependent on hydration status and influence the estimation of LVMI; 2) measurement of IVS and LVPW thickness are better echocardiographic indicators of LVH in children on RRT than LVMI.

Department of Nephrology, Dialysis and Transplantation; Child Health Center; 04-736 Warszawa, Poland.
REPLACEMENT THERAPY.

P025

COMPARATIVE ANALYSIS OF THE EFFECT OF ACETATE AND
BICARBONATE DIALYSIS ON DIGITAL EEG MAPPING IN BICARBONATE DIALYSIS ON DIG
CHILDREN WITH CHRONIC UREMIA

Cs. Bereczki, Z. Szupera and S. Túri

Eight patients (aged $15.5 \pm 2.6$ years) with chronic renal failure (CRF) being on long term (duration $4 \pm 1.5$ years $x \pm S D$ ) haemodialysis (HD) were investigated. Each patients were treated with acetate (AHD) and bicarbonate HD (BHD). Bioelectric function of the brain was studied prior to and following AHD and BHD sessions by digital EEG (Neuromap Plus digital EEG). Mathematical method was used for evaluation of the occipital peak frequency, power spertra comparative analysis over the frontal and occipital region as well as the absolute and relative topographic mapping. The changes of the power spectra were evaluated by Student $-t$ test and $p<0.05$ change was taken as significant. The occipital peakfrequency was significantly lower, the alpha power decreased and the theta as well as the delta power increased significantly over the frontal region following AHD in 6 out of the 8 patients. In BHD similar changes were observed in 3 out of the same 8 patients. The differences in the output were significant between AHD and BHD.

BHD resulted in less changes in the EEG power spectra than AHD. The changes were more pronounced over the frontal than the occipital region. Supposedly BHD carries less toxic effect on the brain function.

Department of Paediatrics, A. Szent-Györgyi Medical University, Korányi Str. 14, H-6725 Szeged, Hungary

$\mathrm{PO} 26$

PLASMA LIPIDS AND APOLIPOPROTEINS IN CHILDREN TREATED WITH CONTINUOUS AMBULATORY PERITONEAL DIALYSIS (CAPD) C.J. Stefanidis, B. Skandami, A. Mitsioni, K. Michelis, V. Deligianni. PAEDIATRIC AGE.

M. Greco, E. Spada. R. Boldrini, C. Bosman, M. Rapicetta, G. Rizzoni.

We have already shown that $15-20 \%$ of the children on haemodialysis (HD) or with a renal transplant (RT) are positive for hepatitis C virus (HCV). (Pediatr Nephrol 1993 $7: 424-427$ ). Little or no data is available on the medium term outcome, liver histology and HCV-genotype of the paediatric HCV-positive patients (pts)

Patients and methods: 14 pts (mean age 16 yrs) were studied; 9 had received a RT (5F, $4 \mathrm{M})$ and 5 were on chronic $\mathrm{HD}(2 \mathrm{~F}, 3 \mathrm{M})$. All of them were previously found to be positive for anti-HCV antibodies (ELISA and RIBA ORTHO 2nd generation) and HCV-RNA by the polymerase chain reaction (PCR) using 5 ' non coding region primers. We evaluated: ALT, AST and gammaGT every month and considered abnormal a value more than double the normal value for our laboratory; -anti-HCV antibodies (ELISA and RBA) every 6 months: -HCV-RNA by PCR, repeated a year after the lst determination; percutaneous liver biopsy; - HCV-genotypes determined using core region sets of primers according to Okamoto's method.

Results: All pts were followed-up for 6-32 months (mean 25, median 27) after 1st known positivity for anti-HCV antibodies, 7 out of 14 pts have always had normal transaminase levels whereas in 7 pts transaminases have increased. All pts continuously resulted positive by ELISA and RIBA tests. During follow-up HCV RNA positivity was confirmed by PCR, 2-3 times, in all pts. 2 pts on HD have been transplanted and in one, a liver biopsy showed normal histology 24 months after RT: both of them have normal transaminase values. The histological liver results. (Knodell Index), in the 7 pts who have or had presented a rise in serum transaninase showed: chronic persistent hepatitis in 1 (score 7 ), minimal changes in 3 (score 1-2), normal liver histology in the other 3 (score 0). Three different HCV genotypes were identified in our pts: 2 pts had type I, 9 pts type II, 1 pts type IV and 2 pts had coinfection of genotypes II and IV together

In conclusion: After a median follow-up of 27 months (range 6-32): no spontaneous clearance of $\mathrm{HCV}$ infection was observed indicating that all pts are potentially infectious. Fifty percent of our HCV-positive pts have always had normal transaminase and $\gamma \mathrm{GT}$ values. HCV-RNA positivity in immunocompromised pts is not necessarily associated with hepatic cytolysis.

$\mathrm{HCV}$-genotype II is prevalent in our population

The low grade of liver damage in our pts on renal replacement therapy, suggests that there is no tendency towards progressive liver diseases, at least in the short term.

Division of Nephrology and Dialysis, Bambino Gesù Children's Research Hospital. Piazza S. Onofrio 4, 00165 Rome, Italy
The hyperlipidimic effect of CAPD has been documented in adult patients. However there is little information about children on CAPD. Plasma lipids and lipoproteins were measured in 15 children on (CAPD) and compared with those of 9 children on hemodialysis and with normal children. All parameters were expressed as meantSEM and were compared with the Student's t-test. The age of patients ranged from 0.8 to 16 years $(8.4 \pm 2.7$ years) and the dialysis period from 1.8 to 7.1 years $(3.4 \pm 0.7$ years). CAPD patients had a significant higher cholesterol, triglycerids, LDL-C and ApoB than children on hemodialysis and normal children. However children on CAPD maintained normal levels of $H D L-C, A p o A-1, L p(a)$ and $A p o B$.

\begin{tabular}{lrrrrc} 
& \multicolumn{2}{c}{ CAPD } & \multicolumn{3}{c}{ Hemodialysis } \\
& Mean & SEM & Mean & SEM & $\mathrm{p}$ \\
CHOL & 245 & 14 & 174 & 11 & 0.002 \\
TG & 259 & 32 & 155 & 16 & 0.04 \\
HDL-C & 49 & 3 & 42 & 3 & N.S. \\
LDL-C & 147 & 12 & 101 & 9 & 0.01 \\
VLDL-C & 49 & 8 & 31 & 3 & N.S. \\
ApoA-1 & 158 & 7 & 143 & 9 & N.S. \\
ApoB & 152 & 9 & 82 & 6 & $<0.0001$ \\
Lp(a) & 53 & 9 & 55 & 12 & N.S.
\end{tabular}

Elevated values of triglycerides were constantly noticed in $12 / 15$ patients and of cholesterol in $9 / 15$ patients. There was no correlation between the quantity of giucose absorbed or the age of patients or the dialysis period and the development of high triglyceride levels. Whether these differences are of any clinical significance has to be determined in future longterm studies.

Division of Nephrology and Biochemistry "A \& P Kyriakou". Children's Hospital, Athens, 14562 , Greece. 
COMPARATIVE EVALUATION OF CHANGES NN TOTAL BODY BONE MTNERAL DENSITY (TB BMD) IN UREMIC CHILDREN ON HEMODIALYSIS (HD)VS CONTINUOUS AMBULATORY PERTTONEAL DIALYSIS (CAPD)

B. Materna, R. Grenda, R. Lorenc

Osteodystrophy is the effect of altered mineral and hormonal metabolism due to renal insufficiency. Dialysis partly corrects the metabolic disturbances, but does not protect bones against hyperparathyroidism. The aim of this study was to evaluate the dynamics of bone changes in uremic children treated by two types of dialysis: hemodialysis (HD) vs continuous ambulatory peritoneal dialysis (CAPD), using non-invasive dual energy

X-ray absorptiometry(DEXA).

Group I (HD) $n=18$, and group II (CAPD) $n=13$ were compared with a group of healthy, age-matched control children $(n=315)$. There were no statistically significant differences in the mean age: $(2,95 \pm 3,7$ vs $12,25 \pm 3,8$ years $)$ and time of dialysis $(1,67 \pm 1,5$ vs $2,19 \pm$ 1,45 year) between groups I and II. The patients from both groups were treated with phosphate binders (calcium acetate, calcium carbonate) and an active metabolite of vitarnin D (alphacalcidol, one-alpha). The mean calcium concentration in the dialysis tluid was $1,75 \mathrm{mmol} /$. Total body bone muneral density, s-PTKi, $\mathrm{Ca}$, phosphorus, $A F$ activity were measured at the beginning of the study and after 12 months.

Results: 1/ TB BMD values in group I and II were significantly lower in comparison with the control group at the beginning as well at the end of the study. (T-student test: $p<0,05$ ) 2 / there were no statistically significant differences in TB BMD values in both groups at the beginning and end of the study (T-student test: $p<0,05$ ). 3/ A statistically significant decrease was found in the TB BMD in both groups over the 12 month period of observation, which correlated with the increase in the PTH level. 4/ During the entire study period, the serum calcium, phosphates, alkaline phosphatase activity and PTH levels did not differ significantly between treated groups or among patients in the same group, and the mean levels of these parameters remained within normal limits.

Conclusion: Regardless of the method of dialysis and pharmacological therapy used in the treatment of uremic children, ultrasensitive diagnostic methods demonstrate that the total body bone mineral density tends to decrease with time.

Child Health Center, Department of Nephrology, Dialysis and Kidney Transplantation 04-736 Warsaw, Poland
MEDICAL AND PSYCHOSOCIAL REHABILITATION OF YOUNG ADULTS RECEIVING RENAL REPLACEMENT THERAPY SINCE CHILDHOOD: A SINGLE CENTER EXPERIENCE.

U. Querfeld, B. Korten, G. Naumann, D.V. Michalk

Few pediatric centers have studied long-term rehabilitation in their patients with end-stage renal disease (ESRD). This study describes the experience of a single center. A total of 29 patients, $(14 \mathrm{~m}, 15 \mathrm{f})$, aged $25.3+4.0(18-34)$ years receiving renal replacement therapy since childhood participated in the study. Medical and psychosocial rehabilitation were assessed by a personal questionaire and a standard psychological questionaire (Freiburger Persönlichkeitsinventar, FPI) evaluating psychological and personality traits. The FPI scores were compared to an aged-matched control population of young adults with longstanding diabetes mellitus (DM) type I. Results: Sixteen patients (pts) were treated with dialysis (D) and 13 had a functioning renal transplant (TPL; mean GFR $\left.75(11-109) \mathrm{ml} / \mathrm{min} / 1.73 \mathrm{~m}^{2}\right)$. The duration of renal insufficiency ( $=$ time since first dialysis) was $12.8+5.3$ years. Weight was $4.2 \% \pm 16.3 \%$ above and height was $4.5 \% \pm 10.1 \%$ below, the $3^{\text {rd }}$ percentile for age. Hypertension was present in $\overline{6 / 16} \mathrm{D}$ pts and 6/12 TPL pts. Hypercholesterolemia was present in $4 / 16$ and $7 / 12 D$ and TPL pts, respectively. Hepatitis $B$ antibody (Hbs-AB) was present in $8 / 16 \mathrm{D}$ pls and 6/10 TPL pts; $8 / 16$ pts on D and 1/10 TPL pts had antibodies against Hepatitis C. Osteodystrophy was present in 13/16 D and 9/12 TPL pts. Anemia was present in 11/16 D and 2/12 TPL pts. Only 5 of 26 ESRD pts, but 12 of 26 diabetic pts were married. Vocational training/school performance was not markedly different in renal and diabetic pts. The FPI scores showed that ESRD pts had more emotional stability and tended to be more relaxed than DM pts, while DM pts were less worried about health problems. Conclusion: Young adults receiving renal replacement therapy since childhood had a multitude of continuing medical problems. Educational training and social adaptation (with the exception of marriage) were comparable to young adults with DM while psychological profiles showed substantial differences.

University Children's Hospital, Cologne, Germany
P028

RISK FACTORS IN FAMILIES WITH A CHILD ON DIALYSIS TREATMENT

G.M.Hulstijn-Dirkmaat ${ }^{*}$ and E.H.W.Damhuis

Burn-out or "parent-fatigue" is a well-known phenomenon in the treatment of children undergoing renal replacement therapy. Therefore an adequate assessment of a family's psychosocial adjustment, stress tolerance and coping capacitics in an early stage of the treatment is of major importance for an effective disease management. In order to identify risk factors for burn-out in families with a child on dialysis treatment a study on parental stress and family characteristics was performed in 18 families (4 with a patient on HD and 14 on CAPD, mean age 8.2 years, mean duration of the treatment 3.2 yrs and of the disease $6.1 \mathrm{yrs}$.

Two standardized questionnaires were devised: one is focused on stress due to the CAPD/HD treatment, experienced by parents themselves; the second method aims the paediatrician's assessment of demographic and psychosocial factors, parental coping capacitics and family functioning.

The results of the parental stress questionnaire revealed that considerable differences were found between individual families: range $5.4 \%-89.0 \%$,mean $32.6 \%$. Significant more stress was experienced by parents with an older child (> 5 yrs) and by parents whose child had a failed transplantation. Surprisingly no differences were found between fathers and mothers $(T=.91, p<0.001)$ and no influences of the duration of the treatment and socio-economic status could be established. Psychosocial factors more than medical issues, and in particular concern about the future, proved to be burdening for the great majority of the parents $(77.0 \%)$.

Assessment by paediatricians of risk factors by means of the family characteristics checklist showed that the mean risk seore is low $(14.2 \%$, range $0.0-34.1 \%)$. However comorbidity and behaviour prohlems of the child, social isolation and fixation on the disease were noticed frequently as risk factors for parental burnout and ineffective disease management. Only a significant correlation between the outcome of the parental stress questionnaire and the parental coping subscale of the family characteristics checklist as assessed by the paediatricians was found $(r=61, p<0.05)$. Both methods have proved to be appropriate for repeated measurerients during the course of the treatment. A systematic use might identify specific problems, implement practical and therapcutic support in order to prevent burn-out of patients and parents.

*Present address: Departments of Medical Psychology and Paediatric Nephrology, University of Nijmegen, P.O.Box 9101, 6500 HB Nijmegen, the Netherlands
P0 30

INSULIN LIKE GROWTH FACTOR (IGF) BINDING PROTEINS IN CHRONIC RENAL FAILURE (CRF), DIALYSED AND TRANSPLANTED CHILDREN D.MORIN - F.AUDRAN , J JONES ,Ch.SULTAN , R.DUMAS

Growth failure mechanisms in CRF children are partly related to a decreased IGF bioactivity due to an increased IGF-binding proteins (IGFBP) plasma levels. We studied IGF-1, IGFBP-1 and IGFBP-3 plasma levels by RIA and serum IGFBP by ligand blotting in 4 groups of children : Group A $(n=10)$ : Children on peritoneal dialysis. (PD) Mean age : 13.7 years (2 to 18 )

Group $B(n=15)$ : Children on hemodialysis (HD). Mean age : 11.4 years (7.4 to 15$)$

Group $C(n=10): C R F$ children. Mean age : 8.5 years ( 3.5 to 14). Mean GFR : $23.4 \mathrm{mV} / \mathrm{mn} / \mathrm{m}^{2} 73$ (10.6 to 49$)$.

Group $D(n=5)$ : Transplanted children. Mean age : 14 years (11.8 to 17).

Mean GFR : $67.3 \mathrm{mV} / \mathrm{mn} / \mathrm{m}^{2} 73$ (48.4 to 78.2 )

Age related range for IGF-1 and IGFBP-1 were obtained from 116 children aged 2 months to 16 years and for IGFBP-3 from Diagnostic System. Ligand blotting was performed in the serum of 15 age-matched controls. RIA for IGF-1 levels were within the normal range in the 4 groups. RIA for IGFBP-1 and IGFBP-3 plasma levels were increased in the 3 groups of uremic children

Ligand blotting showed increased IGFBP-1 and IGFBP-2 levels, but conversely, the levels of IGFBP-3 remained normal in the groups $A, B$ and C. In the transplanted children, RIA for IGF-1, IGFBP-1, IGFBP-3 and ligand blotting showed normal IGFBP plasma levels. In one patient, the samples obtained in the following days after renal transplantation showed samples obtained in the following days after renal transplantation showed
that RIA plasma levels for IGFBP-1 and IGFBP-3 dropped drammaticaly as the renal function improved.

Our data showed high RIA plasma levels for IGFBP-1 and IGFBP-3 in uremic children. The discrepancy observed with the ligand blotting results for IGFBP-3 could be related to low molecular weight IGFBP-3 forms. which are accumulated because of a low renal clearance. PD does not seem to be more efficient than $\mathrm{HD}$ in limiting such an accumulation.

Present address : Service de Pédiatrie I, Hôpital Arnaud de Villeneuve, Avenue Doyen Gaston Giraud. 34295 - Montpellier cedex 5 - France. 
$\mathrm{P} 031$

INSULIN-LIKE GROWTH FACTORS (IGFS) AND IGF BINDING PROTEINS I-3 IN PRETERMINAL CHRONIC RENAL FAILURE (CRF): RELATIONSHIP TO GROWTH AND GLOMERULAR FILTRATION RATE (GFR)

B. Tönshoff*, A.M. Wingen, W.F. Blum, O. Mehls, and the European Study Group for Nutritional Treatment of Chronic Renal Failure in Childhood

IGFs and their binding proteins (IGFBP) may play a role in the growth disturbance in $\mathrm{CRF}$. To further evaluate this hypothesis, a large group $(\mathrm{N}=109)$ of children (63 boys, 46 girls; age $11.5 \pm 4.4 \mathrm{yrs}$; height SDS, $-1.36 \pm 1.47$; range, -4.69 to 1.85 ) with preterminal CRF (GFR $29.3 \pm 13.7 \mathrm{ml} / \mathrm{min} / 1.73 \mathrm{~m}^{2}$; range, $8.0-67.4$ ) was investigated in a cross-sectional study. IGF-I, IGF-II, and IGFBP-1, -2 , and -3 were measured by specific RIAs. The IGFBP-3 RIA recognizes both intact IGFBP-3 $(\mathrm{Mr}$, $45 \mathrm{kDa}$ ) and low-molecular-weight fragments. To account for the age-dependency of these parameters, all values were referred to their normal ranges by calculating SDS Mean ( \pm SD) IGF-I $(0.08 \pm 1.51$ SDS $)$ and IGF-II $(0.04 \pm 1.12$ SDS $)$ were normal Decreased IGF-I or IGF-II (<-2 SDS) was found in $14 \mathrm{resp} .3$ individuals, increased levels $(>2$ SDS) in 8 resp. 3 subjects. Mean IGFBP-1 (1.05 \pm 0.92 SDS) was slightly, mean IGFBP-2 $(3.23 \pm 2.13$ SDS $)$ and IGFBP-3 $(2.58 \pm 1.33$ SDS $)$ were markedly elevated. The normal linear relationship between height SDS and IGF-I SDS in healthy prepubertal children $(n=75, r=0.66, P<0.001)$ was preserved in $\mathrm{CRF}(\mathrm{n}=79, \mathrm{r}=0.41, \mathrm{P}<0.001)$, whereas the normal relation between height and IGFBP-3 $(r=0.61, P<0.001)$ was disrupted in $C R F(r=0.17, N$.S.). In CRF, height was negatively correlated to IGFBP-1 $(\mathrm{N}=109, \mathrm{r}=-0.36, \mathrm{P}<0.001)$ and IGFBP-2 $(r=-0.33, P<0.001)$. The calculated amount of free IGF-I (i.e. ratio total IGFI/(IGFBP-3 minus IGF-II)) was well correlated with longitudinal height $(r=0.47$ $\mathrm{P}<0.001)$. GFR was inversely correlated with IGFBP-1 $(\mathrm{N}=109, \mathrm{r}=-0.43$, $\mathrm{P}<0.001)$, IGFBP-2 $(\mathrm{r}=-0.52, \mathrm{P}<0.001)$ and IGFBP-3 $(\mathrm{r}=-0.28, \mathrm{P}<0.005)$. In conclusion: (1) IGF-I is an important determinant of longitudinal growth in children with CRF. (2) The inverse correlation of IGFBPs with residual GFR is consistent with reduced renal clearance of IGFBPs in CRF. (3) Accumulating IGFBPs in CRF interfere negatively with longitudinal growth.

*Present address: Department. of Pediatrics, SUNY at Stony Brook, New York 11794-8111, USA;

University Children's Hospitals Heidelberg, Essen, and Tuebingen, Im Neuenheimer Feld 150, 69120 Heidelberg, Germany
P033

THE EFFECTS OF RECOMBINANT HUMAN GROWTH HORMONE ( $\mathrm{KhGH}$ ) ON RENAL FUNCTION IN CHRONIC RENAL FAILURE

H.Maxwell, D.R.Nair and L.Rees

RhGH increases glomerular filtration rate (GFR) and effective renal plasma flow (ERPF) in normal subjects, through the action of insulin-like growth factor 1 (IGFI). RhGH is effective in improving growth in chronic renal failure (CRF), but the effects on renal function in these children are not known. We have therefore assessed GFR and ERPF, by clearance of inulin and PAH, in 18 children with CRF before, after 1 week and after 1 year of rhGH treatment. Results were correlated with circulating GH and IGFI levels.

Patient details : 15 children had congenital structural problems, 3 had focal segmental sclerosis (FSGS). Mean age(range) was $9.1(4.9-13.9)$ yrs, GFR $19(9-58) \mathrm{mls} / \mathrm{min} / 1.73 \mathrm{~m} 2$, HtSDS $-3.0(-4.8$ to -1.8$)$ and height velocity (HVel) $4.5(1.7-6.5) \mathrm{cm} / \mathrm{yr}$.

Results : HVel increased to $9.5(4.8-12.7)$ on $\mathrm{rhGH}(\mathrm{p}<0.0001)$ with a significant improvement in HtSDS to -2.4(-4.8 to -1.1). Two children required dialysis after $0.75 y r s$ and $i$ cnild was electively transplanted atter $0.5 y r s$. There were no other serious adverse events. After 1 week of $\mathrm{rhGH}$ there was no change in GFR [day7 22(6-56)], but ERPF increased from 77(34-271) to 96(33-276) $(p<0.005)$. There was a downward trend, but no significant change, in filtration fraction from $0.25(0.15-0.37)$ to $0.24(0.10-0.41)$ during this time. In the 15 children who completed 1 year of treatment, GFR was unchanged at 20(9-59) and ERPF elevated, but not significantly so, at 99(24-428). Filtration fraction was $0.23(0.10-0.36)$. Creatinine rose during the study, from $280(66-472)$ umol/ to $375(85-574)$ in the 15 who completed 1 year $(p<0.0001)$, despite no averall change in GFR. Urea fell from 18.2(9.5-30) umol/l to 12.8(5.3-22.5) after 1 week $(p<0.0001)$, and increased to $19.2(7.2-30)$ after 1 year. Fasting IGFI rose from $0.77(0.30-1.59) \mathrm{u} / \mathrm{ml}$ to $1.5(0.31-3.40)$ after 1 week $(p<0.005)$ and $1.65(0.51-3.97)$ at 1 year. Fasting growth hormone $(\mathrm{GH})$ increased from $9.8(0.5-37.7) \mathrm{mu} / \mathrm{l}$ to $23.6(4.2-54.9)$ on day $7(p<0.001)$, and $24.2(4.0-76.3)$ at 1 year. There was no correlation between the changes in IGFI or GH and the changes in renal function.

Conclusions : The significance of an increase in ERPF at 1 week is unclear, but long term follow-up of renal function is indicated in these children. It is not known if rhGH affected progression of CRF in 2 children who required dialysis. In the remaining children, there was no apparent adverse effect of $\mathrm{mGH}$ on GFR at 1 year. Creatinine values alone are inadequate for monitoring GFR

Paediatric Nephrology, Royal Free Hospital, Pond St, London, NW3 2 QG.
P032

THE EFFECTS OF RECOMBINANT HUMAN GROWTH HORMONE (RhGH) ON INSULIN-LIKE GROWTH FACTOR BINDING PROTEINS (IGFBP) IN RENAL TRANSPLANTATION

H.Maxwell, J.Jones, S.P.A.Rigden and L.Rees

Poor growth may occur in chronic renal failure (CRF) and after renal transplantation (RT). One possible mechanism may be increased binding of the $\mathrm{GH}$ mediator, insulin-like growth factor (|GFI) to its binding proteins, in particular to IGFBP3 and 1. This would result in less free IGFI. This is thought to be the case in CRF where both BP1 and BP3 are elevated. Little is known of their interaction with IGFI in RT. IGFBP3 is the main carrier protein; IGFBP1 appears to have other functions as its levels are inversely correlated to insulin levels. We have studied IGFI, BP3 and BP1, in short children with renal transplants, before and after $\mathrm{hG}$ GH ( $1 \mathrm{iu} / \mathrm{Kg} / \mathrm{wk}) .17$ children were studied after 1 week then 3 monthly for 1yr. Mean age(SD) 13.1(2.2) yrs, GFR 55(26) $\mathrm{mls} / \mathrm{min} / 1.73 \mathrm{~m} 2$, and $\mathrm{HtSDS}-3.3(0.8)$. All were on alternate day prednisolone equivalent to $10.2(3.8) \mathrm{mg} / \mathrm{m} 2$. Height velocity (HV) increased from $3.7(1.4)$ to $00.0(2.5) c i n i t y r$ ( $\tilde{s}<0.001)$. Bothi prednisolone dosage $(p<0.006)$ and age $(p<0.02)$ were significantly negatively correlated with HV on rhGH. GFR did not increase the predictive value of these two variables. $|G F|$ levels rose from $1.25(0.36) \mathrm{u} / \mathrm{ml}$ on daya to $2.77(1.26)$ on day $7(p<0.001)$ and remained elevated throughout the year of rhGH. Increase in IGFI at one week was predictive of HV over the year $(r=0.759, p=0.0036)$. Mean fasting IGFBP1 fell from $110.8(77.7) \mathrm{ng} / \mathrm{ml}$ on dayo to $26.6(23.2)$ on day $7(p=0.0025)$, increased to $61.6(43.2)$ by 3 months and remained at this level. Day0 values are well above the normat range, in contrast to previous published data in RT. The pattern of change is opposite to that seen with insulin values in RT on rhGH. There was a tendency for IGFBP1 values to be higher in children with lower GFRs on higher doses of prednisolone, but this was not significant. Fall in IGFBP1 was greatest in those with highest levels $(r=0.972, p<0.001)$ who tended to show a poorer response to treatment. 7 children had IGFBP3 measured during treatment; values were in the upper normal range on day0, $3.9(0.6) \mathrm{mg} /$. increased to $5.3(1.3)$ at one week and remained elevated at that level. The significance of circulating IGFI and IGFBPs in the response to $\mathrm{hGH}$ in RT remains to be determined.

Dept Paediatric Nephrology, Royal Free Hospital, London.

\section{P0 34} EFFECT OF COMBINED TREATMENT WITH rhGH AND rhIGF-1
ON GROWTH OF UREMIC RATS

G.T. Kovacs, J. Kovacs, J. Oh, E.B. Hunziker, O. Mehls

In uremia there is a secondary resistance to growth hormone (GH) which is partly due to reduced production of IGF-1 and increased binding to IGF-BP's. In order to investigate whether the treatment with IGF-1 with or without $\mathrm{GH}$ is able to stimulate growth in uremic rats, $160 \mathrm{~g}$ female SD-rats were treated with solvent, $1.5 \mathrm{mg} / \mathrm{GF}-1 / \mathrm{kg} / \mathrm{bid}$ s.c., $3.75 \mathrm{lU} \mathrm{GH} / \mathrm{kg} / \mathrm{bid}$ or both substances for 12 days. The animals were divided in two subgroups: subtotal nephrectomy (U) and sham-operated pairfed control rats $(\mathrm{Co})$. Both peptides had a positive effect on lenght (L) and weight (W) gain which was due to the increased ratio of weight gain over food intake. The combined treatment with rhGH and rhIGF-1 showed additive effects (table), which was confhneü by duse response expunhenta.

\begin{tabular}{l|cc|c|c}
\hline & \multicolumn{2}{|c|}{ Uremia } & \multicolumn{2}{c}{ Control } \\
& - W (gm) & $-\mathrm{L}(\mathrm{cm})$ & $-W(\mathrm{gm})$ & $-\mathrm{L}(\mathrm{cm})$ \\
\hline Solv. & $27.3 \pm 10.1$ & $3.2 \pm 0.5$ & $47.6 \pm 8.7$ & $3.4 \pm 0.5$ \\
GH & $57.6 \pm 13.4$ & $4.1 \pm 0.5$ & $71.9 \pm 9.1$ & $4.1 \pm 0.6$ \\
IGF & $39.0 \pm 10.0$ & $4.2 \pm 0.6$ & $54.9 \pm 8.5$ & $4.1 \pm 0.4$ \\
IGF \pm GH & $68.9 \pm 5.0$ & $4.9 \pm 0.5$ & $84.7 \pm 8.2$ & $4.7 \pm 0.5$ \\
\hline
\end{tabular}

Both peptides were also able to counterbalance the growth depressing effect of methy/prednisolone (MP). Again, cotreatment with rhGH and rhlGF-1 had additive effect in MPtreated animals. $(W$ in $U$ after 7 days: MP 5.6 $\pm 4.9, M P+I G F$ $16.2 \pm 7.2, \mathrm{MP}+\mathrm{GH} 10.2 \pm 5.3, \mathrm{MP}+\mathrm{IGF}+\mathrm{GH} 19.3 \pm 2.9 \mathrm{gm}$; $\mathrm{L}$ in $\mathrm{U}_{\mathrm{i}} \mathrm{MP}$ 1.6 $\pm 0.3, \mathrm{MP}+\mathrm{IGF} 2.2 \pm 0.3, \mathrm{MP}+\mathrm{GH} 2.0 \pm 0.4$, $\overline{M P}+\mathrm{IGF}+\mathrm{GH} 2.4 \pm 0.2 \mathrm{~cm})$.

In summary: IGF-1 is able to stimulate growth in uremic rats.

The effect is additive to the growth promoting effect of rhGH This points to different pathways for both peptides.

Present address: University Children's Hospital, INF 150, 69120 Heidelberg, Germany 
P035

MORPHOMETRY OF UREMIC RAT GROWTH PLATE

A Cobo, *E Carbajo, F Santos, G Orejas, S Málaga

To gain insight into the alterations of bone growth plate in growth failure of chronic uremia, a morphometric study of tibia proximal growth plate was performed in $5 / 6$ nephrectomized rats (NX, $n=4$ ) and sham animals (SHAM, $n=4$ ). Toluidine blue stained sagital sections $(5-6 \mu \mathrm{m})$ from ethanol fixed and methylmethacrylate embedded tibias were analyzed. Widths (XISEM) of growth plate (GPW), proliferative (PZW) and hypertrophic zones (HZW) were calculated. Results were as follows:

\begin{tabular}{|c|c|c|c|}
\hline & $N x$ & SHAM & value \\
\hline GPW $(\mu \mathrm{m})$ & $798 \pm 39$ & $594 \pm 57$ & 0.01 \\
\hline $\mathrm{PZW} \quad(\mu \mathrm{m})$ & $180 \pm 11$ & $159 \pm 19$ & NS \\
\hline $\mathrm{HZW}$ ( $\mu \mathrm{m})$ & $575 \pm 29$ & $385 \pm 34$ & 0.003 \\
\hline PZW/GPW (8) & $23 \pm 0$ & $27 \pm 1$ & 0.003 \\
\hline $\mathrm{HZW} /$ GPW (8) & $72 \pm 0$ & $64 \pm 1$ & 0.002 \\
\hline
\end{tabular}

Growth plate modifications in uremia are rather due to alterations in the hypertrophic than proliferative zone. This is consistent with an abnormal metabolism of chondrocytes as shown by a lower mean area of extracellular matrix per cell (EMA) in the hypertrophic zone of $\mathrm{NX}$ rats $(0.23 \mathrm{vs}$ $\left.0.66 \mu \mathrm{m}^{2}\right)$, this parameter being similar in the proliferative zone of both groups.

Pediatric Nephrology and *Anatomy. Hospital Central and School of Medicine. University of Oviedo.

Julián Clavería sn. 33006 oviedo. Asturias, Spain

P036

IGF-I INCREASES VITAMIN D RECEPTOR (VDR) EXPRESSION AND $1,25(\mathrm{OH})_{2} \mathrm{D}_{3}$ MEDIATED PROLIFERATION OF GROWTH PLATE CHONDROCYTES IN PRIMARY CULTURE

\section{G. Klaus, L. Weber, U. Hügel, J. Grulich-Henn, O. Mehls}

Disturbance in metabolism of vitamin $\mathrm{D}$ and of the somatotrope hormon axis are important factors in the pathogenesis of growth retardation in uremic children. Both, $1,25(\mathrm{OH})_{2} \mathrm{D}_{3}$ and IGF-I stimulate growth of chondrocytes in culture. However, at present it is unknown, whether these hormones interact on the cellular level of the growth plate. Therefore we investigated the effects of $1,25(\mathrm{OH})_{2} \mathrm{D}_{3}$ IGF-I and their combination on (i) DNA synthesis, (ii) IGF-I receptor expression and (iii) regulation of the VDR.

Methods: Primary cultures of growth plate chondrocytes were obtained from upper tibial growth plate of $60 \mathrm{~g}$ SD rats by collagenase digestion. Cells were cultured in serumfree F-12/DMEM (1:1) medium, $1.2 \mathrm{mmol} / 1 \mathrm{Ca}^{++}, 2 \mathrm{mg} / \mathrm{ml} \mathrm{BSA}, 37^{\circ} \mathrm{C}, 5 \%$ $\mathrm{CO}_{2}$. Proliferation was determined by radiothymidine incorporation into TCA precitible material. IGF-I receptor was measured by specific binding of ${ }^{125} \mathrm{~J}$-IGF-I and VDR by Scatchard analysis using $\left[{ }^{3} \mathrm{H}\right]-1,25(\mathrm{OH})_{2} \mathrm{D}_{3}$.

Results: $1,25(\mathrm{OH})_{2} \mathrm{D}_{3}\left(10^{-13}-10^{-8} \mathrm{M}\right)$ or IGF-I $(10-80 \mathrm{ng} / \mathrm{ml})$ dosedependently increased radiothymidine incorporation with a maximum at $10^{-12} \mathrm{M}$ and $60 \mathrm{ng} / \mathrm{ml}$ respectively. Coincubation with $1,25(\mathrm{OH})_{2} \mathrm{D}_{3}\left(10^{-12} \mathrm{M}\right)$ and IGF-I $(60 \mathrm{ng} / \mathrm{ml})$ for $48 \mathrm{~h}$ stimulated DNA synthesis more than each of the hormones alone (solvent $10747 \pm 1004 \quad \mathrm{cpm} /$ well; $\quad 1,25(\mathrm{OH})_{2} \mathrm{D}_{3} \quad 18626 \pm 1321 ; \quad$ IGF-I $\quad 18247 \pm 910$ $1,25(\mathrm{OH})_{2} \mathrm{D}_{3}+$ IGF-I $\left.28979 \pm 1122 ; \mathrm{p}<0.01\right) \cdot 1,25(\mathrm{OH})_{2} \mathrm{D}_{3}\left(10^{-12}-10^{-8} \mathrm{M}\right) \mathrm{did}$ not influence specific binding of $125 \mathrm{~J}$-IGF-I in rapidly growing or confluent cells after 24 or $48 \mathrm{~h}$ (solvent: $100 \pm 3 \% ; 1,25(\mathrm{OH})_{2} \mathrm{D}_{3} 10^{-12} \mathrm{M}$ for $24 \mathrm{~h}: 92 \pm 2 ; 1,25(\mathrm{OH})_{2} \mathrm{D}_{3}$ $10^{-12} \mathrm{M}$ for $48 \mathrm{~h}: 104 \pm 1.9 ; \mathrm{n.s}$ ). In contrast Scatchard analysis demonstrated a dosedependent increase of maximal binding capacity $\mathrm{N}_{\max }$ for $\left[{ }^{3} \mathrm{H}\right]-1,25(\mathrm{OH})_{2} \mathrm{D}$ in cells incubated with IGF-I (solvent: 2153 bound molecules/cell; IGF-I $20 \mathrm{ng} / \mathrm{m}$ 3574; IGF-I 60ng/ml 12230).

Conclusion: In cultured growth plate chondrocytes IGF-I increases VDR expression and stimulates $1,25(\mathrm{OH})_{2} \mathrm{D}_{3}$ driven proliferation. $1,25(\mathrm{OH})_{2} \mathrm{D}_{3}$ does not influence expression of the IGF-I receptor. Because conentrations of both hormones are decreased in uremia, this synergistic effect of IGF-I and $1,25(\mathrm{OH})_{2} \mathrm{D}_{3}$ on proliferation of growth plate chondrocytes may be involved in renal stunting of growth.

University Children`s Hospital, Heidelberg, INF 150, D - 69120 Heidelberg p037

SERUM GROWTH HORMONE (GH) PROFILE IN UREMIC RATS E García, C Rey, J Rodríquez, v Martínez, A Cobo, E' Santos

To examine whether GH secretion is affected by CRF, the pulsatile GH secretory pattern was investigated in male S-D rats aged $25 \pm I$ days, grouped in $5 / 6$ nephrectomized (NX, $\mathrm{n}=6$ ) and sham operated (SHAM, $\mathrm{n}=7$ ) rats. Ten days after second operation, serum urea nitrogen of WX rats was higher than that of SHAM animals (126士23 vs $14 \pm 1 \mathrm{mg} / \mathrm{d} 1, \mathrm{p}<0.001$ ). Incremental gains in body weicht and length were decreased $(p<0.005)$ in the NX rats $\{23.4 \pm 10.0$ vs $73.2 \pm 2.8 \mathrm{~g} .2 .7 \pm .7$ vs $5.5 \pm .2 \mathrm{~cm}$ ). The cumulative food intake (149.4124.9 vs $206.8 \pm 7.5 \mathrm{~g}, p<0.05)$ as well as food efficiency $(0.131 \pm .031$ vs $0.353 \pm .008 \mathrm{~g}$ food consumed/g weight gained, p<0.0001) were also lower in the NX animals. Animals underwent double catheter implantation and serum GH was measured in samples obtained every 10 minutes over a 6 -hour period 19.00 to 15.00 hours). GH profile was analyzed by PULSAR program:

\begin{tabular}{|c|c|c|}
\hline & $\mathrm{NX}$ & SEAM \\
\hline $\begin{array}{c}\text { Total Area } \\
(\mathrm{min} \times \mathrm{ng} / \mathrm{ml})\end{array}$ & $20533 \pm 5801$ & $35044 \pm 6413$ \\
\hline $\begin{array}{c}\text { Number of peaks } \\
\text { (range) }\end{array}$ & $\begin{array}{c}2 \\
(1-3)\end{array}$ & $\begin{array}{c}2 \\
(2-3)\end{array}$ \\
\hline $\begin{array}{c}\text { Peak Height } \\
(n g / m 1)\end{array}$ & $46.73 \pm 11.44$ * & $80.30 \pm 6.91$ \\
\hline Peak Lenght (hr) & $1.81 \pm .17$ & $1.67 \pm .09$ \\
\hline $\begin{array}{c}\text { Peak Area } \\
\{\text { min } \times \text { ng } / \mathrm{m} 1\rangle\end{array}$ & $3396.2 \pm 1151.7$ & $4264.1 \pm 444.0$ \\
\hline $\begin{array}{c}\text { Baseline ievels } \\
(\mathrm{ng} / \mathrm{m} 1)\end{array}$ & $10.72 \pm 2.17$ * & $5.23 \pm 0.51$ \\
\hline
\end{tabular}

As shown in the Table, severe uremia modifies the pattern of $\mathrm{GH}$ secretion in male rats. This may be relevant in the subnormal growth secondary to CRF.

Pediatrics. Hospital Central of Asturias and *Hospital Alvarez Buylla. School of Medicine. University of oviedo.Julián Clavería 6. 33006 Oviedo. Asturias, Spain
P038

TN VITRO GROWTH HORMOINE (GH) SECRETION IN UREMTA J Rodríguez, MJ García-Boto, C Rey, V Martínez, E García, P Fernández, F Santos

To examine whether GF secretion is affected by chronic renal failure, the GH secretory response of dispersed pituitary cells perifused with GH-releasing hormone (GHRH) was cells perifused with GH-releasing hormone (GHRH) was
investigated in male s-D rats aged $25 \pm$ lays, grouped in $5 / 6$ nephrectomized ( $\mathrm{NX}, \mathrm{n}=6$ ) and sham-operated (SHAM, $n=9$ ) animals. Ten days after nephrectomy, NX rats had higher (p<0.0001) serum urea nitrogen (XtSEM) than SHAM ( $99 \pm 10$ vs $12 \pm 0 \mathrm{mg} / \mathrm{d} 1$ ). Incremental gains in body weight and length of NX rats were decreased $(8.5 \pm 1.9$ vs $71.3 \pm 1.5 \mathrm{~g}$ and $1.7 \pm 0.2 \mathrm{vs}$ $5.5 \pm 0.2 \mathrm{~cm}, \mathrm{p}(0.0001)$. Basal $\mathrm{GH}$ secretory rate was similar NX and SHAM $(7.22 \pm 0.53$ vs $8.09 \pm 0.44 \mathrm{ng} / \mathrm{min} / 10 \mathrm{million}$ cells, respectively) and both groups showed a high relationship between the log of GHRH dose and $\mathrm{GH}$ release (NX: $r=0.897$, $p<0.03$; SHAM: $r=0.932, p<0.02)$. As shown in the Figure, GH response tended to be depressed in NX rats.

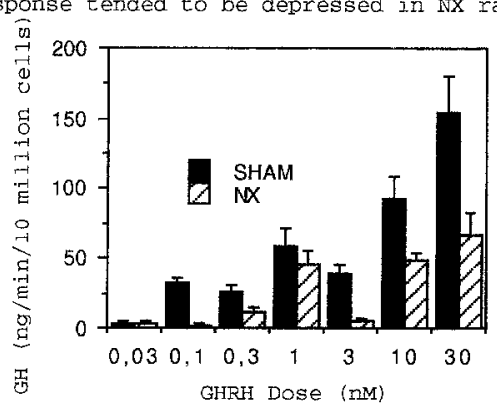

The results suggest that, in contrast to that observed in moderate renal insufficiency (KI 1992,41:356-60), "in vitro" ability of pituitary cells to secrete $\mathrm{GH}$ is adversely impaired by severe uremia

Pediatrics and *Pharmacology. Hospital Central of Asturias and school of Medicine. University of oviedo. c/ Julián claveŕ́a 6. Oviedo, 33006 Asturias. Spain. 
P039

THE CHANGES IN SERUM TYPE I AND III PROCOLLAGEN, INSULIN LIKE GROWTH FACTOR-I (IGF-I) AND INSULIN-LIKE GROWTH FACTOR BINDING PROTEIN-3 (IGFBP-3) LEVELS IN CHILDREN WITH CHRONIC RENAL FAILURE (CRF)

P.Cinaz. N.Buyan*, N.Gökçora, S.Elbeg, E.Hasanoğlu

Serum carboxyterminal propeptide of type I procollagen (PICP) and aminoterminal propeptide of type III procollagen (PIIINP) concentrations can be used as markers of bone formation and the evaluation of children with growth disorders. We measured the serum levels of these collagens by radioimmunoassay (RIA), IGF-I (by immunoradiometric assay) and IGFBP-3 (by RIA) levels in 24 children aged between 4-14 years with $C R F(n=12$ dialysis, $n=12$ non-dialysis) and in 12 age-matched healthy controls.Fifteen patients were in the prepubertal and nine were in the pubertal stage.

Mean serum IGFBP-3 and PIIINP levels in the dialysis patients were higher than the control group, the difference between the groups was statistically significant $(\mathrm{p}<0.05)$. It seemed that pubertal stage of the patients did not affect the levels of PICP, PIINP and IGFBP-3 while senum IGF-I levels in pubertal patients were significantly higher than those in prepubertal patients $(\mathrm{p}<0.001)$. There was no significant correlation between PICP and PIINP in the patients. Neither PICP nor PIINP correlated with height-z score, bone age, IGF-I or IGFBP-3.

It was concluded that serum PIINP levels elevated in the patients with CRF as osteoclastic activity is likely to be increased in those patients. Further investigations into the effects of these collagens on growth failure associated with CRF, are needed.

*Present address : Gazi University,Faculty of Medicine, Departments of Pediatric Nephrology, Endocrinology and Nuclear Medicine Beşevler 06500 Ankara, TURKEY
P041

SOMATIC DEVELOPMENT OF PUBERTAL BOYS WITH PRETERMINAL CHRONIC RENAL FAILURE (CRF) AND AFTER RENAL TRANSPLANTATION (TX)

E. Wühl, F. Schaefer, K. Schärer and 'Cooperative Study Group for Pubertal Development in Chronic Renal Failure'

Earlier studies on pubertal development in CRF and TX patients were usually performed crossectionally in populations with different sex and modes of therapy. 7 prepubertal boys with CRF and 10 after TX aged $>10$ yrs were followed in a prospective study by biannual measurements of anthropometric variables. At last observation all patients had passed peak height velocity (PHV). No patient changed the mode of treatment or received growth hormone. Controls were taken from the first Zürich longitudinal growth study. Results: PHV was attained at $14.7 \pm 1.2$ yrs in $\mathrm{CRF}$ and $14.4 \pm 1.7 \mathrm{yrs}$ in TX, in presence of a mean bone age of 12.7 and 11.0 yrs and a mean serum creatinine of $378 \pm 286$ and $127 \pm 69 \mu \mathrm{mol} / \mathrm{\Lambda}$, respectively. The mean size of PHV was reduced to $8.2 \pm 1.4 \mathrm{~cm} / \mathrm{yr}$ in CRF and $6.9 \pm 2.4 \mathrm{~cm} / \mathrm{yr}$ in TX. Mean height SDS at PHV was more severely reduced: $-1.6 \pm 1.5$ SDS in CRF and $-2.4 \pm 1.9$ SDS in TX, similar to prepubertal values, suggesting that growth retardation was mainly due to insufficient prepubertal growth. The relation of sitting height to leg length at PHV was higher in TX than in CRF patients possibly related to the suppressive effect of corticosteroids on extremity growth. Fat mass was significantly higher in TX than in CRF patients. Pubertal stages at PHV were normally distributed. The increase of testicular volume (TV) to $4-6 \mathrm{ml}$ was delayed in $50 \%$ of both groups. At PHV mean TV was below the 50th centile $(12 \mathrm{ml})$. in $8 / 11$ boys and subsequent testicular growth was even more delayed. In conclusion pubertal patients with CRF and after TX have reduced PHV in presence of a persistently low height SDS and retarded testicular growth. Fat mass is higher in TX than in CRF patients.

University Children's Hospital, INF 150, 69120 Heidelberg, Germany
P0 42

OCCURENCE OF SEVERE RENAL OSTEODYSTROPHY DUE TO PARATHYROID ADENOMA DURING A TREATMENT WITH rhGH IN A CHILD WITH CHRONIC RENAL FAILURE D.MORIN - F.DALLA VALE, ML.DUMAS ,H.VALETTE, R.DUMAS .

\section{RENAL TUBULAR ACIDOSIS \\ M.-S. Ghuysen, E. Pinto, J.-P. Guignard}

Failure to thrive is commonly associated with the presence of chronic metabolic acidosis. The aim of this study was to evaluate the effect of mild renal tubular acidosis (RTA) on growth, and the response to alkali therapy. Twenty-four children (mean age 21 months; range 2 months - 13 years) with RTA were studied by current acidification tests, and followed for a mean duration of 26 months (range 6-81 months). Treatment with sodium bicarbonate or sodium citrate was adjusted every 1-3 months so as to maintain the actual plasma bicarbonate and base excess in the normal range. The presenting symptoms were failure to thrive $(96 \%)$, anorexia $(54 \%)$, vomiting $(29 \%)$, polyuria $(8 \%)$ and rickets $(4 \%)$. Group A (proximal $R T A)$ inciuded is children and group B (distal RTA) 5 children. Mean plasma bicarbonate at the time of diagnosis was $17.5 \pm 5 \mathrm{mmol} / \mathrm{l}$ in group $A$ and $17.0 \pm 4 \mathrm{mmol} / \mathrm{l}$ in group B. Urine calcium excretion was normal in group $A(0.48 \pm 0.38 \mathrm{~mol} / \mathrm{mol}$ creat) and moderately elevated in group $B(1.98 \pm 1.22)$. To achieve normal plasma bicarbonate levels, group A required $4.2 \pm 2.8 \mathrm{mmol} / \mathrm{kg}$ per day and group $B 2.1 \pm$ $0.2 \mathrm{mmol} / \mathrm{kg}$ per day of sodium bicarbonate. Height and weight were measured at 3 months intervals. Height was expressed in standard deviation score (SDS) for each child and growth rate over time measured in terms of changes in SDS for height. The following mean results for both groups were: -1.48 SDS at diagnosis; -1.12 SDS at 6 months after initiating treatment; -0.88 SDS after 1 year; -0.79 SDS after 2 years; -0.53 SDS after 3 years and -0.06 SDS after 4 years. We conclude (1) that appropriate alkali therapy in children with $R T A$ results in catch-up growth and (2) that the presence of occult RTA should be looked for whenever failure to thrive is present in a child.

Service de Pédiatrie, CHUV, 1011 Lausanne - Switzerland
A 5-year-old girl was admitted with acute renal failure due to Henoch Schonlein nephritis. The renal biopsy showed crescentic glomerulonephritis and in spite of intensive treatment including high dose steroid therapy and plasmapheresis, her renal function remained severely impaired. Peritoneal dialysis had to be started and she was maintained on home CAPD for 18 months. Peritoneal dialysis was then stopped because of a significant improvement in her renal function. The treatment consisted of a significant improvement in her renal function. The treatment consisted
of a low protein and phosphate diet, calcium carbonate as phosphate binder and oral 1 alpha hydroxyvitamin $D$. As her growth velocity dropped dramatically, from $5 \mathrm{~cm} /$ year at the beginning of the disease to 1 $\mathrm{cm} / \mathrm{year} 36$ months later, rhGH therapy was started at 9 years of age. She ther efore received $0,6 \mathrm{w} / \mathrm{kg} /$ week during the first 12 months and after that rhGH was increased to $1,2 \mathrm{u} / \mathrm{kg} /$ week.

\begin{tabular}{|l|c|c|c|c|c|}
\hline $\begin{array}{l}\text { rhGH treatment } \\
\text { months }\end{array}$ & 0 & 12 & 18 & $\begin{array}{c}\text { STOPPED } \\
20\end{array}$ & 24 \\
\hline Height-SDS & -3.05 & -2.3 & -2.05 & -2.08 & -2.01 \\
\hline $\begin{array}{l}\text { Creatinine } \\
\text { plasma level } \\
\text { ( } \mu \text { moV). }\end{array}$ & 246 & 255 & 318 & 394 & 409 \\
\hline $\begin{array}{l}\text { PTH plasma } \\
\text { level* (pg/ml) }\end{array}$ & 134 & 395 & 810 & 847 & 1472 \\
\hline
\end{tabular}

* Normal values : $10-55 \mathrm{pg} / \mathrm{ml}$

The rhGH therapy had to be stopped after 20 months of treatment because of an uncontrolled high intact PTH plasma level, with severe bone abnormalities. As her renal function was still deteriorating, hemodialysis was started 5 months later but failed to control hyperparathyroidism, in spite of intravenous 1 alpha hydroxyvitamin $D$. At that time, ultrasound scan and thallium-technetium scintigraphy showed a large parathyroid adenoma. She thercfore underwent surgical parathyroidectomy. The parathyroid adenoma and two parathyroid glands were removed. Six hours after surgery, her calcium plasma level dropped from 3 to 1.85 mmoll and her intact PTH plasma level from 1400 to $90 \mathrm{ng} /$.

This case raises the question of a possible relationship between rhGH therapy and the occurence of parathyroid adenoma.

Present address : Service de Pédiatrie I, Hôpital Arnaud de Villeneuve, Avenue Doyen Gaston Giraud.-34295. Montpellier cedex 5-France. 
P043

TREATMENT WITH GROWTH HORMONE INCREASES LIPOPROTEIN(A) SERUM LEVELS IN CHILDREN WITH CHRONIC RENAL INSUFFICIENCY.

U. Querfeld", D. Haffner, E. Wühl, D.V. Michalk*, O. Mehls

We investigated wether treatment with recombinant human growth hormone ( $\mathrm{hGH}$ ) in children with growth failure due to chronic renal insufficiency (CRF) has an effect on serum lipoprotein(a) [LP(a)] levels. $\mathrm{Lp}$ (a) was measured in 13 patients treated with $\mathrm{hGH}(1 \mathrm{IU} / \mathrm{kg} /$ week) for 6 to 9 months. All children were on conservative treatment; median age was 8.3 years (1.6-14.5), median $\mathrm{Ccr}$ was $24 \mathrm{ml} / \mathrm{min} / 1.73 \mathrm{~m}^{2}$ (845). Morning blood samples were obtained in 3 month intervals. Lp(a) was analyzed by a one-step immunoassay (Immuno, Heidelberg). All measurements were performed in triplicate.

Results: In 5 patients, no $L p(a)$ could be measured either before or after treatment (probably "O-phenotype"). In the other patients, the median Lp(a) serum level at baseline was $37 \mathrm{mg} / \mathrm{dl}$; $6 / 8$ patients had serum $L p(a)$ levels $>30 \mathrm{mg} / \mathrm{dl} \quad(30-98 \mathrm{mg} / \mathrm{dl})$ before the start of treatment. Although $\mathrm{Lp}(\mathrm{a})$ serum levels showed considerable variation during treatment, a net increase (14\%-175\%, median $47 \%$ ) could be observed in all patients (last measurement compared to first). Median $L p(a)$ levels at 3,6 and 9 months were 53,60 , and $61 \mathrm{mg} / \mathrm{dl}$, respectively.

These data indicate that treatment with $\mathrm{GH}$ in children with CRF leads to increases in serum $L p(a)$ concentrations. $L p(a)$ should be monitored in studies evaluating effects of rhGH treatment. Further data are needed to determine the magnitude of the effect of rhGH on Lp(a) and to establish therapeutic guidelines for rhGH treatment of children with CRF and high $L p(a)$ levels.

University Children's Hospitals of Cologne and Heidelberg, Germany

PO 44

ALTERED EXTRACELLULAR NEUROTRANSMITTER MILIEU IN HYPOTHALAMIC MEDIAL PREOPTIC AREA (MPOA) OF UREMIC CASTRATE RATS - IN VTVO EVIDENCE FOR CENTRAL DYSREGULATION OF GONADOTROPIC AXIS

J. Kovács, F. Schacfer, J. Culman, A. Bandt, O. Mehls, K. Schärer

A central nervous defect is presently discussed as the primary abnormality underlying disturbed pubertal development and fertility in chronic renal failure. We have recently identified a reduction of hypothalamic gonadotropin-releasing hormone $(\mathrm{GnRH})$ secretion in the castrate uremic rat model The pulsatile secretion of GnRH from neurons in the MPOA is regulated by a complex neuronal network. Catecholaninergic and scrotoninergic neurons exert predominantly stimulatory effects on GnRH rclcase. To elucidate possible alterations of the local neurotransmitter milicu, we implanted stcreotactically microdialysis probes in the MPOA of $5 / 6$ nephrectomized and control rats. The animals had been orchidectomized to exclicue confounding fucduack effects by sex steroids. On the study day, the microdialysis probes were perfused continuously with artificial cerebrospinal fluid After an equilibration pcriod of $2 \mathrm{~h}$, dialysate samples were collected every $10 \mathrm{~min}$ for $4 \mathrm{~h}$ in the awake, unrestrained animals. In each dialysate sample, norepinephrine $(\mathrm{N})$, epincphrine (E), DHPG (the major catecholamine metabolite), DOPAC (dopamine i.sctabolitc) and 5-HIAA (serotonin metabolite) were measured by HPLC and electrochemical detcction. The integrated mean dialysate concentrations of NE $(0.22=0.22$ vs. $0.56 \pm 0.41 \mathrm{pg} / 40 \mu \mathrm{l}$ tube $)$ and $\mathrm{E}(0.65 \pm 0.41$ vs. $1.13 \pm 0.53$ $\mathrm{pg} / \mathrm{tube}$ ) were significantly reduced in the uremic animals $(\mathrm{p}<0.01)$, whereas DHPG was increased $(22.5 \pm 7.5 \mathrm{vs} .12 .8 \pm 5.8 \mathrm{pg} /$ tube). 5 -HIAA concentrations were reduced in the urcmic animals to $20 \%$ of the concentrations observed in controls $(1.3 \pm 1.1$ vs. $6.4 \pm 4.5 \mathrm{pg} /$ tubc $\mathrm{p}<0.0001)$ DOPAC concentrations did not differ between uremic and control rats. Our results suggest deficient local release and altered metabolism of catccholamines, and the decreased 5-HIAA concentrations indicate low cxtraccllular scrotonin concentrations in the MPOA of uremic rats. In summary, our findings provide in vivo evidence for a deficient stimulatory input of superior neuronal systems to the hypothalamic GnRH pulse generator in experimental urcmia.

Pediaric Nephrology Division, University Children's Hospital, Im Neuenheimer Feld 150, D-69120 Heidelber

Supported by Deutsche Forschungsgemeinschaft
P0 45

RENAL TUBULAR HANDLING OF POTASSIUM IN CHILDREN WITH . INSULIN-DEPENDENT DIABETES MELLITUS (IDDM)

J. Rodriguez Soriano, A. Vallo, G. Ariceta, P. Martul, and I. Rica

Tulassay et al (Pediatr Nephrol 1992; 6 (5): C100) have proposed that aldosterone bioactivity is impaired in IDDM and that transtubular potassium gradient (TTKG) is a characteristic marker of early and persistent renal involvement. To ascertain this fact we studied two groups of children with IDDM: A) at onset of the disease, and B) after an evolution of several years.

A) This study was carried out in 10 children $(4 \mathrm{M}, 6 \mathrm{~F})$ with a mean age of $4.9+3.7$ years, both before therapy and after one month of insulin administration. Mean duration of symptoms was $30_{ \pm} 24$ days. At onset, TTKG $(3.4 \pm 1.2)$ and FEK $(9.5 \pm 4.6 \%)$ were diminished but became normal after therapy $(6.4 \pm 1.8$ and $17.4 \pm 5.6 \%$, respectively), Calciuria persisted slightly elevated $(5.6+2.4$ vs $3.4+$ $2.0 \mathrm{mg} / \mathrm{kg} / \mathrm{day}$ ). Albumin excretion rate was identical before and after therapy $(0.21 \pm 0.1$ vs $0.22 \pm 0.2 \mu \mathrm{g} / \mathrm{m} 2 /$ day $)$. TTKG related inversely with Hb1AC $(r=-0.66)$ and calciuria $(r=-0.39)$.

B) This investigation was performed in 73 children $(42 \mathrm{M}, 31 \mathrm{~F})$ with a mean age of $11.6+2.4$ years and a follow-up of $54 \pm 36$ months. Patients were grouped according to values of TTKG: 30 had a low TTKG $<4(3.1 \pm 0.6)$ and 43 had a normal TTKG $>4(5.7 \pm 2.5)$. Patients of the first group, compared to those of the second one, were of the same age, had identical duration of follow-up, and presented similar values for calciuria, $\mathrm{CCr}$, albumin excretion rate, PRA and plasma aldosterone. However, they presented significantly higher values for HbIAc $(8.8 \pm 1.8 \%$ vs $7.9 \pm 1.4 \%$, $\mathrm{p}<0.05)$ and glycosuria (1592+1232 vs $441 \pm 557 \mathrm{mg} / \mathrm{kg} / \mathrm{day}, \mathrm{p}<0.01)$. Conclusions. This study indicates that TTKG is a simple indicator of reversible tubular dysfunction in the course of IDDM which depends fondamentally upon the metabolic control of the disease. Our findings do not support the conclusion of Tulassay et al that TTKG is a valid marker of early and persistent renal involvement.

Divisions of Nephrology and Endocrinology, Department of Pediatrics, Hospital de Cruces and Basque University Schol of Medicine, Bilbao, Spain.

P046

RENAL TUBULAR CALCIUM AND PHOSPHATE REABSORPTION AND PARATHYROID FUNCTION IN EARLY DIABETES MELLITUS D. MORIN", F. DALLA VALE , P. GARANDEAU, B. ROLIN, R. DUMAS

Hypercalciuria and hypophosphatemia frequently occur in early diabetes mellitus. Recently, transient hypoparathyroidism has been described during diabetic ketoacidosis*. We studied 15 children ( 7 girls), mean age : 7 years (3 to 14), admitted because of the occurence of diabetes mellitus Blood samples were taken for calcium, phosphate, magnesium bicarbonate, intact PTH, 1,25 dihydroxyvitamin D plasma levels on day 1 , before receiving any treatment and on day 30, after one month of insulin therapy. At the same time, calcium/creatinine urinary ratio and the therapy. At the same time, calcium/creatinine urinary
tubular reabsorption of phosphate (TRP) were measured.

\begin{tabular}{|c|c|c|c|}
\hline & Day $1^{* *}$ & Day $30^{* *}$ & p \\
\hline HCO3 mmoVh & $18.4 \pm 7.4$ & $24.1 \pm 3.1$ & NS \\
\hline P mmoh & $1.41 \pm 0.28$ & $1.58 \pm 0.2$ & NS \\
\hline $\mathrm{Mg}$ mmoh & $0.82 \pm 0.14$ & $0.9 \pm 0.06$ & \\
\hline Ca mmolh & $2.41 \pm 0.14$ & $2.37 \pm 0.16$ & NS \\
\hline $\begin{array}{l}\text { PTH pg/mi } \\
(10-55)\end{array}$ & $8.9 \pm 6.6$ & $18.5 \pm 16.1$ & 0.07 \\
\hline $\begin{array}{l}1,25(\mathrm{OH})_{2} \mathrm{D}_{3} \mathrm{pg} / \mathrm{ml} \\
(28-40)\end{array}$ & $23.4 \pm 8.2$ & $28.8 \pm 7.5$ & NS \\
\hline UCa/UCr mg/mg & $0.66 \pm 0.73$ & $0.17 \pm 0.2$ & 0.02 \\
\hline TRP\% & $83.2 \pm 14.3$ & $85.7 \pm 5.5$ & NS \\
\hline
\end{tabular}

\section{* mean value \pm sd}

On day 1 hypercalciuria was a constant finding and we found an invers correlation between the $\mathrm{UCa} / \mathrm{UCr}$ ratio and the plasma bicarbonate level $(p<0.05)$. On day 1 the mean PTH plasma level was below the normal range and was significantly correlated with the bicarbonate plasma level (p<0.05). On day 1, the TRP was below the normal range (mean : 74\%) only in the 7 patients with metabolic acidosis (HCO3 $<18 \mathrm{mmol}$ ) nevertheless, in the whole group of patients, the TRP was significantly correlated with the bicatbonate plasma level $(p=0.02)$. On day 30 the mean PTH plasma level returned within the normal range.

The renal tubular calcium and phosphate reabsorption are impaired in early diabetes mellitus., especially in patients with metabolic acidosis. The cause of the transient hypoparathyroidism remains unknown.

* Mallet et al . Pediatr Res. 1993 ; 5:S78 (Abstract)

Present address : Service de Pédiatrie 1.Hôpital Arnaud de Villeneuve Avenue Doyen Gaston Giraud.34295. Montpellier cedex 5 - France. 
P0 47

TUBULAR URATE TRANSPORT DISORDERS IN PATIENTS WITH FAMILIAL RENAL HYPOMAGNESEMIA SYNDROMES

J. Zawadzki

The mechanism of tubular urate transport disorders leading to hyperuricemia was studied by the pyrazinamide and probenecid tests in 11 patients (mean age $11.7 \pm 3.6$ years) with familial renal hypomagnesemia hypercalciuria (group I: serum $\mathrm{Mg} 0.51 \pm 0.08 \mathrm{mmol} / \mathrm{l}$, urine $\mathrm{Ca} 9.9 \pm 3.2$ $\mathrm{mg} / \mathrm{kg} / \mathrm{d}$ ). The results were compared with those of 3 boys aged $13.2 \pm 2.6$ years with isolated familial renal hypomagnesemia (group II: serum $\mathrm{Mg} 0.48 \pm$ $0.11 \mathrm{mmol} / \mathrm{l}$, urine $\mathrm{Ca} 0.6 \pm 0.1 \mathrm{mg} / \mathrm{kg} / \mathrm{d}$ ).

Results: (mean \pm SD) in groups I and II were, respectively: serum creatinine: $1.2 \pm 0.4$ and $0.6 \pm 0.1 \mathrm{mg} / \mathrm{dl}$; serum uric acid (U.A.): $6.7 \pm 1.7$ and $3.5 \pm$ 1.3. $\mathrm{mg} / \mathrm{dl}$; FEUA: $5.8 \pm 1.1$ and $11.2 \pm 3.2 \%$; presecretory reabsorption of U.A. (Pre.R.): $99.2 \pm 0.4$ and $99.7 \pm 0.3 \%$ filtered load (F), tubular secretion of U.A. (T. Sec.): $32.5 \pm 5.7$ and $58.3 \pm 9.6 \%$ (F), postsecretory reabsorption of U.A. (Post. R.): $82.7 \pm 5.3$ and $80.6 \pm 6.4 \%$ secreted load (S). Normal adults: Pre. R. 99. $5 \pm 0.2 \%$ (F).; T. Sec. $40.4 \pm 2.4 \%$ (F).; Post. R. $76.6 \pm 1.4 \%$ (S). (Nephron 1983, 35:183).

Conclusions

1. Hyperuricemia is a characteristic symptom in familial renal hypomagnesemia - hypercalciuria and results from decreased tubular secretion and/or increased postsecretory reabsorption of urate, probably as a consequence of nephrocalcinosis.

2. In isolated familial renal hypomagnesemia, increased tubular secretion is accompanied by an equal increase in reabsorption of urate secreted into the tubule. This is probably the result of the lowered intracellular $\mathrm{Mg}$ content in the proximal tubule and/or tubular $\mathrm{Mg}$ transport defect in this part of the nephron.

Child Health Center, Department of Nephrology, Dialysis and Kidney Transplantation, 04-736 Warsaw, Poland

TWO DISTURBANCES OF WATER AND ELECTROLYTE METABOLISM IN PATIENTS WITH TUBERCLLOUS MENINGITIS: CEREBRAL SALT WASTING (CSW) AND THE SYNDROME OF INAPPROPRIATE ANTIDIURETIC HORMONE SECRETION (SIADH)

H. Mocan*, E. Erduran, Y. Aslan

In this study, the disorders of electrolyte and water metabolism in 14 patients with tuberculous meningitis were evaluated. Cerebral salt wasting(CSW) in eight patients and the syndrome of inappropriate antidiuretic hormone secretion (SIADH) in Sik patients were recorded. It was determined that denyoratation (ivos), law urine gravity (lOOX), polyuria $(100 x)$, hyponatremia $(100 x)$, renal salt wasting $(100 x)$, low plasma renin activity (100x). Dow Dlasma aldosteron concentration $(87.5 x)$, in patients with CSW and otherwise hig urine grav:ty $(100 x)$, low urine output $(100 x)$, hyponatrenia (100x), low plasma renin activity (B3. $3 \%$ ), high plasma aldosteran concentration (5OX) in patients with SIADH. It was thought that the cause of CSW and may be due to effect of natriuretic hormone. The clinic and laboratory findings of CSW and SIADH should be distinguished because of different treatment modalities for each.

- Present address: Department of Pediatrics, Karadeniz Technical University Faculty of Medicine, Trabzon/TURKEY. po 49

RENAL FUNCTIONAL AND MORPHOLOGICAL ABNORMALITIES IN CHILDREN WITH DIABETES MELLITUS TYPE I A. Raes ${ }^{1}$ J.G.J. Vande Walle $e^{1}$. M. Craen ${ }^{2}$

Children with Diabetes Mellitus type I (DM-I) have a $10-40 \%$ risk to develop diabetes nephropathy (?). Micro-albuminuria, altough earliest sign of renal damage, indicates an irreversible, progressive evolution to renal failure, that only can be retarderd.

To identify earlier patients at risk for diabetic nephropathy, we studied 27 children $(12,8 \pm 2.8 y)$ with DM-I for $7.8 \pm 2.5 \mathrm{y}(>5 \mathrm{y}$ ), without microalbuminuria for renal function (GFR, $R P F, F F$, FE $\mathrm{Na}$ ), dopamine-mobilisable functional reservecapacity (DM-FRC), renine (PRA), aldosterone (AID), renal morphology on ultrasound (US) and bloodvolume (BV: Cr*-radiolabelled RBC and $I^{ \pm 31}-$ albumine).

Altough GFR $\left(134 \pm 34 \mathrm{ml} / \mathrm{min} / 1.73 \mathrm{~m}^{2}\right)$ and $\mathrm{RPF}$

$\left(488 \pm 166 \mathrm{ml} / \mathrm{min} / 1.73 \mathrm{~m}^{2}\right)$ were higher than a control group, they let us not identify hyperfiltration in

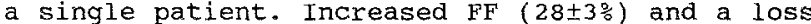
of DM-FRC (-10\%, normal + 15\%) suggest a hyperfiltration in all patients. Absence of DM-FRC was not related to dopamine-resistance, because dopanine induced natriuresis persisted. In contradiction with findings in aduIts, we observe no increased $B V$, nor suppression of PRA and AID. On US renal hypertrophy was a constant finding (ventro-dorsal and latero-lateral axis: $p<0.01)$. And this hypertrophy was already present in $6 / 7$ patients at diagnosis of DM-I. No correlation with HgbAlC, age or duration on $\mathrm{DM}-\mathrm{I}$ was found.

Departement of pediatric ${ }^{1}$ nephrology and

zendocrinology, Ghent, Belgium
P050

Italian Registry of Pediatric Renal Biopsies. $R$ Coppo and $S$ Maringhini for the Renal Biopsy Registry of the Italian Renal Immmopathology Group.

The Italian Registry of renal biopsies has been recording the histological features of renal biopsies since 1987. In 1992 a "Pediatric window" of this Registry was opened. During the first year of activity the Registry recorded 154 renal biopsies from 16 Italian centers.

The clinical indications to the renal biopsy in pediatric age included persistent microscopic hematuria (25\%), often associated with a fully developed nephritic syndrome (15\%). or recurrent gross hematuria (17\%). The renal biopsy in these cases mostly showed glomerulonephrit is (GN) with prevalent IgA mesangial deposits (14.3\% of the total). In contrast with the past decade, the renal biopsy was performed only in selected cases of children, with nephrotic syndrome, who failed to respond to conventional treatment (7.8\% Focal segmental glomerular sclerosis, $11 \%$ mesangial proliferative GN, $8,4 \%$ mesangiocapillary GN, 2.6\% membranous GN, $18.8 \%$ minimal changes GN)

The clinical indications to perform renal biopsy in acute renal failure or rapidly progressive GN were limited to $8 \%$ of the cases.

The Registry is structured as a prospective investigation and some essential clinical data have been recorded each year to allow a prospective evaluation of renal biopsies performed during the pediatric age.

Nephrology and Dialysis Dept, Regina Margherita Hospital, Piazza Polonia, 94 - 10126 Torino Italy. 
P051

SEXUAL DIMORPHISM OF RENIN AND ANGIOTENSINOGEN mRNA EXPRESSION IN FAWN-HOODED RATS.

A.P. Provoost, F.F. Jung, D. Diamant, S-S. Tang, and J.R. Ingelf inger

The fawn-hooded (FH) rat with hypertension and severe proteinuria (FHH) is a model for spontaneous glomerulosclerosis, more marked in males than in females. The FHH is characterized by early glomerular hypertension. A relatively normotensive strain with less protcinuria (FHL) does not develop carly lesions. We previously showed persistance of an immature pattern of renin expression in young male FHH rats (JASN 4: $773,1993)$. To examine further the contribution of the intrarenal reninangiotensin system (RAS) to the renal lesions we compared expression of renal renin and angiotensin (ang-n) mRNA in 25 week old male $(m)$ and female (f) FHH and FHL rats, and in castrated male (c) FHH and FHL. Systolic blood pressure (SBP; mm Hg), urinary protein excretion (UPV; $\mathrm{mg}$ /day), and macroscopic renal sclerosis scores (RSS; scale 0-5) were also determined.

\begin{tabular}{lllllc} 
& (n) & SBP & UPV & \multicolumn{1}{c}{ RSS } & PRC \\
mFHH & $(9)$ & $181 \pm 15$ & $168 \pm 71$ & $2.4 \pm 0.5$ & $17.1 \pm 4.8$ \\
cFHH & $(10)$ & $168 \pm 11$ & $157 \pm 41$ & $1.2 \pm 0.7$ & $19.6 \pm 3.9$ \\
fFHH & $(5)$ & $171 \pm 7$ & $94 \pm 75$ & $1.0 \pm 1.0$ & $18.6 \pm 3.7$ \\
mFHL & $(7)$ & $153 \pm 12^{*}$ & $29 \pm 5^{*}$ & $0.7 \pm 0.9^{*}$ & $21.7 \pm 2.2$ \\
cFHL & $(7)$ & $143 \pm 10^{*}$ & $33 \pm 26^{*}$ & $0.4 \pm 0.7$ & $19.9 \pm 4.0$ \\
fFHL & $(5)$ & $138 \pm 12^{*}$ & $10 \pm 5^{*}$ & $0.0 \pm 0.0$ & $30.3 \pm 4.1^{*}$
\end{tabular}

fFHL (5) $138 * 12^{*} \quad 10+5^{*}$

All data mean \pm sd, ${ }^{*} p<0.05$ vs identical FHH group mcan (ANOVA). SBP, UPV and RSS were highest in FHH, and slightly higher in m than in f. $c$ rats had slightly lower SBP and RSS than m, but UPV was not different. Ang-n mRNA was higher in $m$ than in $f$ or $c$. FHH had higher ang-n mRNA than FHL. Renin mRNA was higher in $f$ and $m$ FHL than in $\mathrm{FHH}$ and tended to increase in c. These data suggest that there is an androgen-dependent scxual dimorphism in the RAS in FH rats. Intrarenal and plasma renin do not correlate with RSS. In contrast, the elevated intrarenal ang-n mRNA may be a marker of renal damage.

Department of Pediatric Sutgery, Erasmus University, P.O. Box 1738, 3000 DR Rotterdam, The Netherlands,

Department of Pediatric Nephrology, Massachusetts Gencral Hospital, Boston, MA, USA

P052

EVALUATION OF FACTORS INFLUENCING AMBULATORY BLOOD PRESSURE MONITORING (ABPM) IN 70 HEALTHY OR UNTREATED HYPERTENSIVE (HT) CIIILDREN

Ph.Barthe, S.Cassadou, Y.Aragon*, Ch.Thomas-Agnan*, R.Ghabril, F.Heitz, F.Bouissou Objective :To describe ABPM profiles recorded in unselected group of children and try to evaluate the individual role of some determinants in the large variability observed in these profiles. This study is designed as a retrospective exploratory one with application of a special statistical method.

Subjects and methods : 70 children (38M., 32F.) 11,54y, of mean age ( 3 to $17,8 \mathrm{y}$.) had an ABPM for known or suspected arterial HT. 33 proved to be exempt from underlying pathology, 23 had a nephrologic disease (including $3 \mathrm{CRF}$ ) and 14 an extra renal pathology. ABPM were recorded by a Spacelabs 90202 oscillometric device.

The mean nycthemeral BP values in comparaison with the 97,5perc. BP values following Nancy curves, allowed to determine for each child a defined tensional level : normal (N) $<97,5$ perc.,borderline(B)<97,5perc, $+10 \mathrm{mmHg}$, hypertensive(HT) $>97,5$ perc. $+10 \mathrm{mmHg}$. Mean percentage of elevated (>97,5perc) BP, daytime/overnight mean BP differences, and hourly mean BF values were reldined ds depentant variabics; anid asce, sid, ineight, weight, and body mass index as independant ones. Slice inverse regression method (K.C.Li. $1991 \mathrm{~J}$. of American Statistical Association, 86,316-42) was applied for multivariate analysis.

Results : $72.8 \%$ of children had N tensional level, $20 \%$ B and $17,2 \%$ HT level for Syst. and/or Diast.BP. Diast.BP was more often elevated than Syst.BP (23vs15). B or HT level concerned mainly children with underlying pathology $(59 \%$ vs $15,1 \%)$.

- Mean percentages of elevated BP values were 11,9 for Syst.BP and 20,9 for Diast.BP in $N$. levels subjects. They increased significantly in $B$ and $H$ T levels.

- Day-night BP mean differences were 8,5 mmHg for Syst. BP and 9,0 for Diast. BP in N level subjects and tended to decrease in higher level groups.

- In considering the sole influence of the 5 independant variables upon the mean hourly BP values as a dependant vectorial variable, the preliminary results of the slice inverse regression method application tended to show:

That the role of age emerged at first in a part of $57 \%$, in decreasing the intra individual variability of hourly mean $\mathrm{BP}$ values.

The major role of weight, influencing for $98 \%$ the hourly BP elevation degree from the 97,5 Nancy percentile.

The poor involvement of sex and height in these relations.

That $4.00 \mathrm{pm}$. was the moment when these relations are the best adjusted

Conclusion : This particular approach of ABPM seems to be of some help in understanding tensional variations in children.

Unité de Néphrologie Pédiarrique - CHU Purpan - 31059 Toulouse Cédex - FRANCE

* Université des Sciences Sociales - Toulouse I
P 053

A 10-12-YEAR FOLLOW-UP OF BLOOD PRESSURE IN CHILDREN AND ADOLESCENTS WITH ESSENTIAL HYPERTENSION

A. Gregorǐ and I. Schmidt

The aim of the research is a longitudinal follow-up of blood pressure in children and adolescents (schoolchildren) with essential hypertension. From 1978 to 1981 blood pressure was measured during regular systematic check-ups in 8583 children and adolescents of both sexes, aged from 7-19 years, using a mercury manometer according to recommendations of the 1977 Report of the Task Force on blood pressure control in children. The prevalence of hypertension in this study was $1.2 \%$ (103 out of 8583 schoolchildren); 96 (93\%) schoolchildren had essential, $7(7 \%)$ had secondary hypenension. Among 96 children and adolescents with essential hypertension $23(24 \%)$ were obese, $45(47 \%)$ had systolic, 6 $(6 \%)$ diastolic and $45(47 \%)$ systolic and diastolic hypertension. After the 10-12-year follow-up, 62 (65\%) out of 96 investigated individuals with essential hypertension came for a control check-up. Among these 62 individuals, $14(23 \%)$ were obese, $21(34 \%)$ had hypertension, 29 (47\%) borderline hypertension, 12 (19\%) normotension, 17 (27\%) systolic, $9(15 \%)$ diastolic and $24(39 \%)$ sustolic and diastolic hunertensinn. The 10-12-vear followup of mean blood pressure (RR) in children and adolescents with essential hypertension is listed in the tables.

\begin{tabular}{|c|c|c|c|c|}
\hline \multirow[b]{3}{*}{ Years } & \multicolumn{3}{|c|}{ Systolic RR } & \\
\hline & & & & \\
\hline & $\overline{\mathrm{x}}$ & SD & $\overline{\mathrm{x}}$ & SD \\
\hline 0 & 140.37 & 14.78 & 97.67 & 7.58 \\
\hline \multirow[t]{3}{*}{10} & 144.82 & 17.66 & 99.85 & 11.50 \\
\hline & \multicolumn{2}{|c|}{$\mathrm{p}>0.10, \mathrm{r}=0.34$} & \multicolumn{2}{|c|}{$p>0.10, r=0.32$} \\
\hline & \multicolumn{2}{|c|}{$\mathrm{mm} \mathrm{Hg}$} & \multicolumn{2}{|c|}{ Percentiles } \\
\hline Years & $\overline{\mathrm{X}}$ & SD & $\overline{\mathrm{X}}$ & SD \\
\hline 0 & 84.63 & 10.09 & 91.04 & 10.91 \\
\hline 10 & 85.56 & 10.57 & 90.48 & 11.04 \\
\hline
\end{tabular}
Conclusion: Our results show the longitudinal or tracking correlation as 0.32 for systolic and 0.53 for diastolic blood pressure. After the 10-12-year follow-up a statistically significantly lower frequency of systolic $(p<0.05)$ and a significantly higher frequency of diastolic $(\mathrm{p}<0.05)$ hypertension was established.

Present address: Department of Paediatrics, Maribor Teaching Hospital, Ljubljanska 5, 62000 Maribor, Slovenia.

P054

COMPARISON OF DIASTOLIC AND SYSTOLIC FUNCTION OF THE LEFT VENTRICLE IN CHILDREN ON DIALYSIS AND CHILDREN WITH SUSTAINED ESSENTIAL HYPERTENSION AND GOOD RENAL FUNCTION

M.Litwin, W.Kawalec, E.Cichocka, J.Latoszyñska, R.Grenda

An aim of the study was to compare independently influence of uremia and sustained essential hypertension (HA) on systolic and diastolic function of the left ventricle. Echocardiographic (M-mode, 2D, ECHO-Doppler) measurements were performed in 3 groups of patients (pts): group $I \mathrm{n}=14 \mathrm{pts}$ on continuous ambulatory peritoneal dialysis (CAPD);group II $\mathrm{n}=16 \mathrm{pts}$ on hemodialysis (HD) and group III $n=23$ pts with HA. Pts from groups I and II were normotensive and were examined in a state of good hydration, after emptying peritoneal cavity, and in a day beiween HD sessions. All obtained results were indexed per square meier of body surface area. Statistically significant differences were found in values of (average values): MAP (I): 88 - (II) 89 vs (III) $106 \mathrm{mmHg}$ ( $p<0.001$ ); LVIDd (I) 40 - (II) 37 - vs (III) $44 \mathrm{~mm}(\mathrm{p}<0.001$ ); IVSd (I) 8.4 - (II) 7.3 vs (III) $10.4 \mathrm{~mm}$ (p<0.001); LVPWd (I) 7.5 - (II) 6.8 vs (III) $9.3 \mathrm{~mm}$ (p<0.001); EDVI (I) 71 - (II) 50 vs (III) $27.5 \mathrm{ml}(\mathrm{p}<0.001)$; EDVI/LVPWI (I) $9-$ (II) 8.3 vs (III) 3.0 ( $\mathrm{p}<0.001)$; EDVI/LVMI (I) 1.19 vs (II) 0.7 vs (III) 0.4 (p<0.001); EF (I) 0.58 - (II) 0.6 vs (III) 0.75 (p<0.001); CI (I) 4.8 - (II) 5.1 - (III) $3.9 \mathrm{l} / \mathrm{min}$ (p<0.001); TPRI (I) 1471 - (II) 1550 vs (III) 2366 dynes $\times \mathrm{s} \mathrm{x} \mathrm{cm} / \mathrm{m}^{2}(\mathrm{p}<0.00 \mathrm{I}) ; \mathrm{V}$ peak A (I) 58 - (II) 51 vs (III) $44 \mathrm{~cm} / \mathrm{s}(\mathrm{p}<0.005)$; E/A (I) 1.2 - (II) 1.3 vs (III) 1.94 (p<0.001). There were no significant differences in LVMI between groups.

We conclude that despite significantly lower values of MAP and TPRI, uremic pts (groups I , II) have significant impairement of left ventricular systolic and diastolic function in comparison with pts suffering from sustained essential hypertension (group III).

Child Health Centre; Department of Nephrology, Dialysis and Transplantation; 04736 Warsaw, Poland 
P055

\section{PERCUTANEOUS TRANSLUMINAL ANGIOPLASTY FOR RENOVASCULAR HYPERTENSION IN CHILDREN}

\section{A.Kolský, J.H.Peregrin, K.Vondrák, J.Kováč, J.Střibrná}

The first percutaneous transluminal renal angioplasty (PTRA) was performed in our department in 1980, and the first PTRA in a child was performed in an 11-year-old boy in 1986. To date, we have undertaken a total of 306 PTRA procedures in 281 patients (of these numbers, 15 PTRAs were carried out in 12 patients below 15 years of age). In 13 cases of children, the disease was fibromuscular dysplasia, most often intimal dysplasia; one was, judging by clinical manifestations, arteritis, and one procedure was performed in a renal graft in a four-year-old girl. While involvement was unilateral in 8 cases, it was bilateral in two, and three-vessel disease was present in one case (2 main arteries, one accessory artery). PTRA was technically successful in nine patients (75\%), In adults, technical success was achieved in $91.8 \%$. However, the prevalent conditions in our adults were atherosclerosis $(55.9 \%)$, fibromuscular dysplasia $(33.8 \%)$, and renal graft artery stenosis (10.3\%). All the nine children with successful PTRA showed a favourable clinical response. Two technical failures were managed by surgery; a third one had the only serious complication (right renal artery occlusion and subtotal occlusion of the left renal artery due to arteritis as suggested by angiography). PTRA failure was followed by progression of chronic renal insufficiency and the patient had to be included into a dialysis programme. The procedure is performed, in small children, under total anesthesia; in older ones, only premedication is used. The less favourable results in children are apparently due to the predominant diagnosis, intimal fibromuscular dysplasia. Despite this, PTRA remains to be a suitable method of first choice in children. Surgical management is not indicated until PTRA has failed.

Department of Pediatricts, Thomayer Teaching Hospital

Vídeřská 800, 14059 Prague 4, Czech Republic

P056

EFFECT OF LECTINS ON THE ENDOCYTIC CAPACITY OF RAT GLOMERULAR MESANGIAL CELLS(MC)N VITRO.

JC Davin*,J Foidart,E Heinen,C Dechenne,P Mahieu.

Lectins are endogenous components of many pathogenic bacteria,virus and alimentary antigens. They can bind to IgA molecules to form nephritogenic complexes depositing in glomeruli in a mesangial pattern and provoking a segmental and focal glomerulonephritis (Davin et al, 1989). In order to clarify the mesangial toxicity of the lectin component of IgA-lectin complexes, we have tested the effects on $M C$ in vitro of 2 lectins, wheat germ agglutinin (WGA) and concanavalin A (ConA), recognizing respectively $\mathrm{N}$-acetyl-Bglucosaminosyl and alpha-mannosyl residues. Both bind to $\mathrm{MC}$ surface in vitro and induce capping phenomena, appearance of microvilli, vacuoles formation and contraction, as shown by photonic, immunofluorescence and scanning electron microscopy. The incubation of MC with both lectins enhanced endocytosis of gold particle (GP) and promoted bridging formation between sheep erythrocytes (E) or zymozan particules (ZP) and MC surface followed by phagocytosis, in 10 to $20 \%$ of MC. These effects were dose dependent, complement independent and specific, as suppressed by the corresponding hapten. Both endocytosis and phagocytosis required a mobilization of the cellular cytoskeleton. The lectin-binding to $\mathrm{MC}$ and the lectin-mediated endocytosis stimulated their PGE2 production rate without modifying their 12HETE production rate. By contrast, the lectin-mediated phagocytosis of $E$ or $\mathrm{ZP}$ determines a stimulation of the lipooxygenase-but not of the cyclooxygenase-activity. It is concluded that lectin-binding to cell surface can mediate internalisation of particles and secretion of inflammatory products by MC. This phenomenon may partly explain IgA-lectin complexes nephrotoxicity.

*Present address:AMC,Amsterdam University, The Netherlands.
P057

ENDOTHELIN (ET-1) AND CYCLOSPORIN A (CYA) ACT ON INTERCELLULAR ADHESION MOLECULES IN MDCK CELLS ${ }^{p}$ L.B.Zimmerhackl, F.Kraemer, H.Hoschützky ${ }^{1}$, M.Kramer, C.Kölmel and M.Brandis. Dept. of Pediatrics, Albert-Ludwigs-University and ${ }^{1}$ Max-Planck-Institute for Immunbiology, D-79106 Freiburg The zonula adherens $(Z A)$, formed by the ca-dependant adhesion molecule $E$ cadherin, is essential for differentiation, cell proliferation and cell function. In proximal tubular cells (LLCPK-1) CyA has a toxic effect with functional and morphological disruption of the ZA. This effect is enhanced by ET-1 $\left(10^{-12} \mathrm{M}\right.$; Mesa et al. Eur J Clin Inv 23:22, 1993). We evaluated these observations in model of the distal tubule. For this purpose MDCK cells were grown on collagen coated filters (COSTAR) and CyA was applied with or without ET-1 for $24 \mathrm{~h}$ into the apical or the basolateral compartment. Parameters of cellular functions were: transepithelial resistance (TER), release of cytoplasmatic/ membranous enzymes (LDH, GGT) and morphologic changes. $\mathrm{ZA}$ was evaluated by cadherin turnover (puls-chase), immunprecipitation and fluorescence-immunochemistry.

Results: In MDCK cells 24h CyA did not show toxic effects, the monolayer was intact, enzymes were not released and morphological changes could not be seen, in contrast to LLCPK-1. TER increased concentration dependant after CyA. but not after addition of ET-1. ET-1 alone had no toxic effect and did not change any parameter. CyA did not influence the synthesis of cell adhesion proteins in pulse-chase. There was no change in configuration and anchorage with the cytosceleton ( $\alpha$-catenin/cadherin) in immunprecipitation. H7, an inhibitor of protein kinase $\mathrm{C}$, or streptomycin $\mathrm{A}$, inhibitor of tyrosine kinase were able to suppress the increase of TER, whereas Quabain, an inhibitor of the Na-K-ATPase, showed no effect.

In conclusion, CyA did not alter morphological structures, but functional proteins such as protein kinases. The increased TER after CyA is not caused by reduced transcellular ion transport, but rather an indirect effect of increased paracellular resistance. It seems that protein kinases play a role in regulation of the cell-cell interaction in MDCK cells.

("supported by th German research foundation (DFG Zi 314)

\section{P058}

IS PERLECAN THE HEPARAN SULFATE PROTEOGLYCAN (HSPG) FROM THE HUMAN GLOMERULAR BASEMENT MEMBRANE (GBM)?

L.P.W.J. van den Heuvel, J.H. Veerkamp, L.A.H. Monnens and J.H.M. Berden.

To characterize the human GBM HSPG in more detail the primary structure of a large HSPG core protein was determined from cDNA clones. Using the murine cDNA clones for Engelbreth-Holm-Swarm HSPG (Noonan et al,, J. Biol. Chem. (1991) 266, 22939-22947) we screened a specific primed cDNA. library from human kidney and isolated 6 different cDNA clones. The remaining of the sequence was cloned by reverse transcriptase PCR. The complete nucleotide sequence as well as the deduced amino acid sequence showed almost complete homology with the human perlecan described previously from the fibrosarcoma cell line (Kallunki et al., J. Cell Biol. (1992) 116, 559-571) and from colon carcinoma cells (Murdoch et al., J. Biol. Chem. (1992) 267, 8544 8557 ). The cDNA sequence codes for a $466 \mathrm{kDa}$ protein with a 21 -residue sigriä peptide. Also the mullidomain structure was observed. Polyclonal antibodies were prepared against synthetic peptides derived from the $\mathrm{N}$ - and $\mathrm{C}$ terminus of the GBM HSPG molecule (N-terminus: VTHGLRAYDGLSL; Cterminus: QHRAQAGANTRPCPS). In indirect immunofluorescence studies on human kidney sections these antibodies displayed a linear fluorescence of all renal basement membranes. Only the polyclonal antibody against the amino terminus reacted with native human GBM HSPG in ELISA and Western blotting studies. An in vitro expression vector (in pET8c) was prepared for part of domain III of the core protein. The in E. coli expressed recombinant protein reacted in ELISA and Western blotting studies with polyclonal and monoclonal ( 2 out of 18 ) antibodies prepared against the core protein of isolated human GBM HSPG. These observations give the first direct evidence that the entire human perlecan molecule is present in the human GBM. Proteo-lysis occurring during the extensive isolation procedure of human GBM HSPG may be an explanation for the smaller core protein we and other people found. However perlecan may not be the only HSPG present in human GBM. In vitro expression vectors are in preperation for the 5 different structural domains of perlecan. The recombinant proteins obtained with these vectors will be used for studies on the structural and functional role of these domains in the GBM.

Depts. of Paediatrics, Biochemistry and Nephrology, University of Nijmegen, Nijmegen, The Netherlands. 
P059

DIFFERENTIAL EFFECTS OF RECOMBINANT HUMAN INSULIN-LIKE GROWTH FACTOR-I (rhIGF-I) ON RENAL MICROVASCULATURE IN THE RAT JUXTAMEDULLARY NEPHRON PREPARATION

B. Tönshoff, F.J. Kaskel, L.C. Moore

In rats, rhIGF-I increases renal plasma flow, but the exact site of action of IGF-I on renal microvasculature has not been investigated. We performed videometric measurements of changes in vessel lumen diameter of interlobular arteries (ILA), mid-to-late afferent arterioles (MAA), terminal, juxtaglomerular afferen arterioles (JAA) and early efferent arterioles (EA), to investigate responses to luminal rhIGF-I $\left(10^{-8} \mathrm{M}\right)$ under different perfusion pressures $(\mathrm{PP})$ in the bloodperfused juxtamedullary nephron preparation in vitro. The perfusate is a Krebs solution with $6 \%$ bovine albumin and a Het of $30 \%$. During IGF-I, JAA lumen diameter increased rapidly by $16.1 \pm 4.9 \%$ (SEM, N=8) from $13.2 \pm 1.3 \mathrm{~mm}$ to $15.0+1.1 \mathrm{~mm}(\mathrm{P}<0.001$, ANOVA $\mathrm{RM})$. The relative dilation in MAA $(9.9$ $+2.6 \%, N=9, \mathrm{P}<0.001)$ and ILA $(8.2+1.2 \%, \hat{v}=6, \mathrm{P}<0.001)$ were less pronounced. In contrast, the early EA $(\mathrm{N}=4)$ did not vasodilate during IGF-I (D lumen diameter $1.1 \pm 1.4 \%$, N.S.). The autoregulatory response to an increase of PP from 60 to $120 \mathrm{mmHg}$ was not attenuated by IGF-I (JAA, control: $12.0 \pm$ $2.5 \%$ vasoconstriction, IGF-I: $14.5+2.1 \%$ N.S.), but slightly enhanced in the MAA (control: $16.6 \pm 4.5 \%$, IGF-I: $23.3 \pm 5.1 \%, \mathrm{P}<0.05$ ) and ILA (control: $16.9 \pm 1.5 \%$, IGF-I: $23.8 \pm 3.4 \%, \mathrm{P}<0.05$ ). Pretreatment with the competitive nitric oxide (NO) inhibitor l-NAME completely abolished the IGF-I-induced vasodilation. Stimulation of cultured endothelial cells with IGF-I resulted in a rapid, dose-dependent increase in NO release. Inhibition of endothelial prostaglandin production by indomethacin also blunted the IGF-I-induced vasodilation. In conclusion, rhIGF-I induced a moderate increase of lumen diameter exclusively in preglomerular juxtamedullary microvessels, providing the first direct observations of IGF-I-mediated renal vasodilation. This effect is mediated by increased endothelial production of $\mathrm{NO}$ and requires the presence of an intact endothelial prostaglandin synthesis. Renal autoregulatory capacity appears not to be reduced, but rather slightly enhanced by IGF-I.

Departments of Physiology \& Biophysics, and Pediatrics, SUNY, Stony Brook, New York 11794-8111, USA

P060

\section{DEVELOPMENTAL CHANGES OF H/K-ATPase IN RAT COLON} R.Aizman, * Z-M.Wang, M.Yasui, G.Celsi, A.Aperia

- The H/K-ATPase enzyme plays an important role in maintaining potassium homeostasis by actively transporting $\mathrm{K}^{+}$in exchange of $\mathrm{H}^{+}$across epithelial membranes. Different $\mathrm{H} / \mathrm{K}$-ATPase isoforms have been characterized. It has recently been shown that the $\mathrm{H} / \mathrm{K}$ ATPase isoforms expressed in the cortical collecting duct and in the distal colon are identical. Yet, little is known about developmental changes of the enzyme in neither tissues. This study was aimed to evaluate the ontogeny of $\mathrm{H} / \mathrm{K}$-ATPase in the distal colon. Sprague-Dawley rats of different ages (10-, 20-, and $>60$-day-oid, $n=6$ in each group) were studied. The amount of $\mathrm{H} / \mathrm{K}$ ATPase mRNA was determined by Northern blot. The results indicate that the H/K-ATPase mRNA is approximately 2-3 folds more abundant in the young that in the adult colon. The $\mathrm{H} / \mathrm{K}$ ATPase activity was determined as the hydrolysis of ATP at $\mathrm{pH}=7$ in tissue homogenate. During postnatal maturation the activity of $\mathrm{H} / \mathrm{K}$ pump significantly decreased (from $0,43 \pm 0,10$ to $0,17 \pm 0,07$ $\mu \mathrm{molPi} / \mathrm{h} / \mathrm{mg}$ protein for 10 - and 60-day-old rats, respectively). In contrast, the $\mathrm{Na} / \mathrm{K}$-ATPase activity increased with age (from $4,99 \pm 0,38$ to $7,32 \pm 0,72 \mu \mathrm{molPi} / \mathrm{h} / \mathrm{mg}$ protein, $\mathrm{p}<0,05)$. The $\mathrm{pH}-$ sensitivity of H/K-ATPase was determined in 10- and 60-day-old rats. In both age groups the enzyme was inactive at $\mathrm{pH}=4$, the maximum activity was achieved at $\mathrm{pH}=7$, while at higher $\mathrm{pH}$ the enzyme activity was decreased. In conclusion, the colonic H/KATPase is more abundant and, at physiologic $\mathrm{pH}$, more active in young than in mature rats. This may reflect the ability of infants to conserve potassium in physiological conditions for growing organism. However, during pathological changes in luminal $\mathrm{pH}$ the rats could lose potassium due to the inhibition of $\mathrm{H} / \mathrm{K}$-ATPase and decrease of $\mathrm{K}+$ reabsorption.

"Present address: Department of Pediatrics, Karolinska Inst. St.Göran's Children's Hospital, S-11281, Stockholm,Sweden
P061

THE ROLE OF ENDOTHALIUM-DERIVED RELAXINE FACTOR(EDRF) ON THE UASODILATORY EFFECT OF ANGIOTENSIN CONUERTING ENZYME INHIBITORS

H. Mocan*, A. dkteñ, E. Erduran, O. Guimal

The physiological role of the endotheliun-derived relaxing factor (EDRF) is not yet elear. However, EDRF has been inplicated in the local wechanisus involved in blood flow regulation, as well as in soue pathological conditions, such as hypertersion or cerebral vasospast. In this study, the effect of nethylen blue (MB) as EDRF blocking agent was investigated on isolated husan unbilical artery strips that treated by angiotensin converting enzyne (ACE) inhibitars (captopril, enalapril, cilazapril and lisinoprill. The unbilical arterial strips pretreated by BaCle. Afterthat, the effect of ACE inhibitors were studied; in both mib-treated and untreated group. Captopril, enslaprif and cilazapril respectively caused $60 \%, 42 x, 37 \%$ vasodilation on isolated hunan unbilical artery strips in MB-untreated group, while 17x, 22X, $14 x$ in $B B$-treated group, at $10^{-5}$ concentrations. Lisinopril had no effect in any concentrations. The yasodilatory effects of ACE inhibitors in M-treated group were found significantly lower than in MB-untreated group $(p(0.05)$.

Qur results suggest that EDRF lay play an enhancing role on the vasodilatory effect of ACE inhibitor.

- Oresent address: Departaent of Pediatrics, Karadeniz Technical University Faculty of Medicine, Trabzon/TURKEY

P062

COMPARISON OF GLOMERULAR FILTRATION RATE AS MEASURED BY CONSTANT INFUSION OF INULIN WITH AND WITHOUT URINE COLLECTIONS H.Maxwell, D.R.Nair and L.Rees

Measurement of glomerular filtration rate (GFR) involving collection of urine is difficult in children. We performed constant infusion inulin clearances on 32 occasions in 14 children with chronic renal failure (CRF), then calculated the GFR by two different methods; one with (UrC) and the other without (PIC) urine collections.

Methods : A bolus of inulin was given followed by an constant infusion. After 1 hour, $4 \times$ forty minute urine collections were made; UrC is the mean of these 4 clearances. PIC relies on the fart that at steady state the cutantity of inulin infused cquals that excreted in the urine, so replacing UV/P with Inulin Infused/ P. To calculate PIC, the mean of the 4 values of plasma inulin was used. Steady state was taken as less than $10 \%$ variation in plasma inulin

Patients : Mean (range) age $8.8(4.9-13.6)$ years, GFR 21(9 - 58) $\mathrm{mls} / \mathrm{min} / 1.73 \mathrm{~m} 2$

Results : On 3 occasions, steady state was not acheived. Mean GFR by UrC was $21.2 \pm 2.4(6.4-58.1)$, and by PIC $21.8 \pm 2.4(6.6$ - 56.5). The mean \pm SD (range) difference between the two methods was $0.5 \pm 2.6(-6.5$ to 5.0$), n=29$. The difference was not related to GFR. Correlation was high, $r=0.979(p<0.001)$, with $\mathrm{PIC}$ values being slightly higher, $\mathrm{UrC}=(0.98 \times \mathrm{PIC})-0.17$.

Conclusion : Values obtained by constant infusion of inulin with and without urine collection give nearly identical results. Urine collection is time consuming and may be incomplete in young children or those with bladder abnormalities. PIC is easier to perform, but is only accurate when steady plasma levels are acheived.

Paediatric Nephrology, Royal Free Hospital, Pond St, London, NW3 2QG. 


\section{QUANTITATIVE AND QUALITATIVE ANALYSIS OF FEBRILE PROTEINURIA IN CHILDREN \\ M. Kirschstein. R. Jensen, K. Clausen, J. Clausen, B. Schröder}

The association of proteinuria with fever was first described in the 19th century, but studies about its incidence, duration, character and pathogenesis differ widely.

In a prospective study incidence, duration and pattern of febrile proteinuria in 31 children with febrile illness (body temperature > $38,5^{\circ} \mathrm{C}$ ) were investigated by sodium dodecyl sulphate polyacrylamide gel electrophoresis (SDS-PAGE) and quantitative measurement of urinary total protein, $\lg G$, transferrin, albumin, $\alpha$--microglobulin and retinol binding protein using an immunoluminometric assay.

All children had normal renal function. Urinary total protein was increased in only $39 \%$ of all patients whereas $58 \%$ revealed pathologic patterns of proteinuria appiying SDS-PAGE and $61 \%$ had raised urinary levels of one or more specific proteins. The urinary proteins excreted during fever showed a tubular pattern, only $4(13 \%)$ children revealed a mixed glomerular and tubular pattern of proteinuria. A weak correlation between height of body temperature and urinary protein excretion was only found for $\alpha_{1}$-microglobulin and no other protein. Febrile proteinuria was of short duration and already on the fourth day free of fever not longer detectable. Patterns of febrile proteinuria did not differ between viral and bacterial infections.

Because febrile proteinuria mainly consists of low molecular weight proteins dipstick methods are of no value for its detection.

The short duration as well as the prevalence of tubular patterns of proteinuria suggest that most likely acute phase reactants or cytokines lead to a temporary tubular dysfunction during episodes of fever rather than an antigen-antibody induced abnormal glomerular permeability.

Dept. of Pediatrics, Medical University of Lübeck, Kahlhorststraße 31-35, D-23538 Lübeck

\section{P064}

\section{MICROPROTEINURIA. IN NEWBORN INFANTS}

G.Avino, F.Cirillo, M.Esposito Salsano, M.Maiorana, D.Magri, M.Pedullà L.Valentino and G.Lama

Department of Pediatrics II University Naples Italy

Microproteinuria (MP) is an valid prognostic index of renal damage. It appears before macroproteinuria and expresses proteins with a low molecular weight (less than $40.000 \mathrm{D}$ ), essentially constituited by $\mathrm{B}_{2}$ microglobulin (B2M) and microalbumin (MA). B2M is a low molecular weight protein $(11.800 \mathrm{D})$ and costitutes the light chain of the major histocompatibility complex class I antigens. It is freely filtered by the renal glomerule and for the $99.9 \%$ reabsorbed and catabolized by the proximal convoluted tubule; its daily excretion is between $30-370 \mathrm{mcg} /$ day. B2M study proves its utility because allows to value functional maturity of renal tubules and to diagnose precociously tubular damage.The range of MA is between $20-200 \mathrm{mcg} / \mathrm{day}$ and increases in glomerular hyperfiltration . Study aim: to evaluate MA and $B_{2} \mathrm{M}$ in newborn infants with hydronephrosis and after resolution. Our study includes 86 newborn infants affected by hydronephrosis diagnosed in prenatal (60 pts) and in postnatal age $(26$ pts).The patients were divided in two groups.Group A: 34 newborn, 30 male and 4 female with functional hydronephrosis.Group B: 52 newborn, 15 females and 37 males with obstructive uropathy. In all of them $\mathrm{Crcl}$ was normal increasing significantly with patients'age $\left(54.55 \pm 11.56 \mathrm{ml} / \mathrm{m}^{\prime} v s \quad 90 \pm 18.42 \mathrm{ml} / \mathrm{m}^{\prime}\right)$. $B_{2} \mathrm{M}$ and $M A$ have been evaluated at admission and 6-12 months after spontaneous resolution in the functional forms and after surgical and or endoscopic correction in the obstrucive forms. Student $t$ test has been utilized for statistical analysis. At the diagnosis in the group A, MA mean values resulted statisticaliy higher than healthy group $(12.28 \pm 7.64$ vs $8 \pm 3.34$, p< 0.01 ); at 16-12 months began normal . BDM values were within the normal range at diagnosis and at follow-up.In the $B$ group, B2M and MA mean values have been significantly bigher than the control group $(42 \pm 82.7 \mathrm{vs}$ $4.9 \pm 2.3(p<0.0001): 32 \pm 38.4$ vs $8 \pm 3.34(p<0.005)$ and persisted at high values at 12 months of follow-up: $15.88 \pm 23.69$ vs $4.9 \pm 2.3$ ( $p<0.005)$; $30.25 \pm 38.95$ vs $8 \pm 3.34(p<0.01)$ and after resolution of urophathy that has been achieved in 19 patients.MP is a good index of glomerulotubular injury and important prognostic element following evolution of renal damage. In the obstructive uropathy precocious surgical allows to improve the functionality of the affected kidney but not to recovere glomerulotubular injury as shown by the persistence of $\mathrm{MA}$ and $\mathrm{B}_{2} \mathrm{M}$ high value.
MOLECULAR CONTROL MECHANISMS GOVERNING PROLIFERATION AND DIFFERENTIATION DURING HUMAN KIDNEY ORGANOGENESIS. C. R. Burrow, P. D. Wilson.

Identification of key molecular determinants which regulate the complex series of events which characterize nephron assembly from mesenchymal progenitor cells during embryonic development will ulti-mately depend on validation in appropriate experimental systems. Initial progress in molecular cloning of transcription factor genes has resulted in the cloning of a novel human POU gene, KDN-1, which likely regulates epithelial differentiation in the distal nephron. KDN-1 transcription is restricted to the brain and kidney during normal human embryogenesis. KDN-1 is a class III POU gene which is most closely related to mouse brain- 4 and is thought to function as a cell and tissue-specific transcription factor which regulates octamer-dependent RNA polymerase II transcription in the collecting duct epithelial cells of the fetal and adult kidney. Studies in progress are directed towards identification of the transcriptional regulatory targets of $K D N-1$, and to identification of cis-acting regulatory elements which direct the highly regulated developmental pattern of $K D N-1$ expression.

A model system has also been developed to study metanephric blastemal nephroblast proliferation and differentiation into the characteristic tubular and glomerular epithelial cell type which arise during renal development Nephroblast-rich areas of 14-16 week human fetal kidneys are microdissected from the outer cortical rim, plated on gelatin in defined medium, passaged and grown in continually proliferating suspension culture in serum-free conditioned medium from a Wilms' tumor cell line, G401 (G401CM). A secreted soluble peptide factor(s) (NB-GF) found in G401-CM is essential to sustain proliferation of these undifferentiated nephroblasts in vitro and biochemical characterization and purification of this factor is underway. Nephroblast culture with $10 \%$ fetal bovine serum in the absence of NB-GF results in the conversion of nephroblasts to differentiated epithelial celis. Epithelial differentiation is associated with extensive alterations in gene expression including modifications in vimentin, cyiokeratin, syndecan, E-cadherin, alkaline phosphatase, beta-2 Na-K ATPase, N-myc, Pax-2, WT-1, and N-CAM expression which reproduce in vivo observations during nephron induction. It is anticipated that this cell culture model system can be used to identify and study the function of transcription factor genes which regulate coordinate gene expression during lineage commitment and epithelial differentiation in human kidney organogenesis.

The Johns Hopkins University School of Medicine, Division of Nephrology Department of Medicine, Ross 947, 720 Rutland Avenue, Baltimore, MD 21205, USA.

P066

HYPERTENSION IN CHILDREN WITH VESICOURETERAL REFLUX (VUR). D. Siapera, A. Mitsioni, C.J. Stefanidis. and K. Michelis.

Hypertension is considered as a major complication of VUR, however there is little information about the incidence of this problem. We analysed the values of blood pressure (BP) and other related clinical data collected from 177 children with primary VUR managed in our Division. The male to female ratio was 0.39 . The age of our patients (pts) on diagnosis was $2.6 \pm 0.2$ years and the follow up period ranged from 1.6 to $11.5(3.5 \pm 2)$ years. VUR of grade IV and $V$ was diagnosed at the $25 \%$ of pts and 112 pts (63\%) had renal scars at the DMSA scan. BP was measured with Dinamap 845.

At the end of follow up period 6 pts had hypertension (Systolic and diastolic BP > 95th percentile in three measurements). Systolic BP > 75 th pereentile was documented at $47 \%$ of pts and diastolic $B P>75$ th percentile at $29 \%$. Systolic BP $>75$ th percentile had the $58 \%$ of pts with VUR of grade IV and V and $43 \%$ of pts with VUR < of grade IV $\left(x^{2}=2.1 p=0.20\right)$. In addition systolic $B P>75$ th percentile had the $51 \%$ of pts with renal scars and $41 \%$ of pts without renal scars $\left(x^{2}=0.4\right.$ $p=0.5$ ). It is of interest that all $71 \mathrm{pts}$ with age at diagnosis $<2$ years had a systolic BP $>75$ th percentile, compared with the $32 \%$ of pts aged $>2$ years $\left(x^{2}=108 \quad p<0.0001\right)$. Similarly diastolic BP $>75$ th percentile occurred at the $61 \%$ of pts $<2$ yrs and at the $19 \%$ of older pts $x^{2}=25 p<0.0001$ ). Our results indicate that hypertension is a rare complication of VUR despite its grade and the presence of renal scars. However there was an increased number of pts with higher BP in children with VUR diagnosed before the second year of age.

Division of Nephrology "A. \& P. Kyriakou" Children's Hospital Athens 11527 Greece. 
P067

CONGENITAL REFLUX NEPHROPATHY: A MULTICENTER STUDY IN 74 SUBJECTS

L.Acerbi, B.M.Assael*, M.Bosio, L.Carmignani, C.A.Dell'Agnola, S.Guez, M.Lanata, G.Manzoni,G.Marra, M.L.Melzi, E.Secco, G.Selvaggio, G. Sersale, C. Ticozzi, M.Vegni

A multicenter study was performed to caractherize the patients with prenatally suspected and postnatally confirmed VUR and to establish the presence and entity of any damage already present at birth. We also compared the diagnostic procedures adopted by the participating centers. The study identified 74 cases and the follow up ranges now from 1 month to 10 years. In $80 \%$ of cases the presence of a fetal pyelic dilatation (found at 20-38 weeks of gestation) led to the diagnosis, in the other cases a renal US was performed as a routine investigation in the presence of other congenital malformations. In all cases a voiding cystography was performed within one month after birth, and all subjects were given continuous daily antibiotic prophylaxis. In $85 \%$ of the cases a MAG3 renal scintigraphy was obtained, while in the other cases this was performed with DMSA or DTPA. in 34 .The degree of reflux ranged from grade 2 to grade 5 . High grade reflux $(>3)$ was present in $89 / 114$ renal units. The male sex prevailed (4:1), but there was no difference in severity of reflux between males and females. Renal scan was abnormal in $40 \%$ of the refluxing units. When a monolateral damage was present we could evaluate the reduction in renal uptake, which was severely reduced slightly reduced $(30-44 \%)$ in 6 . This related to the degree of reflux. Bilateral reflux was associated to moderate/severe renal failure in 8/40 neonates. Neocystostomy was performed in $25 \%$ of the cases at a mean age of 9 months. It was successful in $90 \%$ of the cases. In the unoperated renal units with reflux > grade 3 (55 units) second cystography, solar performed in only 33 cases at a mean age of 19 months, showed a spontaneous resolution of the reflux in $10(30 \%)$.

These results demonstrate that vesicoureteric reflux is associated to a congenital renal damage (renal displasia). The prevalence of males and the severity of the reflux distinguishes these cases from refluxes diagnosed at older ages.

"Clinica Pediatrica de Marchi, University of Milano, Via Commenda 9, 20122 Milano, Jtaly
The refiuxing uriñs were $1 i 4$. Tihe reflux was bilateral in 40 cases and monolateral (relative uptake $<9 \%$ ) in 3 renal units, moderately reduced $(10-29 \%)$ in 3 , and

P069

THE DIAGNOSTIC VALUE OF THE URETERO-VESICAL JET (UVJ) FREQUENCY IN UNALATERAL OBSTRUCTIVE UROPATHES

P. Winkler (1) , J. Strehlau (2) , D.E. Müller - Wiefel (2)

The pulsatile jet-style influx of urine into the bladder may be visualized by colour-coded doppler-ultrasound (CU). It can be used to identify flow reductions in obstructive uropathies (OU) and parenchymal destructions. To assess the reliability of this technique we evaluated parameters of UVJ in 176 investigations of 128 patients aged 1 day to 18 years. Using a standard CU-technique (Acuson 128; $3 \mathrm{Mhz}$ sector- / $5 \mathrm{Mhz}$ linear) jet-frequency, intensity, -character and localisation were registered for $10 \mathrm{~min}$. and correlated to age and weight, hydration within 1 and 2 hours and diagnosis. All results of 67 investigations in 40 children with unilateral nephropathies 18 dysplasias, 6 hydronephroses, 8 ureteropelvic obstructions, 12 dista ureteral obstructions, 5 ureterceles, 4 ureteral stones) were compared to a standard Tech-MAG3-isotopic nephrogram (ING). Obstructions were considered relevant if tracer elimination after furosemide was below $50 \%$. In 10 infants both procedures were done prospectively under identical conditions on the same day. In 24 children with reflux uropathy 28 results were compared to a standard mictionary cystogram.

Results: In 32 children with not-relevant obstructions or parenchymal lesions due to the ING the jet-frequency was slightly diminished on the incriminated side (mean 8.5 vs $12.5 / 10 \mathrm{~min}, \mathrm{p}<0.031$, but this effect was not observed in proximal lesions. In $90 \%$ of all children with relevant obstructions due to the ING the UVJ was completely absent at the affected side (mean 0.0 vs $12.5 / 10 \mathrm{~min})$. This difference was highly significant both in proximal $\langle p<0.00007)$ and distal $(p<0.00005$ ) lesions. False positive results were observed in 11 of 176 examinations (low hydration, full bladder); false negative in 2 (Specifity $94 \%$, Sensitivity $95 \%$ ). In reflux-patients there was no correlation of any jet-parameter to the degree of reflux as shown by cystography.

Conclusions: The reduction of UVJ-frequency adds a specific, sensitive and reliable functional parameter to standard uftrasound in relevant obstructive uropathies. Data correlated well with results of ING. In reflux-uropathy the UVJ-examination seems to be of no value.

Kernklinik (2) and Dpt. Pediatric Radiology (1) University-Children 's Hospital Hamburg - Eppendorf, Martinistr. 52, D-20246 HH, Germany

$\mathrm{P} 070$

COVERT URINARY PROTEIN AND ENZYME EXCRETION IN PATIENTS WITH REFLUX NEPHROPATHY.

EIRfidah, C Jamieson, A V Murphy, J R Mackenzie, R W Logan and T J Beattie

Regardless of the nature of the insult to the kidney, chronic renal failure is characterised by progressive glomerulosclerosis. Despite advances in the management of urinary tract infection in childhood, a substantial proportion of adults entering end stage renal failure programmes have an underlying diagnosis of chronic pyelonephritis.

Covert excretion of urinary proteins is well recognised in other nephropathies, particularty diabetic nephropathy, as the earliest sign of underlying glomenlar disease. However, there are limited data available in patients with reflux nephropathy.

A study was carried out to evaluate the presence of covert protein and enzyme excretion in 71 patients known to have reflux nephropathy. The patients were divided into three groups on the basis of the severity of the renal scarring on Tc99M Dimercaptosuccinic acid [DMSA].

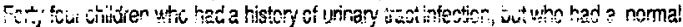
TC99M DMSA scans served as controls.

All patients and controls were normotensive and had normal renal function estimated by either creatinine or $51 \mathrm{Cr}$ EDTA clearance.

Urinary microalbumin [Alb] Beta 2 microglobulin [B2M], $\mathrm{N}$-acetylglucosaminadase [NAG] creatinine $[\mathrm{Cr}]$ was estmated in both an early moming urine [EMUU] and 24 hour urine sample.

The median range of Alb/Cr ratio [mg/mmol] for the three groups on EMU was $0.7-1$. [control 1.1][N.S.] and on 24hour urine was $1.2-1.6$ icontrol 1.35] [N.S.]. The median range for $\mathrm{B2M} / \mathrm{Cr}$ ratio [ $\mu \mathrm{g} / \mathrm{mmol}$ ) tor the three groups on EMU was $6.0-8.5$ [control 8.5] [N.S.] and for 24 hour urine 6 - 11 [control 11][N.S.]. The median range for NAG/Cr ratio [umolesMU/hour/mmol] for these three groups on EMU was $9-11$ [control 9] [N.S.] and for 24 hour rine was $8-12$ [control 9.5][N.S.]

We conclude that there is no significant difference in urinary excretion between patients with reflux nephropathy and controls and no correlation with the degree of renal scarring.

Present Address: Renal Unit, Royal Hospital for Sick Children YORKHILL Glasgow G3 8SJ
PREPUTIAL ENTEROBACTERIAL COLONIZATION AND RELATION TO THE FECAL FLORA IN HEALTHY BOYS- ASPECTS OF PATHOGENESIS IN PYELONEPHRITIS

K-J Lidefelt* ${ }^{*}$ Bollgren I Kuhn

In infancy, a majority of pyelonephritic episodes occur in boys. $95 \%$ of infections are caused by virulent, e.g. P-fimbriated E.coli and $1-2 \%$ by Klebsiella/Enterobacter (K/E). Kolonization of the prepuce with uropathogens recruited from the fecal flora is a crucial step in development of pyelonephritis. In healthy boys little $\mathrm{i}$ known about this microenviroment. This study analyzes preputial colonization of $E$. coli and $K / E$ and P-fimbriation of E.coli. The fecal flora as a reservoir for preputial colonizers was also studied.

Desion: 86 healthy boys 3 mo old were studied. E.coli and KJE were quantitatively estimated after preputial irrigation. The predominant fecal flora When a boy showed morphologically identical isolates in preputial and fecal specimen, identity was tested using a highly specific fingerprinting method .

Results and conclusions: E.coli was found in 28/86 preputial samples (a lower carriage rate than earlier reported), and in $47 / 86$ of fecal samples. Equal proportions, $7 / 28(25 \%)$ and $11 / 47(23 \%)$ of preputial and fecal E.coli strains were P-fimbriated suggesting that this virulence factor is not cruciai for colonization of the prepuce. In a minority of boys $(27 \%)$ identical bacteria (E.coli , K/E) were cultured from both preputium and feces, indicating that the prepuce is an ecological niche separated from the fecal flora. In $34 / 86(39 \%)$ of boys no enterobacteriae were found preputially. Among the 7 boys colonized with $P$-fimbriated $E$.coli in both prepuce and feces, one boy aquired pyelonephritis two months later.

"Department of pediatrics, Sachs Chidrens Hospital P.O. Box 17912, S-11895, Stockholm Sweden was determined. Isolates of E.coli were analyzed for presence of P-fimbriae 
D071

DEVELOPMENT OF PREPUTIAL MICROFLORA IN HEALTHY INFANT BOYS ASPECTS OF PATHOGENESIS IN PYELONEPHRITIS

B. Fogström, and I. Bollgren*

Pyelonephritis affects about $1 \%$ of Swedish boys, and the majority are infected during the first half year of life. Colonization of the prepuce with Escherichia coli is an important step in the ascending infection of the urinary tract, convincingly proven by the finding that there is a tenfold reduction in incidence of pyelonephritis among circumcised as compared to uncircumcised boys. In e.g. US this has even been used as an argument for general circumcision assuming that preputial colonization with uropathogens is widespread. In the present study, we investigated the preputial microflora during the first eight months of life.

Material: Ten healthy infant boys with normal deliveries participated. In order to minimize influence from hospital bacterial flora, only boys who went home from the delivery unit within the first day of life, were included. All were breastfed during the whole study period.

Method: Sampling was performed by preputial irrigation at 5 days, 1 month, 3 months and 8 months of age ( 40 samples). Serial dilution and aerobic and anaerobic cultivation of irrigation fluid was performed. The microflora was quantitatively estimated. Anaerobic strains were identified by gas-liquid chromatography.

Results: $10^{5}-10^{6}$ bacteria/sample were obtained, and about $50 \%$ were anaerobic. An average of 2.5 aerobic and 5.5 anaerobic strains/sample were identified. Staphylococcus epidermidis was the only stable colonizer and predominated in $75 \%$ of the samples. Otherwise, the composition of the flora changed considerably over the study period. E. coli was recovered in $9 / 40$ samples and was predominant in one sample. Only one boy was repeatedly colonized with E.coli. Lactobacilli was frequently isolated during the first month. Bacteroides gradually increased.

Conclusion: Preputial colonization with E.coli is scanty and sporadic in healthy boys. The present findings do not support the idea that general circumcision is justified for prevention of pyelonephritis.

* Present address: Department of Pediatrics, Sachs' Children's Hospital, P.O. Box 17912, S-118 95 Stockholm, Sweden

\section{P072}

DYSFUNCTIONAL BLADDER SYMPTOMS IN CHILDREN AT 9 YEARS FOLLOW-UP AFTER ACUTE CYSTITIS E Lötin Nordlund, I Bollgren, K Lidefelt

During 1983-84, thirty-nine children ( 29 girls, 10 boys, median age 5 years) presenting a single episode of cystitis, were investigated for bacterial virulence pattem and bladder emptylng capacity during a period of six months, following the index infection

The aim of the present study was to determine the correlation between initial clinical and bacteriological findings, considered as suspected risk factors and long term outcome, such as recurrent lower urinary tract infections and micturition problems.

Three factors were chosen: 1) squatting as a symptom of urgency

2) presence of residual urine

3) bacterial virulence, ie P-fimbriation of $E$ col In this nine years' follow-up study, $36 / 39$ children ( 27 girls, 9 boys) and one of the parents were interviewed and records reviewed, focusing on UT/s, dysfunctional voiding including dayinightwetting, constipation and radiological findings. Urodynamic screening was performed.

Results: Nine of 36 children, all girls had developed recurrent UTIs. Persisting symptoms correlated to initial squatting during 1983-84. Among the nine girls with initial squatting, 7 had recurrent UTIs, 3 had urgency incontinence and 5 constipation still at the nine year follow-up. Five were nightwetting at nine yrs or older. Seven of the nine girls in this group had been infected with non-P. fimbriated $\mathrm{E}$ coli at the index infection. Residual urine and nonvinulent bacteria also correlated with persisting symptoms. In contrast, 10/11 children, infected by $P$-fimbriated $E$ coli at the index cystitis, were free from recurrent UTIs and incontinence.

We conclude that the three factors can serve as risk indicators when we try to identify children needing a more careful follow-up, among all those presenting an uncomplicated cystitis. The finding that bladder dysfunction seems to be correlated with nonvirulent bacteria, suggests the bladder dysfunction to be the primary cause and the infection a secondary phenomenon.

Department of Pediatrics, Karolinska Institute, Sachs Children's Hospital, Box 17912, S-118 95 , Sweden
$\mathrm{P} 073$

\section{BLADDER CAPACITIES IN VOIDING PROBLEMS L.Szabo}

Incontinence, dysuria, nocturnal enuresis are common disorders in children. 172 patients with different micturition problems /nocturnal enuresis(n.e.):117, urge incontinence(u.i.):14, stress incontinence(s.i.):5, mixed incontinence(m.i.):15, dysuria(d):8, infrequent voiders(i.v.):15, frequent voiders(f.v.):8, and 165 healthy control(c) children had 696 micturitions. Spontaneous capacities were measured after 329 micturitions. 37 pts and 165 controls drank $15 \mathrm{ml} / \mathrm{bw}$ tea and micturated when they had first and maximal sensation of bladder fullness. The spontaneous capacities (mean +SD $\mathrm{ml}$ ) were in n.e. $149+126$, in s.i. $150+120$, in u.i. $100+70$, in m.i. $175+125$, in d. $160+115$, in i.v. $165+95$, in f.v. $75+65$. The difference was significant $(p<0.05)$ between in patients with urge incontinence and nocturnal enuresis. The bladder volumes at first sensation were $160+70$ in n.e., $170+220$ in s.i., $80+50$ in u.i., $190+75$ in d., $190+50$ in i.v. and $140+80$ in $c$. The differences were significant $(p<0.05)$ between dysuria and controls, infrequent voiders and controls, urge incontinence and dysuria, urge incontinence and infrequent voiders, $(p<0.01)$ between urge incontinence and controls. The bladder capacities were $200+140$ in n.e., $260+215$ in s.i., $260+80$ in d. and $225+115$ in $c$. The first sensation bladder capacities were significantly decreased in children with urge incontinence, and increased in patients with dysuria, and infrequent voiders. The sensation of bladder fullness is diminished in these patients. In nocturnal enuresis the spontaneous, first sensation and bladder capacities were normal.

Ilnd Children Department (Nephrology), Child Health Centre, Borsod County Teaching Hospital, Miskolc, H-3501, POB 188. Hungary
P074

\section{CLINICAL OUTCOME OF MILD HYDRONEPHROSIS: A FOLLOW-UP} STUDYIN 79 CASES

G.MARRA, E.SECCO, M.L. MEL.ZI, S. GUEZ, B. TADINI, G. BARBIERI C.A. DELL'AGNOLA, B.M. ASSAEL

Between 1985 and 1993 mild hydronephrosis (anteroposterior dilatation of the pelvis between $0.5 \mathrm{~cm}$ and $1.5 \mathrm{~cm}$ ) was diagnosed prenatally and confirmed postnatally in 79 infants (43 males and 36 females- 95 renal units). The aim of our study was to describe the postnatal natural history and management of mild hydronephrosis $\quad$. A ${ }^{99}$ Tc-MAG3 renal scan and a voiding cystography were performed within the first month life in all cases. Then the infants were followed with ultrasound examinations performed every $6-12$ months. If the dilatation worsened the child underwent a second scan

Results.

Cystography allowed to diagnose reflux in 23 renal units ( $28 \%$ ): the reflux grade was $1-111$ in 13 cases and grade $I V-V$ in the other 20 renal units. The first renal scan was normal in all patients (normal uptake and normal elimination of MAG3) .

We followed these cases for a mean period of 39 months (12-108 months). In 38 renal units $(53 \%)$ the dilatation diminished during the follow up; in 17 cases it disappeared completely ;

in $19(21 \%)$ it remained unchanged and in $15(21 \%)$ it worsened. Of these, in 11 cases a second scan showed the presence of obstruction (Elimination T1/2 $>20 \mathrm{~min}$ after i.v. furosemide) and in 2 the uptake was abnormal. These cases were eventually operated on. The renal scan was normal in the other 4 renal units and they are still folowed up.

Conclusions. These results indicate that a voiding cystography and a prolonged follow up are necessary in patients with mild hydronephrosis diagnosed before birth.

CLINICA PEDIATRICA DE MARCHI. VIA COMMENDA 9

20122 MILANO. ITALY 
P075

URINARY TRACT INFECTION (UTI) AND SEVERE ACUTE GASTROENTERITIS (GE)

Isam I. Juabeh

In order to establish the incidence of UTI in GE, we studied prospectively (42 months) alf children $<3$ years old $(n=861)$ who were admitted to our pediatric ward from July 1990 to January 1994 with severe acute GE. The severity of the GE was determined clinically. Urine cultures were taken on admission by SPA (49\%), bag (31\%), or catheter (20\%). All positive bag samples were confirmed by repeated SPA or catheter. The presence of $>10,000$ colonies $/ \mathrm{mm} 3$ in catheter or any number in SPA samples was considered a pasitive test. Urinalysis, complete blood count, serum electrolytes, and BUN were determined on admission according to standard laboratory procedures. The correlation between various clinical parameters and the presence of UTI was calculated using chi square and odds ratios (OR).

Reliable urine cultures were available in 824 out of 869 children (95\%) The overall incidence of UTI was $6 \%(47 / 824), 27$ girls and 20 boys. E.coli was isolated in 41 and Proteus mirabilis in 6 children. When comparing patients with $(n=47)$ and without $U T !(n=777)$ we found no difference in relation to age. Females with GE were at a higher risk of having UTI than males $(p<0.01$, OR=2.15). UTI was related to the severity of the GE. The presence of moderate to severe dehydration $(p<0.02 ; O R=2.77)$, fever $\left(>38.5^{\circ} \mathrm{C}\right.$ per rectum; $\left.p<0.01 ; O R=2.15\right)$, leukocytosis ( $\left.>15,000 / \mathrm{mm}^{2} ; \quad p<0.001 ; \quad O R=2.72\right)$, hypernatremia ( $>150 \mathrm{meq} / \mathrm{l} ; \mathrm{p}<0.01 ; \mathrm{OR}=2.92$ ), metabolic acidosis (serum $\mathrm{HCO}^{-}$ $<15 \mathrm{meq} / \mathrm{l} ; \mathrm{p}=0.01 ; \mathrm{OR}=2.23)$, and elevated BUN $(>20 \mathrm{mg} \%$; $p=0.002 ; \quad O R=2.87$ ) were all significantly associated with UTI. More than 5 WBC/high power field on urinalysis was also strongly associated with UTI ( $p<0.001$; OR $=4.09$ ).

This study shows that acute GE is still a common problem in our young childhood population, especially during the summer. There was a high incidence of UTl among these children. The presence of UTI proved to be a measure of the severity of GE. Appropriate urine cultures (preferable by SPA) should be taken routinely, particularly in the more severe cases.

Address: Pediatric Department, Augusta Victoria Hospital, Mount of Olives, East Jerusalem, P.O.Box 19178, Fax 972-2-273542, Israel.

P076

URINARY EXCRETION OF N-ACETYL- $\beta$-GLUCOSAMTNIDASE (NAG) AND THE ISOENZYME B (NAG B) IN CHIIDREN WTTH URINARY TRACT INFECTION. P. Koukoutsakis, A. Fretzayas, Ch. Stavrinadis, D. Gourgiotis, N. Karli, Th. Tsoukatou, C. Sinaniotis.

NAG is a Iysosomal enzyme mainly present in the proximal convoluted tubule. The purpose of the present study was to investigate whether tota1 NAG and NAG B can be of value in the differentiation between acute pyelonephritis (AP) and acute cystitis (AC) in children with urinary tract infection (UTI). The population under study consisted of 47 children with UTI ( 32 with $\mathrm{AP}$, mean age $1.6 \pm 2.8$ years, and 15 children with $\mathrm{AC}$, mean age $6 \pm 4.3$ years) and 12 healthy children (mean age $5.7 \pm$ 4.6 years). The diagnosis of $\mathrm{AP}$ and $\mathrm{AC}$ was based on established clinical signs/symptoms and laboratory findings. The urinary $N A G$ and $N A G B$ activity was significantly raised in patients with AP $(x=8.96 \pm 16$ and $x=2.73 \pm 4.5)$ than in those with $A C$ $(x=1.47 \pm 1.46$ and $x=0.52 \pm 0.4)$ and in the controls $(x=0.6 \pm 0.25$ and $x=0.13 \pm 0.5)$. A considerable dispersion of values was observed as it is evident from the rate of SD. Further analysis of values of $N A G$ and $N A G B$ in order to differantiate $A P$ from $A C$ showed: sensitivity $97^{\circ}$ and $81^{\circ}$, specificity $47^{\circ}$ and $73^{\circ}$, positive predictive value $80 \%$ and $87^{\circ}$, negative predictive vałue $87 \%$ and $60 \%$ respectively. In children with $A P$, with and without reflux (VUR), NAG and NAG B values were significantly raised. In children with $A C$ and VUR, the activity was equally raised, while in 1 child with AC but without VUR these enzymes were also elevated. It is concluded, that: a) Increased excretion of NAG and NAG $B$ it seems to be of little value in the level diagnosis of UTI, b) in cases with $A C$ higher values of NAG and NAG B possibly indicate the presence of VUR.

Present address: 2nd Department of Pediatrics, University of Athens, "P. \& A. Kyriakou" Children's Hospita1, 11527 Athens, Greece.
$\mathrm{P} 077$

VALUE OF TUBULAR PROTEINURIA IN DIAGNOSIS OF ACUTE PYELONEFRITIS.

J.G.J. Vande Walle, A. Raes, A. De Naeyer

Diagnosis of acute pyelonefritis (APN) in young children is difficult: clinical history and examination are often not conclusive and correct midstream sampling are impossible. However every APN asks for correct therapy and completary investigations. The diagnosis APN can be confirmed by a DMSA, CT or labelled granulocytes, but this examinations are to expensive to use as screening methods.

Tubular proteinuria is increased during acute pyelonefritis : Beta2-microglobuline is a

sensitive method but because of $\mathrm{T}^{\circ}$ and $\mathrm{pH}$-dependency difficult to handle. Therefore we studied urinary alphal-microglobiline/creatinine ratio (Ualmg/cr) in control group ( $I: n=180$ ),

62 UTI-patients (II) and 44 patients with uropathy without infection (III). Correlation with DMSA-scan was made in II and III. Normal values Ualmg/cr are $<11 \mathrm{ug} / \mathrm{g}$ creat. All patients of group III, or only cystitis $(n=18 / 62)$, had a $U$ almg/cr within normal ranges and a negative DMSA-scan. 44/62 patients with UTI had a positive Ualmg/cr (> $11 \mathrm{ug} / \mathrm{g}$ creat.) and positive DMSA-scan, indicating APN. In $13 / 44$ the clinical diagnosis of APN was not made before the positive Ualmg/creat-results were available.

Conclusion: Tubular proteinuria (alphal-microglobulin) is an usefull, cheap screening method to differentiate between higher and lower UTI.

Departement of pediatric nephrology, UZG, De Pintelaan 185, 9000 Ghent, Belgium

P078

\section{DOES URINE INTERLEUKIN-6 INDICATE THE SEVERITY OF URINARY TRACT INFECTION (UTI)?}

M Benson*, U Jodal, A Andreasson, S Mărild, E Stokland, B Wettergren, C Svanborg

Asymptomatic Bacteriuria (ABU) and febrile UTI have the same incidence in small children, $1-2 \%$. In children with bacteriuria and fever, it may be difficult to distinguish between pyelonephritis and $A B U$ with concomittant infection. A local inflammatory marker like urine Interleukin- 6 (IL-6) could be useful for this. Material and methods. 40 children with $\mathrm{ABU}$ found at screening of 3371 babies $<1$ year, and 48 consecutive children $<6$ years with febrile UTI and no signs of other infections. Results. None of the children with ABU and $63 \%$ of those with febrile UTI responded with urine IL-6. In the febrile group urine Il -6 was correlated to age, and the proportion of urine IL-6 responders was higher in those $<1$ year. Gender, inflammatory response and bacterial virulence were compared in $\mathrm{ABU}$ and febrile $\mathrm{UTI}<1$ year; The proportion of girls, levels ofurine IL-6, pyuria, CRP and $\mathrm{MSR}$, proportions of P fimbriated and hemolysin producing E.coli were significantly higher in febrile UTI. In the combined population < 1 year, urine IL-6 was significantly higher in girls, vesicoureteric reflux, $\mathrm{P}$ fimbriated or hemolysin producing E.coli. Furthermore urine IL- 6 was correlated to pyuria, CRP and $\mathrm{mSR}$. In the febrile group both urine and serum IL-6 was higher in children with reflux.Conclusions. Urine IL-6 was related to the severity of symptoms, age, gender, reflux, other inflammatory markers and bacterial virulence in small children with UTI.

*Present address: Department of Pediatrics, East Hospital, Gothenburg University, S-41685 Gothenburg, Sweden. 
P079

PREDICTION OF RENAL SCARRING AFTER PYELONEPHRITIS FROM THE PATTERN OF ACUTE CHANGES ON THE DMSA SCAN

B. Jakobsson, U. Berg and L. Svensson

Acute pyelonephritis (APN) is a common disease in childhood and often results in permanent renal damage. It would be of value if children at risk for developing renal scarring could be identified as early as possible in order to be able to concentrate our efforts towards these children. The aim of this study was to find out if the pattern of changes on the DMSA scan during infection could be related to the later development of renal scarring. Children with APN were investigated with a DMSA scan within 5 days from admission, after 2 months and after 2 years. Abnormal DMSA scans at the time of infection from 41 children, 14 boys and 27 girls, aged $0.2-9.1$ (median 0.9) years were reviewed. Each scan was evaluated with regard to renal swelling, the nature of the defect, focal, diffuse or both, the size of the defect graded on a scale 1 to 3 and the localization of defects. Renal swelling was determined by comparing renal surface area related to body weight at infection with that of 2 months. Renal surface area was measured planimetrically on the DMSA scan by a computor. 59 of 82 kidneys $(72 \%)$ had DMSA changes during infection and 29 kidneys (35\%) had persistent changes after 2 years. Renal surface area related to body weight decreased from $1.8 \pm 0.06 \mathrm{~cm}^{2} / \mathrm{kg}$ during infection to $1.6 \pm$ $0.05 \mathrm{~cm}^{2} / \mathrm{kg}$ at 2 months $(\mathrm{p}<0.01$ ). Renal swelling did not predict later abnormality on the DMSA scan. After 2 years persistent DMSA defects were more frequently seen in kidneys with grade $2-3$ defects during infection. At 2 years $80 \%$ of kidneys with focal defects during infection had become normal, while only $34 \%$ of kidneys with diffuse abnormality, with or without focal defects, had become normal. Separate renal function was significantly decreased in kidneys with diffuse abnormality both during infection and at 2 years. It is

concluded that children with APN and severe diffuse defects in DMSA uptake, compromizing renal function, run a greater risk of developing persistent renal damage than children with focal defects.

Department of Pediatrics, Karolinska Institute, Huddinge University Hospital, S-141 86 Huddinge, Sweden

P080

PRENATAL BIOCHEMISTAY OF FETAL URINE DOES NOT PREDICT RENAL FUNCTION IN THE FIRST YEAR OF LIFE IN INFANTS WITH SEVERE CONGENITAL HYDPONEPHAOSIS

S.Guez, B.M.Assael, M.L.Melzi, G.Marra, E.Secco, G.Sersale, B.Tassis, U.Nicolini

Extremely elevated fetal urinary concentrations of sodium and calcium (Reference values for gestational age Nicolini et al Br J Obst Gynaecol, 1992. 99:46-50) have been associated with severe renal dysplasia and non functioning kidney at birth. It is not known however whether there is a correlation between $\mathrm{Ca}$ and/or $\mathrm{Na}$ in fetal urine and the extent of renal damage as assessed after birth. We could measure these electrolytes in the urine of 10 fetuses (on 1-7 occasions each, range of gestational ages 23-36 weeks; total amount of evaluated samples: 28 ) with antenatal diagnosis of severe dilatations of the urinary tract. Postnatal diagnosis was: severe obstruction of pyolourgteric iunction (6 cases. 5 unitateral), megabladder with megaureter ( 2 cases, 1 uniiateral), grade 5 reflux (2 case, 1 unilateral). All infants had normal serum creatinine in the postnatal follow up (3-9 months). Kidney damage was evaluated postnatally based on upatike of $99 \mathrm{Tc}$ MAG3, parenchymal appearance at ultrasound, renal growth. Out of the six fetuses with unilateral involvement, moderate/severe damage was correctly predicted in $2 / 4$ kidneys, while normal kidneys were correctly predicted in $2 / 2$ cases. When fetal urine had been studied on more than one occasion flucfuating concentrations of the electrolytes prevented a straight evaluation in 1/2 cases. Other sources of error were: puncturing the wrong site (e.g. megabladder instead of dilated pelvis), evaluation at an early gestational age ( $<30$ weeks). Our data suggest that when $\mathrm{Ca}$ and $\mathrm{Na}$ fetal urinary concentrations are consistently elevated poor renal outcome can be confidently predicted. Normal fetal data cannot be assumed as sufficiently sensitive to predict good renal function. The selection of cases who could benefit of invasive procedures in utero is still a dilemma.

Clinica Pediatrica De Marchi, University of Milano, Via Commenda 9, 20122 Milano
P081

STRUCTURAL- FUNCTIONAL RELATIONSHIPS AND SYMTOMS AT ONSET IN CHILDREN WITH IgA-NEPHROPATHY (IgAN). U.B. Berg and G. Jaremko

77 children ( 48 boys) with biopsy-verified IgAN at the age of 2.5-18.4 (median 12.7) years were followed 0.6-20.6 (median 8) years from onset. First clinical symtoms, appearing at 1.9-16.0 years of age, were registered and renal function was followed every 2 nd to 3 rd year by glomerular filtration rate (GFR) and effective renal plasma flow (ERPF) determined by clearances of inulin and PAH. Urinary albumin (UAlbV) and IgG excretions (UIgGV) were determined in short term urine samples. In the renal biopsy specimens, the fractions of glomeruli showing global sclerosis (GGS), segmental sclerosis (SGS) and cellular crescents (CR) were calculated. Glomerular mesangial expansion (MV), mesangial cell proliferation (MP) as well as interstitial inflammation (II), and fibrosis (IF) were assessed on a five degree scale. The first signs of renal disease were macroscopic hematuria \pm proteinuria $(\mathrm{MaH})$ in $40 \%$, microscopic hematuria \pm proteinuria $(\mathrm{MiH})$ in $33 \%$, acute nephritic syndrome with elevated serum creatinine (AN) in $21 \%$ and nephrotic syndrome thematuria (NS) in $6 \%$. Patients with initial AN and NS had lower GFR both at time of renal biopsy (median 1.4 years after onset) and at follow-up than patients with MaH or MiH. GFR in NS patients decreased significantly, $53 \pm 13$ to $26 \pm 11 \mathrm{ml} / \mathrm{min}$ per 1.73 sq.m. 3 of $5 \mathrm{NS}$ patients are now transplanted and the other two have a GFR of 31 and $14 \mathrm{ml} / \mathrm{min}$ per 1.73 sq.m. 0.8 and 3.9 years from onset. UAlbV and UIgGV did not differ between $\mathrm{AN}, \mathrm{MaH}$ or $\mathrm{MiH}$. Significant correlations were seen between GFR at time of biopsy and GGS, SGS $(r=0.657, p<0.001)$ and CR as well as MV, MP, IF and II. There were also significant correlations between the structural parameter and last GFR performed. Systolic and diastolic blood pressures related to SGS, CR, MV and MP but not to interstitial changes. UAlbV and UIgGV related to SGS $(r=0.76$ and 0.66 respectively, $p<0.001)$ and to MV but not to MP, IF and II. Conclusions: Children with IgAN and NS have a poor prognosis and those with an elevated serum creatinine at onset showed lowered GFR at follow-up. A high proportion of segmentally sclerosed glomeruli predicts a poor prognosis.

Department of Pediatrics and Pathology, Huddinge University Hospital, S14186 Huddinge, Sweden

P082

ALTERED GLYCOSYLATION OF SERUM IGA IN PATIENTS WITH IgA NEPHROPATHY.

R. Coppo, P. Cirina, P. Brusa*, A. Amore, L.Peruzzi, B.Gianoglio, L.Cattel*

Several observations, including an abnomal binding of serum IgA to some lectins and to mesangial matrix glycoproteins, are consistent with the hypothesis of an altered glycosylation of the IgA molecules in patients with IgA nephropathy (IgAN).

To investigate this pathogenetic mechanism, we compared in healthy controls and IgAN patients the profile of IgA eluted from Sepharose column (4B-CNBr) conjugated with lectins. One lectin from each of the 5 groups classified on the basis of their preferential binding to sugar residues was used : [a] Concanavalin $A ;$ b) wheat germ agglutinin; c) Soybean; d) Ulex; e) Limulus]. Affinity chromatography bound proteins were eluted by the sugars corresponding to the lectins in solid phase : for group a) Mannose, b) N-Acetyl-glucosamine, c) N-Acetyl-galactosamine, d) L-Fucose, el Sialic acid and were examined in high pressure liquid chromatography (HPLC) (columns: Zorbax GF-250 and Bio-sil SEC-250). Eluted peaks were analyzed by SDS-polyacrylamide gel electrophoresis.

By HPLC, sera from IgAN patients showed, in comparison to controls, an highly increased second peak of con A binding IgA eluted with mannose $(300 \mathrm{kDa})$ and a new peak at lower molecular weight (150 $\mathrm{kDa}$ ). The sugar eluted peak was slightly higher in IgAN than in controls in soybean and wheat Germ Agglutinin and vlex colums. Conversely, the binding capacity of the lectin Limulus, specific for sialic acid, was highly decreased in IgAN patients in comparison to controls.

These data suggest an altered glycosylation of IgA molecules in sera from patients with IgAN, including a defective expression of sialic acid and an increase in mannose contents.

Nephrology and Dialysis Dept, Regina Margherita Hospital,

Piazza Polonia, 94 - 10126 Torino Italy. 
P083

INTEGRIN EXPRESSION ON MESANGIAL CELLS: MODULATORY ROLE OF IgA, ABNORMALLY GLYCOSYLATED IgA AND IgA/IgG and IgA/LECTIN AGGREGATES

L. Peruzzi, A. Amore, P. Cirina, B. Gianoglio, MG. Porcellini, \#I. Trusolino, \#PC. Marchisio, R. Coppo

Cultured mesangial cells (MC) express cell-matrix adhesion receptors, including the widest and best known family of integrins. They constitute focal contacts between MC and glomerular basement membrane (GBM), foundamental for the regulation of glomerular haemodynamics.

We investigated whether integrin expression on cultured human MC could be modulated by IgA native or pre-treated by carbohydrate specific enzymes or IgA/IgG and IgA/lectins aggregates.

Human MC displayed strong adhesion to glass coverslip in basal conditions and expressed mostly alpha3-B3 and at lower intensity $\beta 1$ chains of integrins, as judged by immunofluorescence staining. After 12 hours MC produced large amount of fibronectin (F) and laminin (L).

Polymeric IgA and even more aggregated IgA and aggregated IgA/IgG strongly decreased MC adhesion, integrin expression and MC matrix production. On the opposite, Con A and IgA aggregated with Con A increased B1, B3 and alpha3 expression. IgA pretreated with Mannosidase and Neuraminidase allowed increased adhesion of MC in comparison to untreated IgA, while adhesion was decreased on IgA treated with NAC-Galactosidase, Fucosidase, NAC-Glucosaminidase.

The expression of $B 3$ chain as well as the production of fibronectin and laminin were variously influenced by the IgA glycosylation.

Our data suggest that the interactions of native polymeric IgA, IgA with altered glycosylation, aggregated IgA or IgA/IgG or IgA/lectins result in structural rearrangement of glomerular integrins. This phenomenon might lead to modifications in the transmission of MC contraction to the GBM, possibly regulating the glomerular haemodynamics and the production of mesangial matrix.

Nephrology and Dialysis Dept, Regina Margherita Hospital, Piazza Polonia, 94 - 10126 Torino Italy.

\section{P084}

CELL. MEDIATED IMMUNITY CHANGES IN PRIMER IgA NEPHROPATHY A. Keskinoğlu, S.Mir, C.Kabasakal, N.Betin, A.Cura

To investigate the immunogenesis of primer IgA nephropathy (IgAN), we wanted to determine serum immunglobulin levels and changes in cell mediated immunity of patients with lgAN during acute and remission periods. The study was done on 15 patients ( 10 male, 5 female; mean age $11.0+3.5$; range 5 to 16 years) admitted with recurrent macroscopic hematuria and 16 normal children. None of the patients had the symptoms of systemic diseases. Percutaneous renal biopsy was performed and revealed $\operatorname{lgA}$ deposits in mesangium and glomerular capillaries IgAN was diagnosed in all patients. Six of the patients were in acute phase; nine were in remission phase. CD3 (T-cell), CD19 (B-cell), CD4, CD8, the ratio of CD4/CD8, natural killer cells, activated T-celis(HLA-DR+CD3), IL-2 receptors (IL$2 R$ ), surface $\lg (s \mid g) A, G, M(+)$ binding $B$ cells were determined using BectonDickinson's monoclonal antibodies on flowcytometer. HLA-A, -B, -C, -DR,-DQ were assessed with the microlymphocytotoxicity test. Results:

\begin{tabular}{|c|c|c|c|}
\hline & Rिule (II-í) & ritinsalwal (i1-b) & invinis (ni=10) \\
\hline $\operatorname{CD} 3(\%)$ & $71.8 \pm 8.9$ & $65.3 \pm 12.0$ & $69.3 \pm 9.3$ \\
\hline CD19 & $9.7 \pm 4.8$ & $8.4 \pm 3.1$ & $7,3 \pm 3.6$ \\
\hline $\mathrm{CO} 4$ & $39.0 \pm 8.7$ & $34.5 \pm 6.9$ & $42.3 \pm 13.0$ \\
\hline $\operatorname{CDB}$ & $26.5 \pm 6.4$ & $36.6 \pm 6.2$ & $31.4 \pm 4.6$ \\
\hline $\mathrm{CD} 4 / 8$ & $1.28 \pm 0.48$ & $0.92 \pm 0.28$ & $1.42 \pm 0.54$ \\
\hline Active-T cell & $6.3 \pm 1.9$ & $4.2 \pm 2.2$ & $4.7 \pm 2.1$ \\
\hline IL-2R & $10.2+2.4$ & $4.2 \pm 1.8$ & $3.5 \pm 2.1$ \\
\hline $\lg A(m g / d l)$ & $212+22$ & $186 \pm 33$ & $107 \pm 67$ \\
\hline $\lg C$ & $1413 \pm 184$ & $913 \pm 86$ & $854 \pm 122$ \\
\hline $\lg M$ & $158 \pm 27$ & $78 \pm 29$ & $98 \pm 31$ \\
\hline IgA binding $B$ cell (\%) & $55.9 \pm 4.8$ & $65.8 \pm 3.1$ & $8.9 \pm 0.6$ \\
\hline IgG binding $B$ cell & $32.1 \pm 8.7$ & $12.4 \pm 3.2$ & $13.8 \pm 1.2$ \\
\hline igM binding $\mathrm{B}$ cell & $17.3 \pm 4.2$ & $6.8 \pm 2.1$ & $6.5 \pm 0.8$ \\
\hline
\end{tabular}

The association of HLA-A2, - B5, -B18, -DR4, -DR11, -DQ7 to lgAN was observed. in acute phase, relative increase in CD4 and a significant decrease in CD8 was determined. The significant increase in IL-2R and activated $T$ cells pointing out to the activation of $T$ cells, are considered to be the results of CD4 activation in acute phase. This gives rise to increase in serum levels of $\lg A,-G,-M$ and surface IgA, IgG, IgM binding $B$ cells in acute phase. Delayed suppressor activity indicated by low levels of CD8, may be considered responsible for IgAN activity.

Ege University, Department of Pediatrics, 35100 - Bornova, Izmir, TURKEY.
P085

IgG SUBCLASSES IN SERA AND CIRCULATING COMPLEXES IN IgA NEPHROPATHY

JC Davin*,P de Mauregard,J Nagy,P Mahieu.

It has been previously suggested that IgA1-IgG circulating complexes could play a pathogenic role in IgA nephropathy since their detection is correlated with clinical signs (Schena et al,1989). Since IgG subclasses differ by their effector proprieties, such as the ability to activate the complement system, and are therefore able to induce various degrees of inflammation, we have looked for the presence of IgG subclasses in circulating complexes in 47 patients presenting with $\operatorname{IgA}$ nephropathy (13-65y)(A). Controls were 17 normal adult volunteers (B). The technique used was an ELISA determination of the IgG subclasses content of $2.5 \%$ polyethylene glycol (PEG) precipitates of sera (M.W.> $1,000 \mathrm{Kd}$ ). The IgG subclasses were also determined by ELISA in sera. The followings were observed:1) Mean IgG1 and IgG2 plasma levels were respectively decreased and increased in $A(p<0.05) ; 2)$ The mean IgG subclass content of PEG precipitates was increased only for IgG1 $(p<0.05) ; 3)$ no correlation was observed between $\operatorname{IgA}$ and $\operatorname{IgG}$ subclasses content of PEG precipitates. In conclusion, we have confirmed that IgG1-but not IgG2-plasma levels are reduced in IgA nephropathy. This could favour relapsing infections often seen in those diseases during hematuric bouts. Although reduced in serum, IgG1 is the main $\operatorname{IgG}$ isotype in circulating complexes. This could be of pathogenic significance since $\operatorname{IgG} 1$ is the more potent $\mathrm{C} 4$ activator $\mathrm{IgG}$ subclass and severe histologic lesions are associated with C4bp glomerular deposits (Miyazaki et al, 1984). Finally, the lack of correlation between IgA and IgG subclasses content of 2.5 PEG precipitates pleads against the presence of mixed IgA-IgG circulating complexes.

*Present address:AMC,Amsterdam University, The Netherlands.

P086

INHIBITION OF EXPERIMENTAL IgA NEPHROPATHY BY COLCHICINE

A Amore, I Peruzzi, B Gianoglio, P Cirina, *IM Sena, R Coppo Colchicine (COL) is a well known inmunomodulating drug successfully used in several inflammatory diseases. COI disrupts microtubules by inhibiting tubulin polymerization. The interruption of the signal transmission from surface receptor to cytoskeleton inhibits several cell responses. COL prevents renal al lograft rejection by inhibiting adhesion molecule function on epithelial cell surface (JASN 1992, $3: 847)$

Lectins bind to mesangial cells (MC) and intra-aortically injected IgA-lectin aggregates (Aggr) induce IgA mesangial deposits.

To investigate the possible effects of colchicine on the development of experimental IgA nephropathy induced by $\mathrm{IgA} /$ lectin Aggr, we intraortically injected $500 \mu \mathrm{g}$ of Concanavalin A (Con A) /polymeric IgA Aggr in Lewis rats. We considered two groups of animals: A) pretreated for 4 days by daily gavage with COI $0.04 \mathrm{mg} / \mathrm{kg}$ and B) pretreated with shame gavage. Rats were anaesthesized and the aorta was cannulated until the renal artery origins and then injected with Con A I IgA Aggr. Rats were sacrificed 1 hour later.

After Aggr injection, Con $A / I g A$ deposits were detected by SDS polyacrylamide gel electrophoresis on renal tissue homogenates. On the contrary, the pretreatment with COL prevented any IgA or lectin deposit formation. The binding to cultured MC was inhibited as well by COL.

We speculate that COI might influence cell surface receptor expression and function on MC, as demonstrated for endothelial cell, preventing the mesangial trapping of IgA/Con A Aggr.

Nephrology and Dialysis Dept, Regina Margherita Hospital. Piazza Folonia, 94 - 10126 Torino Italy. 
P087

LACK OF IgA GALACTOSYLATION IN IgA NEPHROPATHY (IgAN).

JC Davin*, J Nagy, M Malaise, P Mahieu.

In patients presenting with IgA nephropathy, clinical and experimental data suggest a pathogenic role for mesangial IgA deposition secondary to IgA blood accumulation. The latter could result either from an increased production or from a decreased clearance. Ig are cleared by the liver after binding to the asialogycoprotein receptors of hepatocytes recognizing terminal beta-galactosyl residues. The high IgA clearance, as compared to IgG, is due to the preferential exposition of terminal betagalactose molecules on oligosaccharides $\mathrm{N}$-linked (common to IgG and IgA) or O-linked (specific of IgA1) to heavy chains. In the present work, we have tested the hypothesis according to which, blood accumulation of IgA in IgA nephropathy results from a reduced IgA clearance secondary to a lack of IgA galactosylation. In order to verify this hypothesis, plasma IgA was purified from 37 patients (age range:7-35y) by affinity chromatography. The expression of terminal GAL residues was appreciated in patients and in a control group of 20 normal volunteers), by measuring the binding of purified IgA to a lectin binding specifically to beta-galactose residues (Peanut Agglutinin:PNA) according to a specific ELISA previously described (Davin et al, 1991). Although the mean values were not significantly different in both groups, ten out of the 37 patients presented with a binding-capacity of IgA to PNA inferior to the lowest values measured in the control group. Our results suggest therefore that a lack of galactosylation of IgA is present in some patients with IgAN.This abnormality can be responsable for a reduced IgA clearance and subsequent blood and mesangial accumulation.

*Present address:AMC,Amsterdam University, The Netherlands.

\section{P088}

DIAGNOSTIC VALUE OF IMUNOHISTOCHEMICAL DETECTION OF THE TERMINAL COMPLEMENT COMPLEX (C5b-9) IN CHILDREN WITH GLOMERULOPATHIES

L'. Podracká, M. Šašinka, A. Boor, I. Jurkovič

The assembly of the $\mathrm{c} 5 \mathrm{~b}-9$ complex of complement has been established to play an important role for induction of membrane damage and inflamation in glomerular injury. In the present study, renal tissue samples were obtained by kidney biopsy from 22 children with glomerular diseases ( 8 cases of nephrotic syndrome, 14 patients with chronic glomerulonephritis) for immunofluorescent evaluation of IgG, IgA, IgM, C3, fibrinogen and the neoantigenes of the terminal c5b-9 complement complex. In this group histological findings and the presence of c5b-9 deposits were correlated with clinical, biochemical and immunologlcal parameters. Glomerular c5b-9 deposits were present in 8 cases ( 3 with membraneous nephropathy, 3 with IgA nephropathy and 2 with membranoproliferative glomerulonephritis). We found significant correlations between $\mathrm{C} 5 \mathrm{~b}-9$ and IgA and $C 3$ deposits respectively (spearman $s$ rank correlation coeffients $r=0.83, p<0.05$ and $r=$ $0.67, \mathrm{p}<0.05$ respectively) with the strongest intensity of deposits being observed in cases of membranous nephropathy. In addition, we found significant relationships between $C 5 b-9$ deposits and urinary protein and serum levels $(p<0.05)$. No significant correlation was found between $\mathrm{C} 5 \mathrm{~b}-9$ and the serum levels of $\mathrm{C3}, \mathrm{C4}, \mathrm{AH} 50$ or $\mathrm{CH} 50$. Importantly, the presence of $c 5 b-9$ deposits fared worse than those without deposits even with the same histopathological type of glomerulonephritis. These data suggest, that the presence of glomerular C5b-9 deposits may reflect disease activity in patients with glomeruloneoiritis.

Depart. of Pediat. Univ. Hospit. SNo Vo.1, 04055 Košice, Slova'k republ it
P089

MEMBRANOPROLIFERATIVE GLOMERULONEPHRITIS IN TWO FAMILIES EVIDENCE OF $X$-LINKED INHERITANCE?

* A Bakka logiu, o soylemezoglu, U Saatci, K Tinaztepe, $S$ Ozen, R Topaloglu, $N$ Besbas.

Evidence of a genetic basis in membranoproliferative glomerulonephritis (MPGN) has been previously referred to. We present six male children with MPGN in two families. In the first family two boys of age 10 and 13 years presented with a nephrotic and nephritic syndrome in subsequent years. one elder sister and two brothers were healthy. These patients, as well as those of the second family, were unresponsive to both corticosteroid and immunosuppressive therapy. The creatinine clearances at 2 and 3 years followup are 35 and $16 \mathrm{ml} / \mathrm{min}$, respectively. In the second famity four male sibs of a consanguineous marriage were affected; three presented with nephrotic syndrome at the ages of 7,3 and 3.5 years and one with proteinuria at 10 months of age. Two sisters were healthy. The first sibling died due to renal failure, second is on chronic hemodialysis therapy, third has a clearance of $65 \mathrm{ml} / \mathrm{min}$ at 5 years follow-up. The youngest sib has persistent proteinuria with a norma? renal function. In all the presented six patients above, MPGN type I were diagnosed with LM, IF and EM studies. Familial studies in al1 patients and unaffected members showed normal complement levels, immunoglobulins, $T$ cell subsets and the unaffected members had normal urinalysis and renal function. HLA studies revealed HLA A2 to be common in all affected patients. In the first family the affected males shared DR2 antigen whereas in the second family DR4 was shared. Although molecular genetic studies are not performed yet, we suggest that the development of MPGN in males and the healthy sisters maybe compatible with an $x$ linked inheritance. We also suggest that the early development of the disease and severe prognosis may be related to the genetic basis of the disease.

*Department of Pediatric Nephrology, Hacettepe University 06100 Ankara Turkey

$\mathrm{P} 090$

ATHEROGENTCITY OF BLOOD SERUM FROM CHILDREN WITH CRONIC GLOMERULONEPHRITIS

T.V. GOZALISHVILI 1$\}$, V.V. TERTOV, V.G. PINELIS

We have examined the sera from 15 patients (pts), age 4-14 years, with nephotic syndrom associated with hematuria and/or hypertension (NSH). Renal biopsy have been performed in 13 children and the morphological entities were FSGS in 6, MCGN in 5 and Mesang. PGN in 2 pts. Twenty five normal children seta (NCS) were used as controls. Low density lipoproteins (LDL) have been obtained from sera by ultracentrifugation. Smooth muscie cells (SMC) from unaffected human aortic intima were isolated by collagenase and elastase. On the seventh day of cultivation the examined sera or LDL were added to SMC. The total choles terol (cho) content extracted from cells was determined by cholesterol analysis kits (Mannheim, FRG). Our resalts revealed that adding of LDL isolated from sera of NSH pts at the concentrations $10,20,50,100$ and $200 \mathrm{pg} / \mathrm{mI} \mathrm{re}$. sulted in increasing cho content in cultured sMc to $53 \pm 5$. $75 \pm 6 ; 123 \pm 4 ; 170 \pm 9 ; 200 \pm 16 \mathrm{~kg} / \mathrm{mg}$ protein, respectively, i.e. sh w. A "atherogenic" properties. LDL isolated from NCS at i same concentrations have not changed the intracellu. ir cho levels (mean $47 \pm 4 \mu \mathrm{g} / \mathrm{mg}$ protein). The sera from NSH pts exposed to delipidization at the concentrations $5,10,20$ and $40 \%$ also have not induced the increase of Cho content in cultured cells. During the SMC cultivation in the presence of both delipidizated sera from NSH

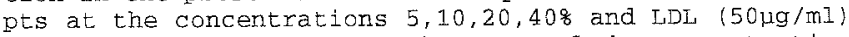
isolated from the same sera increase of Cho concentration in cells in direct proportion has been observed $(r=0,81)$. Sera from NSH pts depleted of IgG and IgM were significantly loosing the ability (80 and $25 \%$, respectively) to increase cho content in cultured SMC. We suggest that LDL from sera of NSH ots are modified lipoproteins, differing from native LDI and are capable to form autoantibodies. LDL-containing immune complexes facilitate the accumulation of lipids in cultured human smooth muscle cells. 


\section{P091}

TYPES I, III, IV, $v$ COLLAGEN AND FTBRONECTIN (FW) IN GLOMERULI OF CHILDREN WITH KIDNEY DISEASES

T.V. GOZALISHVILI:*], B.V. SHEKHONIN, T.V. SERGEEVA, A.N. TSYGIN, A.N. PARTENADZE, and V.A. VARSHAVSKY

The relationship between the initial immunologic injury of glomeruli and its progression to glomerular sclerosis remains an important unsolved problem. Localization of several extracellular matrix (ECM) proteins in renal glomeruli was examined in 18 boys and 16 girls, aged 6-14 yr. The hystological diagnoses of patients were: 4 cases with minor glomerular abnormalities (MGA), 6-with focal secmental glomerulosclerasis (FSGS), 15-with mesangioproliferative GN (Mesang.PGN), 5-with mesangiocapillary (MC) GN and 4-with membranous nephropathy (Membr.n). The immunofluorescence was performed on fixed serial cryostat sections routinely in the indirect variant. Antibodies to collagen types I, III, IV, $V$ and FN were obtained and characterized as described earlier (Atherosclerosis 67,9-16, 1987). Our study results showed that increased amounts of collagen types IV, $V$ and $F N$ stained in glomeruli with mesangial and capillary pattern in al1 cases examined, with mesangial staining of FN more prominent in the cases with mesangial types of GN. Only in MCGN the synechiae between peripheral capillary loops of some glomeruli contained interstitial collagen, type III. Iarge aggregates of type III collagen were often seen around the glomerulus in the cases of FSGS Mesang. PGN and MCGN. In the sclerotic glomerulus the composition of ECM was quite different. The regions of peripheral capillary loops were stained diffusely for collagen types IV, $V$ and FN. There was prominent accumilation of collagen types I and III (component not found in normal glomeruli) in MCGN and in $1 / 3$ cases of Mesang. PGN. The only collagen found in FSGS was type III. These date suggest that ECM composition in sclerotic glomeruli depends on GN morohologic type and might give a clue for clarifying the pathogenesis of progressive renal scarring.

(*) Institute of Pediatris RAMS, 117296 Moscow, Russia

\section{P092}

POSSIBLE PATHOGENIC ROLE OF NATURAL ANTIBODIES DIRECTED AGAINST MUCOSAL ANTIGENS IN NEPHROPATHIES.

M Livecchi, JC Davin*, M Malaise, J Foidart and P Mahieu.

Anti-alpha-galactosyl antibodies (anti-GAL) are human natural antibodies directed against GAL epitopes present in numerous animal species but lacking in normal individuals because of alpha 1-3 galactosyltransferase repression. We have previously shown (Kidney Int, 1987) that anti-GAL might be involved in IgAcontaining immune complexes (IgA-CIC) formation and hematuric episodes determination in IgA nephropathies. In the present work, we have tested the hypothesis according to which anti-GAL could also be responsable for glomerular lesions by direct binding to renal structures. We have isolated human anti-GAL by affinity chromatography and studied their in vivo and in vitro binding to mouse renal structures, exposing GAL epitopes. We have shown by ELISA, radioimmunoassay, passive hemagglutination and immunofluorescence blocking studies that anti-GAL reacted with mouse basement membrane laminin.After IV injection, anti-GAL mainly accumulated in kidneys, liver, spleen and lungs. Moreover, in primary cultures, anti-GAL was shown to impair the attachment of mouse glomerular epithelial cells to mouse laminin and to elicit complement-dependent cell damage. Our experiments suggest therefore that anti-GAL could induce glomerular lesions in man after glomerular deposition of GAL bacterial antigens.

*Present address: AMC, Amsterdam University, The Netherlands
P093

\section{THE SUCCESSFUL USE OF PLASMA EXCHANGE IN THE} TREATMENT OF AGGRESSIVE IGA NEPHROPATHY

Redfearn A, Sharp J, Lambert HJ, Coulthard MG.

Introduction Aggressive rapidly progressive crescentic $\lg A$ nephritis is rare in childhood and has occasionally been treated with plasma exchange (PE). However, it has been impossible to judge whether it was effective because of concurrent immunosupressive drug treatment. We describe 3 children treated with $P E$ alone.

Cases 3 children (7.6 to 10.1 yr) were treated with PE only for aggressive biopsy proven crescentic IgA nephritis. The pre-PE GFR ( $\mathrm{ml} / \mathrm{min} / 1.73 \mathrm{~m}^{2}$, calculated from plasma creatinine and height) fell from 56 to 35 over 5 days in case 1, and from 37 to 16 over 10 days in case 2 Case 3 presented with a GFR of 30 and was treated at once. PE was with an $\mathrm{ml} / \mathrm{kr}$ usinn $4.5 \%$ albumin, then 2 units of FFP. Initial treatment was 9 PEs in 2 weeks, and then according to response.

Results All 3 showed a rapid rise in GFR, reaching 73 to 84 by a month.

- Case 1 had 18 PEs in one month; 1 year later she is well, off all treatment, with no albuminuria, and a GFR of 95 .

- Case 2 (whose father was also found to have mild IgA disease) had 38 PEs in 3 months, then 26 more in months 6 to 11 after a relapse. Three biopsies performed after $0.5,1$ and 5 months of treatment were much improved with resolution of crescents and of interstitial and tubular changes. At 1 year his GFR is 95 , and he has mild albuminuria.

- Case 3 had 28 PEs in 3 months; 17 in the 1 st, 8 in the 2 nd, 3 in the 3rd. At 6 months her GFR is 85 , but she has persistent albuminuria.

Conclusion All 3 children had very aggressive $\lg A$ nephritis, and showed a dramatic improvement in renal function with PE alone which has persisted at 1 to 6 months after stopping therapy. Avoiding using immunosupressive drugs could be a major advantage; a multicentre tria should be considered to evaluate the role of PE versus drug therapy.

Department of Paediatric Nephrology, Royal Victoria Infirmary, Newcastle upon Tyne, NE1 4LP, UK.

P094

A RETROSPECTIVE STUDY OF PLASMA-EXCHANGE (PE) IN CHILDREN WTTH VASCULITIS, SYSTEMIC LUPUS ERYTHEMATOSUS (SLE) AND IDIOPATHIC RAPIDLY PROGRESSIVE GLOMERULONEPHRITIS (IRPGN).

A. Gianviti, R.S. Trompeter, T.M. Barratt, M.F. Lythgoe, M.J. Dillon.

A retrospective study was performed to evaluate the efficacy of PE in children with vasculitis, SLE and IRPGN. Forty-eight cases, who underwent PE, were reviewed; 25 males and 23 females. They presented at the Hospital for Sick Children between 19791993. Mean age at the onset was $8.5 \mathrm{y}$ (range 1.4-15.9 y); 17 cases had HenochSchonlein purpura, 6 had SLE, 11 had polyarteritis nodosa, 2 had Wegener's granulomatosis and 12 had IRPGN. Treatment consisted of steroids and cytotoxic agents plus PE because of the severe clinical picture at the onset or during the course of the disease. Two groups were considered depending on the main clinical features leading to PE. Group A: 33 cases with severe renal involvement (acute renal failure, crescents > $50 \%$ ); group B: 15 cases with a cerebral disease (5 cases), a systemic deterioration or flare-ups of disease activity ( 9 cases) and refractary thrombocytopenia (1 case with SLE). The patients were evaluated 2 months after PE (short term outcome) (STO) and at the longest follow-up available (long-term outcome) (LTO). Results (Table)

\begin{tabular}{|c|c|c|c|c|c|c|c|c|c|}
\hline & & \multicolumn{4}{|c|}{ STO } & \multicolumn{4}{|c|}{ LTO } \\
\hline & & \multicolumn{2}{|c|}{ GOOD } & \multicolumn{2}{|c|}{ BAD } & \multicolumn{2}{|c|}{ GOOD } & \multicolumn{2}{|c|}{$\overline{B A D}$} \\
\hline & Tot. $\mathrm{N}$ & $\mathrm{N}$ & $(\%)$ & $N$ & $(\%)$ & $\mathrm{N}$ & $(\%)$ & $\mathrm{N}$ & (\%) \\
\hline Gr. A & 33 & $25^{*}$ & (76) & 8 & (24) & $20 * *$ & (63) & 12 & (37) \\
\hline Gr. B & 15 & 8 & (53) & 7 & (47) & 10 & (67) & 5 & (33) \\
\hline$\overline{A L L}$ & 48 & 33 & $(69)$ & 15 & (31) & 30 & (64) & 17 & (36) \\
\hline
\end{tabular}

*mean creatinine pre-PE $443 \mathrm{umol} / \mathrm{l}$, post-PE $87 \mathrm{umol} / 1$ ( $p<0.05$ ); ** l case lost.

Considering patients in group $\mathrm{A}$ and also all the cases together $(\mathrm{N}$ in $\mathrm{B}$ too small for analysis) it was observed that the timing between disease onset and start of PE was significantly different in those who recovered compared with those who did not (group A: 1 month vs. 4 months, $\mathrm{p}=0.02$; all cases: $1 \mathrm{~m}$ vs. $5 \mathrm{~m}, \mathrm{p}=0.006$ ). Conclusion: if started early after disease onset, PE can be effective in improving the outcome in children with vasculitis, SLE and IRPGN. However this treatment should be limited to severe cases in which, performed by experienced staff, it is a relatively safe procedure. A randomized controlled trial might clarify the value of PE in treating these disorders. However there would be difficulties in recnuitment in view of the rarity of these conditions in childhood. Furthermore, if only severe cases were to be treated, the decision of how to randomize them would be very difficult to make.

Present address: Institute of Child Health, 30 Guilford Street, London WCIN 1EH. 
P095

REDUCED ACUTE CYCLOSPORIN A NEPHROTOXICITY BY ENALAPRIL IN RATS

Ali Anarat, Aytül Noyan, Gülfiliz Gönlüşen, Naci Duman, Iihan Tuncer.

The purpose of this study was to identify if enalapril is administered in conjuction with cyciosporin A (cyc-A) might reduce its nephrotoxicity. To evaluate this 60 rats in 5 groups were included in this study. Groups were designed as follows. Group 1; control group, Group 2; Rats treated with oral enalapril for 7 days. Group 3; Rats treated witn oral Cyc-A (100 mg/kg/day) for 7 days. Group 4; Rats treated with Cyc-A and enalapril for 7 days. conjuction with enalapril. At the end of the therapy rats were sacrified and BUN, serum creatinin, plasma Cyc-A levels were studied. Also renal specimens were evaluated by electron and light microscopy. Mean BUN and serum creatinin concentrations were not statistically different between the significant difference between mean Cyc-A levels. $(p>0,05)$. Morphologically acute Cyc-A nephrotoxicity is evaluated by the following features. a) Tubuler vacuolisation (TV) b) Tubuler necrosis (TN) c) Tubuler microcalsification (TMC) d) Peritubuler capillary conjestion e) Juxtaglomeruler apparatus hypertrophy. Morphological lesions were scored semiquantitatively on a scale from 0 (not present) to $4(+)$ (very severe). We didn't observe any of this morpological changes in group 1 and 2 . When compared Group 4 with Group 3 there is a statistically significant decrease in tubuler necrosis $(p<0,05)$. However when compared group 5 with group 3 there is statistically significant decrease both in tubuler vacuolisation $(p<0,01)$ and tubuler necrosis $(p<0,01)$. In conclusion, enalapril can be administered as a prophylactic drug before Cyc-A therapy to reduce Cyc-A nephrotoxicity.

Çukurova University School of Medicine Departments of Pediatric Nephrology and Pathology. 01330-Balcall-Adana-Turkey. Group 5; Rats treated with enalapril for 7 days and then treated Cyc-A in groups $(p>0,05)$. In groups treated with Cyc-A there were no statistically

P097

LONG TERM NEPHROTOXICITY OF COMBINED CISPLATINUM, IFOSFAMIDE AND METHOTREXATE IN PATIENTS WITH OSTEOSARCOMA

P Cochat*, A Hadj-Aïssa, L Dubourg, M Brunat-Mentigny

The long term prognosis of osteosarcoma has improved in recent years, but one can question the renal side effects of a theoretical nephrotoxic combination of cisplatinum (CDDP), ifosfamide (IFX) and methotrexate (MTX).

The renal function of 17 patients ( 12 girls) aged 10 to 20 years at the time of therapy was investigated 1 to 8 years after the last treatment. Drug dosage was adapted to tumour response on the basis of a standard protocole including CDDP $\left(600 \mathrm{mg} / \mathrm{m}^{2}\right)$, IFX $\left(36 \mathrm{~g} / \mathrm{m}^{2}\right)$ and MTX $\left(84 \mathrm{~g} / \mathrm{m}^{2}\right.$ before puberty and $56 \mathrm{~g} / \mathrm{m}^{2}$ when puberty is achieved). Individual drug dosage was expressed as a percentage of the recomacnded schedule for each antitumuor agen. The glomerular filtration rate (GFR) was assessed by creatinine clearance measured from plasma and $24 \mathrm{~h}$ urine collection, concomitantly with other renal parameters.

GFR ranged from 61 to $156 \mathrm{ml} / \mathrm{min} .1 .73 \mathrm{~m}^{2}$ (mean $\pm \mathrm{SD}=109 \pm 27$ ). There was a good correlation $(\mathrm{r}=0.705, \mathrm{p}<0.01)$ between GFR and the total amont of chemotherapy (i.e. CDDP + IFX + MTX). When analysed separately, the GFR was also well correlated with the total CDDP $(r=0.772, p<0.01)$ and IFX $(r=0.826, p<0.01)$ dosage, but there was no correlation with the cumulated dosage of MTX. Moreover, those patients with decreased GFR show mild tubular involvement (i.e. increased fractional excretion of potassium, magnesium, sodium and calcium). On follow-up, no patient has reached end-stage renal failure because of the nephrotoxic side effects of the treatment.

It is concluded that combined CDDP, IFX and MTX might be responsible for mild renal impairement in patients who recover from osteosarcoma. The decrease in GFR is correlated with the total amount of CDDP and IFX, independently from MTX dosage.

* Unité de Néphrologie Pédiatrique, Hôpital Edouard Herriot and Université Claude Bernard, 69437 Lyon. France

P098

P096

CHRONIC RENAL FAILURE FOLLOWING ACCIDENTAL CISPLATINUM OVERDOSAGE

P Cochat*, Y Gillet, C Glastre, S Colon, D Floret, M Brunat-Mentigny

Cisplatinum (CDDP) is known to be responsible for vascularmediated acute renal failure (ARF) both in children and adults. Chronic renal failure (CRF) has been reported in adults, mainly with pre-existent decreased GFR, and is exceptionally related in children. A 4-year-old girl suffering from rhabdomyosarcoma was first treated with vincristine, actinomycine and ifosfamide, 6 courses over 5 months, leading to complete tumour remission. Afterwards renal function tests were normal $\left(\mathrm{Cin}=130 \mathrm{ml} / \mathrm{min} / 1.73 \mathrm{~m}^{2}, \mathrm{Cpah}=686\right.$ $\left.\mathrm{ml} / \mathrm{min} / 1.73 \mathrm{~m}^{2}\right) .3$ months later, she received vincristine + paraplatin + teniposide (4 courses), then CDDP + vepeside because of a local relapse. She accidentally received $150 \mathrm{mg}$ CDDP per day over 2 consecuitive days (day 1 and 2) instuad of $150 \mathrm{mg}$ divided over 5 days. By 48 hours following day 2, she presented with oliguric ARF, metabolic acidosis, increased liver enzymes and sudden deafness. CDDP plasma levels were not significantly influenced by 3 haemodialysis nor by 4 plasmaphaeresis sessions. Later on she required regular haemodialysis because of overt CRF. Renal biopsy was first contra-indicated because of thrombocytopenia ; it was performed on day 27 and revealed severe acute tubular necrosis without significant glomerular or vascular involvement. The GFR improved slightly that allowed haemodialysis to be discontinued on day 84.3 months after CDDP poisoning, the child had advanced stable $C R F\left(C\right.$ in $=11 \mathrm{ml} / \mathrm{min} / 1.73 \mathrm{~m}^{2}$ on day $178, \mathrm{SCr}=610 \mu \mathrm{mol} / \mathrm{L}$ on day 177 ), normal liver tests but definite complete nerve deafness. It is concluded that : 1) chronic CDDP nephrotoxicity is uncommon in children with previous normal renal function, 2) the risk of CRF is a dose-dependent phenomenon, 3 ) the clearance of CDDP by high-flux membrane haemodialysis or plasmaphaeresis is ineffective because of prompt tissue binding, 4) the risk of nerve deafness is increased by combined renal failure and persistent CDDP intoxication.

* Unité de Néphrologie Pédiatrique, Hôpital Edouard Herriot and Université Claude Bernard, 69437 Lyon. France
HYPERCALCIURIA, PARENTERAL NUTRITION (PN) AND METABOLIC BONE DISEASE (MBD)

Y.Erishberg, A.M.Tershakovec, B.S.Kaplan.

MBD in adults on long-term $P N$ has been widely investigated. The exact mechanism underlying this process has not been determined though

hypercalciuria has been commonly observed. Our aim was to evaluate calcium and bone metabolism in children on long-term PN in whom most of the intake is delivered intravenously overnight. Four persons (3 Eemales; age $7-21 y$ ) were evaluated for 24 hours to monitor temporal changes associated with PN administration. In all persons urinary calcium excretion increased dramatically $(40-60$ fold)

during $P N$ administration and returned to normal $4-6$ hours following its cessation. Hypercalciuria was associated with increased GFR (CCL). Decreased urinary calcium reabsorption was also noted. During PN infusion we observed increased fractional excretion of magnesium but not phosphorus. Serum levels of calcium, phosphorus, magnesium and bicarbonate remained normal. other factors known to effect bone formation such as vitamin D metabolites, PTH, calcitonin, cortisol, TSH, FT4, insulin fluoride, somatomedin $C$ or urinary hydroxyproline did not vary with PN administration. Howeer, urinary aluminum levels were increased in all persons. Renal ultrasound was normal and so was bone mineral density determined by DEXA.

Efforts to monitor and maximize calcium balance are indicated. Though the hypercalciuria may predispose patients receiving $P N$ to MBD, the individuals studied here had normal bone density despito significant hypercalciuria.

Division of Pediatric Nephrology, Shaare Zedek Medizal Center (YF), Jerusalem, Israel and Dept of Pediatrics, CHOP (AT, BSK), Philadelphia, USA. 
P099

URINARY CALCIUM AND OXALATE EXCRETION IN HEALTHY CHLDREN AND PATIENTS WITH HEMATURIA, HYPERCALCIURIA AND RENAL STONIS G. S. Reusz, M. Dobos, D. Byrd, M. Miltényi, T. Tulassay,

Aim of the study: to establish normal values for calcium/creatinine $(\mathrm{Ca} / \mathrm{cr})$ and oxalate/creatinine $(\mathrm{Ox} / \mathrm{cr})$ ratio in infants and children and to compare it to values obtained in patients with haematuria, hypercalciuria and nephrolithiasis.

Patients and methods. Healthy controls: 416 children (aged 1 day-14.5 years). Patients: 137 children with postglomerular baematuria, 27 with nephrolithiasis. Oxalate was measured by ion-chromatography. Nomogramms of Marshall were used to calculate urine saturation to calcium oxalate. Results. $\mathrm{Ca} / \mathrm{cr}$ was normally distributed, $\mathrm{Ox} / \mathrm{cr}$ had lognormal distribution. $\mathrm{Ca} / \mathrm{cr}$ was the lowest in the first days of life, the highest between 7 month -1.5 years (mean $\pm \mathrm{SD}=0.39 \pm 0.28 \mathrm{mmol} / \mathrm{mmol}$ ), a slight decrease could be observed until the age of 14 years $(0.34 \pm 0.18)$. The highest $\mathrm{Ox} / \mathrm{cr}$ values were measured during the first month of life (geometric mean $/$ range $/=133 / 61-280 / \mu \mathrm{mol} / \mathrm{mmol}$ ), followed by gradual decrease until 14 years $(25 / 6-73 /)$. Thirty-six haematuric children had hypercalciuria $(26 \%), 23$ had absorptive, 13 renal subtype. Children with absorptive hypercalciuria on calcium restricted diet had significantly higher oxalate excretion than patients with renal hypercalciuria and the control group (38/28-49/ versus 22/16-29/ and 23/22-27/ respectively, $\mathrm{p}<0.01$ ). Stone patients had higher calcium oxalate urine saturation (Activity product $=A P$ ) than patients with hematuria and the normal population (mean $+\mathrm{SD}=1.18+0.05$ vs $1.06+0.03, \mathrm{p}<0.03$ and $0.84+0.03, \mathrm{p}<0.001$ respectively).

Conclusion. The measurement of $\mathrm{Ca} / \mathrm{cr}$ and $\mathrm{Ox} / \mathrm{cr}$ is suitable for screening of hypercalciuria and hyperoxaluria. The interpretation of the results requires age specific reference values. Both calcium and oxalate determinations should be part of the evaluation of patients with hematuria, hypercalciuria or nephrolithiasis.

First Department of Pediatrics; Semmelweis University, H-1083 Budapest, Bókay u 53, Hungary
P101

HEMOLYTIC UREMTC SYNDROME, CLINTCAL ASPECTS AND OUTCOME OF AN OUTBREAK, REPORT OF 28 CASES

A. Y. Elzouki*, K. Mirza, A. Mahmoud, A. Al-Sowailem

Hemolytic Uremic Syndrame (HUS) characterized by microangiopathic hemolutic anemia, thrombocytopenia and acute renal failure. There are two main sub-groups, the typical form of HUS follows a diarrheal prodrome (D+HUS) and the atypical form without the diarrheal prodrame (D-HUS). We have studied 28 children with Hus over a period of 15 months 1992 - 1993. The median age was 2.2 years (range 6 months-6 years). All children had a prodromal diarrhea, hypertension was present in $11 \%$ neurological complication in $39 \%$. All patients had oliguria or anuria 16 oliguric and 12 anuric, mean duration of anuria 16 days (range 7-42 days). Serum creatinine on admission ranaed between 112-1064 umol/L (mean 453 umol/L). The lowest hemoglobin level and platelet count during hospitalization ranged between $(37-87 \mathrm{~g} / \mathrm{L})$ and $(7-147 \times 10 \times \mathrm{L})$ respectively. Leukocytosis on admission was present in 22 patients, low $\mathrm{C} 3$ was present in 11 patients $(34 \%)$ and 4 patients had low $\mathrm{C4}$. All patients received fresh frozen plasma transfusion, a total of 25 patients received dialysis therapy, 19 patients were treated with peritoneal dialysis (PD) 7 patient with hemodialysis (HD) and 5 patients with bath $H O \& P D$. Mean duration of dialysis 18 days range 3-5.6 days. Only one patient died mortality rate 3\%. The median duration of hospital stay was 28 days range 8-90 days. We conclade that HUS is emerging as an important clinical and public health problem, early comprehensive management including dialysis therapy, aggressive management of hypertension, fresh frozen plasma transfusion, nutritional support improved the outcome and decrease the mortality and morbidity in patient with HUS.

* Maternity \& Children's Hospital

Department of Pediatric Nephrology

P. O. Box 7855

Riyadh 11117 Saudi Arabia
P100

ALKALI THERAPY and MEDULLARY NEPHROCALCINOSIS IN RENAL TUBULAR ACIDOSIS TYPE 1

A.Nayır*, A.Kadıŏlu, A.Sirin, S.Emre,I.Bilge, E.Tonguc,A.Kıyak,F.Tanman

It is generally accepted that in patients with type 1 renal tubular acidosis (dRTA) when alkali therapy is initiated during infancy or early childhood, medullary nephrocalcinosis (MN) is preventable by longterm administration of alkali. The aim of this study is to determine the echographic changes of MN in dRTA patients undergoing alkali therapy.

Fourteen children with dRTA ( 8 girls, 6 boys) aged 1 month to 8 years (median age 9 months) were followed-up for 6 months to 4 years (median 42 months). MN was classified according to Weber (1st degree: normal renal ultrasound, 2nd degree: lightly increased echoes at the apex of medullary renal pyramids, 3rd degree diffusely increased echogenicity of renal pyramids, and 4th degree: high level echoes in the medullary region). When the study began ten patients were classified 3 rd degree and four were 4 th degree.During the follow-up period blood, urine and uitrasonographic determinations were carried out at intervals of 3-6 months. Alkali therapy (1-4 mEq/kg NaHCO3 p.o) was conducted according to need and systemic acidosis was controlled within a period of $1-3$ months. Blood $\mathrm{pH}$ values increased from $7.09 \pm 0.06$ to $7.33 \pm 0.03$ ( $p<0.001$ ), bicarbonate rose from $9.8 \pm 2.98$ to $21.8 \pm$ $2.12(p<0.001)$. Calciuria decreased from $11.2 \pm 2.01 \mathrm{mg} / \mathrm{kg} / 24 \mathrm{~h}$ to $3.46 \pm 0.85 \mathrm{mg} / \mathrm{kg} / 24 \mathrm{~h} \quad(p<0.001)$. In the follow-up period blood bicarbonate and urine calcium levels were in the desired ranges (bicarbonates $20 \mathrm{mEq} /$, urine calcium $<5 \mathrm{mg} / \mathrm{kg} / 24 \mathrm{~h}$ ). Glomerular filtration rate (GFR) was stable and $\mathrm{MN}$ echographic degrees remained unchanged.

Conclusion: In spite of correction of systemic acidosis and hypercalciuria in IRTA, no remarkable change appeared in echographic degree of MN after a four-year follow-up

Istanbul University School of Medicine, 39390, Istanbul,Turkey
P102

HEMOLYTIC UREMIC SYNDROME NOT ASSOCIATED WITH DIARRHEA : D(-) HUS, SINGLE CENTER EXPERIENCE WITH 20 PATIENTS.

W. Proesmans, E. Sercu and L. Goos

The recent paper by Fitzpatrick et al. (J Pediatr 1993) on the most unfavorable experience with $\mathrm{D}(-) \mathrm{HUS}$ prompted us to study our own patients over the period 1969 1993. From the 172 HUS-patients hospitalized in our Unit, 20 (11\%) had no prodromal diarrhea. There were 5 boys and 15 girls. Their age ranged from 5 mo to 14 yrs. They all presented with acute renal failure, acquired hemolytic anemia and thrombocytopenia. Based on the outcome, two subgroups could be identified. Fourteen patients (A) had a complete cure with a follow-up of 10 yrs in 11 of them. The 6 remaining patients (B) did not recover : 3 of them died in the acute phase, 2 went into end stage renal failure and the last one has severe arterial hypertension and mild renal insufficiency. The table gives the characteristics of both subgroups.

$\begin{array}{llll} & \text { GROUP A } & \text { GROUP B } & \\ \text { inumber } & 14 & 5 & \\ \text { age (median) } & 4 \text { yrs } & 4 \text { yrs } 10 \text { mo } & \\ \text { sex }(\mathrm{M} / \mathrm{F}) & 4 / 10 & 1 / 5 & \mathrm{NS} \\ \text { min. } \mathrm{Hb}(\mathrm{g} / \mathrm{dl}) & 6.95 & 5.6 & \mathrm{NS} \\ \text { min. } \mathrm{Plat} .\left(\mathrm{mm}^{3}\right) & 20,000 & 32,000 & \mathrm{NS} \\ \text { WBC }\left(\mathrm{mm}^{3}\right) \text { adm. } & 10,500 & 8,850 & \mathrm{p}=0.2 \\ \text { max. S-creat. }(\mathrm{mg} / \mathrm{dl}) & 1.0 & 5.8 & \mathrm{p}<0.001 \\ \text { hypertension } & 0 / 14 & 5 / 6 & \mathrm{p}<0.001 \\ \text { oligoanuria } & 1 / 14 & 6 / 6 & \mathrm{p}=0.01 \\ \text { dialysis } & 4 / 14 & 6 / 6 & \mathrm{NS} \\ \text { convulsions } & 1 / 14 & 3 / 6 & \mathrm{NS}=0.02 \\ \text { recurrence } & 2 / 14 & 3 / 6 & \mathrm{NS} \\ \text { death acute phase } & 0 / 14 & 3 / 6 & \\ \text { chron. renal. fail. } & 0 / 14 & 2 / 6 & \end{array}$

These results are at variance with most of the recent information published on D(-)HUS. It is therefore important to stress that there is a variant of $\mathrm{D}(-) \mathrm{HUS}$ characterized by a very mild renal course and an excellent outcome. In other words, we should reconsider the recently developed notion that D(-)HUS is a disorder with almost invariably severe course and gloomy outcome.

Renal Unit. Department of Pediatrics. University Hospital Gasthuisberg University of Leuven. B-3000 Leuven. Belgium 
P103

OUTBREAK OF HEMOLYTIC UREMIC SYNDROME (HUS) DUE TO FOOD CONTAMINATION BY VEROTOXIN PRODUCING BACTERIA

G. Deschênes, S. Benoit, J.C. Desenclos, F. Grimont, M. Collin, E. Maillot, S. Baron, P. Mariani, P. Grimont, H Nivet.

Acute HUS in children is mainly due to verotoxin-producing enterobacteria, either sporadic or epidemic. The contaminated food is rarely identified. We observed an outbreak of 4 cases ( 1 girl, 3 boys) from a french village (2000 inhabitants) between March 1992 and May 1993. All cases had prodroms with fever, diarrhea (with blood in 3), then acute renal failure (creatininemia 160 to $320 \mathrm{~mol} / \mathrm{l}$ ), anæmia (hemoglobin : 5 to $10.2 \mathrm{~g} / 100 \mathrm{ml}$ ), schistocytosis (1 to $20 \%$ ) and thrombocytopenia in $3 / 4$ cases (44000 to $75000 / \mathrm{mm} 3)$. Ultrasound examination showed enlarged colon walls (4/4), high renal vascular resistance (4/4) without diastolic flux in 2 cases. Renal biopsy was performed in 2 , revealing glomerular microangiopathy. Peritoneal dialysis was carried out in 3/4 (duration: 3 to 12 days). One child died with neurological complications despite 2 plama exchanges. Three children recovered with normal renal function without proteinuria or hypertension. Verotoxin VT2 gene was identified by polymerase chain reaction in the stools of 2 .

All children had eaten, some days prior diarrhea, a junket made with unpasteurized goat's milk from the same farm. A case control study showed HUS occurrence was linked to the consumption of this milk product $(\mathrm{CI}=95 \%$; odds ratio: $1.8-\infty ; \mathrm{p}=0.006)$. VT 2 gene was isolated from the involved goat's milk product and from the stools of goats and cows of the farm but not from stools of the farm employee. The farmer was then obliged to pasteurize milk.

In conclusion: 1) HUS due to verotoxin could be fatal, 2) milk and milk products have to be pasteurized for children, 3) study of the verotoxin children.

Pædiatric Nephrology Unit. Hôpital de Clocheville F-37044 Tours cedex. FRANCE producing bacteria in livestock could be a way to prevent acute HUS in

P105

A SECOND OUTBREAK OF HAEMOLYTIC-URAEMIC SYNDROME (HUS) IN NORTTERN ITALY.

Tozzi, F. Principato, A. Niccolini, Caprioli, I. Luzzi, G. Zacchello, G. Montini, G. Rizzoni.

During a nationwide surveillance study on tus ongoing since May 1988, two outbreaks occurred in Northern Italy in 0111 has already been reported. This second outbreak occurred, already been reported. This second outbreak accur bed and consisted of 15 cases. They were residents in a area of previous 5 years. Median age was 3.5 years (range 4 mths-10 yrs); prodromal diarrhoea was present in 15 cases and it was bloody in 9. All patients had acute renal failure and 12 needed dialysis. Neurological involvement was observed in 5 cases in the acute phase of Hus. Three months follow-up was available in all patients: 12 cases (808) recovered; 2 were in chronic renal failure and 1 died. Stool and serum samples were collected from $14 / 15$ patients and from 28 household contacts of $9 / 15$ cases. Stools were examined for verotoxin
producing $\mathrm{E}$. Coli (VTEC) isolation and free verotoxin (VT): sera were examined for VT neutralizing antibodies (abs) and for abs to the lipopolysaccharides of three major VTEC serogroups (0157, 0111, 026) by ELISA. Thirteen out of 14 cases had evidence of VTEC infection; 8 by $\mathrm{E}$.Coli 0157,2 by 111 and 1 by 086 ; only 2 relatives showed risk factors for the infection. Two non related age-matehed neighbours were asked about their children's eating habits and exposure to farm animals. The study showed a significant and exposure to farm animals. The study showed a significant association of hus cases with exposure to chicken coops from samples collected from some chickens.

Conclusion: VTEC infection is an emerging problem in Italy considering that two epidemics were reported in the last two years. The importance of a nationwide surveillance system was confirmed in order to identify outbreaks scattering over a large area and over a long period of time. The detection of three VTEC serogroups suggested multiple infections or sources of infection that had, however, been absent in previous years. The exposure to chicken coops could have been a vehicle of VTEC infection. However we cannot exclude that this was an indicator of exposure to other sources of infection associated with living in rural areas. This result has to be investigated further, especially considering that
live poultry has never been identified as a reservoir of VTEC.

Present address: Division of Nephrology and Dialysis, Bambino Gesu' Children's Research Hospital, pias, Bambino Gesu' Children's Research
Sant'onofrio 4 - 00165, Rome - Italy.

P106

P104

HAEMOLYTIC-URAEMIC SYNDROME (HUS) IN CHILDREN: CLNICAL VEROTOXIN PRODUCING E. COLI INFECTION (VTEC). A. Gianviti*, F. Principato, A.E. Tozzi, A. Niccolini, A. Caprioli, I. Luzi, G. Rizzoni.

Eighty-seven HUS patients, 58 VTEC positive $(t)$ and 29 VTEC negative ( - ), were evaluated to assess differences between VTECt and VTEC- cases in terms of clinical presentation and outcome. The following features were considered: age at onset, prodromal diarrhoea (D), the occurrence of acute renal of white blood celis (WBC) and polymorphonuclear cells (PMN) at the onset. VTEC positivity was assessed examining stools for VTEC isolation and free verotoxin (VT). and sera for VT ipopolysaccharides of three major VTEC serogroups (0157 0111,026 ) by ELISA. Patients were evaluated 1 year after the acute phase of Hus. Recovery was defined as creatinine clearance $\geq 80 / \mathrm{ml} / \mathrm{min} / 1,73$ sqm, normal blood pressure, absence Table

$\begin{array}{ccccccccc}\text { Table } & \text { N }(8) & \text { AGE(mo) } & \text { D } & (8) & \text { ARF (8) } & \text { NEU (8) } \\ \text { VTEC }+ & 58 & (67) & 36 & 47 / 57(82) & 55(95) & 25(43) \\ \text { VTEC - } & 29(33) & 44 & 16 / 28(57) & 29(100) & 11(38)\end{array}$
WBC counts were available in 49 VTEC+ and 29 VTEC- cases; PMN counts in 38 VTEC + and 22 VTEC- cases. The mean values were not significantly different between the two groups. (WBC Year follow-up was available in 57 VTEC+ and 28 VTEC- cases.
Forty-five (798) VTEC+ recovered in comparison with 12 (438) VTEC- $(p=0.001)$. VTEC infection was significantly associated with prodromal diarrhoea which has often been reported a good prognostic factor. Therefore we evaluated the effect of VTEC positivity on recovery after 1 year follow-up controlling for infection was correlated with a good outcome (R.R. 0.2 , C.I. $0.1-0.3)$. Conclusion: VTEC positivity was an independent factor significantly associated with a favourable outcome. However VTEC infection was also associated with the presence of $D$ even though $D$ did not influence the outcome. No significant differences were found between VTEC+ and VTECcases in terms of age, ARF, NEU, WBC and PMN at onset. outcome.

Present address: Division of Nephrology and Dialysis Sant'onofrio 4 - 00165 , Rome - Italy.

\section{AN OUTBREAK (10 observations) OF HEMOLYTIC UREMIC SYN- DROME DUE TO O111 B4 VEROCYTOTOXIN-PRODUCING E COLI (VTEC) IN FRANCE : PERSON TO PERSON TRANSMISSION \\ R. Novo *, P. Berquin *, B. Boudailliez *, P. Mariani-Kurkdjian ** E. Malou *, I. Capek *, D. llef *}

Over a 3 months period (sept-dec 1992), 10 children (age 1-5 years $n: 4$ $5-13$ years $n: 6$ ) from the same region ( $10 \mathrm{~km}$ radius in Southern Picardy) developped typical hemolytic uremic syndrome (HUS) : all children expressed prodromal bloody ( $n: 5)$ and non bloody $(n: 5)$ diarrhea, thrombopenia, hemolytic anemia and acute renal failure : 5 out of the ten cases requires dialysis during a mean period of 14 days (range 6-22), one of them presented neurologic involvement treated by plasma exchange. All children survived and recovered normal renal function, but one. A PCR procedure, using two pairs of VT1 and VT2 specific oligonucleotide primers and an internal control, has been used to detect VT genes directly from the patients stools samples. We also studied the stools samples of 14 healthy adults of the children's family. VT2 gene was detected in 7 out of 9 children and in 5 out of 14 adults stools samples. A VT2 producing E. Coli 0111 of the 14 tested.

An epidemiological investigation conducted by a questionnaire suggested a person to person spread : 1) retrospective case-control study showed significant absenteeism rate in school $A$, where the first 4 cases were detected, compared to a control school (odd ratio 2.77 (IC $1.46-5.26$ ) switching to 15 (IC $2.54-115.6$ ) if considering only nursering school). When documented absenteeism was due to gastroenteritis. 2) All food samples from household cultured for VTEC were negative. 3) Retrospective cohort study perfomed in $89 \%$ of children attending school A showed no linkage between beverage or food and gastroenteritis. Such outbreak underline the necessity of information in public health service in order to 1) isolate causal VTEC strain and contaminated foods; 2) organise hygienic steps, even though prescriptions of prophylactic antibiotic seem controversial.

(*) Paediatric Department, CHU Nord, 80054 Amiens,

$\left.{ }^{(*}\right)$ Microbiology Laboratory, Hôpital Robert Debré, 75019 Paris,FRANCE B4 was isolated in 7 children stools out of the 9 and in 3 adults stools out 


\section{P107}

RENAL PATHOLOGY IN FATAL CASES OF DIARRHOEA ASSOCIATED HAEMOLYTIC URAEMIC SYNDROME

A report by the British Association for Paediatric Nephrology: CD Inward, AJ Howie, MM Fitzpatrick, F Raafat, DV Milford, CM Taylor

We reviewed autopsy kidneys of cases of haemolytic uraemic syndrome with a diarrhoeal prodrome (D+HUS) These presented since verocytotoxin producing $\mathrm{E}$ coli (VTEC) emerged as the leading cause of D+HUS. From 18 cases referred, 3 were excluded because of an atypical history. The median duration of illness from the onset of diarrhoea to death was 8 days (range 4-42). All had a systemic neutrophilia (median 21 , range $15-49.8$ $\left.\times 10^{9} / 1\right)$. VTEC infection was confirmed in 6 cases. The 15 cases had relatively uniform pathological features. All had glomerular thromboses to various extents, with conqested rather than ischaemic alomeruli. Arteriolar thromboses were common at tne nilum of glomeruli and sometimes also seen proximally, including in interlobular arteries. There were cortical infarcts in 5 cases with extensive thrombosis. Of the excluded cases, 2 were clearly different from this pattern, with mesangial hypercellularity and double basement membranes, and in one case crescents. Kidney sections from 13 D+HUS cases were stained immunohistologically for the neutrophil markers, neutrophil elastase and CD15. The number of neutrophils per 100 glomerular cross sections were counted and compared with sections from 9 control autopsy kidneys. Neutrophil elastase staining: D+HUS median 929, range 117-1262; controls 156, 17-486 $(p<0.01)$. CD15 staining: D+HUS 587, 34-1271; controls $81,13-328 \quad(p<0.01)$. There was no correlation between peripheral blood neutrophil count and the number of glomerular neutrophils. We show that the pathological features of $D+H U S$ are homogeneous and that the main site of damage is in glomerular capillaries or possibly in glomerular capillaries and hilar arterioles. Neutrophil accumulation in the glomerulus is an important pathological feature.

The Children's Hospital, Birmingham, BI6 8ET, UK

\section{P108}

\section{PLASMA CYTOKINE LEVELS IN THE HEMOLYTIC UREMIC SYNDROME.}

N.A.C.J. van de Kar, R.W. Sauerwein, PNM Demacker, G.E. Grau, V.W.M. van Hinsbergh, L.A.H. Monnens.

The cytokines tumor necrosis factor $\alpha$ (TNF $\alpha)$ and its soluble TNF receptors 55 and 75 (sTNFR55, sTNFR75), interleukin-1 $\beta$ (LL-1 $\beta$ ) and interleukin-6 (IL-6) were measured in the plasma from 13 patients with the hemolytic uremic syndrome (HUS) on admission. No significant changes in the plasma-levels of TNF $\alpha$ and IL- $1 \beta$ were detected in the HUS patients as compared to those levels in the plasma of healthy control children and children with chronic renal failure. Significantly elevated levels of IL-6 were found in the plasma of those four HUS patients, who had extra-renal manifestations, consisting of seizures, loss of consciousness, coma and pancreatic necrosis compared to the HUS patients with only renal problems, who had IL-6 levels below detection level. Although the exact function of IL-6 in the plasma of HUS patients is still unknown and the group of HUS patients is small, plasma IL-6 is associated with the severity and outcome of the disease. Whereas local production of cytokines in the kidney as observed by other investigators appear to be more important in the pathogenesis of HUS than circulating cytokines, circulating cytokines may contribute tot the severity of the disease in patients with extra-renal manifestations. Plasma levels of sTNR55 and sTNFR75 were significantly elevated in all HUS patients compared to the healthy controls, but they were also elevated in the children with chronic renal failure. This indicates that elevated levels of circulating STNFR should be carefully interpreted when kidney failure exist.

Department of Pediatrics, Sint Radboud Hospital, P.O. Box 9101, 6500 HB Nijmegen, The Netherlands.
P109

ACTIVATION OF THE OXIDATIVE BURST OF POLYMORPHONUCLEAR LEUCOCYTES IN THE HAEMOLYTIC URAEMIC SYNDROME (HUS) D.A. Hughes, G.C. Smith, T.J. Beattie, A.V. Murphy, J.E. Davidson

An increased polymorphonuclear leucocyte (PMN) count is associated with a poorer outcome in diarrhoea-associated (D+) HUS. Evidence for the PMN role in pathogenesis includes increased activation as shown by adhesion to cultured endothelial cells, fibronectin degradation and raised serum elastase.

Priming and activation of circulating PMN's was studied in 11 patients with $\mathrm{D}+$ HUS and 10 controls. The oxidative burst of purified PMN's in response to stimulants (FMLP, PMA, opsonized zymosan) was measured by chemoluminescence (CL). Peak CL response (mV) and time to peak were recorded Serum elastase $(\mu \mathrm{g} / \mathrm{L})$, used to confirm PMN activation, was measured in 8 of 11 patients and 33 controls, using an automated immunoassay (IMAC Elastase Merck). Statistical analysis was carried out using a two-sample t-test, assuming

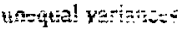

$\begin{array}{llll} & \text { Patients } & \text { Controls } & \text { P } \\ \text { PMN Elastase } & 306.2 & 24.6 & <0.0001 \\ \text { geometric mean }(+2 S D) & (155.4-603.5) & (8.0-75.5) & \end{array}$

Peak CL

mean (range)

FMLP

$48.3(11.6-174)$

- PMA $283(161-392)$

$65.5(18.1-150.1)$

- Zymosan

$428(217-1050)$

$262(129-417)$

NS

$480(307-793)$

There was no difference in times to peak response.

Despite PMN activation, demonstrated by raised serum elastase, the circulating PMN is not in a primed or activated state. These data support the hypothesis that endothelial cell interaction is necessary for PMN activation in the pathogenesis of D+ HUS.

Department of Paediatric Nephrology, Royal Hospital for Sick Children, Yorkhill, Glasgow, G3 8SJ, Scotland

P110

ABDOMINAL ECHOGRAPHIC FINDINGS IN CHILDREN WITH HÆMOLYTIC URAMIC SYNDROME (HUS)

H. Vergeron, G. Deschênes, J. Mocaer, S. Benoit, D. Sirinelli, C. Maurage, H. Nivet

Thirteen children (6 girls, 7 boys) with HUS, aged from 9 months to 7 years, were included in this study. Enterocolitis occurred in all cases, 8 patients presenting with bloody diarrhea. Diagnosis of HUS was based on hemolytic anæmia with schistocytosis in $13 / 13$ patients, thrombocytopenia in $12 / 13$ and acute renal failure in 12/13. Glomerular thrombotic microangiopathy was found on renal biopsy in 3 patients. Eight patients required peritoneal dialysis. One patient died from neurological complications despite 2 plasma exchanges. Ten patients recovered normal renal function, 1 had residual proteinuria and 1 remained in chronic renal failure.

Abdominal ultrasonography was performed in all patients. Thickening of the colon wall was observed in $8 / 13$ patients. Intestinal intussusception was associated with thickening of the colon wall in 4 patients. It occurred 2,3 and 5 days before renal symptoms in 3 children and at the onset of anuria in the fourth patient. Contrast enema confirmed the diagnosis and reduced the intussusception in all 4 cases. Thickening of the colon wall without ultrasound features of intestinal intussusception was observed in 4 other patients at the onset of anuria. In addition, intraperitoneal fluid was observed in 6/9 patients before commencing peritoneal dialysis and was the only abnormal feature in 1 patient. Abdominal ultrasonography was normal in 4 patients.

A colon specimen for histological study was obtained in the patient who died. Thickening of the colon wall with swelling of the submucosa was associated with diffuse ulcerations of the mucosa and fibrinous thrombosis of small vessels. Examination of the small intestine was normal.

In conclusion, 1) colon or peritoneal abnormalities are detected by abdominal ultrasonography in $70 \%$ of patients with HUS, 2) enterocolitis symptoms could be associated with intestinal intussusception.

Prdiatric Nephrology Unit. Hôpital Clocheville F-37044 Tours cedex. FRANCE 


\section{UNUSUAL ASSOCIATION OF ANTI CIQ AND ANTI MPO AUTOANTIBODIES IN A "LUPUS LIKE" FAMILIAL VASCULITIS}

\section{S. PALOMERA, D. SAHALI, B. LEROY, V. FREMEAUX-BACCHI, A. BENSMAN}

We report three siblings (2 boys, I girl) who developed similar multisystemic auto immune disease, including a skin rash, pulmonary haemorrhage and glomerulonephritis. Biological evaluation showed similar abnormalities : circulating immune complexes, with low $\mathrm{C}_{3}$ and hemolytic $\mathrm{C} 4$ and $\mathrm{C} 2$ complement components, an auto antibody directed against the collagen-like region (CLR) of Cla fraction. All showed a genetic deficiency of the $\mathrm{C} 4$ fraction of complement : one null C4 allele in two (C4 BQO) and two null $C 4$ alleles in the older boy. (C4 $A Q O B Q 0$ ). Perinuclear ANCA with ant- MPO specificity were present during the illness and before the cllinical manifestations. Antinuclear and antiglomerula basement membrane antibodies were negative. Cutaneous biopsies showed similar leucocytoclastic vasculitls, with deposits of $\lg M$. $\lg A$ and C3 at he dermalepidermal junction. Renal lesions ranged from focal to diffuse endo and extracapillar proliferation in two.patients Caracteristic voluminous deposits (IgG, Clq, C3) were seen in the arteriolar walls with similar patterns in all children, even in the younger boy who had only mild hematuria and normal renal biopsy on light microscopy.

Despite pulses of methyiprednisolone and cyclophosphamide, the rena conditions of the older boy rapidly worsened. Two years after a cadave renal transplantation there was no flare and his clinical status improved The younger siblings responded well to methylprednisolone pulses. Autoantibodies to the CLR region of Clq have been reported in hypocomplementemic urticariai vasculitis syndrome and in systemic lupus erythematosus with glomerulonephritis. The occurence of both pneumorenal syndrome and anti Clq and anti MPO autoantibodies had not previously been reported to our knowledge. The relationship between pquciimmune ANCA vasculitis and lupus-like disease will be discussed.

Hôpital Armand Trousseau - 7557l PARIS Cédex 12
6 THIOGUANINE INTRA ERYTHROCYTE LEVEL IN TRANSPLANTED CHILDREN UNDERGOING AZATHIOPRINE TREATMENT.

E.Bouissou, S.Billy, B.Martinez C.Gay P.Pouget M.Remesy N.Raynaud G.Houin, Ph Barthe.

Azathioprine (AZA), a widely used immunosuppressive drug in transplantation, has a variable pharmacokinetics ; its main plasmatic metabolite 6 Mercaptopurine (6MP) has a very changeable bioavailability. In kidney transplanted children we have previously found a positive correlation between the $6 \mathrm{MP}$ area under the curve at 3 hours (AUC 3 ) and the clinical immunosuppressive effect. However it is well known that both immunosuppressive and side effects depend of its intra cellular metabolites, mainly 6 Thioguanine (6TGN) which has a longer half-life of several days.

We report our experience with the monitoring of intra erythrocyte 6TGN(E6TGN) in 46 children with a kidney transplant ( mean age : 12 y., 2 to $18 \mathrm{y}$; ; time from transplantation :2 to $10 \mathrm{y}$; triple sequentidi ther apy : ATG, Cyclosporine - SteroidAZA ). E6TGN level ( 81 determinations )was assessed by HPLC (results : picomol / 8. $10^{8}$ red blood cells). A repeat evaluation of 6 TGN has been done in 28 children. The mean level of E6TGN was $168 \pm 15$ pmol for $8.10^{8} \mathrm{RBC}$ ( range 0-522); it did not increase with time, and was remarkably stable if repeated. We did not find any correlation with age, renal function, AZA dose ,plasma - 6 MP kinetics, or hematological parameters.Furthermore we demonstrated a bimodal distribution of E6TGN among the children : a high level group (12 children : $377 \pm 29$ range 251 522) and an other with a "normal" level ( 34 children : $119 \pm 6$ range 0-215; $p=<0.00[$ ). These two groups were not different for age, renal function, time from transplant, hematological parameters, rejection episodes or AZA dose. But the incidence of viral infections or cutaneous wart was higher in the high level group (79\% versus $27 \% \quad \mathrm{p}=0.015$ ) and the children with cutaneous warts exhibited a higher E6TGN concentration ( $224 \pm 32$ vs $139 \pm 17, p=0.013$ ).

These results suggest that E6TGN level could be very useful in transplantation : first to assess the AZA treatment compliance especially in adolescents, and second to prevent the possible long term over immunosuppression and the risk of malignancies which is increased in these patients. Larger studies are necessary to confirm this last point The bimodal distribution in cells could be explained by a difference of enzymatic activity.

Unité de Néphrologie Pédiatrique, Laboratoire

de Pharmacocinétique -CHU PURPAN - 31059 TOULOUSE
P112

MONTTORING OF GRAFT REJECTION DURING THE FIRST MONTH OF TRANSPLANTATION BY COLOR DOPPLER ULTRASOUND.

P. Brun, A. Azancot-Benisty, A. Maisin, Y. Sentou, V. Baudouin, MA. Macher, C. Loirat

A color doppler ultrasound examination was performed in 32 transplanted children (mean age : 11.5 years, $3-20$ ) at day 1 , day 2 , then weekly during the first month of transplantation and in case of rejection episodes. Peak systolic velocity, end diastolic velocity (PSV and EDV, $\mathrm{m} / \mathrm{s}$ ) and resistive index (RI = PSV - EDV/PSV) were measured on main renal artery (RA) and intrarenal arteries (IA). Five patients had an acute tubular necrosis, 10 had acute rejection episodes and 17 had a nomal renal function. Results are indicated in the following table:

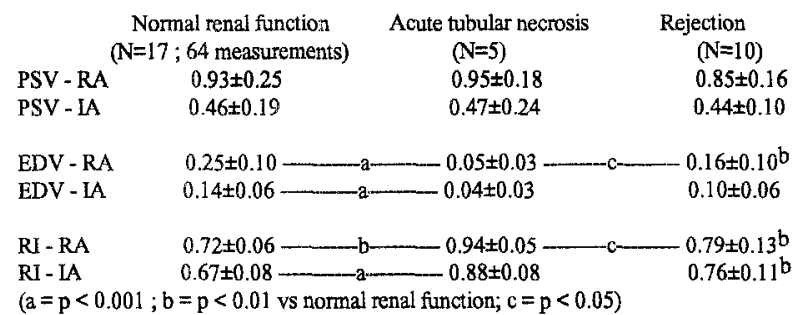

In patients with nomal renal function, no significant changes were observed in the values of PSV, EDV or RI during the first month of transplantation. Patients with acute tubular necrosis and rejection episodes had significantly higher $R I$ in main renal and in intrarenal arteries than patients with normal renal function. Patients with acute tubular necrosis had significantly higher RI than patients with rejection only in main renal artery. During rejection, RI increased in 7 cases, decreased in 2 cases and did not change in 1 case. Reversed flow in diastole were observed in acute tubular necrosis ( 2 cases) and in rejection episodes ( 2 cases). In conclusion, the overlapping of vascular resistance measurements by color doppler ultrasound do not allow a reliable differenciation between acute tubular necrosis and rejection episodes. After duresis recovery, an increase in RI is most often associated with graft rejection, but no change in the RI does not exclude this diagnosis.

Service de Néphrologie, Hopital Robert Debré, 48 Bd Sérurier 75019 Paris, France.
P114

IMMUNOHISTOCHEMICAL STUDY OF ALFA SMOOTH MUSCLE ACTIN AND TGF-BETA IN RENAL BIOPSIES OF KIDNEY TRANSPLANTED CHILDREN. L. Murer, F. Anglani, B. Andreetta, R. Dall'Amico, G. Basso, A. Borsatti, G Zacchello

Interstitial fibrosis is one of more frequent histopathological findings in rena biopsies from long-term renal allografts, as a conseguence of CsA nephrotoxicity, cronich rejection or both. Fibrosis could be seen either as the final result of the repair mechanism of renal damage or as a progressive lesion. TGF-beta induces in fibroblat cell culture an expression of alfa smooth muscie actin (ASMA), wich is an indirect marker of proliferation and extraceliular matrix production. In this study we have investigated the immunohistochemical distribution of ASMA and TGF-beta proteins in renal biopsies of long-term kidney transplanted children. Ripetitive biopsies performed at one and two years after transplantation of 7 patients (2 F.and $5 \mathrm{M}$, mean age $15.2+4 \mathrm{y}$, all CsA treated) were analyzed. Paraffin embedded sections were processed with an immunoperoxidase technique using monoclonal antibodies anti ASMA (Boehringer Mannheim) and anti TGF-beta (Serotec). The intesity and extension of positive immunostaining and the grade of fibrosis was scored semiquantitatively from absent $\theta$ to important $(+++)$. Normal renal tissues obtained from nephrectomies for renal tumors was employed as control. In normal renal tissue fibrosis was absent, and the ASMA and TGF-beta immunostaining was observed only on muscular wall of vessels and vascular endothelium respectively. In kidney transplant biopsies of the first year an interstitial fibrosis was observed in $4 / 7$ cases (2 mild and 2 moderate), an ASMA positivity of interstitial cells in $7 / 7$ (5/7 mild and $2 /$ moderate) and of mesangilal cells in $1 / 7$. A TGF-beta immunostaining was present in glomeruli in 6/7 cases (all moderate), and in tubules and/or interstitium in $4 / 7$ cases. In the second year biopsies fibrosis was present in $6 / 7$ cases ( mild, 3 moderate and 1 severe); alfa-actin positivity becomes moderate in 4 and severe in 1 biopsy with a glomerular staining in $5 / 7$ cases; an increasing of TGFbeta positivity of interstitium and tubules was observed in $5 / 7$ cases. The mean plasma creatinine of the patients was $105.1+50.1 \mathrm{umol} / \mathrm{L}$ and $229.1+244.2$ umol/L at the first and second biopsy respectively. According to our experience, in tranplanted kidney there is an intersitial ASMA positivity and TGF-beta glomerular expression. An enanched ASMA expression went in parallel with the appereance of TGF-beta positivity in interstitium and tubules. An upregulation of these markers expression seems to correlate with the progression of interstitial peritubular and periglomerular fibrosis as well as with the fall of renal function. 
P115

FLOW-CYTOMETRY MONTORING OF ANTLYMPHOCYTES GLOBULIN THERAPY IN PEDIATRIC RENAL TRANSPLANTATION

P. Brun, G. Sterkers, A. Maisin, V. Baudouin, MA. Macher, C. Loirat.

In 35 recipients (mean age : 11.5 years, $3-20$ ) initially treated by prednisone, azathioprine and daily infusion of rabbit antilymphocyte globulin (ALG Fresenius : 22 cases, $2.9 \pm 0.20 \mathrm{mg} / \mathrm{kg} / \mathrm{d}$; ATG Mérieux : 13 cases, $1.4 \pm 0.2$ $\mathrm{mg} / \mathrm{kg} / \mathrm{d}$ ) during $11 \pm 3$ days, total lymphocytes (coulter analysis of full blood count), $\mathrm{CD} 2+\left(\mathrm{T}\right.$ and $\mathrm{NK}$ cell) and $\mathrm{CD}_{3}{ }^{+}$( $\mathrm{T}$ cell) (flow-cytometric analysis, Becton Dickinson) were measured before and during AIG/ATG therapy. Results are shown in the following table:

$\begin{array}{lccccc}\left(\mathrm{N} / \mathrm{mm}^{3}\right) & \text { Pre- Tx } & \text { day } 1 & \text { day 2-3 } & \text { day 6-8 } & \text { day } 10-11 \\ & & & & & \\ \text { Lympho } & 3000 \pm 1040 & 470 \pm 340 & 460 \pm 270 & 810 \pm 500 & 780 \pm 460 \\ \mathrm{CD}_{2}^{+} & 2380 \pm 780 & 210 \pm 150 & 140 \pm 90 & 270 \pm 230 & 160 \pm 130 \\ \mathrm{CD}{ }_{3}^{+} & 232 n \pm 750 & 170 \pm 130 & 110 \pm 80 & 235 \pm 230 & 160 \pm 120\end{array}$

Twenty one children experienced one or more rejection episodes at $76 \pm 57$ days ( $5 \mathrm{~d}-6$ months). The lowest $\mathrm{CD}_{2}{ }^{+}$and $\mathrm{CD}_{3}{ }^{+}$cell counts were observed at $4 \pm 3$ days post-Tx and were significantly higher in patients who experienced rejection episodes in comparison with those who did not $\left(\mathrm{CD}_{2}^{+}: 144 \pm 128 / \mathrm{mm}^{3}\right.$ vs $59 \pm$ $40 / \mathrm{mm}^{3}, \mathrm{p}=0.03 ; \mathrm{CD}_{3}^{+}: 122 \pm 120 / \mathrm{mm}^{3}$ vs $\left.47 \pm 32 / \mathrm{mm}^{3}, \mathrm{p}=0.04\right)$. The lowest total lymphocyte cell counts, observed at $3 \pm 3$ days post-Tx, were not different between the 2 groups $\left(438 \pm 331 / \mathrm{mm}^{3}\right.$ vs $\left.295 \pm 185 / \mathrm{mm}^{3}\right)$. Twelve patients experienced 13 opportunistic infections with a favorable outcome (cytomegalovinus : 7 , pneumocystis carinii : 4 , legionella : 1, varicella zoster : 1 ). Comparison of patients with or without opportunistic infections showed that the number of total lymphocytes was similar in the 2 groups $\left(393 \pm 280 / \mathrm{mm}^{3}\right.$ vs 323 $\pm 240 / \mathrm{mm}^{3}$ ), whereas $\mathrm{CD}_{2}{ }^{+}$and $\mathrm{CD}_{3}{ }^{+}$cell counts were higher, although not significantly, in the infected patient group (CD2:131 $\pm 133 / \mathrm{mm}^{3}$ vs $83 \pm$ $59 / \mathrm{mm}^{3}, \mathrm{CD} 3: 107 \pm 129 / \mathrm{mm}^{3}$ vs $69 \pm 52 / \mathrm{mm}^{3}$ ). Nine of these patients had experienced a rejection episode leading to reinforcement of immunosuppressive regimen before the infectious complication. In conciusion, count of $\mathrm{CD}_{2}{ }^{+}$or $\mathrm{CD}_{3}{ }^{+}$cells is a more accurate method for monitoring ALG/ATG therapy than total peripheral lymphocyte counts. Adaptation of antilymphocyte globulin dosage to maintain $\mathrm{CD}_{2}{ }^{+}$or $\mathrm{CD}_{3}{ }^{+} \mathrm{T}$ cell around or below 50 cells $/ \mathrm{mm}^{3}$ appears warranted in order to optimize the efficiency of this treatment.

Service de Néphrologie,Hopital Robert Debré 48 Bd Sẻnurier75019 Paris,France.

P116

CYCLOSPORINE NEPHROTOXICITY IN CHILDREN: A COMPARISON OF RENAL AND LIVER TRANSPLANT RECIPIENTS

C. Holmberg, J. Laine, H. Jalanko, K. Rönnbolm, L. Krogerus, F. Fyhrquist, K Höckerstedt, and M. Leijala

Cyclosporine A (CsA) is potentially nephrotoxic for all solid organ transplant recipients. We prospectively investigated renal function and histopathology in 45 renal (RT) and 16 liver transplanted (LT) children during 3 years after transplantation (Tx) (median age at LT $5.4 \mathrm{yrs}$, at RT 2.7 yrs). Both groups were on triple immunosuppression (CsA+Aza+MP) CsA target concentrations were $200-300 \mu \mathrm{g} / \mathrm{L}$ at Tx and 50-100 after 6 months in RT and $500-600 \mu \mathrm{g} / \mathrm{L}$ at Tx and $100-200 \mu \mathrm{g} / \mathrm{L}$ after 1 year in LT children. CsA was administered in 3 doses/day to pre-school children. 51C-EDTA- PAH-, lithium- and sodium clearances, measurements of serum and urinary electrolytes, and maximal urinary concentrating capacity tests were performed. Protocol kidney biopsies were taken at 18 and at 36 months. In $L T$ recipients the mean GFR was $121.5 \mathrm{ml} / \mathrm{min} / 1.73 \mathrm{~m} 2$ before $\mathrm{Tx}$ 86.3 at discharge and 119.4 after 36 months. In RT recipients mean GFR was $73.0 \mathrm{ml}$ $\mathrm{min} / 1.73 \mathrm{~m}^{2}$ at discharge. It remaincd stable and was $77.7 \mathrm{ml} / \mathrm{min} / 1.73 \mathrm{~m}^{2}$ after 3 ycars. The mean renal plasma flow was stable in both groups ranging between 433 and 611 $\mathrm{ml} / \mathrm{min} / 1.73 \mathrm{~m} 2$ in LT and between 337 and $387 \mathrm{ml} / \mathrm{min} / 1.73 \mathrm{~m}^{2}$ in RT recipients. The most common abnormalities in tubular function were hyperuricemia, hyperkalemia and decreased urinary concentrating capacity (incidences $53 \%, 18 \%$ and $83 \%$, respectively, at 36 months in RT children). The patients with hyperkalemia received significantly higher CsA doses than the normokalemic patients (mean dose 20.5 vs $10.2 \mathrm{mg} / \mathrm{kg} / \mathrm{d}, \mathrm{p}<0.01$ ). In LT recipients hyperkalemia occurred in 13-19\% during the first 6 months only. Hyperuricemia and decreased concentrating capacity occurred constantly during follow-up with incidences of $17-44 \%$ and $40-63 \%$, respectively. In neither RT nor LT recipients could histopathological diagnosis of CsA nephrotoxicity be made. However, focal fibrosis, tubular epithelial atrophy, mesangial matrix increase and mesangial cell proliferation were common in both groups.

In conclusion, severe or progressive CsA nephrotoxicity did not occur in either RT or LT recipients. Mild functional CsA nephrotoxicity manifesting as hyperuricemia, hyperkalemia, and decreased urinary concentrating capacity was relatively common, especially after renal Tx. In LT children this occurred predominantly during the first 6 months after Tx. Renal effects of CsA seem to be potentiated by immunologic and ischemic factors related to renal $\mathrm{Tx}$.

Children's Hospital, University of Helsinki, Stenbäckinkatu 11, FIN-00290, Helsinki, FINLAND

\section{P117 \\ CONVERSION FROM SANDIMMUN $\circledast$ TO A NEW ORAL FORMULA- TION OF CSA IN PAEDIATRIC RENAL TRANSPLANT RECIPIENTS A. Bökenkamp, B. Enke, G. Otfner, P.F. Hoyer and K. Wonigeit*}

Background: The use of Cyclosporine A (CSA) has significantly improved the outcome of renal transplantation. Absorption of the initial formulation of CSA (Sandimmun $\odot$ ) requires the presence of bile and shows great variablility with concomitant food intake. Recently, a new oral formulation of CSA (Sandimmun Optoral $($ ) ) with a more predictible pattern of absorption has become available.

Aim of the study: What is the conversion dose from Sandimmune to Optoral $\Theta$ in paediatric renal transplant recipients? Does conversion to Optoralie reduce CSA trough level variation in children with excessive trough level variability under Sandimmun $B$ ?

Patients and methods: 9 paediatric renal transplant recipients without concomitant liver disease (age $15.7 \pm 5.8$ years, time post transplantation $4.1 \pm 1.8$ years) are currently switched from Sandimmun(e) to Optoral(B). Conversion is done on a 1:1 basis. Before conversion, these children had had at least three unexplained variations of trough level of more than 50 $\mathrm{ng} / \mathrm{mi}$ on 12 consecutive outpatient controls. CSA whole blood levels were measured with an EMIT immunoassay with a target range of 80 to 120 $\mathrm{ng} / \mathrm{ml}$ in this group of patients. The study protocol includes CSA absorption profiles before and after switch to Optoral $\otimes$, studies on bile acid resorption and an evaluation of food intake. After conversion to Optoral $\circledast$, the variability of CSA trough levels will be re-assessed.

Results: Resorption kinetics in the first 5 patients show greater bioavailability with less variation with Optoral $($ compared to Sandimmun $Q$ : With Optorale, a mean peak level of $830 \mathrm{ng} / \mathrm{ml}$ (range 672 - 984) was found after 1 to 2 hours. With Sandimmun $\Theta$, this was $283 \mathrm{ng} / \mathrm{ml}$ (range 89 to 507 ), the peak level was observed after 4 to 8 hours post ingestion. In 3 of the 5 patients, peak levels did not exceed $200 \mathrm{ng} / \mathrm{ml}$.

Conclusion: In some renal transplant recipients with excessive trough level variability under Sandimmune this may be due to impaired resorption of CSA in this formulation. Whether the improved bioavailability of Optoral(B) in these patients diminishes trough level variation is currently being investigated.

Kinderklinik, Medizinische Hochschule Hannover, 30623 Hannover, FRC

* Abteilung Abdominal- und Transplantationschirurgie, Medizinische Hochschule Hannover, 30623 Hannover, FRG

P118

NITROGEN BALANCE AND ANTHROPOMETRIC PARAMETERS IN CHILDREN WITH RENAL TRANSPLANTS ON CYCLOSPORINE A ALONE

L. Ghio *, M. Picca, M. Giani, D. Colombo, F. Marchesi, B. Damiani, A. Tarantino, A. Edefonti

Altered body composition with decreased muscle mass has been described in renal transplanted adult patients maintained on Cyclosporine A (CsA). Negative nitrogen balance $(\mathrm{Nb})$ and decreased muscle mass are probably related to corticosteroids (Cs) and have been reported in children with renal transplants $(\mathrm{Tx})$. No data are available on nutritional parameters of children treated with CsA alone.

Eight children, mean age $11.5 \pm 1.7 \mathrm{yr}$, mean follow-up after $\mathrm{Tx} 1.6 \pm 0.7 \mathrm{yr}$ Eight chiddren, mean age $11.5 \pm 1.7 \mathrm{yr}$, mean follow-up after $\mathrm{Tx} 1.6 \pm 0.7 \mathrm{yr}$,
mean weight $30.2 \pm 5.9 \mathrm{Kg}$, treated with $\mathrm{CsA}$ alone for $10.7 \pm 7.4 \mathrm{mo}$, with normal renal function (creatinine clearance $82.1 \pm 15.9 \mathrm{~m} / \mathrm{min} / 1.73 \mathrm{sqm}$ ), were studied while on a free diet. Protein (DPI) and caloric intake (Cal), $\mathrm{Nb}$, urea nitrogen appearance (UNA) and anthropometric measurements (height standard deviation score $=$ HSDS, arm fat area $=$ AFA, mid arm muscie circumierence = MAMC) were evaluated al transplantation and at the time of the study.

Results:

$\begin{array}{cccc}\begin{array}{c}\text { DPI } \\ (\% \text { RDA })\end{array} & \begin{array}{c}\text { Cal } \\ (\% \text { RDA })\end{array} & \begin{array}{c}\text { UNA } \\ (\mathrm{mg} / \mathrm{min})\end{array} & \begin{array}{c}\mathrm{Nb} \\ (\mathrm{mg} / \mathrm{kg} / \mathrm{day})\end{array} \\ 192.3 \pm 43.5 & 80.9 \pm 20.2 & 3.77 \pm 0.29 & 68.6 \pm 45.9\end{array}$

A direct correlation was found between $\mathrm{DPl}$ and $\mathrm{Nb}(\mathrm{r}=0.878 ; \mathrm{p}=0.001)$. $\mathrm{Nb}$ was zero at $108.94 \%$ recommended daily allowance (RDA) of DPI. HSDS improved after Tx $(p=0.025)$ as did MAMC $(p=0.366)$ and AFA $(p=0.102)$

In conclusion, children with normal post-Tx renal function treated with CsA alone showed a positive $\mathrm{Nb}$ and an improvement of anthropometric parameters but $\mathrm{DP}$ had to be higher than $110 \%$ RDA to obtain a positive $\mathrm{Nb}$ and to avoid the risk of malnutrition. This data underlines the need for trying to utilize CsA as sole immunosuppressive agent in children with renal $T x$

*Present address: Pediatric Dialysis Unit, Department of Pediatrics II, University of Milan, via Commenda, $9-20122$ Milan, italy (FAX n $2-55195341)$ 
P119

BONE MINERAL DENSITY IN CHILDREN BEFORE AND DURING TWO YEARS AFTER RENAL TRANSPLANTATION J Feber*, P Cochat, P Braillon, C Glastre, L David, PJ Meunier

Successful renal transplantation is supposed to correct the majority of bone mineral metabolism disturbances induced by chronic renal failure. We examined bone mineral density (BMD) in 14 children ( 8 girls) aged $8 \pm 4$ years at the time of renal transplantation (Tx). Dual energy $\mathrm{X}$-ray densitometry of lumbar vertebrae $\left(\mathrm{L}_{1}-\mathrm{L}_{4}\right)$ was performed within one year preceding $T x\left(M_{0}\right), 6,12$ and 24 months after Tx $\left(M_{6}, M_{12}\right.$ and $M_{24}$, respectively). The results of $B M D$ obtained in $g$ of hydroxyapatite per $\mathrm{cm}^{2}$ of spine projected area were subsequently transformed to $\mathrm{Z}$ scores $(\mathrm{Z})$ for normal paediatric population. All patients had a well functioning renal graft at $\mathrm{M}_{6} . \mathrm{M}_{12}$ and $\mathrm{M}_{24}$, median serum creatinine levels were 54,63 and $84 \mu \mathrm{mol} / \mathrm{L}$, respectively. $\mathrm{BMD} \pm \mathrm{SD}$ decreased from initial level of $0.65 \pm 0.18$ at $\mathrm{M}_{0}$ to $0.59 \pm 0.16$ at $\mathrm{M}_{6}(\mathrm{p}<0.05)$. BMD ( $\pm \mathrm{SD}$ ) measured at $\mathrm{M}_{12}$ $(0.61 \pm 0.15)$ and $\mathrm{M}_{24}(0.67 \pm 0.16)$ was not significantly different from $\mathrm{M}_{0}$. Similar significant $(\mathrm{p}<0.01$ ) decrease of $\mathrm{BMD}$ expressed in median $\mathrm{Z}$ was observed between $\mathrm{M}_{0}(0.192)$ and $\mathrm{M}_{6}(-1.04)$, remained significantly $(p<0.01)$ lower at $\mathrm{M}_{12}(-0,93)$ and increased to -0.52 at $\mathrm{M}_{24}\left(\mathrm{p}<0.05\right.$ vs $\left.\mathrm{M}_{0}\right)$. A negative correlation was found between cumulative prednisone dose and BMD in $\mathrm{g} / \mathrm{cm}^{2}$ at $\mathrm{M}_{6}\left(\mathrm{r}^{2}=\right.$ $0.603, p<0.08), M_{12}\left(r^{2}=0.532, p<0.05\right)$ and $M_{24}\left(r^{2}=0.40, p<\right.$ $0.05)$. There was no correlation between cumulative prednisone dose and Z. Mean 6-month cyclosporine trough levels did not correlated with any of BMD expressions.

In conclusion, children after kidney transplantation experienced a significant decrease of bone mineral density during the first 6 months after operation despite normal graft function. Progressive improvement of BMD was noted 12 and 24 months after transplantation.

Department of Paediatrics, Edouard Herriot Hospital, Lyon, France

*1st Paediatric Clinic, Hospital Motol, Prague, Czech Republic

P120

ROLE OF THE DONOR IN THE POST TRANSPLANT RENAL FUNCTION

L Dubourg*, P Cochat, A Hadj-Aïssa, B Parchoux, X Martin, L David

The donor - i.e. cadaver (CD) or living related (LD), large or small size - might influence the outcome of the graft function. The GFR of 78 patients (age : mean \pm SD 10.4 \pm 4.9 , range $0.7-23.3$ ) has been

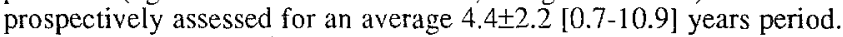
The patients were divided into 2 groups according to the donor: LD $(n=17)$ and $C D(n=61)$; the CD group was further divided into 2 subgroups regarding the donor size to recipient size ratio : $C D 1$ (ratio $<1, n=30$ ) and $\mathrm{CD} 2$ (ratio $>1, n=17$ ). The GFR was assessed by Cin at $3(\mathrm{M} 3, \mathrm{n}=59), 6(\mathrm{M} 6, \mathrm{n}=68), 12(\mathrm{M} 12, \mathrm{n}=64), 24(\mathrm{M} 24, \mathrm{n}=55), 36$ $(\mathrm{M} 36, \mathrm{n}=44), 48(\mathrm{M} 48, \mathrm{n}=31)$ and $60(\mathrm{M} 60, \mathrm{n}=17)$ months post transplant. The mean \pm SD GFR $\left(\mathrm{ml} / \mathrm{min} .1 .73 \mathrm{~m}^{2}\right)$ was $68.9 \pm 25.6$ at M3, $70.8 \pm 23.2$ at M6, $73.9 \pm 23.1$ at M12 and $73.0 \pm 22.9$ at M24. The GFR was not different between LD and $C D$ at $M_{3}(78.2 \pm 22.2$ and $66.6 \pm 26.1$, respectively). The GFR of CD improved significantly between $\mathrm{M} 3$ and $\mathrm{M} 6(66.6 \pm 26.1$ and $73.5 \pm 22.1$, respectively, $\mathrm{p}=0.01)$ and was higher than that of LD after M12 (76.7 123.5 and $62.1 \pm 17.2$ at $\mathrm{M} 24$, respectively, $\mathrm{p}=0.02$ ). The GFR was lower in $\mathrm{CD} 1$ compared to $\mathrm{CD}_{2}$ at $\mathrm{M} 33(59.3 \pm 20.6$ and $79.4 \pm 30.4$, respectively, $\mathrm{p}=0.01)$ but there was no longer any difference at $\mathrm{M} 6$ and afterwards. The absolute GFR was comparable in both subgroups at $\mathrm{M}_{3}$ and became significantly higher in the CD1 subgroup at M6, suggesting a functional adaptation of the graft to the recipient's condition.

These results show that the GFR of kidney transplant children is independent from the type of donor - cadaver or living related during the early postoperative period. In the long term, 1) a progressive decrease in GFR was noted in living donor recipients ; 2) it is suggested that the small size of the graft in cadaver transplant recipients has no deleterious effect since GFR improves more rapidly in those patients and reaches adjusted GFR comparable to patients who received a graft from cadaver donors of larger size.

* Unité de Néphrologie Pédiatrique, Hôpital Edouard Herriot and Université Claude Bernard, 69437 Lyon, France.

\section{P121}

\section{AMBULATORY BLOOD PRESSURE (ABPM) PROFILES IN TRANSPLANTED PAEDIATRIC PATIENTS N Lingens, E Dobos, $K$ Schärer}

ABPM profiles during 24 hours were applied in 27 paediatric patients (pts) aged 6,3 to 24,3 (median 15,6) years who had been transplanted (TX) $1,5-8,4(4,3)$ years previously. ABPM data were analysed for 24 hours fluctuations. ABPM day-time values were compared with the mean of 10 concomitant casual BP recordings. Antihypertensive therapy was scored by the number and dosing of drugs. Renal function was determined by single-injection-inulin clearance (CIN, median 66, range $18-116 \mathrm{ml} / \mathrm{min} / 1,73 \mathrm{~m}^{2}$ ). Immunosuppressive therapy was analysed additionally. ABPM confirmed hypertension or normotension measured by casual BP recordings in $74 \%$ of pts. The physiological nocturnal drop of BP was attenuated $(<10 \%)$ or reversed in $12 / 27$ pts. No relation was found between nocturnal drop and CIN. Renal artery stenosis was detected in $3 / 8$ hypertensive pts with a reduced nocturnal drop but never with a drop $>10 \%$. Antihypertensive therapy given to $67 \%$ at the time of ABPM correlated with cumulative prednisolone dose $(r=0,47)$ and with $\operatorname{CIN}(r=$ $-0,37, p=0,06$ ) but not with the mean cyclosporin (CsA) dose and plasma levels. We conclude that in paediatric pts transplanted for $>1,5$ years casual $\mathrm{BP}$ recordings do not well reflect BP as assessed by ABPM. The nocturnal drop is attenuated in $44 \%$ of pts and may be a sign of renal artery stenosis, chronic rejection or recurrent disease. Antihypertensive therapy is related to the cumulative steroid dose but less to renal function and not to the dose and plasma level of CsA.

Division of Paediatric Nephrology, University Children's Hospital, INF 150, 69120 Heidelberg, Germany

P122

AMBULATORY BLOOD PRESSURE MONITORING IN CHILDREN AND YOUNG ADULTS AFTER RENAL TRANSPLANTATION F. Krull, A. Hegerhorst, P.F. Hoyer and G. Offner

24-hour ambulatory blood pressure monitoring was performed in a group of 88 patients ( 43 female, 45 male, median age 16 years, range $5.5-26$ ) after renal transplantation. Immunosuppression consisted of prednisolone and additional cyclosporine or azathioprine or a combination of all three drugs. Median creatinine clearance was $49 \mathrm{ml} / \mathrm{min} / 1.73$ sqm (range 7.5 129). 76 of these patients were on antihypertensive therapy, 63 of them receiving a combination of 2 or more antihypertensive drugs. Mean blood pressure was $128 \pm 12 / 81 \pm 10 \mathrm{~mm} \mathrm{Hg}$ at daytime and 121 $\pm 13 / 73 \pm 12 \mathrm{~mm} \mathrm{Hg}$ at night. Only 31 of the patients had a physiviogicai circauian patien wiiiı a normal úrop oi systuiic and diastolic blood pressure at night. 12 children revealed a paradox blood pressure profile with elevated values at night. Circadian blood pressure variation showed no relation to renal function and antihypertensive treatment. The incidence of target organ damage, i.e. cardiac hypertrophy and hypertensive retinopathy, correlated with elevated blood pressure levels at day and at night and with a decreased drop of blood pressure at night, but showed no correlation to casual blood pressure values. As a consequense of ambulatory blood pressure monitoring antihypertensive medication was changed in 27 patients.

Ambulatory blood pressure monitoring gives new insight into the individual cardiovascular risk of hypertensive patients after renal transplantation and should be performed in all of them.

Kinderklinik Medizinische Hochschule Hannover, Konstanty-Gutschow Str. 8

D30625 Hannover, FRG 
P123

NEPHROPROTECTION: IMPROVENENT OF ORGAN PRESERVATION SOLUTIONS BY TAURINE

P. Wingenfeld ${ }^{1}$, T. Minor ${ }^{2}$, S. Strübind ${ }^{1}$, U. Gehrmann ${ }^{1}$, W. Isselhard ${ }^{2}$ and D. Michalk

A cell culture model was used to study, if organ preservation solutions like the university of wisconsin (JW) or the Euro Collins solution (BC) could be inproved by the addition of the amino acid taurine $(T)$, a physiological osmo- and calciumregulator and free radical scavenger. In order to sivulate the conditions of renal transplantation proximal renal tubular cells (LLC PR 1 ) were cultured aerobically $\left(37^{\circ} \mathrm{C}, \mathrm{pO}_{2} 140 \mathrm{mufig}\right.$ 48 hours), then stored hypoxically in uw or EC supplemented with different taurine concentrations ( $\mathrm{BC} 0.5-1$; UW $1-10 \mathrm{mmol} / 1$ ) for different tine courses (UW: 9,21 EC: 5,7 hours; $\left.\mathrm{pO}_{2}<8 \mathrm{mmHg}, 4^{\circ} \mathrm{C}\right)$ ) and afterwards reoxygenated again $\left(30 \mathrm{~min}, \mathrm{pO}_{2} 140\right.$ $\mathrm{mmHg}, 36^{\circ} \mathrm{C}$. After each experimental period we determined the percentage of remaining cells and measured viability by trypan blue exclusion test. The product of both parameters was regarded as survival index. Additionally the leakage of lactate dehydrogenase (LDH) was measured in the supernatant of the cultures and the high energy phosphate content (ATP, ADP, AMP) of the cells was determined.

\begin{tabular}{|c|c|c|c|c|c|c|}
\hline \multirow{2}{*}{$\begin{array}{l}\text { Results: } \\
\text { Hypoxia }\end{array}$} & $T+$ & $\mathrm{T}+$ & $\mathrm{T}-$ & $\mathrm{T}+$ & T- & $\mathrm{Tt}$ \\
\hline & $\begin{array}{l}\text { remaining } \\
\text { cells }\left[\begin{array}{l}0 \\
6\end{array}\right]\end{array}$ & $\begin{array}{c}\text { Viability } \\
{[\because[3]}\end{array}$ & \multicolumn{2}{|c|}{$\begin{array}{l}\text { survival index } \\
{[0 \times 5] \times 10^{3}}\end{array}$} & \multicolumn{2}{|c|}{$\begin{array}{c}\text { LDH leakage } \\
{[\mathrm{U} / \mathrm{l}]}\end{array}$} \\
\hline $5 \mathrm{~h} \mathrm{EC}$ & $58-71$ & $61-76 c$ & 3.44 & $-5.33 \mathrm{~b}$ & 24.8 & $-15.2 \mathrm{a}$ \\
\hline $7 \mathrm{~h} \mathrm{EC}$ & $57-93 a$ & $46-62 b$ & 2.78 & $-5.84 b$ & 41.3 & $-33.5 b$ \\
\hline $9 \mathrm{~h} \mathrm{dW}$ & $68-100 b$ & $89-91$ & 5.99 & $-9.01 b$ & 11.3 & $4.2 \mathrm{~b}$ \\
\hline $21 \mathrm{~h}$ ow & $69-87 a$ & $84-91 c$ & 5.76 & $-7.96 \mathrm{~b}$ & 14.1 & $-4.9 \mathrm{C}$ \\
\hline \multicolumn{5}{|c|}{ Recovery after bypoxia and reoxygenation } & \multicolumn{2}{|c|}{ RTP content } \\
\hline $5 \mathrm{~h} \mathrm{EC}$ & $93-131 a$ & $96-96$ & 8.03 & $-10.68 a$ & 38 & $57 \mathrm{a}$ \\
\hline $7 \mathrm{~b}$ EC & $83-120 b$ & $91-95 a$ & 8.18 & $-11.41 a$ & 37 & $63 \mathrm{~b}$ \\
\hline $9 \mathrm{~h} \mathrm{WW}$ & $94-147 b$ & $96-97$ & 8.95 & $-14.25 \mathrm{~b}$ & 20 & - 50 a \\
\hline & $85-94$ & $96-95$ & 8.01 & $-9.00 \mathrm{a}$ & 34 & $-59 a$ \\
\hline
\end{tabular}

Taurine inproved the viability and the survival index of the cells after hypoxia and reduced the loss of the intracellular enzye during hypoxia. Posthypoxic outcome an the energy metabolism were significantly inproved. The most efficient taurine concentration depended on the used solution and the duration of hypoxia. For longer preservation times higher concentrations were needed. The taurine induced protective effect overlasted the period of hypoxia and lead to a markedly improved posthypoxic recover of the cultures and their energy metabolism.

Department of Pediatrics ${ }^{2}$ and Institute for Experimental Medicine ${ }^{2}$

University of Cologne, Joseph Stelzmann Strasse 9, D-50924 Cologne, FRG

\section{P124}

\section{KIDNEY TRANSPLANTATION IN COLLAGEN TYPE III GLOMERULOPATHY \\ L.MARTINAT,A.AUVRIGNON,D.SAHALI,S.PALOMERA,A. BENSMAN}

Anti-GBM antibody nephritis and loss of allografts have been reported following renal transplantation of Alport's patients. But little data are available on the graft outcome of other complex GBM diseases such as collagen type III glomerulopathy.

We report two siblings from consanguineous kindred who underwent renal allografts, for one of whom we have a five year follow. Protelnuric without hematuria was detected when the children were three month old and both of them developed a steroid resistant nephrotic syndrome before the age of 12 months. Renal biopsies showed similar morphological findings with a diffuse expansion of the mesangia matrlx and widening of capillary walls. Electron microscopy revealed an accumulation of fibrillar collagen. in the lamina rara interna and mesangial matrix, identified by immunohistochemistry os type III collagen (Dr MC. Gubler). This morphology is reminiscent of nail patello syndrome (NPS) nephropathy, but the lack of extrarenal signs of the NPS series and the integrity of the lamina densa preclude this. They developed terminal renal failure 6 and 15 years after the onset of proteinuria. Two years after starting hemodialysis,both children were given renal allografts from cadaver donors. The sister experienced two interstital acute rejection episodes,both steroid responsive, 1 and 22 months after the transplantation. Her brother has free of rejection to time. Clinical evaluation relevant to ultimate outcome of graft showed no proteinuria or hematuria. Their serum creatinine levels were 80 and 140 micromol per liter, respectively.

In conclusion, the prognosis of kidney transplantation in collagen type III glomerulopathy seems excellent. The fear of the occurence de novo of autoimmune process such as anti GBM antibody disease was not confirmed by our experience.

Hôpital Armand TROUSSEAU, 75571 PARIS CEDEX 12
$\mathrm{P} \uparrow 25$

FOLLOW-UP OF RENAL FUNCTION IN CHILDREN WITH ORTHOTOPIC LIVER

M.H. Yntema-Kalff, W.Chr.C. Reitsma-Bierens*, M.J.H. Slooff, C.M.A. Bijleveld.

Renal function was studied in 41 consecutive OLT patients who survived the postoperative period for at least one year. Of them 19 were girls and 22 boys. Mean age at time of transplantation was 4.1 year ( 4 months - 15.8 years). All patients were treated with quadruple immunosuppressive therapy. Cyclosporine $A(C y A)$ was started from day two onwards, but only if the creatinine clearance was above $50 \mathrm{ml} / \mathrm{min} / 1.73 \mathrm{~m}^{2}$. The first four weeks CyA trough levels were maintained between $200-250 \mathrm{ng} / \mathrm{ml}$, thereafter between 100 200 (HPLC). According to the protocol CyA was stopped two years after OLT; in 6 children earlier because of serious renal $(n=3)$ or cerebral $(n=3)$ side-effects, in 3 children CyA was continued beyond two years because of recurrent rejection Glomerular filtration rate (GFR) and effective renal plasma flow (ERPF) were measured by means of a continuous infusion technique with iothalamate$\mathrm{J}^{125} /$ hippuran- ${ }^{131(1)}$. Results mean \pm SEM in $\mathrm{ml} / \mathrm{min} / 1.73 \mathrm{~m}^{2}$ were as follows:

$\begin{array}{llll} & 1 \text { ycar after OLT } & 2 \text { ycar after OLT } & 3 \text { year after OT } ? \\ \text { GFR }(90-145)^{* *} & 119 \pm 8(n=41) & 114 \pm 9(n=27) & 141 \pm 14(n=16) \\ \text { ERPF }(327-679)^{* *} & 571 \pm 38(n=41) & 572 \pm 44(n=27) & 645 \pm 46(n=16) \\ \text { CyA }(\mathrm{mg} / \mathrm{kg} / \mathrm{dg}) & 9.6 \pm 0.7(n=39) & 7.7 \pm 0.7(n=21) & 6.6 \pm 1.1(n=3)\end{array}$

CyA $(\mathrm{mg} / \mathrm{kg} / \mathrm{dg}) \quad 9.6 \pm 0.7(\mathrm{n}=39) \quad 7.7 \pm 0.7(\mathrm{n}=21) \quad 6.6 \pm 1.1(\mathrm{n}=3)$

\section{** normal range}

Mean values of GFR and ERPF remained normal up to 3 years after OLT. However 9 children (22\%) had a decreased GFR after one year (mean $67 \pm 5$ ) persisting in 8 during the follow-up period. In 32 out of 41 children GFR and ERPF were measured preoperatively. GFR was normal (mean $132 \pm 11$ ), ERPF was increased (mean $689 \pm 58$ ). Of those 32 patients, 9 had a decreased GFR before OLT (mean $67 \pm 3$ ), 8 of them recovering to normal values thereafter. There was no significant difference in mean values of GFR and ERPF in patients with and without CyA.

In conclusion: In contrast to the literature $(2,3,4)$ in our patients there is no detrimental effect on kidney function in the first years after OLT. This is probably due to careful immunesuppresion with $\mathrm{CyA}$. Vasodilatation as reported in end stage hepatic failure is likely to be the cause of the preoperative increased ERPF. After replacement of the liver the ERPF decreases accordingly to normal values.

1DonkerNeth]Med 1977;2097.

*Present addres: Beatrix Children's Hospital, University of Groningen, Oostersingel 59, 9713 EZ Groningen, The Netherlands.
P126

RENAL FUNCTION FOLLOWING BONE MARROW TRANSPLANTATION (BMT) IN CHILDREN

L.Patzer, L. Hempel, J. Misselwitz, F. Ringelmann. L, Zimmerhack1, M. Brandis, F. Zintl

Disturbances of renal function after BMT are well established today. We studied 32 patients [mean age 11.6 (3.6 - 40.3) years] before undergoing BMT and up to one year. Patients were divided into four groups according to Cyclosporine $A$ (CsA) administration and conditioning schedule: Group A ( $5 \mathrm{AML}, 3 \mathrm{ALL}, 1 \mathrm{Mb}$. Hodgkin, $1 \mathrm{NHL}$ ); Autologous BMT conditioned with chemotherapy; Group B (4 AML, 3 ALL, 3 CML): Allogeneic BMT (CsA administration) and conditioning with chemotherapy, Group C (6 ALL $2 \mathrm{CML}, 1 \mathrm{NHL}$ ): Allogeneic BMT conditioned with total bocty irradiation (TBI) and VP16; Group D (1 AML, 1 ALL, 1 NHL): Autologous BMT and TBI. The mean age and sex did not differ remarkable. We investigated glomerular filtration rate (GFR) with single-shot inulin clearance before BMT, day 30;102;0.5 and 1 year after. Tubular parameters alpha-1-microglobulin (A1MG), Tamm-Horsfall-protein (THP), intestinal alkaline phosphatase (IAP), alanine-amino-peptidase (AAP) and $\mathrm{B}$-N-acetylghucosaminidase (NAG) were measured at the same time and once a week in the acute phase of BMT additionally

Results: The GFR before BMT was normal or elevated in all patients compared with a normal group. The GFR was not affected at any time in group A as well as in group B. In group C the GFR decreased remarkably with a minimum at day 102 and returned to a normal value at 1 year. This effect may be discussed as the toxic effect of CsA on kidneys injured by TBI.

Tubular function: The excretion of AIMG was significantly increased in group $A$ in the first 30 days after BMT with maximal 12 -fold elevation at day 1 before BMT but returned to a normal level at day 30 . In group $B$ we found the same effect and in addition an increase of AIMG excretion from day 60 in patients who developed a severe graft versus host disease (Gvhd). In group $C$ the maximal elevation (15-fold) as well as normalisation of A1MG excretion was reached later. The excretion of THP was not decreased below the normal range in all groups at any time. The activity of NAG was elevated during the first month after BMT in all three groups and showed normal values later on except in patients with Gvhd. The activity of IAP and AAP in urine was elevate during the acute phase of BMT

Conclusion: Because of the pretreatment with nephrotoxic chemotherapy and/or TBI the tubular function in the first 30 days after BMT is markedly disturbed but the prognosis seems to be good. The main nephrotoxic agent after BMT is CsA. Patients with a severe Gvhd show the most severe disturbances of renal function.

Department of pediatrics; Friedrich Schiller University, 07745 Jena; Kochstraße 2; FRG Department of pediatrics; Albert-Ludwigs-University, 79106 Freiburg; Mathildenstr. 1; This study is supported by grant Deutsche Krebshilfe M107/91/Br 
P127

IN VITRO EXPRESSION OF MUTATIONS IN THE V2-RECEPTOR GENE - CONFIRMATION OF THEIR ROLE IN THE PATHOGENESIS OF X-LINKED NEPHROGENIC DIABETES INSIPIDUS

A.F. van Lieburg, M. Verdijk, N. Knoers, E. Afer", R. Pastina*, F. Fahrenholz", B.A. van Oost

Nephrogenic diabetes insipidus (NDI) is a rare hereditary disorder characterized by the inability of the kidney to concentrate urine in response to arginine vasopressin (AVP). Patients usually present in the first year of life with periods of severe dehydration, polyuria, polydipsia, fever, feeding difficulties and failure to thrive. In patients with X-linked $\mathrm{NDI}$ a variety of mutations in the vasopressin V2 receptor (V2R) gene have been found. Although it is generally thought that these mutations result in receptor inactivation, biochemical evidence for this assumption has only been obtained for one amino acid substitution in the intracellular region of the protein (Rosenthal et al.).

We studied 3 mutations (Tyr205Cys, Val206Asp anf Thr204Asn) in the third extracellular domain of the V2R by transient expression in COS-cells. Mutations were introduced into V2RcDNA by site directed mutagenesis. Following ligation of the modified $\mathrm{cDNA}$ into the $\mathrm{pSG} 5$ expression vector, COS cells were transfected and the binding of ${ }^{3} \mathrm{H}$-labeled AVP was assessed. In COS cells transfected with the Tyr205Cys or Val206Asp construct, binding of AVP was absent. COS cells with the Thr204Asn mutation expressed vasopressin receptors. Both the number and affinity of this mutated $\mathrm{V} 2$ receptor were reduced by one order of magnitude compared to the expressed wild-type V2 receptor. These data confirm that the three mutations studied cause NDI. Although the patient with the Thr204Asn mutation shows the same clinical features as the patients with the other mutations, the possibility exists that this patient is able to respond to high doses of a V2R-agonist.

Departments of Pediatrics and Human Genetics, University Hospital Nijmegen, P.O. Box 9101, $6500 \mathrm{Hb}$ Nijmegen, The Netherlands

- Max Planck Institute for Biophysics, Frankfurt, Germany

\section{P 128}

\section{AUTOSOMAL NEPHROGENIC DIABETES INSIPIDUS CAUSED BY MUTATIONS IN THE AQUAPORIN 2 WATER CHANNEL, GENE}

A.F. van Lieburg, P.M.T. Deen, M.A.J. Verdijk, V.V.A.M. Knoers, B.A. van Oost, L.A.H. Monnens, C.H. van Os

Congenital nephrogenic diabetes insipidus (NDI) is a rare hereditary disease characterized by inability of the distal nephron to concentrate urine in response tot the hormone arginine vasopressin. Patients usually present in the first year of life with periods of severe dehydration, polyuria, fever, anorexia, vomiting and failure to thrive. In most families the disease is caused by rnutations in the X-chromosomal vasopressin $\mathrm{V} 2$ receptor gene, resulting in an $\mathrm{X}$-linked recessive mode of inheritance. However, an autosomal mode of inheritance has also been described. It has been postulated that in these families the disease is caused by a renal post-receptor defect. Cloning of the human aquaporin 2 water channel gene, which is located on chromosome 12 , made it possible to test whether mutations in this gene cause autosomal NDI. In four families with non-X-linked NDI AQP2-mutations were detected. In three of these families patients were homozygous for a missense mutation or a deletion. Parents of the patients were consanguineous. The patient of the fourth family was a compound heterozygote for 2 different mutations. This patient showed a normal extra-renal respons to DDAVP. Expression studies in Xenopus oocytes revealed that the mutated water channels are indeed non-functional.

These results prove that NDI has at least two distinct genetic causes. Furthermore, detection of AQP2-mutations in patients with NDI can increase knowledge of the relationship between structure and function of the AQP2 water channel gene.

Depts of Pediatrics, Human Genetics and Cell Physiology, University of Nijmegen, P.O. Box 9101, 6500 HB Nijmegen, The Netherlands
P129

GENETIC BASIS OF FAMILIAL HYPOTONIC POLYURIA OF NEUROGENIC ORIGIN AUTOSOMAL DOMINANT NEUROGENIC DIABETES INSIPIDUS.

L. Kovács*, J.F. McLeod, S. Rittig, M-B. Gaskill, G.S. Bradley and G.L. Robenson

Familial hypotonic polyuria may be either nephrogenic or neurogenic in origin; differentiation between the two conditions has important therapeutic consequences. Autosomal dominant neurogenic diabetes insipidus (ADNDI) is a disorder manifested during the first years of life by severe hypotonic polyuria and polydipsia due to the deficiency of the antidiuretic hormone, arginine vasopressin (AVF). By genetic linkage analysis the disease locus was mapped to chromosome 20 , near the gene that codes for the vasopressin-neurophysin II (VPNPII) precursor. Recently, we found various point mutations of the VPNPII gene in affected members from 6 Caucasian kindreds. The suggestion that mutations of the VPNPII gene might be responsible for the disease phenotype is strongly supported by recent linkage studies in a large kindred, in which genetic analysis revealed a single base $(G \rightarrow A)$ substitution in a part of exon 1 that codes for the signal peptide (JCEM 77, 1993. 599). This unique mutation should alter the cieavaye site between the signai peptide and the AVP moit:y and thus interiert with proteolytic processing of the precursor. Since it also eliminates a restriction site,

restriction analysis of the PCR amplified VPNPII gene was used to screen for mutations in 20 healthy controls as well as in 48 members ( 26 affected and 22 unaffected) from four generations of the kindred. This showed a perfect match between the mutation and the disease phenotype. Consistent with the mutation site, gel filtration of unextracted plasma collected from a 2.5 year old female carrier before the onset of polyuria revealed not only normal amounts of AVP, but also abnormally large amounts of macromolecular component of AVP immunoreactivity. The amounts of "big" AVP as well as AVF itself were much lower or absent in plasma from this patient after the onset of clinical disease two years later. We postulate that a point mutation in exon 1 of the VPNPIl gene causes ADND in this kindred by directing the synthesis of an abnormally processed protein precursor that gradually destroys the neurosecretory neurons in which it is produced.

Paradoxically, evaluation of the clinical course of ADND in aftected kindreds revealed complete recovery from polyuria in elderly males. How these subjects regained the capacity to concentrate their urine up to $480 \mathrm{mOsm} / \mathrm{kg}$ remains unknown, since their plasma AVP was in the same low range as in the family members with severe polyuria carying the same mutation. The recognized AVP independent causes could be also excluded because their GFR, thyroid and adrenal function were completely normal.

*Present address: Department of Pediatrics, Comenius University Medical School Limbová 1,83340 Bratislava, Slovakia.

Department of Medicine, Northwestern University, Chicago, llinois and

Department of Nephrology C, University of Aarhus, Aarhus, Denmark.

P130

THE PROGRESSION OF ALPORT'S SYNDROME TO RENAL FAILURE 0 . Koskimies, H. Pajari and H. Kääriäinen

In a nationwide study in Finland 51 patients, 31 males and 30 females, from 25 families were diagnosed to have Alport's syndrome. The diagnostic criteria were hemat- or proteinuria in combination with 2 of the following findings: hearing loss, ophtalmological changes, basement membrane splitting or affected family member.

In the majority of the patients the first sign was microscopic hematuria. The mean age of detection of hematuria was 8.8 ( range 0.1 to 36.5 ) years in males, and 7.0 ( 0.5 to 20.0 ) years in females. The mean follow-up time of the male patients was 12.6 ( 2.4 to 31.9 ), and of the female patients 13.1 ( 1.5 to 34.0 ) years. During the follow-up 16 male and 9 female patients developed renal insufficiency ( $R I$ ). The mean age when RI was detected was 22.8 ( 8.6 to 43.8 ), and 25.4 ( 15.4 to 33.0 ) years in males and females respectively; dialysis treatment of these patients was necessary 3.0 and 3.6 years later. None of the 11 men who are over 30 years old, and 8 of the 14 women, have normal GFR.

Although the first symptoms occur at the same age, the affected females seem to have more slow progression to RI. Still, 9 women had developed RI already in early adulthood; whether this is due to a different mutation or due to exogenous factors, is not yet known. So far the mutation of type IV collagen 5 chain gene of only one of these patients has been described ( N. Saarinen et al. Nordiske Nyredage, May 22-25, 1993, Reykjavik, Iceland).

Children's Hospital, University of Helsinki, 00290 Finland 


\section{P1 31}

CLINICAL AND MORPHOLOGICAL FEATURES IN ALPORT SYNDROME (AS) IN WHOM A MUTATION IN THE COL4A5 GENE WAS DEMONSTRATED.

L. Massella,G. Mazzucco, P. Barsotti, T. Faraggiana, A. Renieri, A. De Nigris, LGalli, M. Scri, T. Neri, A. Turco, M. Meroni, A. Sessa, M. De Marchi, G. Monga and G. Rizzoni. Bambino Gesu Children Research Hospital, Roma; Dpt. of Biomed, Sci. Mnd Hum and G. Rizzoni. Torino, Dpt. of Pathol., Univ. of Roma, Dpt. of Mol. Biol., Siena; Med. Gen. Univ. of Parma; Torino, Dpt. of Pathol., Univ. of Roma, Dpt. of Mol. Biol., Siena; Med. Gen. Univ. of Parma
Genet. and Biol, Univ. of Verona; Dpt. of Nephrol., General Hospital of Vimercate; Dpt of Sci. Clin. Biol. Univ. of Torino, and Partecipants to Italian Multicenter Study: A. Antonelli (Lucca), G. Banfi (Milano), B.Basolo (Torino), D.A. Caringella (Bari), M. Conti (Cagliari), R. Coppo (Torino), Cossu (Sassari), G. Chianilli, (Acquaviva), C. Danesino (Pavia), N. Di Paolo (Siena), F Fasciolo (Brescia), Forabosco (Modena), R Gusmano (Genova), M Giani Milano), E Goti (Bergamo), E. Imbasciati (Lodi), G Lama (Napoli) D. Lamperi (Genova) G C. Lati (Firenze) A Lupo (Verong) E Lisi (Macerata) S. LiVolti (Catania), M T Masuzzo (Mavarat Mignani (Rimi) (V. Mile (Cres), C. Messina), R Penzo (Bari) A Petuci (Savoli), Penza (Bri), A. Petrucei (Savona), M.V. Pellanda (B.Del Grappa), L. Per. Pinciaroli (Catnzaro), M. Ragaiolo(Ascoli PIceno), P. Riegler (Bolzano), G. A. Rossin (Civitavecchia), M. Sasdelli (Arezzo), M. Savi (Parma), S. Schiavano (Casarano), F. Scolari (Brescia), O. Semia (Savigliano), R. Tenconi (Padova), Zelante (S. Giovanni Rotondo)

AIM To evaluate the clinical spectrum of AS by verifying the presence of classica diagnostic criteria and morphological features of families with AS in which a mutation in the COL4AS gene was demonstrated by Southern Blotting and/or PCR/SSCP.

PATIENTS AND METHODS In 22 families with an established mutation we revised the criteria actually fulfilled for diagnosis (1. family history of haematuria, with or without renal failure; 2. typical changes of glomerular basement membrane (GBM) on Electron Microscopy (EM); 3. sensorineural deafness; 4. diagnostic ocular signs). Up to now 18 renal biopsies performed in 16/22 families were carefully and blindly rievaluated.

RESULTS In 8 families information on family history, renal biopsy or ocular examination was incomplete; among the remaining $14,10(71 \%)$ fulfilled 3 classical criteria; $1(7 \%)$ fulfilled 2 criteria and the remaining $3(21 \%)$ fulfilled only one criterion (typical GBM lesions) and were de-novo mutations.

UItrastructural findings were diagnostic for Alport Syndrome in $12 / 18(67 \%)$ patients, weakly suggestive in 1 and not characteristic in 5 .

CONCLUSIONS I)Three out of 14 informative families (21\%) had only typical GBM lesions on EM and were de-novo mutations. Therefore, AS is probably underestimated and must be suspected even if less than 3 criteria are fulfilled. 2) EM lesions may be non speciffc; thus, direct identification of the mutation is critical to allow diagnosis especially in these cases.

Present address: Bambino Gesù Children Research Hospital, Department of Nephrology and Dialysis, P.zza S. Onofrio, 4.00165 Roma.
P133 FAVOURABLE OUTCOME OF A CADAVER ISOLATED KIDNEY ALLOGRAFT IN
A CHILD WITH OXALOSIS

SPALOMERA, C PELATAN, D SAHALI, BLEROY, A BENSMAN

Isolated renal transplantation in primary hyperoxaluria type I (PHI) is quite constanly complicated by a reccurence of calcium oxalate deposits in the kidney leading to rapid graft failure.Successful long term renal allografts have recently been reported in children with grafts from living related donors by using an intensive pretransplantation hemodialysis programme followed by prolonged forced diuresis (Kidney Int. 1992. 38:128-131)

We report the case of a 9 year old boy who underwent a cadaver kidney transplantation for oxalosis (hepatic alanine glyoxylate aminotransferase activity $10 \%$ of control) after 14 months on hemodialysis. A bilateral nephrectomy had been performed previously. The kidney came from a child with two matches ( 1 A. IDR). Cold ischemio lasted 24 hours Immunosuppression was usual.The diuresis which occurred immediatly after transplantation was maintained with a large fluid infusion to prevent the recurrence of calcium oxalate deposits in the kidney; this was replaced by oral fluids and nocturnal tube nasogastric hydratation. Mean diuresis reached $10 \mathrm{l} /$ day in the first week, $8 \mathrm{l} /$ day the second week and never fell below 41 day afterwards. Hemodialysis (during a 4-hour period) was started 8 hours after transplantation and continued daily for 2 weeks. then 3 times a week for a month and 2 times a week for 3 weeks. Sodium citrate, pyridoxine, phosphate, magnesium and hydrochlorothiazide were associated. The post operative course was uneventful creatininemia normalized on day 3 . A renal biopsy on day 40 showed no evidence of calcium oxalate deposits and cristalluria was minimal on

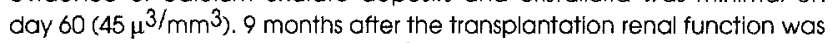
stable with creatinine at about $110 \mu \mathrm{mol} / \mathrm{l}$ and inuline clearance of 58 $\mathrm{ml} / \mathrm{mn} / 1 \mathrm{~m} 73^{2}$. Ultrasound examination of the kidney was normal in spite of persistent hyperoxaluria.

Cadaveric kidney transplantation may be an alternative to combined kidney-liver transplantation. The lack of pre-operative intensive hemodialysis, which is only possible in cases of living related donors did not homper the success of the allograft. Intensive post-operative hemodialysis and continued hyperdiuresis are essential to prevent the reccurence of calcium oxalat deposits in the renal graft.

Hôpital Armand Trousseau 75571 PARIS Cédex 12

P1 34

GENETIC ANALYSIS OF PATIENTS WITH PRIMARY

HYPEROXALURIA TYPE I (PHI)

Y. Frishberg, O. Reiner

PH1 is an autosomal recessive disease caused by a deficiency of the liver-specific peroxisomal enzyme alanine:glyoxylate aminotransferase. Genetic prenatal diagnosis is not yet feasible.

Currently 7 patients with PHI are treated in our center, 6 of Arab-Moslem ancestry and one of Jewish- Lybian extraction.

our initial studies were aimed to detect reported mutations and polymorphisms. We analyzed the PH1 gene from patients and their parents using PCR. In the Jewish patient we found 2 polymorphic mutations at residues 11 and 340 (Pro-Leu and Ile-Met, respectively). However, this analysis did not reveal the GlY-Arg substitution at residue 170 which corresponds to a known point mutation associated with these polymorphisms. A polymorphic intronic duplication (first intron) has been detected in 3 of the obligatory heterozygotes but in none of the patients. Since this polymorphism is mapped closely to 2 point mutations which are missing in these heterozygote parents, we assume that their affected children are not compound heterozygotes. An additional reported mutation that abolishes an Ava-I site has also been examined. Since we have not encountered any of the reported mutations in our patient population, further studies are in progress to detect new point mutations that will enable prenatal diagnosis for this devastating disease.

Division of Pediatric Nephrology (YF), Shaare Zedek Medical Center, POBox 3235, Jerusalem 91031, and Department of Molecular Genetics (OR), Weizmann Institute of science, Rehovot, Israel.
*Present adress: Dr. Sami Ulus Children's Hospital, Pediatric Nephrology Department, 06080 Ankara/Türkjye

Hacettepe Universty Pediatric Nephropathology Department, 06010 Ankara/ Türkiye. 
P135

DIFFUSE MESANGIAL GLOMERULOSCLEROSIS IN THREE FAMILIES: PRENATAL AND POSTNATAL ONSET.

Th. Lennert, L. Neumann, M. Rey, C. Hofstaetter, H. Lobeck, R. Waldherr

We observed 8 children with early onset nephrotic syndrome and diffuse mesangial glomerulosclerosis (DMS) in three families. In family I of Arab origin with consanguinity in three generations, 4 of 11 children died within 4 weeks after birth in a severe nephrotic state with progressive uremia. The 1. child of family II, who died within $24 \mathrm{~h}$, first was misdiagnosed as polycystic kidney disease because of dilated tubules. After a close relation to family I was detected and a second child was presented in the same condition, dying after 6 weeks in uremia, in both children DMS was confirmed histologically. Another pregnancy is currently under investigation (with normal $\alpha$-fetoprotein in serum and amniotic fluid). Family III of consanguineous Turkish origin differed from the first two families in so far as both children were completely healthy at birth. The onset of nephrotic syndrome was at $5 \mathrm{mo}$. in the first and at 3 mo in the second child. The first child died with $7 \mathrm{mo}$. in a steroid resistant nephrotic state with progressive uremia and severe respiratory failure. DMS was diagnosed by biopsy. 2 years later another child was presented with nephrotic syndrome. Biopsy confirmed DMS. As the edematous state was no more controliable and GFR slowly declined, we decided to remove both kidneys and to start CAPD at 4 mo. Two years later the child is still on CAPD, awaiting kidney transplantation. -

These cases demonstrate two different clinical courses of the disease, depending on the time of onset: prenatal or postnatal. It is suggestive to expect elevated $\alpha$-fetoprotein in the prenatal type, but so far this has never been found. The reason could be a rather late start of proteinuria at the end of pregnancy. When we compared the placenta weight/body weight-ratio in the prenatal onset group with their healthy siblings

(ø $23.2 \%$ vs. $13,9 \%$ ), the placenta weight is increased significantly, but still below the rate for Finnish type congenital nephrosis $(>25 \%)$. This aiso would suggest a shorter prenatal duration of proteinuria.

Children's Hospital (KAVH), Klinikum Rudolf Virchow, Free University Berlin, Heubnerweg 6, D 14059 Berlin, Germany

P136

CHILDREN WITH DIFFUSE MESANGIAL SCLEROSIS IN ASSOCIATION WITH THE WILMS TUMOUR ASSOCIATED DELETION REOUIRE BILATERAL NEPHRECTOMY

N J A Webb, M A Lewis, J Bruce, M Lendon, R J Postlethwaite.

A seventeen month old boy presented with renal failure, encephalopathy, hypertension and proteinuria. He had hypospadias with bilaterally descended testes. He was commenced on cycling peritoneal dialysis and antihypertensive therapy. Renal biopsy revealed diffuse mesangial sclerosis. His karyotype was $46 X Y$, and DNA analysis revealed the Wilms tumour associated deletion (WTAD) on the short arm of chromosome 11. A diagnosis of Drash syndrome was made. Prophylactic bilateral nephrectomy was planned despite recovery of renal function and cessation of dialysis. A preoperative abdominal CT scan was entirely normal. At surgery, a firm pale nodule was noted adjacent to the hilum of the left kidney. Histological examination was consistent with a cystic intralobular nephrogenic rest; a premalignant lesion. The appearance of the kidney otherwise was that of diffuse mesangial sclerosis. He is currently well on peritoneal dialysis.

We propose 1] that all children with diffuse mesangial sclerosis in association with the WTAD should undergo bilateral nephrectomy rather than be followed with serial abdominal CT scan or ultrasound examinations and 2] all patients with congenital nephrotic syndrome and early proteinuria require DNA analysis to look for the WTAD.

Royal Manchester Childrens Hospital, Pendlebury, Manchester M27 4HA, United Kingdom
P 137

FABRY 'S DISEASE: GLYCOSPHINGOLIPID LIPIDOSIS - AN ISOLATFO RENAL DAMAGE.

K.Vondrák *, A.Kolský, J.Stejskal, J.Ledvinová, H.Poupětová

Fabry s disease is a very rare $X-1$ inked systemic disorder of glycosphingolipid metabolism resulting from deficiency of the lysosonal hydrolase, alfa-galactosidase $A$. This defect leads to the accumulation of trihexosyl ceramide in various tissues. The authors describe a 15 years old male patient suffering from Fabry's diasease. He was investigated for 2 years for a mild proteinuria below $1 \mathrm{~g} / \mathrm{d}$., mild hypertension and loss of renal concentrating ability. During the last year of investigation s-creatinin raised slowly up to 170 umol/1. Renal biopsy showed severe interstitial inflamation, atrophic or dilatated tubuluses. Most of glomeruluses were enlarged with vacuolised podocytes. An electrormicroscopic invesiligation proved specific granuias of myelin, so called " zebra corpuscles ". Despite an X-linked disease, the family history has beeb negative. The first symptoms in hemizygous usually occure during the second decade of life and consist of attacs of severe acromelalgia. The characteristic features are skin lesions of teleangiectasias and corneal opacities. Renal failure commonly occures in the third or fourth decade. Our patient hasn't any of previous described symptoms and the only sing of Fabry $s$ disease is an isolated kidney disorder. The enzyme activity of alfa-galactosidase A showed only $5 \%$ of normal activity. The same investigation in relatives showed only a partial deficiency in mother and sister, who are heterozygotes without any symptom.

* Present address: Pediatric clinic, Postgraduate Medical Institute, Thonayer s Teaching Hospital, Videnska 800 , 14059 Praha - Krc, Czech Republic.

P138

AMBULATORY BLOOD PRESSURE MONITORING (ABPM) IN CHILDREN AND ADOLESCENTS WITH ASYMPTOMATIC AUTOSOMALDOMINANT POLYCYSTIC KIDNEY DISEASE (ADPKD)

Šikut M. ${ }^{1}$, Seeman T. ${ }^{2}$, Konrad M. ${ }^{2}$, Janda J. ${ }^{1}$, Schärer K. ${ }^{2}$, Zerres K. ${ }^{3}$

Hypertension is a common complication of ADPKD and seems to have an important role in the progression of the disease. We have examined 26 asymptomatic children and adolescents with ADPKD with a mean age of 12.7 years (range 5-18). The diagnosis was made by ultrasonography and/or molecular genetics. Serum creatinine was normal in all children. Blood pressure (BP) was measured over 24 hours (every $20 \mathrm{~min}$. during the day and every 30 min. during the night) using a SpaceLabs 90207 oscilometric monitor. As the normal standards were used 1) european standards for casual BP (de Man at all, 1991) and 2) ABPM standards by Reichert (1993, Homburg/Saar, not pubiisied). By the Man et al., mean systolic BP (SBP) and diastolic BP (DBP) during the day exceeded the $95^{\mathrm{k}}$ percentile (pc) in $5(19 \%)$ and $12(46 \%)$ pts, respectively. SBP and DBP was lower than the $50^{\text {th }} \mathrm{pc}$ in only 3 and $0 \mathrm{pts}$., respectively. SBP and $\mathrm{DBP}$ were significantly higher (both $\mathrm{p}<0.0001$ ) compared to $50^{\text {th }} \mathrm{pc}$. By ABPM standards (whole 24 hours), SBP and DBP were higher than 95 th pc in $7(27 \%)$ and $4(15 \%)$ pts, respectively. All pts exceeded the $50^{\text {th }} \mathrm{pc}$. The night mean values of SBP and DBP were $11 \%$ and $19 \%$ lower as compared to daily values. The BP night decrease of more than $10 \%$ was noted in only 4 pts. After 5-12 months the measurement was repeated in 19 pts. There was a slight but nonsignificant decrease between the first and second measurement.

In conclusion, children and adolescents with asymptomatic ADPKD have a mild to severe elevation of BP, especially DBP. The physiological day/night BP fall was conserved in most cases. The general ABPM-screening of asymptomatic patients with ADPKD is recommended. Early diagnosis and appropriate antihypertensive treatment may improve the late prognosis.

1) I ${ }^{\text {st }}$ Paediatric Department, CZ 15018 Prague

2) Universitäts-Kinderklinik, D 69120 Heidelberg

3) Universitäts-Institut für Humangenetik, D 53111 Bonn 
NEPHROGENIC KAL GENE EXPRESSION MAY EXPLAIN RENAL APLASIAS FOUND IN KALLMANN'S SYNDROME P. J. D. Winyard, V. M. Duke, P. Soothill, P. V. Thorogood, J. T. Norman, P. M.G. Bouloux and A. S. Woolf.

Renal aplasias (RA) commonly cause end-stage renal failure in childhood, yet their pathogenesis is not understood. Unilateral RA occurs in $40 \%$ of patients with X-linked Kallmann's syndrome (KS), a disease caused by mutations of the $K A L$ gene. Therefore, at present, $K A L$ mutations are the only defined human genetic aberrations associated with RA. Anosmia and infertility occur in all KS patients because migration of olfactory and gonadotrophinreleasing hormone (GnRH) neurons into the central nervous system (CNS) is blocked at the olfactory bulb. However, the mechanism underlying RA is unknown. We have investigated the spatial and temporal expression of the $K A L$ gene during human embryogenesis to clarify its role in development. 35 S-labelled riboprobes for in situ hybridisation were transcribed from fulllength human $K A L \mathrm{cDNA}$. At 7 weeks after fertilisation antisense $K A L$ hybridised with glomeruli and tubules of the mesonephros, a fully-differentiated organ at this stage. Within the metanephros, or precursor of the adult kidney, the ureteric bud expressed $K A L$, but the signal from the mesenchyme did not exceed levels of the negative control sense probe. Within the head $K A L$ expression was localised to the developing olfactory bulbs and neuroepithelium of the retina. In contrast, the whole embryo expressed a ubiquitous house-keeping gene. The location of $K A L$ expression within the CNS is consistent with a role for the KAL extracellular matrix protein in the migration of olfactory and GnRH neurons into the brain. KAL gene expression in early nephrogenesis may be essential for normal development of the adult kidney, hence explaining the RA in Kallmann's syndrome.

Medical Unit, Institute of Child Health, London WC1 1EH, Royal Free Hospital, London and UCLMS, London, UK.

P140

TREATMENT OF HYPERLIPIDEMIA IN CHILDREN WITH PERSISTING NEPHROTIC SYNDROME: PRELIMINARY DATA OF A MULTICENTER STUDY USING PROBUCOL.

U. Querfeld' ${ }^{1}$, S. Höfer ${ }^{1}$, D.E. Müller-Wiefel ${ }^{2}$, K. Schärer ${ }^{3}$, B. Kohl', W. Fiehn $^{4}$, D.V. Michalk'

Because of its antioxidative and lipid-lowering properties and since it is effective in reducing proteinuria and the developement of focal sclerosis in rats, we have chosen to use probucol in a pilot study evaluating tolerability and side effects of lipid lowering drugs in children with hyperlipidemia (HLP) associated with the nephrotic syndrome (NS). Patients over 4 years of age with persisting nephrotic proteinuria $\left(>1 \mathrm{~g} / \mathrm{m}^{2} / \mathrm{d}\right.$ ), LDL-Cholesterol $>160 \mathrm{mg} / \mathrm{dl}$ and a GFR $>20 \mathrm{ml} / \mathrm{min} / 1.73$ $\mathrm{m}^{2}$ were admitted to the study after informed consent by their parents. Probucol (2x250 mg) was administered for a total of 12 weeks. Lipoprotein profiles, proteinuria, creatinine clearance and an ECG were monitored every 4 weeks. Side effects were recorded by questionaire. Results: At present, treatment has been started in 7 patients (aged 519.5 years); it was discontinued in 1 patient because of (asymptomatic) QT-prolongation on ECG. Five children have finished 12 weeks of treatment, without reporting side effects. At the end of treatment, reductions in total serum lipids averaged $17 \%$ in triglycerides and $25 \%$ in cholesterol. Cholesterol concentrations in VLDL $(-25 \%)$, LDL $(-31 \%)$ and HDL $(-19 \%)$, as well as apo A-I $(-15 \%)$ and apo B $(-21 \%)$ were also reduced. Proteinuria was reduced by $-19 \%(+3 \%$ to $-49 \%)$ and the creatinine clearance increased by $157 \%(6.5 \%$ - $198 \%)$ compared to start of treatment. These preliminary data indicate that probucol treatment in children with HLP and NS was well tolerated by most patients and had beneficial effects on serum lipoproteins. Further data are clearly needed to substantiate the evaluation of effects of probucol on proteinuria and renal function.

University Children's Hospitals, Cologne', Hamburg ${ }^{2}$ and Heidelberg ${ }^{3}$, Department of Internal Medicine ${ }^{4}$, University of Heidelberg, Germany
BINDING OF A CATIONIC DYE TO RED BLOOD CELLS IN NEPHROTIC CHILDREN

${ }^{*}$ G. Araújo e Sá, E. Mendonça, P. Mendonça and F. Coelho Rosa

Levin et al demonstrated a reduced binding of a cationic dye, alcian blue (AB) to red blood cells (RBC) and platelets from children with steroid - responsive (SR) nephrotic syndrome (NS). These data were not confirmed by other studies.

Material and methods: Using the assay developed by the first authors, we undertook a study to assess the binding of $\mathrm{AB} 8 \mathrm{GX}$-Sigma to $\mathrm{RBC}$ from 29 children with NS ( 22 SR and 7 steroid resistant); 8 of these patients has focal and segmnetal glomerulosclerosis and 7 diffuse mesangial hypercellularity. The study was performed in relapse and, in remission periods of the SR patients. As controls we studied 20 norma children and patients with other protinuric renal diseases. All the assays were performed twice and also repeated with two different $\mathrm{AB}$ solutions in the case of the controls.

Results: In the controls, the percentage of binding was $87.4 \pm 4.9 \%$ (mean \pm $\mathrm{SD})$. In the NS group, binding in relapse was $76.4 \pm 16.5 \%(\mathrm{p}<0.02)$ and in remission $83.3 \pm 12.6(p-n s)$. However in both periods we found individual "normal" and "low" values. Analyses of these data suggested that "normal" values in relapse $(9$ cases) and abnormal ones in remission ( 6 cases) were related with early phases (1st 2 days) of those periods.

Conclusion: These results confirm those reported by Levin et al and suppor the hypotheses of a circulating factor modifying the binding of a cationic dye, such as $A B$, to red blood cells, both in steroid responsive and steroid resistant NS.

Speculation: Normal values in relapse and low values in remission could depend respectively of a low or high concentration of that factor in circulation in the early phases of those periods.

* Present address: Unidade de Nefrologia - Serviço de Pediatria - Hospital Santa Maria Universidade de Lisboa

Av. Prof. Egas Moniz - 1699 Lisboa Codex - Portugal

\section{P142 \\ HIGH SODIUM-LITHIUM COUNTERTRANSPORT (SLC) IS ASSOCIATED WITH SODIUM RETENTION IN CHILDHOOD NEPHROTIC SYNDROME \\ Tulassay T., Dobos M., Külkey O., Reusz G., Sallay P., Tóth P}

Nephrotic syndrome (NS) is characterized by renal sodium retention Several lines of evidence suggest that vasoactive hormones are involved in the sodium retention and thus edema formation in NS. However, the exact mechanism of this process has not been elucidated yet. In order to characterize the cellular transport mechanism of sodium retention in NS we investigated the activity of sodium-lithium countertransport (SLC) in children suffering from minimal change NS (MCNS). The activities of SLC were measured in vitro on red blood cells. Measurements were carried out in 17 children in the edema-forming state of NS, and subsequently at the beginning of remission. The first blood samplings were drawn without any treatment while at the second blood samplings' children were on steroid therapy of $2.0 \mathrm{mg} / \mathrm{kg} /$ day.

\begin{tabular}{|c|c|c|c|c|c|c|}
\hline & $\begin{array}{l}\text { se alt } \\
(\mathrm{g} / \mathrm{L})\end{array}$ & $\begin{array}{l}\text { se cholest. } \\
(\mathrm{mmol} / \mathrm{L})\end{array}$ & $\begin{array}{l}\text { Uprot. } \\
(g / L)\end{array}$ & $\begin{array}{l}\mathrm{U}_{\mathrm{Na}} \\
(\mu \mathrm{m}\end{array}$ & $\underset{\min )^{*}}{\mathrm{Na}^{*}}$ & SLC $^{*}$ \\
\hline Relapse & $\begin{array}{l}19.9 \\
\pm 7.4\end{array}$ & $\begin{array}{l}11.0 \\
\pm 4.3\end{array}$ & $\begin{array}{l}16.2 \\
\pm 18.2\end{array}$ & $\begin{array}{l}36.2 \\
\pm 16\end{array}$ & $\begin{array}{l}6.1 \\
\pm 2.1\end{array}$ & $\begin{array}{l}426 \\
\pm 118\end{array}$ \\
\hline Remission & $\begin{array}{l}30.1 \\
\pm 9.4 \\
\end{array}$ & $\begin{array}{r}10.2 \\
\pm 2.6 \\
\end{array}$ & $\begin{array}{l}0.32 \\
\pm .22 \\
\end{array}$ & $\begin{array}{r}63.4 \\
\pm 30 \\
\end{array}$ & $\begin{array}{l}4.4 \\
+0.9 \\
\end{array}$ & $\begin{array}{r}324 \\
\pm 83 \\
\end{array}$ \\
\hline$<$ & .001 & NS & .001 & .001 & .05 & .01 \\
\hline \multicolumn{3}{|c|}{$\begin{array}{l}{ }^{*} \mathrm{Na}_{\mathrm{i}}=\text { intracellular sodium } \\
(\mathrm{mmol} / \mathrm{RBC})\end{array}$} & \multicolumn{4}{|c|}{$\begin{array}{l}{ }^{* *} \mathrm{SCL}=\text { sodium-litbium countertranspor } \\
(\mu \mathrm{mol} / \mathrm{RBC} \text { R } \mathrm{s} / \mathrm{h})\end{array}$} \\
\hline
\end{tabular}

SLC correlated negatively to serum albumin and $\mathrm{U}_{\mathrm{Na}} \mathrm{V}$. No correlations were found between SLC and $\mathrm{Na}_{\mathrm{i}}$ and serum cholesterol, respectively. Our data prove that SCL is one of the cellular transport mechanisms that is involved in the extracellular sodium retention during edema-forming state in childhood nephrotic syndrome.

Semmelweis University of Medicine, Ist. Department of Paediatrics, Bókay u. 53. H-1083 Budapest/Hungary. Fax: 00-36-1-11 42858 
P143

CLINICAL SYMPTOMS OF HYPOVOLEMIA IN MCNS CORRELATE WITH STIMULATED VASO-ACTIVE HORMONES AND TUBULAR SODIUM RESORPTION.

J.G.J. Vande Walle ${ }^{1,3}$, R.A.M.G. Donckerwolcke ${ }^{1}$ H.A. Koomans ${ }^{2}, J . A$. Joles ${ }^{2}, H$. Van Isselt $2, F$. Derckx ${ }^{2}$

15 children were studied during nephrotic stage (NS) and following remission (REM). Bloodvolume (BV), renine (PRA), aldosterone (Ald) were measured during recumbency. Renal function was assessed following a waterload. The nephrotic patients were divided into 2 groups based on the presence of clinical symptoms of "hypovolemia" (CSt: $n=9, C S-: n=6)$.

\begin{tabular}{|c|c|c|c|c|}
\hline & REM & NS & NS CSt & NS CS- \\
\hline GFR * & $128 \pm 38$ & $100 \pm 24$ & $76 \pm 46$ & $126 \pm 26$ \\
\hline FF \% & $20 \pm$ & $14 \pm \quad 4$ & $14 \pm \quad 3$ & $16 \pm 3.6$ \\
\hline $\mathrm{FE} \mathrm{Na \%}$ & $1.2 \pm 0.9$ & $0.7 \pm 0.9$ & $0.3 \pm 0.3$ & $1.1 \pm 1$ \\
\hline FE LI \% & $34 \pm$ & $23 \pm 12$ & $3.9 \pm 3.1$ & $30 \pm 11$ \\
\hline $\mathrm{FE} \mathrm{H2O}$ & $11 \pm$ & $7 \pm$ & $17 \pm \quad 9$ & $9 \pm 3$ \\
\hline$v \max *$ & $17 \pm$ & $10 \pm$ & $5.4 \pm$ & $11 \pm 4$ \\
\hline PRA $* *$ & $48 \pm 53$ & $174 \pm 199$ & $241 \pm 206$ & $34 \pm 21$ \\
\hline Ald $\mathrm{pg} / \mathrm{ml}$ & $70 \pm 49$ & $473 \pm 436$ & $667 \pm 392$ & $90 \pm 74$ \\
\hline
\end{tabular}

* = ml/min/1.73 $\mathrm{m} 2, * *$ APRC uU/ml, A statistical significant decrease of FF and increase of tubular sodium reabsorption and vasoactive hormones was found only in patients with CSt.

Conclusion: Although the clinical symptoms do not correlate with measurable hypovolemia, in symptomatic patients a lowered GFR, increased vasoactive hormones and increased tubular sodium resorption indicate reduced effective bloodvolume.

Medical Faculty, University of Utrecht ${ }^{1}$, Rotterdam $^{2}$, The Netherlands and Gent ${ }^{3}$, Belgium

\section{P144}

NEPHROTIC SYNDROME (NS) ASSOCIATED WITH CHRONIC GRANULOMATOUS DISEASE (CGD) AND LUPUS ERYTHEMATODES (LE)

C.P. Schmitt, K. Schärer, R. Waldherr, R. Seger, K.-M. Debatin

CGD is an inherited disorder of phagocytes lacking the ability to kill engulfed microorganisms due to defective generation of microbicidal oxygen radicals. The leading symptoms are recurrent severe infections. We observed a boy with a past history of enteritis, repeated lymphadenitis and pneumonitis from early infancy largely resistant to antibiotics. A nitrobluetetrazolium test revealed a severe reduction of oxydative capacity of polymorphonuclear leucocytes. The production of oxygen radicals was reduced by $88 \%$. Molecular genetic studies showed a typical deietion on $x \mathrm{p} 21.1$ Prophylactic use of antimicrobial agents were instituted from the age of 1 year followed by a reduced rate of infection. At the age of 5.5 years the child developed proteinuria rapidly followed by edema, a butterfly rash, splenomegaly and a full NS with microhematuria and normal GFR. Antibodies against various viruses were increased. Serological LE tests were strongly positive and the complement system was activated. Unlike some other rare patients with CGD and associated glomerular disease reported in the literature renal histology revealed diffuse proliferative glomerulonephritis (MPGN like) with mesangial immunglobulin and complement deposits. Other manifestations of urinary tract involvement by CGD were lacking. The patient partly responded to prednisone $\left(60 \mathrm{mg} / \mathrm{m}^{2} / \mathrm{d}\right)$ but developed hypertension. We suspect an association between NS, CGD and LE. The lacking generation of oxygen radicals usually observed in CGD may reduce the clearance of soluble immune complexes from the circulation associated with glomerular disease.
P145

HLA-DR7 PREDICTS THE RESPONSE TO ALKYLATING AGENTS IN STEROIDRESPONSIVE NEPHROTIC SYNDROME (NS) M.Konrad, J.Mytilineos, H.Ruder, G.Opelz, K. Schärer

There is no reliable predictor of the response to alkylating agents in NS although an association was found with the frequency of previous relapses. Since the frequently relapsing NS is closely associated with the HIA-DR7 antigen we have examined retrospectively the time of remission and the occurence of subsequent relapses in 49 children with frequently relapsing Ns treated by cyclophosphamide $(n=43)$ or chlorambucil $(n=6)$, usually applied for 12 weeks. 35 patients were HLA-DR7 posilive and 14 negative with about $75 \%$ being steroid dependent in both groups. HLA typing was performed using serological or DNA typing methods. Renal biopsy showed minimal glomerular changes in all cases. The patients were followed for $>3$ years. Results: A lower proportion of HLADR7 pos. vs. neg. patients remained in remission at 1 year ( 72 vs. $85 \%$ ) and 3 years ( 32 vs. $72 \%$ ) after alkylating therapy $(\mathrm{p}<0.05)$. The mean number of relapses in the first 3 years was only $0.6 \mathrm{vs}$. 1.7 per patient in HLA-DR neg. Vs. pos. patients. When all steroid-dependent patients were combined without respect to the HLA status $44 \%$ were in persistent remission after 3 years vs. $55 \%$ in the patients without steroid dependency (ns). In conclusion, the HLA-DR status seems to predict the response of NS patients to alkylating agents better than the previous frequency of relapses.

Divisions of Pediatrics and Transplantation Immunology, University of Heidelberg, INF 150, D - 69120 Heidelberg
P146 AN ETIOLUGICAL CLASSIFICATION OF $644^{\circ}$ CHILDREN WITH NEPHROTIC SYNDROME

\section{A.Sirin, S.Emre, I.Bilge, H.Alpay, A.Nayır,F.Tanman}

A retrospective study was carried out to determine the etiology of 644 mephrotic children aged 3 months -16 years for the period 1974-1993.413 of 644 children were betueen $1-8$ years of age and did not have any signs or symptoms implicating secondary nephrotic syndrome. They were all given cortico steroid therapy without histopathological evaluation. 320 of 413 cases $(77 \%)$ were found to be steroid responsive. 85 of 93 steroid resistant cases were evaluated by kidney biopsy. Histo pathological findings in this group were as follous:FGS $32 \%$ $(n: 30)$; MesPGN 42\%(n:39);MPGN $10 \%(n: 10)$ and minimal mesangial proliferation were found in 5 cases. 5 patients refused kidney biopsy and in 3 cases biopsy material were inadequate. 12 children < 1 vear of age and 215 chiJdren〉 7 yoare ispre evaluated by biopsy directly. 6 of the patínts < 1 year of age had congenital mephratic syndrame, one patient had MesPGN and only 1 patients had MCNS. FGS-MPGN and minimal mesangial proliferation were the other histapathological findings in this group. 14 of 215 (6.5\%) nephrotic children older than 7 years were admitted to the hospital with Henoch-Schonlein nephropathy. Other histological findings in this group were as follows: Amyloidasis 34\% (n:73); MesPGN 24\%(n:52); MPGN 16\% (n:34); Chronic glomerulonephritis $6 \%$ (n:13). Lupus mephropathy in 3 cases and MCNS anly in 2 cases. Various other histopathological findings $10 \%(n: 21)$. We concluded that the vast majority of the SSNS patients were aged between 1-8 years in our population and amyloidosis is the most frequent disease in the etiology of secondary nephrotic syndrame in our study group.

* Present address: University of Istanbul Faculty of Medicine Department of Pediatric Nephrology 34390 Crapa-Istanbul TURKEY 
P1 47

THE OUTCOME OF NEPHROSIS. A SURVEY IN A FRENCH HOSPITAI J.B. Palcoux, D. Banegas, P. Vanlieferinghen, V. Desvignes

From a total of 90 patients in whom nephrosis was diagnosed before the age of 18 (between $01 / 63$ and $12 / 87$ ) 77 who had had follow-up of more than five years were selected for inclusion. The survey was conducted through home terminals of a French telecommunications system (minitel) and responses to questionnaires were made by telephone or letter. Mean follow-up was 15 years (range, 5-30).

In $79.2 \%$ of patients, the nephrosis was corticosteroid-sensitive (SSN). Of these, $21 \%$ never relapsed, 41 o had infrequent relapses (IR) and 38 were corticosteroid-dependent (CD). The mean number of relapses per child was 6.1 (range, 2-17); 8.5 in the CD group and 4.1 in the IR group. The annual number of relapse per child decreased with the duration of the disease; from $r .9$ uting the Irst year to 0.4 in the fifth. The time between relapses (in the IR group) was 17 months (range, 6 months -7.5 years). At the end of the observation period $70.5 \%$ of the children had been in remission for more than two years without treatment; $27.9 \%$ for less than two years (of whom $70 \%$ were still on treatment); and two patients had died, one of infectious disease, and the other in a road accident. Actuarial remission was $40 \%$ at two years and $25 \%$ at four years. sixteen nephroses $(20.8 \%$ of cases $)$ were corticosteroid-resistant (SRN). At the end of the follow-up, five patients were in remission, three still had mild proteinuria, and eight had developped end-stage renal failure (ESRF). Of these, seven had been transplanted and the other was on hemodialysis. The mean duration of the nephrosis before ESRF was 7.75 years (range, 2.7-18). T'wo patients died of undernutrition and infectiaus diseases. This survey confirms the good prognosis of the SSN (the number of permanent remissions increasing with time) and the bad prognosis of SRN (the number of nephroses evolving into ESRF increasing with the lenght of the follow-up).

Dpt of Pediatrics, Hotel Dieu, 63003 Clemont-Fd - FRANCE

\section{P148}

\section{RED BLOOD CELL GLUTATHIONE-REDOX SYSTEM AND HEMOGLOBIN OXIDATION IN NEPHROTIC CHILDREN} S. Túri, I. Németh, A. Torkos, and I. Haszon

The changes of red blood cell (RBC) reduced (GSH) and oxidized glutathione (GSSG) concentration and hemoglobin (Hb) oxidation were studied in nephrotic syndrome (NS). 41 patients with NS (21 in relapse: group 1; 20 in remission group 2) and 20 controls (group 3) were investigated. GSH and GSSG were measured by a recycling method using glutathione reductase, the oxidative derivates of $\mathrm{Hb}$ (met $\mathrm{Hb}$ hemichrome) by spectrophotometric light-absorption spectrum analysis and OSM3 hemoximeter. Patients in relapse had significantly higher GSH and GSSG than in remission and in controls (GSH: group 1: $9.1 \pm 2.1$, group 2: $7.2 \pm 1.7, p<0.05$, group 3: $7.3 \pm 1.8 \mathrm{uM} / \mathrm{gHb}, \mathrm{p}<0.05$. GSSG:group 1: $14.8+2.2$, group $2: 7.1+2.4, \mathrm{p}<0.001$, group $3: 8.2 \pm 1.8 \mathrm{nM} / \mathrm{gHb}$ $\mathrm{p}<0.001)$. The ratio of GSSG/GSH a sensitive indicator of oxidative stress in vivo and the percentage of metHb were significantly higher in group 1 than in group 2 or $3(\mathrm{p}<0.01)$. An in vitro oxidative stress with acetyl-phenylhydrazine(APH) induced a more pronounced decrease in the concentration of GSH $(p<0.01)$ and a significant increase in the level of metHb and hemichrome in NS both in relapse and remission $(p<0.001)$ There was a positive correlation between RBC GSH and GSSG $(r=0.78$, $\mathrm{p}<0.05$ ).

A measurable oxidative stress of RBC was detected in the relapse of NS characterized by an increase of RBC GSH and GSSG level, GSSG/GSH ratio and a reduced defence against $\mathrm{Hb}$ oxidation. In remission the GSHredox system became normalized but an increased oxidation of $\mathrm{Hb}$ could be detected following an in vitro APH load. On the basis of these results an oxidative stress reflected on the RBC antioxidant defence system might have a role in the pathogenesis of NS.

Department of Paediatrics, A.Szent-Györgyi Medical University,Korányi Str.14, H-6725 Szeged, Hungary
P149

EXPRESSION OF ASMA, TGF-BETA AND ENDOTHELIN IN RENAL BIOPSIES OF PEDIATRIC NEPHROTIC SYNDROME

L. Murer, F. Anglani, A. Scarpa, G. Montini, A. Borsatti, G. Zacchello.

Recently the alfa smooth muscle actin (ASMA), an actin isoform expressed by smooth muscle and fibroblastic cells, has been proposed as a marker of mesangial proliferation and matrix production in glomerular disorders. TGF beta modulates in vitro the ASMA expression of mesangial and fibroblast cells, and regulates the secretion of Endothelin $(E t)$, which is involved in the progession of glomerular diseases.In this study we have investigated the immunohistochemical distribution of ASMA, TGF-beta and Et in renal biopsies obtained from 12 children with hydiopathic nephrotic syndrome: 9 with minimal change disease (MCD) (7 steroid responsive and 2 steroid resistant) and 3 with focal segmental glomerulosclerosis (FSGS). At the time of the biopsy the age of patients was $\mathrm{m}$. $6.5+4.4 \mathrm{y}$, the plasma creatinine $\mathrm{m} .58 . \uparrow+32.1 \mathrm{umol} / \mathrm{L}$ and the proteinuria $\mathrm{m}$. $182.4 \pm 3365.7 \mathrm{mg} / \mathrm{kg} / \mathrm{die}$. The sections were processed with an immunoperoxidase technique using monoclonal antibodies anti smooth-muscle alfa actin (Boehringer Mannheim) and anti TGF-bela (Serotec), and a policional antibody anti-Et1 (Peninsula lab.). The intesity and extension of positive immunostaining was scored from absent $(*)$ to important $(+++)$. Normal renal tissues obtained from nephrectomies for renal tumors was employed as control. In normal renal tissue ASMA immunoreactivity was present only on muscular wall of vessels as well as $7 / 12$ biopsies (all steroid responsive MCD). In 5/12 cases (2 steroid resistant MCD and 3 FSGS) a weak signal was revealed also by the glomeruli and a moderate one by peritubular and periglomerular interstitial cells. In control tissues TGF beta positivity was absent or very weak only on the vascular endo-thelium as well as in $3 / 12$ biopsies (all steroid responsive $M C D$ ). In $9 / 12$ a moderate or important positivity of capillary loop and mesangial cells was observed, and 5 out these 9 biopsies (2 steroid resistant MCD and 3FSGS) presented a TGF-beta staining of interstitium and tubules. Et immunoreactivity was absent or very weak only on vascular endothelium in controls and in 6 steroid responsive and 1 steroid resistant MCD biopsies. In the other 5 cases a more intensive signal was revealed at glomerular, intersitial and/or tubular level. These preliminary results seem to confirm alfa-actin as a marker of glomerular injury also in hydiopathic nephrotic syndrome. An upregulation of ASMA in intersitial cell could suggest an important role of this cellular population in the progression of the disease. The correlation between ASMA, TGF-beta and Et increased expressions in the sequence of events leading to renal damage has be further investigated.

Dept. of Pediatrics, University of Padua, Via Giustiani 3, 35128 Padova, Italy

\section{P150}

\section{SALIVARY PROTEINS IN STEROID-SENSITIVE NEPHROTIC SYNDROME}

\section{T.J. Neuhaus, V. Shah, T.M. Barratt}

It has been suggested that steroid-sensitive nephrotic syndrome (SSNS) is a generalized disorder of membrane negative charge. Albumin and transferrin are present in saliva in small amounts, arising from passive filtration. They have a similar molecular weight (66 vs $77 \mathrm{kD}$ ), but differ in pI (4.9 vs 5.9 ): the albumin/transferrin clearance ratio may be a useful means of assessing charge selectivity. We analysed whole unstimulated saliva after a one hour fast from 10 SSNS children in relapse and in subsequent remission, and compared them with 11 steroid-resistant nephrotic children (SRNS) and 11 healthy children. The aim of the study was to test whether a) albumin filtration was increased and/or b) charge selectivity was altered in SSNS, thereby indicating a more widespread disorder of capillary permeability. Aibumin in saliva (SA) and plasma (PA) were measured by RIA and transferrin (ST. PT) by ELISA (detection limits $0.5 \mathrm{mg} / 1$ and 0.8 $\mu \mathrm{g} / \mathrm{l}$, respectively) and the salivary clearance ratio calculated as (SA/PA)/(ST/PT). The data were analysed using a non-parametric signed rank test for comparing relapse and remission and a rank sum test for comparing remission of SSNS with controls and relapse with SRNS (median data shown).

\begin{tabular}{llrrrr}
\hline & & Relapse & Remission & Control & SRNS \\
\hline Albumin & Saliva (mg/l) & 49.1 & $26.9^{\mathrm{a}}$ & $94.5^{\mathrm{a}}$ & 17.6 \\
& Plasma $(\mathrm{g} / \mathrm{l})$ & 19.7 & $22.6^{\mathrm{a}}$ & $28.3^{\mathrm{a}}$ & 12.5 \\
& Saliva/plasma ratio & 2.5 & 1.0 & 3.6 & 1.2 \\
\hline Transferrin & Saliva $(\mathrm{mg} / \mathrm{l})$ & 4.1 & $3.3^{\mathrm{a}}$ & $5.8^{\mathrm{a}}$ & 2.3 \\
& Plasma $(\mathrm{g} / \mathrm{l})$ & 1.8 & $1.4^{\mathrm{a}}$ & $2.0^{\mathrm{a}}$ & 1.8 \\
& Saliva/plasma ratio & 3.0 & 1.8 & 2.4 & 1.6 \\
\hline Albumin/transferrin clearance ratio & 1.2 & 0.5 & 1.1 & 0.9 \\
\hline
\end{tabular}

$a_{p}<0.05$ remission vs controls

There was no significant difference in SSNS betwcen relapse and remission in saliva, plasma or saliva/plasma ratios for albumin and transferrin. Patients in remission had lower absolute concentrations of albumin and transferrin in saliva than controls, but the salivary albumin/transferrin clearance ratio and saliva/plasma ratios were not significantly different, probably reflecting the lower protein concentrations still present in plasma in early remission. No significant differences between SSNS in relapse and SRNS were found.

We conclude that neither size nor charge selectivity of salivany gland capillary permeability are affected in SSNS.

Medical Unit, Institute of Child Health, 30 Guilford Street, London WCIN IEH, UK. 